DOC.20041020.0016

QA: QA

MDL-NBS-HS-000020 REV 01

October 2004

\title{
Particle Tracking Model and Abstraction of Transport Processes
}

Prepared for:

U.S. Department of Energy

Office of Civilian Radioactive Waste Management

Office of Repository Development

1551 Hillshire Drive

Las Vegas, Nevada 89134-6321

Prepared by:

Bechtel SAIC Company, LLC

1180 Town Center Drive

Las Vegas, Nevada 89144

Under Contract Number

DE-AC28-01RW12101 


\section{DISCLAIMER}

This report was prepared as an account of work sponsored by an agency of the United States Government. Neither the United States Government nor any agency thereof, nor any of their employees, nor any of their contractors, subcontractors or their employees, makes any warranty, express or implied, or assumes any legal liability or responsibility for the accuracy, completeness, or any third party's use or the results of such use of any information, apparatus, product, or process disclosed, or represents that its use would not infringe privately owned rights. Reference herein to any specific commercial product, process, or service by trade name, trademark, manufacturer, or otherwise, does not necessarily constitute or imply its endorsement, recommendation, or favoring by the United States Government or any agency thereof or its contractors or subcontractors. The views and opinions of authors expressed herein do not necessarily state or reflect those of the United States Government or any agency thereof. 
QA: QA

Particle Tracking Model and Abstraction of Transport Processes

MDL-NBS-HS-000020 REV 01

October 2004 


\begin{tabular}{|l|l|l|}
\hline \multirow{2}{*}{ OCRWM } & Model Signature Page/Change History & Page fil \\
\cline { 2 - 2 } & 1. Total Pages: 206 \\
\hline
\end{tabular}

\section{Type of Methematical Modet \\ $\square$ Process Mocel}

Q Abstraction Model

System Mode:

Describe intended ves of Model

The purpose of this report is to document the abstraction model being used in Total System Performance Assessment model calculations for radionuclide transport in the nneturated zone.

\section{Thte}

Particle Tracking Model and Abstraction of Transport Processes

4. Ol (including Rev. No., if applicable):

MDL-NBS-HS-000020 REV OI
5. Total Appenofices
6. No. of Pages in Each Appendix
3 A.10, B-6, C-14

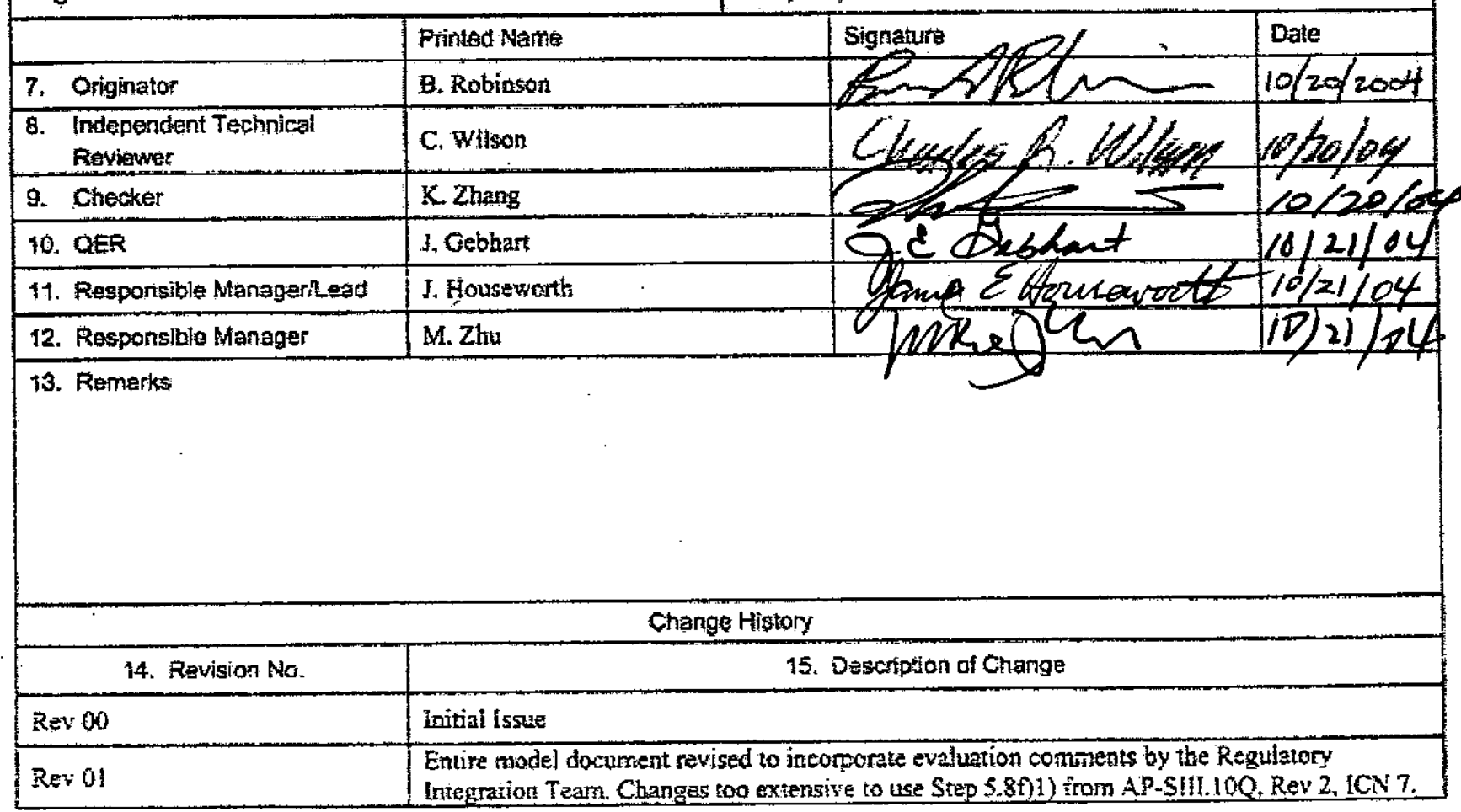


INTENTIONALLY LEFT BLANK 


\section{CONTENTS}

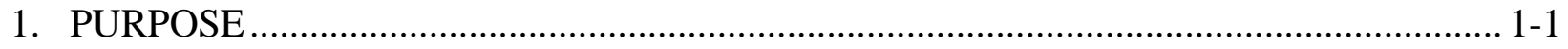

2. QUALITY ASSURANCE ..................................................................................... 2-1

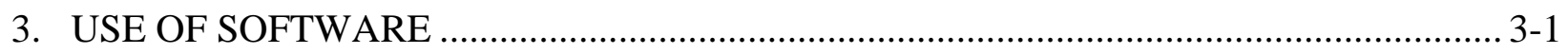

3.1 SOFTWARE TRACKED BY CONFIGURATION MANAGEMENT ...................... 3-1

3.2 EXEMPT SOFTWARE ............................................................................. $3-2$

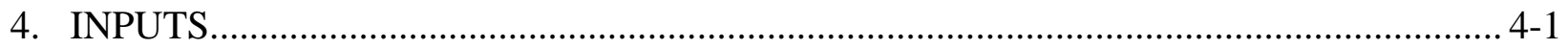

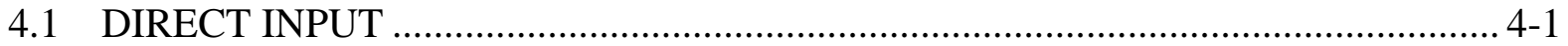

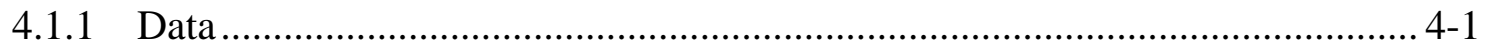

4.1.2 Parameters and Parameter Uncertainty .......................................................... 4-2

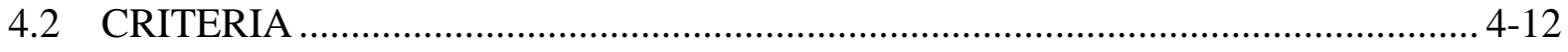

4.3 CODES, STANDARDS, AND REGULATIONS .................................................... 4-15

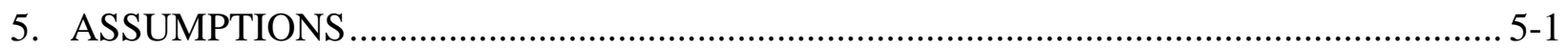

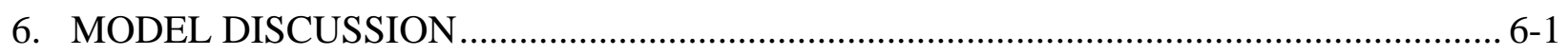

6.1 MODELING OBJECTIVES AND APPROACH.................................................... 6-1

6.2 FEATURES, EVENTS, AND PROCESSES INCLUDED IN THE MODEL .............. 6-3

6.3 THE UZ TRANSPORT ABSTRACTION MODEL .................................................. 6-5

6.4 THE NUMERICAL REPRESENTATION OF THE UZ TRANSPORT MODEL ..... 6-7

6.4.1 Basic Methods...................................................................................... 6-9

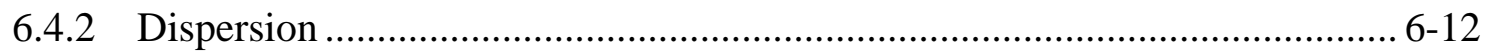

6.4.3 Fracture/Matrix Interaction Submodel................................................... 6-14

6.4.4 Multiple Radionuclides with Decay/Ingrowth................................................. 6-19

6.4.5 Colloid Transport.................................................................................. 6-21

6.4.6 Particle Sources and Sinks ............................................................... 6-24

6.4.7 EBS Random Release Model for Radionuclide Source Terms ...................... 6-25

6.4.8 Climate Change and Water Table Rise ......................................................... 6-28

6.4.9 Interface with GoldSim..................................................................... 6-30

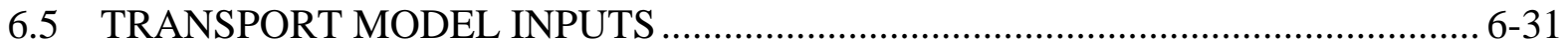

6.5.1 Pre-generated Flow Fields .............................................................. 6-32

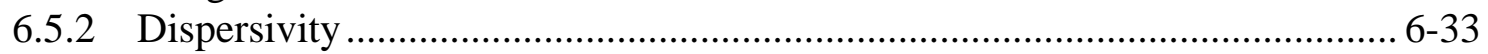

6.5.3 Matrix Porosity and Rock Density ................................................................. 6-33

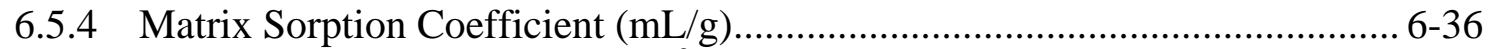

6.5.5 Matrix Diffusion Coefficient $\left(\mathrm{m}^{2} / \mathrm{sec}\right)$...................................................... 6-38

6.5.6 Fracture Residual Saturation and Active Fracture Model Gamma

Parameters (Unitless) ................................................................................... 6-42

6.5.7 Fracture Porosity, Fracture Spacing (m), and Fracture Aperture (m)............. 6-45

6.5.8 Fracture Surface Retardation Factor (Unitless) ............................................... 6-51 


\section{CONTENTS (Continued)}

6.5.9 Colloid Filtration at Matrix Interface........................................................... 6-51

6.5.10 Colloid Size Exclusion............................................................................ 6-52

6.5.11 Colloid Size Distribution ........................................................................ 6-53

6.5.12 Colloid Concentration and Colloid $\mathrm{K}_{\mathrm{c}}$........................................................... 6-53

6.5.13 Fractions of Colloids Traveling Unretarded and Colloid Retardation

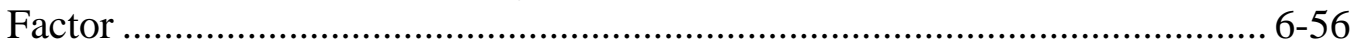

6.5.14 Radionuclide Half Lives (Years) and Daughter Products................................ 6-58

6.5.15 Repository Radionuclide Release Bins........................................................ 6-58

6.5.16 Radionuclide Collecting Bins at UZ/SZ Interface ....................................... 6-60

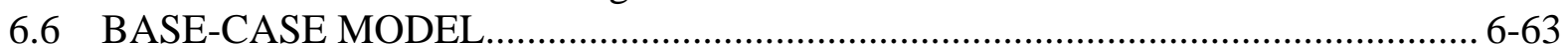

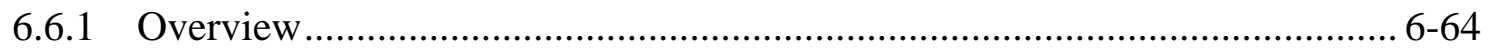

6.6.2 Base-Case Model Results ……………………...................................... 6-66

6.7 EVALUATION OF ALTERNATIVE MODELS AND MODEL

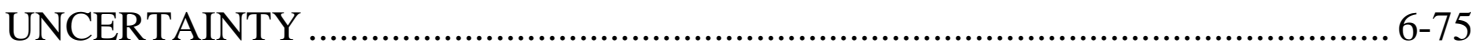

6.8 DESCRIPTION OF BARRIER CAPABILITY ……............................................... 6-77

6.8.1 Analyses of Barrier Capability.................................................................... 6-78

6.8.2 Summary of Barrier Capability....................................................................... 6-81

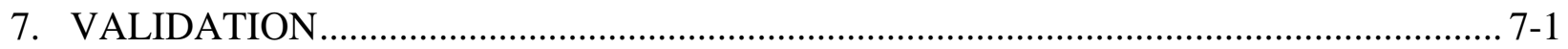

7.1 CONFIDENCE BUILDING DURING MODEL DEVELOPMENT TO

ESTABLISH THE SCIENTIFIC BASIS AND ACCURACY FOR INTENDED

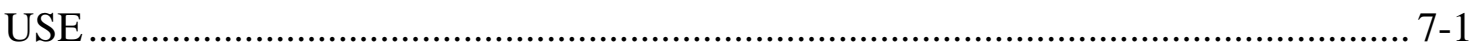

7.2 POST-DEVELOPMENT MODEL VALIDATION TO SUPPORT THE

SCIENTIFIC BASIS OF THE MODEL.............................................................. 7-2

7.2.1 COMPARISONS WITH DISCRETE FRACTURE MODEL ......................... 7-4

7.2.1.1 Test of Advective Transport Between Continua ................................ 7-5

7.2.1.2 Comparisons with Diffusion for Fracture-Dominated Flow ............. 7-5

7.2.1.3 Comparisons with Diffusion and Sorption for Intermediate

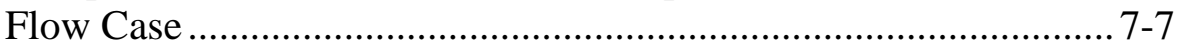

7.2.1.4 Summary of Validation Tests for a Discrete Fracture Model ......... 7-12

7.2.2 Comparison with the Dual-k and MINC Model Formulations on a

Two-Dimensional Cross-Section Model........................................................ 7-13

7.2.3 Comparison with T2R3D Process Model for the Three-Dimensional System............................................................................................... 7-15

7.2.3.1 Comparisons of FEHM and T2R3D for the Dual-k Conceptual

Model..................................................................................... 7-15

7.2.3.2 Influence of Diffusion Coefficient and f/m Interaction ACM ....... 7-16

7.2.3.3 Tests of the Active Fracture Model Implementation........................ 7-18

7.3 SUMMARY OF VALIDATION ACTIVITIES ………………………................ 7-21

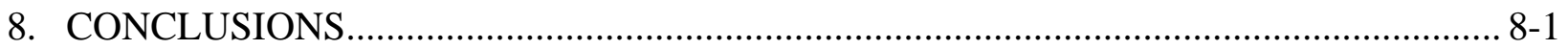

8.1 SUMMARY OF MODELING ACTIVITY ......................................................... 8-1

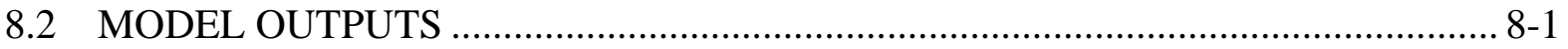

8.2.1 Developed Output ................................................................................. 8-1

8.2.2 Output Uncertainty.......................................................................................... 8-4 


\section{CONTENTS (Continued)}

Page

8.3 HOW THE APPLICABLE ACCEPTANCE CRITERIA ARE ADDRESSED............ 8-5

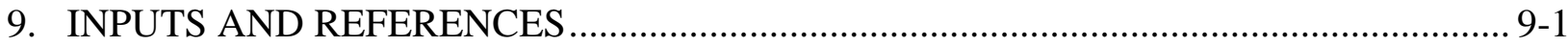

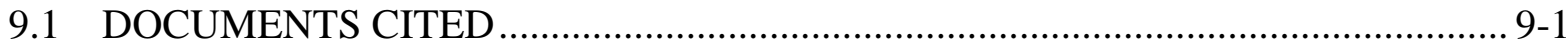

9.2 CODES, STANDARDS, REGULATIONS, AND PROCEDURES ............................. 9-8

9.3 SOURCE DATA, LISTED BY DATA TRACKING NUMBER ……………............. 9-8

9.4 OUTPUT DATA, LISTED BY DATA TRACKING NUMBER ……...................... 9-10

9.5 SOFTWARE CODES ...................................................................................... 9-10

APPENDIX A - DERIVATION OF THE DISTRIBUTION OF WATER CONTENT AND EFFECTIVE PERMEABILITY FOR SAMPLING MATRIX DIFFUSION COEFFICIENT ………………………………………..... A-1

APPENDIX B - DERIVATION OF WATER TABLE COLLECTING BINS ............................1

APPENDIX C - DERIVATION OF FRACTURE-MATRIX INTERACTION SUBMODEL AND GENERATION OF TRANSFER FUNCTIONS ............C-1 


\section{INTENTIONALLY LEFT BLANK}




\section{FIGURES}

6-1. Schematic of the GoldSim-FEHM Coupling........................................................ 6-2

6-2. Schematic of Water Movement and Radionuclide Transport Through the UZ ........... 6-6

6-3. Schematic of the Cell-Based Particle-Tracking Technique ...................................... 6-10

6-4. Schematic of the RTTF Technique for Determining Particle Residence Time in a

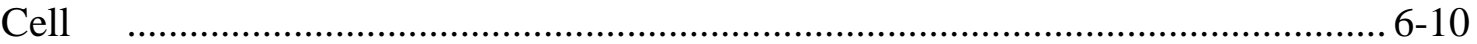

6-5. Schematic of the Fracture Transport Submodel.................................................. 6-18

6-6. Comparison of Software CHAIN and FEHM Transport Results for a Case with a 4-Member Decay-Ingrowth CHAIN and a Retardation Factor of 1.9 for Species 3.. 6-21

6-7. The Structure of the in[ ] Array Passed to FEHM from GoldSim ........................... 6-26

6-8. $\quad$ Flow Chart of EBS Random Release Model ...................................................... 6-27

6-9. $\quad$ Schematic Flow Chart of GoldSim-FEHM Coupling............................................ 6-31

6-10. Cumulative Probability for Matrix Diffusion Under Saturated Conditions................ 6-40

6-11. Comparison of Cation/Anion Distributions with Reimus High/Low Distributions for Unsaturated Conditions ...................................................................................... 6-41

6-12. Comparison of the Distributions with Diffusion Data........................................... 6-42

6-13. Relationship Between Fracture Frequency and Standard Deviation ......................... 6-49

6-14. Relationship Between Fracture Porosity and Frequency ....................................... 6-51

6-15. SMT Repository Release Nodes ..................................................................... 6-61

6-16. FEHM Repository Release Nodes Transformed Based on SMT Release Nodes

(Shown in Figure 6-15) .................................................................................. 6-62

6-17. Source Regions for Radionuclide Release in the SZ Transport Abstraction Model... 6-63

6-18. Base-Case Model Normalized Mass Flux at the Water Table for 36 Radionuclide

Species, Present-Day Mean Infiltration Scenario .................................................. 6-66

6-19. Base-Case Model Normalized Mass Flux at the Water Table for 36 Radionuclide Species, Glacial-Transition Mean Infiltration Scenario......................................... 6-67

6-20. Base-Case Model Normalized Mass Flux at the Water Table for Combined Irreversible Fast and Irreversible Slow Colloids, Glacial-Transition Mean Infiltration Scenario

6-21. Base-Case Model Normalized Mass Flux at the Water Table for Conservative Radionuclides and Sr-90, Glacial-Transition Mean Infiltration Scenario

6-22. Base-Case Model Normalized Mass Flux at the Water Table for Moderately Sorbing Radionuclides, Glacial-Transition Mean Infiltration Scenario ....

6-23. Base-Case Model Normalized Mass Flux at the Water Table for Aqueous Species of Amerecium and Plutonium, Glacial-Transition Mean Infiltration Scenario .......... 6-72

6-24. Base-Case Model Normalized Mass Flux at the Water Table for Aqueous Species of Cesium and Amerecium, Glacial-Transition Mean Infiltration Scenario............... 6-73

6-25. Base-Case Model Normalized Mass Flux at the Water Table for Various Moderately to Strongly Sorbing Radionuclides, Glacial-Transition Mean Infiltration Scenario...

6-26. Normalized Cumulative Breakthrough Curves of the 11 Radionuclides Under Present-Day Mean Infiltration Condition

6-27. Normalized Cumulative Breakthrough Curves of the 11 Species of Radionuclides Under Glacial-Transition Mean Infiltration Condition. 


\section{FIGURES (Continued)}

Page

7-1. Particle-Tracking Abstraction Model Behavior for Advective Transport Between the Fracture and Matrix Continua: No Diffusion or Sorption, Solute Injected into the Fracture, Compared to Theoretical Results......................................................... 7-6

7-2. Comparison of Discrete Fracture Model and Particle-Tracking Abstraction Model: Non-Sorbing Solute Injected into the Fracture for Different Values of Diffusion Coefficient, $f_{f}=0.99$.

7-3. Comparison of Discrete Fracture Model and Particle-Tracking Abstraction Model: Non-Sorbing Solute Injected into the Fracture for Different Values of Diffusion Coefficient, $f_{f}=0.6$

7-4. Comparison of Discrete Fracture Model and Particle-Tracking Abstraction Model: Sorbing Solute Injected into the Fracture for Different Values of Diffusion Coefficient.

7-5. Comparison of Discrete Fracture Model and Particle-Tracking Abstraction Model: Solute Injected into the Fracture for Different Values of Sorption Coefficient, $D_{m}=1 . \mathrm{e}-11$ $7-10$

7-6. $\quad$ Comparison of Discrete Fracture Model and Particle-Tracking Abstraction Model: Solute Injected into the Fracture for Different Values of Sorption Coefficient, $D_{m}=1 . \mathrm{e}-10$

7-7. Comparison of Discrete Fracture Model and Particle-Tracking Abstraction Model: Non-sorbing Solute Injected into the Matrix for Different Values of Diffusion Coefficient.

7-8. Comparison of Discrete Fracture Model and Particle-Tracking Abstraction Model: Sorbing Solute Injected into the Fracture for Different Numbers of Grid Cells in the Flow Path

7-9. $\quad$ Comparison of Particle-Tracking Model with T2R3D Models for a

Two-Dimensional, Mountain-Scale Model: with (and without) Diffusion, for Dual-k and DFM Formulations for the $\mathrm{f} / \mathrm{m}$ Interaction Model.

7-10. Comparison of Breakthrough Curves for Tc-99 for T2R3D and the UZ Transport Abstraction Model: Simulations for Different Present-Day Infiltration Rate Scenarios (Lower, Mean, and Upper).

7-11. Comparison of Breakthrough Curves for Tc-99 for T2R3D and the UZ Transport Abstraction Model: Mean Infiltration Scenario, Diffusion in FEHM Ranging from No Diffusion to High Values

7-12. Breakthrough Curves for Tc-99 Using the UZ Transport Abstraction Model to Investigate the Role $\mathrm{f} / \mathrm{m}$ Interaction Conceptual Model: Simulations for Different Present-Day Infiltration Rate Scenarios (Lower, Mean, and Upper)...

7-13. Breakthrough Curves for Conservative Solute Using the UZ Transport Abstraction Model to Investigate the Role of AFM Parameter Gamma: Dual-k ACM, Simulation for Different Values of Gamma in Rock Units Beneath the Repository..... 


\section{FIGURES (Continued)}

Page

7-14. Breakthrough Curves for Conservative Solute Using the UZ Transport Abstraction Model to Investigate the Role of AFM Parameter Gamma: Discrete Fracture ACM, Simulation for Different Values of Gamma in Rock Units Beneath the Repository 


\section{INTENTIONALLY LEFT BLANK}




\section{TABLES}

3-1. Qualified Software Used in This Report.................................................................. 3-2

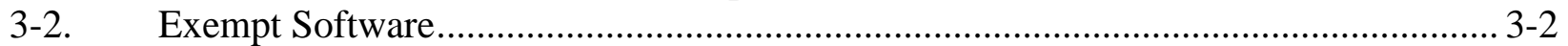

4-1. $\quad$ Input Data Associated with Model Setup and Flow Fields............................................. 4-2

4-2. $\quad$ Transport Input Parameters for the UZ Transport Abstraction Model ........................... 4-3

4-3. Project Requirements and YMRP Acceptance Criteria Applicable to this Model Report............................................................................................................... 4-12

6-1. Included FEPs for This Model Report and Their Disposition in the TSPA-LA........... 6-3

6-2. $\quad$ Dispersivity Used in UZ Transport Abstraction Model............................................... 6-33

6-3. $\quad$ Matrix Porosities Used in the Transport Model......................................................... 6-34

6-4. Matrix Rock Density Values................................................................................... 6-35

6-5. $\quad$ Sorption-Coefficient Distributions for Unsaturated Zone Units................................ 6-37

6-6. $\quad$ Distribution of Water Content and Effective Permeability........................................ 6-43

6-7. $\quad$ Fracture Residual Saturation Values............................................................... 6-43

6-8. $\quad$ Fracture $\gamma$ Parameter for Lower-Bound Infiltration Scenario ..................................... 6-44

6-9. $\quad$ Fracture $\gamma$ Parameter for Mean Infiltration Scenario ...................................................... 6-45

6-10. Fracture $\gamma$ Parameter for Upper-Bound Infiltration Scenario ...................................... 6-46

6-11. Fracture Porosity and Frequency Data................................................................... 6-48

6-12. Grouping of Rock Layers Below the Repository......................................................... 6-49

6-13. Fracture Porosity and Frequency Distribution Data .................................................... 6-50

6-14. Fracture Surface Retardation Factor ………………………………..................... 6-51

6-15. Cumulative Probabilities for Colloid Transport at Matrix Interfaces ........................... 6-52

6-16. Colloid Size Exclusion Factor Used in FEHM ......................................................... 6-53

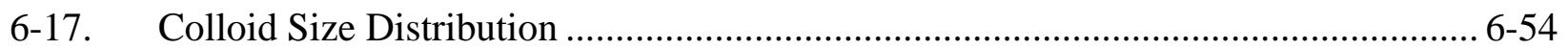

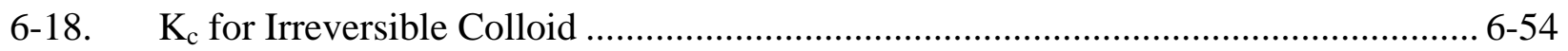

6-19. Colloid Concentration Distribution........................................................................... 6-55

6-20. Radionuclide Sorption Coefficient (mL/g) onto Colloids .......................................... 6-55

6-21. Fractions of Colloids Traveling Unretarded ............................................................ 6-57

6-22. Colloid Retardation Factors ................................................................................ 6-58

6-23. Radionuclide Half-Lives and Daughter Products Used in the TSPA-LA.................... 6-59

6-24. Definition of Repository Release Bins ............................................................ 6-59

6-25. Radionuclides Simulated in Base-Case Run......................................................... 6-65

6-26. Summary of Alternative Conceptual Model Processes and Their Dispositions for the TSPA-LA ………………………...................................................................... 6-76

6-27. Radionuclide Transport Times in Years to the Water Table for Instantaneous

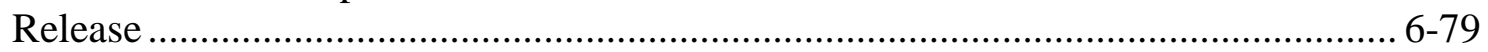

6-28. Radionuclide Transport Times in Years to the Water Table for Continuous

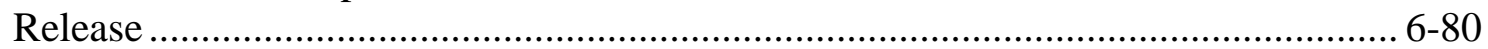

6-29. Colloid Transport Times in Years to the Water Table for Continuous Release .......... 6-80

7-1. $\quad$ Parameter Values for Discrete Fracture Model Test Suite ................................................ 7-4

8-2. Computer Files Comprising the UZ Transport Abstraction Model ............................... 8-2 


\section{INTENTIONALLY LEFT BLANK}




\section{ACRONYMS AND ABBREVIATIONS}

ACM alternative conceptual model

$\mathrm{AD}$ advection-dispersion

AFM

active fracture model

CML carboxylate modified polystyrene latex

DCPT Dual Continuum Particle Tracking Computer Code

DFM discrete fracture model

dll dynamic link library

dual-k dual permeability

EBS engineered barrier system

FEHM finite element heat and mass model

FEP

$\mathrm{f} / \mathrm{m}$

feature, event, and process

LA license application

MINC matrix-fracture system - multiple interactive continua

PA performance assessment

PTn Paintbrush nonwelded vitric tuff

RTTF $\quad$ residence time transfer function

SMT Smeared-source, mountain-scale thermal model (part of Multiscale model)

SZ saturated zone

TDMS technical data management system

TSPA total system performance assessment

TSw Topopah Spring welded unit

TWP technical work plan

UTM Universal Transverse Mercator (map type)

UZ unsaturated zone

YMRP Yucca Mountain Review Plan, Final Report 


\section{INTENTIONALLY LEFT BLANK}




\section{PURPOSE}

The purpose of this report is to document the abstraction model being used in total system performance assessment (TSPA) model calculations for radionuclide transport in the unsaturated zone (UZ). The UZ transport abstraction model uses the particle-tracking method that is incorporated into the finite element heat and mass model (FEHM) computer code (Zyvoloski et al. 1997 [DIRS 100615]) to simulate radionuclide transport in the UZ. This report outlines the assumptions, design, and testing of a model for calculating radionuclide transport in the UZ at Yucca Mountain. In addition, methods for determining and inputting transport parameters are outlined for use in the TSPA for license application (LA) analyses.

Process-level transport model calculations are documented in another report for the UZ (BSC 2004 [DIRS 164500]). Three-dimensional, dual-permeability flow fields generated to characterize UZ flow (documented by BSC 2004 [DIRS 169861]; DTN: LB03023DSSCP9I.001 [DIRS 163044]) are converted to make them compatible with the FEHM code for use in this abstraction model. This report establishes the numerical method and demonstrates the use of the model that is intended to represent UZ transport in the TSPA-LA. Capability of the UZ barrier for retarding the transport is demonstrated in this report, and by the underlying process model (BSC 2004 [DIRS 164500]).

The technical scope, content, and management of this report are described in the planning document Technical Work Plan for: Unsaturated Zone Transport Model Report Integration (BSC 2004 [DIRS 171282]). Deviations from the technical work plan (TWP) are noted within the text of this report, as appropriate. The latest version of this document is being prepared principally to correct parameter values found to be in error due to transcription errors, changes in source data that were not captured in the report, calculation errors, and errors in interpretation of source data.

Note that Section 7.2.3.3 presents the technical justification that the abstraction model properly implements the active fracture model (AFM) with matrix diffusion.

The particle-tracking technique presented in this report, called the residence time transfer function (RTTF) particle-tracking technique (Robinson et al. 2003 [DIRS 171674]), uses a cellbased approach that sends particles from node to node on a finite difference or finite element grid, after keeping each particle at the cell for a prescribed period of time. To incorporate transport mechanisms such as dispersion and matrix diffusion, the residence time of a particle at a cell is computed using a transfer function that ensures that the correct distribution of residence times at the cell is reproduced. This procedure is computationally very efficient, enabling large-scale transport simulations of several million particles to be completed rapidly on modern workstations. This requirement was needed for complex, three-dimensional simulation involving multiple radionuclides. Furthermore, since the cell-based approach directly uses mass flow rate information generated from a numerical fluid flow solution; complex, unstructured computational grids; and the dual-permeability flow model, formulation poses no additional complications. For the present application, the technique was adapted for use in unsaturated, dual-permeability transport simulations. For such systems, numerical techniques are required to allow accurate simulation of dual-permeability systems in which there is a vast disparity in the transport times depending upon whether the transport is in the fractures or the matrix. This 
report outlines the approach and defines the proper use of that approach. Furthermore, colloidfacilitated radionuclide transport can be simulated, and complex source terms and decay chain/ingrowth capabilities have been included in the model.

Like all numerical methods, the particle-tracking technique has limitations that must be considered when deciding whether its use is appropriate for a given application. The key physical and chemical assumptions are advection-dominated transport and linear, equilibrium sorption. Also, the accuracy of the method for dual-permeability flow systems was investigated in detail by performing comparisons to analytical solutions and alternate numerical methods, including the UZ transport process models documented by BSC (2004 [DIRS 164500] and 2004 [DIRS 169861]), and testing of the FEHM code presented in the software documentation (LANL 2003 [DIRS 166306]). Given these results, this report demonstrates that the particle-tracking model can be used in three-dimensional radionuclide transport simulations of the Yucca Mountain UZ as long as the limits on the model are recognized and parameters and inputs are chosen accordingly. Discussion of the limits and applicability are provided in this report. Inputs used in the calculations presented are believed to be representative of those to be used in TSPA model calculations, but this contention must be verified explicitly when the actual parameters to be used in TSPA multiple realization simulations become available. 


\section{QUALITY ASSURANCE}

Development of this report and the supporting modeling activities have been determined to be subject to the Office of Civilian Radioactive Waste Management's quality assurance program as indicated by BSC (2004 [DIRS 171282]). Approved quality assurance procedures identified in the TWP (BSC 2004 [DIRS 171282]) have been used to conduct and document the activities described in this report. The TWP also identifies the methods used to control the electronic management of data during the modeling and documentation activities.

This report discusses ambient radionuclide transport through hydrogeologic units below the repository, which constitute a natural barrier that is classified in the Q-List (BSC 2004 [DIRS 168361]) as "Safety Category" because it is important to waste isolation, as defined in AP-2.22Q, Classification Analyses and Maintenance of the Q-List. The results of this report are important to the demonstration of compliance with the postclosure performance objectives prescribed in 10 CFR 63.113 [DIRS 156605]. The report contributes to the analysis data used to support performance assessment (PA); the conclusions do not directly impact engineered features important to preclosure safety, as defined in AP-2.22Q. 


\section{INTENTIONALLY LEFT BLANK}




\section{USE OF SOFTWARE}

\subsection{SOFTWARE TRACKED BY CONFIGURATION MANAGEMENT}

The computer codes used directly in this modeling activity are summarized in Table 3-1. The computer software code on which the UZ transport abstraction model is based is FEHM V2.21 (LANL 2003 [DIRS 165741]). The qualification status of this and other software is indicated in the electronic Document Input Reference System database. All software was obtained from Software Configuration Management and is appropriate for the application. Qualified codes were used only within the range of validation as required by LP-SI.11Q-BSC, Software Management. Computer files for this report are located in data tracking numbers and identified in the respective discussions in Section 6; the outputs are listed in Section 8.2.

The FEHM V2.21 (LANL 2003 [DIRS 165741]) program is the primary software used to represent physical processes for the Particle Tracking Model and Abstraction of Transport Processes models. Transport calculations were performed using FEHM V2.21 (LANL 2003 [DIRS 165741]). The range of use for FEHM V2.21, as presented in this report, is for tracer transport in unsaturated, isothermal flow through fractured, porous rock. The routine ppptrk V1.0 (LANL 2003 [DIRS 165753]) was used to post-process transport results to obtain cumulative mass breakthrough curves at the water table. The routine discrete_tf V1.1 (LANL 2003 [DIRS 165742]) was used to convert discrete fracture model (DFM) results to transfer functions. The routine fehm2post V1.0 (LANL 2003 [DIRS 165754]) was used to execute multiple FEHM simulations along with pre- and post-processing runs. The range of use for ppptrk V1.0, discrete_tf V1.1, fehm2post V1.0 are for any range of output generated by FEHM V2.21. FEHM V2.21 is coupled with the software GoldSim V7.50.100 (BSC 2003 [DIRS 161572]) for total system performance simulations. There are no restrictions on the range of use of GoldSim V7.50.100 relative to the dynamically linked FEHM V2.21. No software was used prior to qualification.

The particle tracking method, as implemented in FEHM V2.21, was selected for use because this method allows for a numerically efficient calculation of radionuclide transport in the UZ, as required for multiple-realizations of this process in TSPA-LA. In addition, model validation exercises presented in this report show that the transport calculation methodology used in FEHM V2.21 is compatible with other transport methods that have been successfully used to analyze transport processes in field tests at Yucca Mountain (Section 7). The software routines ppptrk V1.0, discrete_tf V1.1, and fehm2post V1.0 were selected because they have been specifically developed to be used with FEHM V2.21. GoldSim V7.50.100 was selected because FEHM V2.21 was dynamically linked to this software for total system performance dose calculations. A more recent version of GoldSim, V8.02, (BSC 2004 [DIRS 169844]) has been implemented for TSPA-LA. However, both versions of GoldSim only act as an input/output interface for the dynamically linked FEHM module for UZ transport. No modifications to FEHM were required for linking with GoldSim V8.02. Therefore, use of the older version in this report has no impact on the results presented. There are no limitations on the use of this software within the range of use identified above. 
Table 3-1. Qualified Software Used in This Report

\begin{tabular}{|c|c|c|c|c|}
\hline $\begin{array}{c}\text { Software } \\
\text { Title/Version (v) }\end{array}$ & $\begin{array}{c}\text { Software Tracking } \\
\text { Number }\end{array}$ & $\begin{array}{c}\text { Platform/Operating } \\
\text { System }\end{array}$ & Code Usage & DIRS \\
\hline FEHM V2.21 & $10086-2.21-00$ & $\begin{array}{l}\text { PC/Windows } 2000 \text {, } \\
\text { and } \\
\text { SUN/OS 5.8, }\end{array}$ & $\begin{array}{l}\text { Generation of transfer } \\
\text { function curve information } \\
\text { using a discrete fracture } \\
\text { model. Simulation of } \\
\text { particle tracking } \\
\text { validation runs. } \\
\text { Abstraction model } \\
\text { simulations. }\end{array}$ & $\begin{array}{l}\text { [DIRS } \\
165741]\end{array}$ \\
\hline GoldSim V7.50.100 & $10344-7.50 .100-00$ & PC/Windows 2000 & $\begin{array}{l}\text { Abstraction model } \\
\text { simulations. }\end{array}$ & $\begin{array}{l}\text { [DIRS } \\
\text { 161572] }\end{array}$ \\
\hline ppptrk V1.0 & $11030-1.0-00$ & SUN/Solaris 7 & $\begin{array}{l}\text { Post-processing of } \\
\text { particle breakthrough } \\
\text { curve information. }\end{array}$ & $\begin{array}{l}\text { [DIRS } \\
165753]\end{array}$ \\
\hline discrete_tf V1.1 & $11033-1.1-00$ & PC/Windows 2000 & $\begin{array}{l}\text { Post-processing of } \\
\text { discrete fracture model } \\
\text { results to convert results } \\
\text { to transfer functions. }\end{array}$ & $\begin{array}{l}\text { [DIRS } \\
\text { 165742] }\end{array}$ \\
\hline fehm2post V1.0 & $11031-1.0-00$ & $\begin{array}{l}\text { PC/Windows } 2000 \\
\text { and } \\
\text { SUN/OS } 5.8\end{array}$ & $\begin{array}{l}\text { Executes multiple FEHM } \\
\text { simulations along with } \\
\text { pre- and postprocessing } \\
\text { runs. Used to execute } \\
\text { the individual simulations } \\
\text { and generation of transfer } \\
\text { function curves used in } \\
\text { the TSPA-LA UZ } \\
\text { transport abstraction } \\
\text { model. }\end{array}$ & $\begin{array}{l}\text { [DIRS } \\
\text { 165754] }\end{array}$ \\
\hline
\end{tabular}

DIRS=Document Input Reference System; FEHM=finite element heat and mass (model); TSPA-LA=Total System Performance Assessment for the License Application; UZ=unsaturated zone.

\subsection{EXEMPT SOFTWARE}

Commercial, off-the-shelf software used in support of this report is listed in Table 3-2. This software is exempt from the requirements of LP-SI.11Q-BSC.

Table 3-2. Exempt Software

\begin{tabular}{|c|c|c|c|}
\hline $\begin{array}{l}\text { Software } \\
\text { Name and } \\
\text { Version (V) }\end{array}$ & $\begin{array}{l}\text { Software } \\
\text { Tracking } \\
\text { Number }\end{array}$ & Description & $\begin{array}{l}\text { Computer and } \\
\text { Platform } \\
\text { Identification }\end{array}$ \\
\hline Fortner Plot & N/A & $\begin{array}{l}\text { The commercial software, Fortner Plot, was used for } \\
\text { plotting the results of breakthrough curve simulations. Only } \\
\text { built-in standard functions in this software were used. No } \\
\text { software routines or macros were used with this software to } \\
\text { prepare this report. The output was visually checked for } \\
\text { correctness. }\end{array}$ & SUN Workstation \\
\hline $\begin{array}{l}\text { Microsoft Excel } \\
97\end{array}$ & N/A & $\begin{array}{l}\text { This standard spreadsheet package is used to perform } \\
\text { simple spreadsheet calculations using built-in formulas and } \\
\text { functions. }\end{array}$ & $\begin{array}{l}\text { IBM PC, Window } \\
2000 \text { Operating } \\
\text { System }\end{array}$ \\
\hline
\end{tabular}




\section{INPUTS}

\subsection{DIRECT INPUT}

Data and parameters used in this report as direct inputs to the UZ transport abstraction model include:

- Numerical grid for the UZ transport model

- UZ flow field for the prevailing climate

- UZ rock properties

- Porosity

- Fracture spacing and aperture

- AFM parameter $\gamma$

- Fracture residual saturation

- Rock density

- UZ radionuclide transport parameters

- Matrix diffusion coefficient

- Radionuclide matrix sorption coefficient

- Colloid size distribution

- Colloid size exclusion factor at fracture-matrix interface

- Colloid filtration factor at matrix interface

- Colloid concentration

- Radionuclide sorption coefficient onto colloid

- Colloid retardation factor

- Repository release locations.

These data and parameters are discussed in greater detail in the next sections.

\subsubsection{Data}

In TSPA simulations, flow fields are pregenerated and saved for use in the UZ transport abstraction model to be used in TSPA analyses. At run time, FEHM reads in the pregenerated flow fields and associated water saturations and uses them in transport simulations. The UZ flow model grid and flow field for the prevailing climate are used in this report as input to FEHM to illustrate the set-up of UZ transport model. The effects of flow field uncertainty on TSPA are investigated through multiple realizations with different climate scenarios and corresponding flow fields.

Data on UZ flow in the repository were developed using the site-scale UZ Flow Model. The sitescale model incorporates the entire UZ in the vicinity of Yucca Mountain UZ; it accounts for the main stratigraphic units using layer-averaged rock properties, and represents the major faults. Relevant rock properties of each hydrogeologic unit (for fractures, matrix, and fault zones) have been calibrated against water saturation data, water-potential data, pneumatic-pressure data, perched-water data, and temperature data (BSC 2004 [DIRS 169857]), Section 6.2, and BSC 2004 [DIRS 169861], Sections 6.2 through 6.4). The flow results also include the effects of preferential flow in the fracture network as implemented in the AFM (BSC 2004 [DIRS 169861], 
Section 6.1.2). The calibrations are conducted for lower, mean, and upper infiltration scenarios for the present-day climate to include this key uncertainty in the parameterization. These data, converted for use in the particle tracking algorithm and include the fracture and matrix flux and the fracture and matrix water saturations, are available in DTN: LB0305TSPA18FF.001 [DIRS 165625] and in the report by BSC (2004 [DIRS 169861]).

Repository location data are used to select repository nodes in the three-dimensional site scale model for releasing radionuclides into the UZ. There is no uncertainty related to this data.

The data in Table 4-1 are used as inputs to FEHM for constructing the UZ transport model. The remainder of this section describes in detail the data sources and rationale for their selection.

Table 4-1. Input Data Associated with Model Setup and Flow Fields

\begin{tabular}{|l|l|l|}
\hline \multicolumn{1}{|c|}{ Data Name } & \multicolumn{1}{|c|}{ Data Source } & \multicolumn{1}{c|}{ DTN } \\
\hline $\begin{array}{l}\text { UZ flow model grid and nine base case flow } \\
\text { fields. preqIA.ini, preqmA.ini, prequA.ini, } \\
\text { monqla.ini, monqmA.ini, monqua.ini, } \\
\text { glaqlA.ini, glaqmA.ini, glaquA.ini, fehmn.grid, } \\
\text { and fehmn.stor }\end{array}$ & $\begin{array}{l}\text { BSC 2004 [DIRS 169861] UZ Flow } \\
\text { Models and Submodels (MDL-NBS- } \\
\text { HS-000006 REV02) }\end{array}$ & $\begin{array}{l}\text { LB0305TSPA18FF.001 } \\
\text { [DIRS 165625] } \\
\text { LB03023DSSCP9I.001 } \\
\text { [DIRS 163044] }\end{array}$ \\
\hline $\begin{array}{l}\text { Repository release bin location } \\
\text { Water saturation }\end{array}$ & $\begin{array}{l}\text { NEVADA_SMT_percolation_BIN_m } \\
\text { a.txt, which contains repository node } \\
\text { location of the thermal model }\end{array}$ & $\begin{array}{l}\text { LL030610323122.029 } \\
\text { [DIRS 164513] }\end{array}$ \\
\hline $\begin{array}{l}\text { BSC 2004 [DIRS 169861] UZ Flow } \\
\text { Models and Submodels } \\
\text { (MDL-NBS-HS-000006 REV02) }\end{array}$ & $\begin{array}{l}\text { LB03023DSSCP9I.001 } \\
\text { [DIRS 163044] }\end{array}$ \\
\hline
\end{tabular}

DTN=data tracking number; UZ=unsaturated zone

\subsubsection{Parameters and Parameter Uncertainty}

The parameters listed in Table 4-2 are inputs to the UZ transport abstraction model. The values of those parameters affect the strength of the transport mechanism to which those parameters are related. The values of the parameters vary from layer to layer, as do the distributions. Rock properties (rock density, fracture porosity, spacing, aperture, AFM parameter $\gamma$, and fracture residual saturation) are used as inputs to the FEHM UZ transport model. The validity and uncertainty of those parameters are documented in the corresponding model reports, Analysis of Hydrologic Properties Data (BSC 2004 [DIRS 170038]), Calibrated Properties Model (BSC 2004 [DIRS 169857]), and UZ Flow Models and Submodels (BSC 2004 [DIRS 169861]). In this report, the mean values of those parameters are used to demonstrate the abstraction of the UZ transport model. The influence of parameter uncertainty on system performance will be studied in TSPA multiple realization runs.

Radionuclide transport properties are used in FEHM for simulating the transport processes of radionuclides in the unsaturated fracture media from repository downward to the water table.

Colloid size distribution, concentration, sorption coefficient, size exclusion, filtration factors, and retardation factors are input parameters to FEHM for simulating colloid-facilitated radionuclide transport in fractured media. Those data are functions of colloid and rock properties and vary from layer to layer. 
The uncertainty and validity of each parameter are addressed in the corresponding documents listed in the parameter source column in Table 4-2 and are also discussed below and in the various subsections of Section 6.5 of this report as indicated in the parameter name column of Table 4-2.

Table 4-2. Transport Input Parameters for the UZ Transport Abstraction Model

\begin{tabular}{|c|c|c|c|c|c|}
\hline $\begin{array}{c}\text { Parameter } \\
\text { Name (Section } \\
\text { Discussed) }\end{array}$ & Parameter Source & DTN & $\begin{array}{c}\text { Parameter } \\
\text { Value(s) }\end{array}$ & Units & $\begin{array}{c}\text { Distribution } \\
\text { (or Single } \\
\text { Value if Fixed) }\end{array}$ \\
\hline $\begin{array}{l}\text { Matrix porosity } \\
\text { Section } 6.5 .3\end{array}$ & $\begin{array}{l}\text { BSC 2003* } \\
\text { [DIRS 161773] } \\
\text { Analysis of } \\
\text { Hydrologic Properties } \\
\text { Data (MDL-NBS-HS- } \\
\text { 000014 REV 00) }\end{array}$ & $\begin{array}{l}\text { LB0210THRMLPRP.001 } \\
\text { [DIRS 160799] }\end{array}$ & $\begin{array}{l}\text { Varies from } \\
\text { layer to layer }\end{array}$ & None & Fixed \\
\hline $\begin{array}{l}\text { Rock density } \\
\text { Section } 6.5 .3\end{array}$ & $\begin{array}{l}\text { BSC 2003* } \\
\text { [DIRS 161773] } \\
\text { Analysis of } \\
\text { Hydrologic Properties } \\
\text { Data (MDL-NBS-HS- } \\
\text { 000014 REV 00) }\end{array}$ & $\begin{array}{l}\text { LB0210THRMLPRP.001 } \\
\text { [DIRS 160799] }\end{array}$ & $\begin{array}{l}\text { Varies from } \\
\text { layer to layer }\end{array}$ & $\mathrm{kg} / \mathrm{m}^{3}$ & Single value \\
\hline $\begin{array}{l}\text { Fracture } \\
\text { porosity } \\
\text { Section } 6.5 .7\end{array}$ & $\begin{array}{l}\text { BSC } 2004 \\
\text { [DIRS 170038] } \\
\text { Analysis of } \\
\text { Hydrologic Properties } \\
\text { Data (ANL-NBS-HS- } \\
\text { 000042 REV00) }\end{array}$ & $\begin{array}{l}\text { LB0205REVUZPRP.001 } \\
\text { [DIRS 159525] } \\
\text { LB0207REVUZPRP.001 } \\
\text { [DIRS 159526] }\end{array}$ & $\begin{array}{l}\text { Varies from } \\
\text { layer to layer }\end{array}$ & None & $\begin{array}{l}\text { Beta } \\
\text { distribution. } \\
\text { Layers are } \\
\text { grouped } \\
\text { together based } \\
\text { on similar rock } \\
\text { properties }\end{array}$ \\
\hline $\begin{array}{l}\text { Fracture } \\
\text { frequency } \\
\text { Section } 6.5 .7\end{array}$ & $\begin{array}{l}\text { BSC } 2004 \\
\text { [DIRS 170038] } \\
\text { Analysis of } \\
\text { Hydrologic Properties } \\
\text { Data (ANL-NBS-HS- } \\
\text { 000042 REV00) }\end{array}$ & $\begin{array}{l}\text { LB0205REVUZPRP.001 } \\
\text { [DIRS 159525] } \\
\text { LB0207REVUZPRP.001 } \\
\text { [DIRS 159526] }\end{array}$ & $\begin{array}{l}\text { Varies from } \\
\text { layer to layer }\end{array}$ & $m^{-1}$ & $\begin{array}{l}\text { Log-normal } \\
\text { distribution }\end{array}$ \\
\hline $\begin{array}{l}\text { Active fracture } \\
\text { model } \\
\text { parameters } \\
\text { Section } 6.5 .6\end{array}$ & $\begin{array}{l}\text { BSC } 2004 \\
\text { [DIRS 169861] } \\
\text { UZ Flow Models and } \\
\text { Submodels (MDL- } \\
\text { NBS-HS-000006 } \\
\text { REV02) }\end{array}$ & $\begin{array}{l}\text { LB0305TSPA18FF.001 } \\
\text { [DIRS 165625] } \\
\text { LB0208UZDSCPMI.002 } \\
\text { [DIRS 161243] } \\
\text { LB0208UZDSCPLI.002 } \\
\text { [DIRS 161788] } \\
\text { LB0302UZDSCPUI.002 } \\
\text { [DIRS 161787] }\end{array}$ & $\begin{array}{l}\text { Varies from } \\
\text { layer to layer } \\
\text { and with } \\
\text { infiltration } \\
\text { scenario }\end{array}$ & None & $\begin{array}{l}\text { Fixed value for } \\
\text { a specific } \\
\text { infiltration }\end{array}$ \\
\hline $\begin{array}{l}\text { Fracture } \\
\text { residual } \\
\text { saturation } \\
\text { Section } 6.5 .6\end{array}$ & $\begin{array}{l}\text { BSC } 2004 \\
\text { [DIRS 169857] } \\
\text { Calibrated Properties } \\
\text { Model (MDL-NBS- } \\
\text { HS-000003 REV02) }\end{array}$ & $\begin{array}{l}\text { LB0208UZDSCPMI.002 } \\
\text { [DIRS 161243] } \\
\text { LB0208UZDSCPLI.002 } \\
\text { [DIRS 161788] } \\
\text { LB0302UZDSCPUI.002 } \\
\text { [DIRS 161787] }\end{array}$ & 0.01 & None & Fixed \\
\hline
\end{tabular}


Table 4-2. Transport Input Parameters for the UZ Transport Abstraction Model (Continued)

\begin{tabular}{|c|c|c|c|c|c|}
\hline $\begin{array}{c}\text { Parameter } \\
\text { Name (Section } \\
\text { Discussed) }\end{array}$ & Parameter Source & DTN & $\begin{array}{l}\text { Parameter } \\
\text { Value(s) }\end{array}$ & Units & $\begin{array}{c}\text { Distribution (or } \\
\text { Single Value if } \\
\text { Fixed) }\end{array}$ \\
\hline $\begin{array}{l}\text { Matrix } \\
\text { permeability } \\
\text { Section } 6.5 .6\end{array}$ & $\begin{array}{l}\text { BSC } 2004 \\
\text { [DIRS 169857] } \\
\text { Calibrated Properties } \\
\text { Model (MDL-NBS- } \\
\text { HS-000003 REV02) }\end{array}$ & $\begin{array}{l}\text { LB0208UZDSCPMI.002 } \\
\text { [DIRS 161243] } \\
\text { LB0208UZDSCPLI.002 } \\
\text { [DIRS 161788] } \\
\text { LB0302UZDSCPUI.002 } \\
\text { [DIRS 161787] }\end{array}$ & $\begin{array}{l}\text { Varies from } \\
\text { layer to layer } \\
\text { and with } \\
\text { infiltration } \\
\text { scenario }\end{array}$ & $\mathrm{m}^{2}$ & $\begin{array}{l}\text { Log-normal } \\
\text { distribution } \\
\text { Layers are } \\
\text { grouped } \\
\text { together based } \\
\text { on similar rock } \\
\text { properties }\end{array}$ \\
\hline $\begin{array}{l}\text { Matrix porosity } \\
\text { (for matrix } \\
\text { diffusion) } \\
\text { Section } 6.5 .6\end{array}$ & $\begin{array}{l}\text { BSC } 2004 \\
\text { [DIRS 170038] } \\
\text { Analysis of } \\
\text { Hydrologic } \\
\text { Properties Data } \\
\text { (ANL-NBS-HS- } \\
\text { 000042 REV00) }\end{array}$ & $\begin{array}{l}\text { LB0207REVUZPRP.002 } \\
\text { [DIRS 159672] }\end{array}$ & $\begin{array}{l}\text { Varies from } \\
\text { layer to layer }\end{array}$ & None & $\begin{array}{l}\text { Beta distribution } \\
\text { Layers are } \\
\text { grouped } \\
\text { together based } \\
\text { on similar rock } \\
\text { properties }\end{array}$ \\
\hline $\begin{array}{l}\text { Colloid } \\
\text { concentration } \\
\text { distribution } \\
\text { Section } 6.5 .12\end{array}$ & $\begin{array}{l}\text { BSC } 2004 \\
\text { [DIRS 170025] } \\
\text { Waste Form and In- } \\
\text { Drift Colloids- } \\
\text { Associated } \\
\text { Radionuclide } \\
\text { Concentrations: } \\
\text { Abstract and } \\
\text { Summary (MDL- } \\
\text { EBS-PA-000004 } \\
\text { REV 01) }\end{array}$ & $\begin{array}{l}\text { SN0306T0504103.005 } \\
\text { [DIRS 164132] }\end{array}$ & $\begin{array}{l}\text { Concentration } \\
\text { will be } \\
\text { sampled } \\
\text { based on the } \\
\text { given } \\
\text { distribution }\end{array}$ & $\mathrm{mg} / \mathrm{L}$ & $\begin{array}{l}\text { Cumulative } \\
\text { distribution }\end{array}$ \\
\hline $\begin{array}{l}\text { Radionuclide } \\
\text { sorption } \\
\text { coefficient onto } \\
\text { colloid } \\
\text { Section } 6.5 .12\end{array}$ & $\begin{array}{l}\text { BSC } 2004 \\
\text { [DIRS 170025] } \\
\text { Waste Form and } \\
\text { In-drift } \\
\text { Colloids-Associated } \\
\text { Radionuclide } \\
\text { Concentrations: } \\
\text { Abstract and } \\
\text { Summary (MDL- } \\
\text { EBS-PA-000004 } \\
\text { REV 01) }\end{array}$ & $\begin{array}{l}\text { SN0306T0504103.006 } \\
\text { [DIRS 164131]] }\end{array}$ & $\begin{array}{l}\text { Values will be } \\
\text { sampled } \\
\text { based on the } \\
\text { given } \\
\text { distribution }\end{array}$ & $\mathrm{mL} / \mathrm{g}$ & $\begin{array}{l}\text { Uniform } \\
\text { distribution } \\
\text { parameter range } \\
\text { depends on the } \\
\text { type of } \\
\text { radionuclides }\end{array}$ \\
\hline $\begin{array}{l}\text { Colloid size } \\
\text { distribution } \\
\text { Section 6.5.11 }\end{array}$ & N/A & $\begin{array}{l}\text { LL000122051021.116 } \\
\text { [DIRS 142973] }\end{array}$ & $\begin{array}{l}\text { Parameter } \\
\text { values are } \\
\text { sampled at } \\
\text { run time }\end{array}$ & None & $\begin{array}{l}\text { Cumulative } \\
\text { distribution }\end{array}$ \\
\hline $\begin{array}{l}\text { Colloid filtration } \\
\text { factors } \\
\text { Section } 6.5 .9\end{array}$ & N/A & $\begin{array}{l}\text { LA0003MCG12213.002 } \\
\text { [DIRS 147285] }\end{array}$ & $\begin{array}{l}\text { Probability of } \\
\text { a particle } \\
\text { being filtered } \\
\text { at matrix } \\
\text { interface. } \\
\text { Varies from } \\
\text { layer to layer }\end{array}$ & None & $\begin{array}{l}\text { Fixed values but } \\
\text { varies with } \\
\text { layers }\end{array}$ \\
\hline
\end{tabular}


Table 4-2. Transport Input Parameters for the UZ Transport Abstraction Model (Continued)

\begin{tabular}{|c|c|c|c|c|c|}
\hline $\begin{array}{c}\text { Parameter } \\
\text { Name (Section } \\
\text { Discussed) }\end{array}$ & Parameter Source & DTN & $\begin{array}{l}\text { Parameter } \\
\text { Value(s) }\end{array}$ & Units & $\begin{array}{c}\text { Distribution } \\
\text { (or Single } \\
\text { Value if Fixed) }\end{array}$ \\
\hline $\begin{array}{l}\text { Colloid size } \\
\text { exclusion } \\
\text { factors } \\
\text { Section } 6.5 .10\end{array}$ & N/A & $\begin{array}{l}\text { LA0003MCG12213.002 } \\
\text { [DIRS 147285] }\end{array}$ & $\begin{array}{l}\text { Probability of a } \\
\text { colloid being } \\
\text { excluded at } \\
\text { fracture-matrix } \\
\text { interface. } \\
\text { Varies from } \\
\text { layer to layer }\end{array}$ & None & $\begin{array}{l}\text { Fixed values } \\
\text { but vary from } \\
\text { layer to layer }\end{array}$ \\
\hline $\begin{array}{l}\text { Fractions of } \\
\text { colloid traveling } \\
\text { unretarded } \\
\text { Section } 6.5 .13\end{array}$ & $\begin{array}{l}\text { BSC } 2004 \\
\text { [DIRS 170006] } \\
\text { Saturated Zone } \\
\text { Colloid Transport } \\
\text { (ANL-NBS-HS- } \\
\text { 000031 REV 02) }\end{array}$ & $\begin{array}{l}\text { LA0303HV831352.003 } \\
\text { [DIRS 165624] }\end{array}$ & $\begin{array}{l}\text { Varies with } \\
\text { transport time }\end{array}$ & None & $\begin{array}{l}\text { Fractions of } \\
\text { colloids } \\
\text { traveling } \\
\text { unretarded are } \\
\text { given. }\end{array}$ \\
\hline $\begin{array}{l}\text { Colloid } \\
\text { retardation } \\
\text { factor } \\
\text { Section } 6.5 .13\end{array}$ & $\begin{array}{l}\text { BSC } 2004 \\
\text { [DIRS 170006] } \\
\text { Saturated Zone } \\
\text { Colloid Transport } \\
\text { (ANL-NBS-HS- } \\
\text { 000031 REV 02) }\end{array}$ & $\begin{array}{l}\text { LA0303HV831352.002 } \\
\text { [DIRS 163558] }\end{array}$ & $\begin{array}{l}\text { Sampled } \\
\text { statistical } \\
\text { values }\end{array}$ & None & $\begin{array}{l}\text { Cumulative } \\
\text { distribution }\end{array}$ \\
\hline $\begin{array}{l}\text { Matrix diffusion } \\
\text { coefficient } \\
\text { Section } 6.5 .5\end{array}$ & $\begin{array}{l}\text { BSC } 2004 \\
\text { [DIRS 170042] } \\
\text { Saturated Zone Flow } \\
\text { and Transport Model } \\
\text { Abstraction (MDL- } \\
\text { NBS-HS-000021 } \\
\text { REV 02) }\end{array}$ & $\begin{array}{l}\text { SN0306T0502103.006 } \\
\text { [DIRS 163944] }\end{array}$ & $\begin{array}{l}\text { Sampled } \\
\text { parameter } \\
\text { values }\end{array}$ & $\mathrm{m}^{2} / \mathrm{s}$ & $\begin{array}{l}\text { Layers are } \\
\text { grouped } \\
\text { together based } \\
\text { on similar rock } \\
\text { properties and } \\
\text { parameters are } \\
\text { sampled for } \\
\text { estimating } \\
\text { matrix diffusion } \\
\text { coefficient }\end{array}$ \\
\hline $\begin{array}{l}\text { Fracture } \\
\text { dispersivity }\end{array}$ & $\begin{array}{l}\text { BSC } 2004 \\
\text { [DIRS 170010], } \\
\text { Table 6.3-3 }\end{array}$ & N/A & 10. & $\mathrm{~m}$ & Fixed \\
\hline $\begin{array}{l}\text { Matrix sorption } \\
\text { coefficient } \\
\text { Section } 6.5 .4\end{array}$ & $\begin{array}{l}\text { BSC } 2004 \\
\text { [DIRS 164500] } \\
\text { Radionuclide } \\
\text { Transport Models } \\
\text { Under Ambient } \\
\text { Conditions (MDL- } \\
\text { NBS-HS-000008 } \\
\text { REV 02) }\end{array}$ & $\begin{array}{l}\text { LA0408AM831341.001 } \\
\text { [DIRS 171584] }\end{array}$ & $\begin{array}{l}\text { Parameter } \\
\text { values are } \\
\text { sampled } \\
\text { based on the } \\
\text { given } \\
\text { distribution }\end{array}$ & $\mathrm{mL} / \mathrm{g}$ & $\begin{array}{l}\text { Distributions } \\
\text { defined in DTN } \\
\text { by rock type } \\
\text { and } \\
\text { radionuclide }\end{array}$ \\
\hline $\begin{array}{l}\text { Radionuclide } \\
\text { half-lives } \\
\text { Section 6.5.14 }\end{array}$ & $\begin{array}{l}\text { Parrington et al. } 1996 \\
\text { [DIRS 103896] }\end{array}$ & N/A: Accepted data & $\begin{array}{l}\text { Varies for } \\
\text { each } \\
\text { radionuclide }\end{array}$ & $\mathrm{Yr}$ & $\begin{array}{l}\text { Fixed value for } \\
\text { each } \\
\text { radionuclide }\end{array}$ \\
\hline
\end{tabular}

DTN=data tracking number.

*This report is cited because it is the source of DTN: LB0210THRMLPRP.001 [DIRS 160799]. Justification for using an output DTN from a source to be superseded by BSC 2004 [DIRS 170038] Analysis of Hydrologic Properties Data (ANL-NBS-HS-000042 REV00) is given in the text of this Section (4.1.2) under the heading "Matrix Porosity". 


\section{Unsaturated Zone Flow Parameters}

The UZ flow data set also provides the hydrologic properties needed to calculate the flowing fracture spacing based on the AFM (Liu et al. 1998 [DIRS 105729], Equation 17). The ratio of the geometric fracture spacing to the flowing fracture spacing is equated to the normalized fracture water saturation raised to an exponent that is the active fracture parameter. (Liu et al. 1998 [DIRS 105729], Equation 17). The active fracture parameter is given in DTN: LB0305TSPA18FF.001 [DIRS 165625] and fracture residual saturation is a uniform value of 0.01 for all climate scenarios as given in DTNs: LB0208UZDSCPLI.002 [DIRS 161788], LB0208UZDSCPMI.002 [DIRS 161243], and LB0302UZDSCPUI.002 [DIRS 161787]. Because the flow model computes water flux using the normalized water saturation (BSC 2004 [DIRS 169861], Appendix E), the uniform value with no uncertainty is appropriate.

\section{Fracture Frequency and Fracture Porosity}

Data for the mean and standard deviation of fracture frequency and fracture porosity for the hydrologic units in and beneath the repository are given in Table 6-5 of the report, Analysis of Hydrologic Properties Data (BSC 2004 [DIRS 170038]; DTN: LB0205REVUZPRP.001 [DIRS 159525]). Fracture frequency is determined from qualified fracture property data developed from field data (BSC 2004 [DIRS 170038], Section 6.1.2). These include detailed line survey fracture data (collected from the Exploratory Studies Facility North and South Ramps, Main Drift, and Enhanced Characterization of the Repository Block Cross Drift, providing spatially varying frequency, length, and fracture dips and strikes) and fracture frequency data from boreholes. A combination of fracture porosity data derived from gas tracer tests in the Exploratory Studies Facility, fracture frequency data, fracture aperture estimates, and the geometry of fracture networks are used to develop representative fracture porosities for the UZ model layers (BSC 2004 [DIRS 170038], Section 6.1.3). See Section 6.5.7 for a complete discussion of the uncertainty treatment for fracture frequency and fracture porosity. Fracture frequency data in the repository host rock provides estimates for the standard deviation of fracture frequency in some, but not all, of the model units. Data from units having standard deviations are used to develop uncertainty data for those without such data.

\section{Matrix Porosity}

Matrix water content is needed to determine the advective transport velocity from the water flux provided by the flow model. Water content is the product of the porosity and the water saturation. Water saturation is an output of the flow model. Matrix porosity is also used by the flow model, although steady-state flow fields are insensitive to this parameter. The two sitespecific data sets for matrix porosity are the thermal property set (DTN: LB0210THRMLPRP.001 [DIRS 160799]) and the hydrologic property set (DTN: LB0207REVUZPRP.002).

For the hydrologic properties set, sample collection and laboratory measurement methodologies, as well as estimates of core uncertainty, are described by Flint (1998 [DIRS 100033], pp. 11-19) and Rousseau et al. (1999 [DIRS 102097], pp. 125-153). Core samples are grouped and analyzed according to the hydrogeologic units characterized by Flint (1998 [DIRS 100033], pp. 19-46) 
and detailed in a Scientific Notebook (Wang 2003 [DIRS 161654], SN-LBNL-SCI-003-V2, pp. $57-83)$.

The thermal properties set matrix porosities are based on DTN: SN0206T0503102.005 [DIRS 160258] and DTN: SN0208T0503102.007 [DIRS 160257]. These data were derived from petrophysical measurements. The first of these two DTNs supplies properties for most of the lithostratigraphic layers except those in the proposed repository horizon. The second DTN deals with thermal properties of the lithostratigraphic layers in the repository horizon, namely the upper lithophysal, the middle nonlithophysal, the lower lithophysal, and the lower nonlithophysal stratigraphic units of Topopah Spring welded tuff. Borehole petrophysical measurements of bulk density and neutron porosity are used to make quantitative estimates of matrix porosity (BSC 2004 [DIRS 169854], Section 4).

The UZ flow and UZ transport models selected the thermal property set for matrix porosity and for consistency, this property set is implemented here, with the exception of porosity values used for matrix diffusion (discussed below). For units below the repository, the matrix porosity differences between the two property sets are not large, ranging from 22 percent to -9 percent difference between the thermal property set and the hydrologic property set in the different hydrologic units, with an average difference of about 3 percent.

Although errors were identified in DTN: LB0210THRMLPRP.001 [DIRS 160799] and these errors have been corrected in DTN: LB0402THRMLPRP.001 [DIRS 168481], there are four reasons why the original data set is being used for radionuclide transport:

1. The corrected data set became available too late to be implemented in TSPA-LA.

2. For most applications, other UZ models supporting TSPA-LA use the properties given in DTN: LB0210THRMLPRP.001 [DIRS 160799]. Therefore, these properties are needed for consistency with other models implemented in TSPA-LA. Those applications that do not use DTN: LB0210THRMLPRP.001 [DIRS 160799] use DTN: LB0207REVUZPRP.002 [DIRS 159672] (not DTN: LB0402THRMLPRP.001 [DIRS 168481]) because this data set contains additional statistical information (standard deviations) for hydrologic properties.

3. The errors in DTN: LB0210THRMLPRP.001 [DIRS 160799] have negligible effect on transport times through the UZ. Profiles along three boreholes between the repository and the water table (BSC 2004 [DIRS 164500], Appendix C) were checked for total porosity (for nonsorbing radionuclides) and total "storage capacity" (porosity plus sorptive storage fraction) using properties from DTN: LB0210THRMLPRP.001 [DIRS 160799] and from DTN: LB0402THRMLPRP.001 [DIRS 168481]. The differences were less than $5 \%$ in all but one case and less than $11 \%$ in the exceptional case, using a matrix water saturation of 0.9 and a sorption coefficient $\left(\mathrm{K}_{\mathrm{d}}\right)$ of $1 \mathrm{~mL} / \mathrm{g}$ for the sorbing cases. These differences are insignificant compared with the order of magnitude uncertainties in transport times shown in the report by BSC (2004 [DIRS 164500], Figures 6-8, 6-33, 6-34, 6-36, 6-38, and 6-39). In addition, sensitivity studies conducted with the mountain-scale THC model using the two thermal property data sets found that the differences in thermal properties and matrix porosity have 
negligible effects on temperatures, gas compositions, and water chemistry (BSC 2004 [DIRS 169866], Appendix VI).

4. The differences in all cases give smaller total porosities and sorptive storage fractions, leading to faster radionuclide transport through the UZ using DTN: LB0210THRMLPRP.001 [DIRS 160799] instead of DTN: LB0402THRMLPRP.001 [DIRS 168481].

\section{Diffusion in Fractured Rock}

Site-specific diffusion cell data were used to develop a correlation between the matrix diffusion coefficient, and the porosity and permeability of the rock matrix under saturated conditions, as discussed in Reimus et al. (2002 [DIRS 163008]) and Saturated Zone Flow and Transport Model Abstraction (BSC 2004 [DIRS 170042], Section 6.5.2.6, Equation 6-19).

The diffusing species ${ }^{3} \mathrm{HHO}, \mathrm{Br}^{-}$, and $\mathrm{I}^{-}$were used in the experiments to define the correlation. Samples of welded and nonwelded volcanic tuffs were taken from Pahute Mesa and the C-holes near Yucca Mountain. The ranges in porosity and permeability of these samples are approximately 0.05 to 0.3 and $10^{-18} \mathrm{~m}^{2}$ to $10^{-14} \mathrm{~m}^{2}$, respectively. The porosity and permeability of rock units in the repository horizon are in approximately the same range (porosity ranges from 0.11 to 0.15 (BSC 2004 [DIRS 170038], Table 6-6) and permeability from $10^{-19} \mathrm{~m}^{2}$ to $10^{-17} \mathrm{~m}^{2}$ (BSC 2004 [DIRS 169861], Table A-1). Reimus et al. (2002 [DIRS 163008], Section 4) found that differences in rock type account for the largest variability in the effective diffusion coefficients, rather than variability between diffusing species, size, and charge. The highest predictability in determining a value of the matrix diffusion coefficient occurs when both matrix porosity and log permeability are known, with log permeability as the most important predictive variable. The correlation, given in Section 6.5.5, accounts for effects of changes in water saturation on diffusion through an adjustment of a correlation derived for saturated conditions to one applicable to unsaturated conditions. The correlation involves matrix porosity and permeability.

Data for matrix porosity and permeability are used to evaluate matrix diffusion. Matrix porosity is taken from the hydrologic parameter set presented in Table 6-6 of Analysis of Hydrologic Properties Data (BSC 2004 [DIRS 170038]; DTN: LB0207REVUZPRP.002 [DIRS 159672]). Note that the porosity data set selected for use in TSPA is thermal properties data set presented in Table 9 (BSC 2003 [DIRS 161773]; DTN: LB0210THRMLPRP.001 [DIRS 160799]). However, the differences in values within and below the repository are, on average, about 3 percent lower for the hydrologic parameter set. The reason for using the hydrologic property set is because this data set provides an estimate of the variance of the porosity, which is used to statistically sample matrix porosity. See Section 6.5 .5 for a complete discussion of the uncertainty treatment.

Matrix permeability is taken from the drift-scale calibrated property sets (BSC 2004 [DIRS 169857], Tables 6-8, 6-9, and 6-10; DTNs: LB0208UZDSCPLI.002 [DIRS 161788]; LB0208UZDSCPMI.002 [DIRS 161243]; and LB0302UZDSCPUI.002 [DIRS 161787]). These permeability values are calibrated against water saturation and water potential values for the lower, mean, and upper bound present-day infiltration cases using one-dimensional models and 
inverse modeling methods (BSC 2004 [DIRS 169857], Section 6.3.2). These cases represent the uncertainty in flux through the UZ and therefore the property sets calibrated to these different infiltration cases represent the uncertainty in the properties that are consistent with the calibration. The subsequent calibrations with the site-scale 3D model did not affect the values of matrix permeability (BSC 2004 [DIRS 169861], Appendix A, Tables A-1, A-2, and A-3).

\section{Fracture Dispersivity}

The fracture dispersivity is set at a fixed value of $10 \mathrm{~m}$. There are few data available on dispersivity distributions at Yucca Mountain site. Neuman 1990 [DIRS 101464] showed that field dispersivity varied with the scale of study. Field tracer tests at the C-holes at Yucca Mountain also showed that on a $100 \mathrm{~m}$ scale, field dispersivity had a range of approximately 3 to $63 \mathrm{~m}$ (BSC 2004 [DIRS 170010], Table 6.3-3). The $10 \mathrm{~m}$ value is toward the lower end of the value from field studies (BSC 2004 [DIRS 170010], Table 6.3-3). The influence of dispersion on radionuclide transport is not expected to be important because the spreading of radionuclides due to matrix diffusion effects have a much greater impact on transport times than longitudinal dispersion over the expected range of longitudinal dispersivities. Although the impact of dispersivity should be very small, the value chosen should be conservative, as higher dispersivity tends to spread the radionuclide plume and reduce the peak value. While it can be argued that for a decaying species, higher dispersivity can allow a greater fraction of the mass to arrive downstream before decaying, the point here is that in comparison to diffusion and large scale heterogeneities, dispersivity effects have a very small influence on the breakthrough curves. This justifies the use of a fixed value for dispersivity rather than treating it as a stochastic parameter (Table 6-2).

\section{Sorption}

The derivation of sorption coefficient probability distributions for the elements of interest on the major rock types in Yucca Mountain involves both an evaluation of available experimental data and sorption modeling. Sorption data have been obtained in laboratory experiments in which crushed rock samples from the Yucca Mountain site were contacted with groundwaters (or simulated groundwaters) representative of the site, spiked with one or more of the elements of interest (BSC 2004 [DIRS 164500], Section A.1). Experimental data were used to evaluate the impact of variations in rock sorption properties within each of the rock types, radionuclide concentrations, sorption kinetics, and water chemistry on sorption coefficients for the elements of interest. The radioisotopes of $\mathrm{Am}, \mathrm{Cs}, \mathrm{Np}, \mathrm{Pa}, \mathrm{Pu}, \mathrm{Ra}, \mathrm{Sr}, \mathrm{Th}$, and $\mathrm{U}$ are treated as sorbing. The radioisotopes of $\mathrm{C}$, I, and Tc are treated as nonsorbing.

The modeling of sorption in the TSPA-LA is based on the linear sorption model, which is characterized by the same lumped parameter for the sorption coefficient $K_{d}$ that is used in the process models. All aqueous radionuclides that travel in fractures are conservatively assumed not to be absorbed by the facture walls (BSC 2004 [DIRS 164500], Section 6.4.2). For radionuclides that travel in the matrix, the partitioning of radionuclides between the solute and the matrix is described by the sorption coefficient for each radionuclide. The matrix sorption coefficients that have been developed for different rock types (zeolitic, devitrified, and vitric) are listed in Table 6-5 with their statistical distributions. These distributions are sampled to represent the uncertainty in sorption in the TSPA-LA. The influence of expected variations in 
water chemistry, radionuclide concentrations, and variations in rock surface properties within each of the major rock types were incorporated into the probability distributions. Effective $\mathrm{K}_{\mathrm{d}}$ values, obtained from batch experiments involving high-concentration solutions, will tend to underestimate the field $\mathrm{K}_{\mathrm{d}}$ values if the expected field concentrations are low and nonlinear sorption prevails (BSC 2004 [DIRS 164500], Section 6.1.2.3).

The evaluation of the effects of sorption on transport also requires specification of the rock bulk density, matrix water content, as shown in Equation 6-2. Matrix water content is the product of the water saturation times the porosity. The matrix porosity used for determining the retardation of sorbing solutes is from the thermal property set, DTN: LB0210THRMLPRP.001 [DIRS 160799], which is the same value of matrix porosity used to determine the advective transport velocity in the matrix, as discussed above. Bulk rock density is computed from grain densities given in DTN: LB0210THRMLPRP.001 [DIRS 160799] by multiplying by the ratio of the grain volume to the bulk volume, which is equal to one minus the porosity. See also the discussion under Matrix Porosity (this section) concerning the use of DTN: LB0210THRMLPRP.001 [DIRS 160799] rather than DTN: LB0402THRMLPRP.001 [DIRS 168481] for grain density.

\section{Radionuclide Sorption onto Colloids}

Colloid transport is represented through radionuclide attachment to colloids that are either reversible or irreversible. For reversible attachment, the degree of partitioning onto colloids is a function of both the colloid concentration and the sorption coefficient for a given radioelement onto the colloid (Section 6.5.12). The groundwater colloid size distribution that was developed for use in the TSPA-LA model was based on data from 79 groundwater samples collected in the vicinity of Yucca Mountain and 11 samples collected from the Idaho National Engineering and Environmental Laboratory (INEEL). Inclusion of the INEEL groundwater colloid data (DTN: LA0002SK831352.003 [DIRS 161771]) was deemed appropriate for inclusion in the data analysis among the groundwater data from the Yucca Mountain area because the climate in Idaho Falls is similarly arid and the field sampling and analytical techniques used at both locations were similar (DTN: SN0306T0504103.005 [DIRS 164132]). Note that the distributions for two ionic strength conditions are presented, however, only the lower ionic strength distribution is used for TSPA because the lower ionic strength distribution results in greater colloid concentrations leading to greater colloid-facilitated radionuclide transport.

Sorption partition coefficients ( $\mathrm{K}_{\mathrm{d}}$ values) have been developed for selected radionuclides onto smectite and iron oxyhydroxides (DTN: SN0306T0504103.006 [DIRS 164131]). Smectite is representative of defense high-level waste glass degradation product colloids and natural groundwater colloids. Iron oxyhydroxides are representative of steel corrosion-generated colloids (assumed to be iron oxyhydroxides). These colloidal constituents may act as pseudocolloids that sorb radionuclides and subsequently be transported from the engineered barrier system (EBS) by seepage waters moving through the repository. The $\mathrm{K}_{\mathrm{d}}$ values for the radioelements $\mathrm{Pu}, \mathrm{Am}$, Th, $\mathrm{Pa}$, and $\mathrm{Cs}$ are drawn from both project-supported experimental work, government publications, and the open literature. For a given radionuclide (except Cs) the maximum value of each $\mathrm{K}_{\mathrm{d}}$ value range is the same to allow for the possibility that iron oxyhydroxide will occur both as iron oxyhydroxides colloids and as coatings on, or microcrystalline aggregates in association with, smectite colloids in the iron-rich waste package environment. For Cs, which attaches more 
strongly to smectite (by ion exchange) than iron oxyhydroxides, the upper value of the $\mathrm{K}_{\mathrm{d}}$ value range is different for iron oxyhydroxides and smectite.

For irreversible attachment, the parameter $K_{c}$ is set to a fixed value of $10^{20}$ that practically ensures that radioelements remain permanently attached to the colloid (Section 6.5.12).

\section{Colloid Filtration and Size Exclusion}

Colloid size exclusion is treated in the model for colloid movement from fractures into the rock matrix. Size exclusion is treated on the basis of effective colloid and matrix pore diameters, where a colloid is excluded from entry into a pore that is smaller than the colloid. The matrix pore size distributions for different rock types were developed from moisture retention curve measurements on rock matrix samples taken from 16 different hydrogeologic units between the repository host rock and the water table at Yucca Mountain (DTN: LA0003MCG12213.002 [DIRS 147285]). The pore size distribution data were used for the average effective colloid diameter of $0.1 \mu \mathrm{m}$, giving the expected fraction of colloids excluded from entering the rock matrix in each hydrogeologic unit.

Colloid filtration is treated in the model for colloid transport between successive rock matrix hydrogeologic units. This is based on physical straining, in which filtration will occur if a colloid attempts to pass though a pore with an effective diameter that is smaller than the colloid effective diameter. Pore size distributions are based on the data discussed above. Colloid size distribution data is available from measurements colloids generated from high-level waste glass corrosion using a dynamic light-scattering method (DTN: LL000122051021.116 [DIRS 142973], MOL.20010216.0003 Section 6.3; see also DTN: LL991109751021.094 [DIRS 142910], MOL.20000124.0207 p. 32 and 34).

\section{Colloid Retardation in Transport Through Fractures}

Colloid retardation in transport through fractures in volcanic tuffs has been investigated in field tests conducted in the saturated zone (SZ) at Yucca Mountain (BSC 2004 [DIRS 170006], Section 6.4). These retardation factors represent the chemical and physical filtration of colloids in the SZ. The field measurements were conducted using fluorescent carboxylate modified polystyrene latex (CML) microspheres ranging in diameter from $280 \mathrm{~nm}$ to $830 \mathrm{~nm}$. Results from laboratory fracture experiments conducted using silica, montmorillonite, and clinoptilolite colloids in addition to CML microspheres suggest that colloid filtration and retardation parameters derived from CML microsphere responses in field tracer tests should be conservative if used to predict natural inorganic colloid transport in fractured systems. The retardation factors have been derived in terms of a cumulative probability distribution representing the uncertainty in retardation factors applied to colloid transport through fractures (DTN: LA0303HV831352.002 [DIRS 163558]). The application of these results to the UZ is based on the similar geologic units (fractured volcanic rocks) and transport processes at the scale governing colloid transport processes. Furthermore, colloid transport in the UZ is expected to be less favorable than in the SZ as a result of the smaller fractures (or possibly water films) in which water flows through unsaturated fractures, leading to a conservative representation of colloid transport in the UZ. In addition to colloid retardation, a fraction of unretarded colloid transport is developed based on the attachment rates derived from the colloid transport field test data 
(DTN: LA0303HV831352.003 [DIRS 165624]). This distribution is tied to the transport time distributions experienced by the colloids (BSC 2004 [DIRS 170006], Section 6.6). Rather than incorporating the full distribution as a function of transport time, a single conservative value for unretarded colloid transport is used as discussed in Section 6.5.13.

\subsection{CRITERIA}

Technical requirements to be satisfied by PA are based on 10 CFR 63.114 [DIRS 156605] and identified in the Yucca Mountain Project Requirements Document (Canori and Leitner 2003 [DIRS 166275]). The acceptance criteria that will be used by the U.S. Nuclear Regulatory Commission to determine whether the technical requirements have been met are identified in the Yucca Mountain Review Plan, Final Report (YMRP) (NRC 2003 [DIRS 163274]). The pertinent requirements and criteria for this report are summarized in Table 4-3.

Table 4-3. Project Requirements and YMRP Acceptance Criteria Applicable to this Model Report

\begin{tabular}{|c|l|l|l|}
\hline $\begin{array}{c}\text { Requirement } \\
\text { Number }^{\mathbf{a}}\end{array}$ & \multicolumn{1}{|c|}{ Requirement Title $^{\mathbf{a}}$} & \multicolumn{1}{c|}{ 10 CFR 63 Link } & \multicolumn{1}{c|}{$\begin{array}{c}\text { YMRP Acceptance } \\
\text { Criteria }^{\mathbf{b}}\end{array}$} \\
\hline PRD -002/T-016 & Requirements for performance assessment & $\begin{array}{l}\text { 10 CFR 63.114 } \\
\text { (a)-(c), (e), (g) } \\
\text { [DIRS 156605] }\end{array}$ & 2.2.1.3.7.3, criteria 1 to 4 \\
\hline
\end{tabular}

${ }^{\mathrm{a}}$ From Canori and Leitner (2003 [DIRS 166275]).

${ }^{\mathrm{b}}$ From NRC (2003 [DIRS 163274]).

YMRP =Yucca Mountain Review Plan, Final Report

The pertinent requirements and acceptance criteria for this report are identified in Section 2.2.1.3.7.3 of the YMRP (NRC 2003 [DIRS 163274]). The criteria and subcriteria are given below, followed by a short description of their applicability to this report. Where a subcriterion includes several components, only some of those components may be addressed. How these components are addressed is summarized in Section 8.3 of this report.

\section{Acceptance Criterion 1: System Description and Model Integration Are Adequate.}

(1) Total system performance assessment adequately incorporates important design features, physical phenomena, and couplings, and uses consistent and appropriate assumptions throughout the radionuclide transport in the unsaturated zone abstraction process;

(2) The description of the aspects of hydrology, geology, geochemistry, design features, physical phenomena, and couplings that may affect radionuclide transport in the unsaturated zone is adequate. For example, the description includes changes in transport properties in the unsaturated zone, from water-rock interaction. Conditions and assumptions in the total system performance assessment abstraction of radionuclide transport in the unsaturated zone are readily identified, and consistent with the body of data presented in the description;

(3) The abstraction of radionuclide transport in the unsaturated zone uses assumptions, technical bases, data, and models that are appropriate and consistent with other related U.S. Department of Energy abstractions. For example, assumptions used for radionuclide transport in the unsaturated zone are consistent with the abstractions of radionuclide release 
rates and solubility limits and flow paths in the unsaturated zone (Sections 2.2.1.3.4 and 2.2.1.3.6 of the Yucca Mountain Review Plan, respectively). The descriptions and technical bases provide transparent and traceable support for the abstraction of radionuclide transport in the unsaturated zone;

(4) Boundary and initial conditions used in the abstraction of radionuclide transport in the unsaturated zone are propagated throughout its abstraction approaches. For example, the conditions and assumptions used to generate transport parameter values are consistent with other geological, hydrological, and geochemical conditions in the total system performance assessment abstraction of the unsaturated zone;

(5) Sufficient data and technical bases for the inclusion of features, events, and processes related to radionuclide transport in the unsaturated zone in the total system performance assessment abstraction are provided;

(6) Guidance in NUREG-1297 and NUREG-1298 (Altman et al. 1988 [DIRS 103597]; Altman et al 1988 [DIRS 103750]), or other acceptable approaches, is followed for peer review and data qualification.

\section{Acceptance Criterion 2: Data Are Sufficient for Model Justification.}

(1) Geological, hydrological, and geochemical values used in the license application are adequately justified (e.g., flow-path length, sorption coefficients, retardation factors, colloid concentrations, etc.). Adequate descriptions of how the data were used, interpreted, and appropriately synthesized into the parameters are provided;

(2) Sufficient data have been collected on the characteristics of the natural system to establish initial and boundary conditions for the total system performance assessment abstraction of radionuclide transport in the unsaturated zone;

(3) Data on the geology, hydrology, and geochemistry of the unsaturated zone, including the influence of structural features, fracture distributions, fracture properties, and stratigraphy, used in the total system performance assessment abstraction are based on appropriate techniques. These techniques may include laboratory experiments, site-specific field measurements, natural analog research, and process-level modeling studies. As appropriate, sensitivity or uncertainty analyses used to support the U.S. Department of Energy total system performance assessment abstraction are adequate to determine the possible need for additional data.

\section{Acceptance Criterion 3: Data Uncertainty Is Characterized and Propagated Through the Model Abstraction.}

(1) Models use parameter values, assumed ranges, probability distributions, and bounding assumptions that are technically defensible, reasonably account for uncertainties and variabilities, and do not result in an under-representation of the risk estimate;

(2) For those radionuclides where the total system performance assessment abstraction indicates that transport in fractures and matrix in the unsaturated zone is important to waste 
isolation: (i) estimated flow and transport parameters are appropriate and valid based on techniques that may include laboratory experiments, field measurements, natural analog research, and process-level modeling studies conducted under conditions relevant to the unsaturated zone at Yucca Mountain; and (ii) models are demonstrated to adequately reproduce field transport test results. For example, if a sorption coefficient approach is used, the assumptions implicit in that approach are verified;

(4) Uncertainty is adequately represented in parameter development for conceptual models, process-level models, and alternative conceptual models considered in developing the abstraction of radionuclide transport in the unsaturated zone. This may be done either through sensitivity analyses or use of conservative limits;

\section{Acceptance Criterion 4: Model Uncertainty Is Characterized and Propagated Through the Model Abstraction.}

(1) Alternative modeling approaches of features, events, and processes are considered and are consistent with available data and current scientific understanding, and the results and limitations are appropriately considered in the abstraction;

(2) Conceptual model uncertainties are adequately defined and documented, and effects on conclusions regarding performance are properly assessed;

(3) Consideration of conceptual model uncertainty is consistent with available site characterization data, laboratory experiments, field measurements, natural analog information and process-level modeling studies; the treatment of conceptual mode uncertainty does not result in an under-representation of the risk estimate;

(4) Appropriate alternative modeling approaches are consistent with available data and current scientific knowledge, and appropriately consider their results and limitations, using tests and analyses that are sensitive to the processes modeled. For example, for radionuclide transport through fractures, the U.S. Department of Energy adequately considers alternative modeling approaches to develop its understanding of fracture distributions and ranges of fracture flow and transport properties in the unsaturated zone.

\section{Acceptance Criterion 5: Model Abstraction Output Is Supported by Objective Comparisons.}

(1) The models implemented in this total system performance assessment abstraction provide results consistent with output from detailed process-level models and/or empirical observations (laboratory and field testings and/or natural analogs);

(2) Outputs of radionuclide transport in the unsaturated zone abstractions reasonably produce or bound the results of corresponding process-level models, empirical observations, or both. The U.S. Department of Energy abstracted models for radionuclide transport in the unsaturated zone are based on the same hydrological, geological, and geochemical assumptions and approximations shown to be appropriate for closely analogous natural systems or experimental systems; 
(3) Well-documented procedures that have been accepted by the scientific community to construct and test the mathematical and numerical models are used to simulate radionuclide transport through the unsaturated zone;

(4) Sensitivity analyses or bounding analyses are provided to support the total system performance assessment abstraction of radionuclide transport in the unsaturated zone that cover ranges consistent with site data, field or laboratory experiments and tests, and natural analog research.

\subsection{CODES, STANDARDS, AND REGULATIONS}

No codes, standards, or regulations, other than those identified in the Project Requirements Documents (Canori and Leitner 2003 [DIRS 166275], Table 2-3) and determined to be applicable in Table 4-3, were used in this analysis/model report. 


\section{INTENTIONALLY LEFT BLANK}




\section{ASSUMPTIONS}

In this section, the assumptions taken to develop the UZ radionuclide transport abstraction model are outlined as the first step toward developing the computational and mathematical models needed in radionuclide transport calculations for the TSPA-LA model. In Section 6.4, the mathematical basis for this algorithm is outlined, and theory is developed to incorporate the effects of sorption, dispersion, and matrix diffusion into this new particle-tracking framework. In the remainder of this section, the fundamental assumptions of the techniques itself and the specific implementation for the UZ transport abstraction model are listed and justified.

Assumption 1: The AFM (Liu et al. 1998 [DIRS 105729]) appropriately accounts for reduced fracture/matrix (f/m) interaction.

Rationale: The reduction in $\mathrm{f} / \mathrm{m}$ contact area is a result of flow focusing. This flow focusing is represented using the active fracture unsaturated flow model. In Section 7.4.1 of the report by BSC (2004 [DIRS 170035]), model validation for the AFM was carried out through a comparison of a one-dimensional, AFMbased model with C-14 data. The analysis showed that the AFM could be used to explain the transport times implied by the C-14 data in boreholes USW UZ-1 and USW SD-12. On the basis of this agreement, it can be assumed that the AFM is a suitable model for addressing fracture-matrix interactions for radionuclides simulated in the abstraction model.

Confirmation Status: This assumption does not require further verification, as the model has been validated for use, as discussed above.

Where Used: Section 6.4.3

Assumption 2: The influence of matrix diffusion in a dual-permeability system can be handled with a subgrid-block model consisting of parallel flow in a discrete fracture and connected matrix.

Rationale: Although the submodel consisting of a repeating system of parallel, equally spaced fractures and parallel flow in the fractures and matrix is an idealization; it captures one of the key features in the UZ system, namely the influence of radionuclide diffusion between fractures and matrix. Furthermore, the influence of sharp concentration gradients in the matrix is implicitly accounted for in the model by incorporating results from a discrete fracture model designed to handle these effects accurately. Therefore, systems with relatively small amounts of matrix diffusion can be simulated, in contrast to implementations of dual-permeability transport that represent the matrix with a single grid block. In numerical modeling, this type of idealization, commonly referred to as "upscaling," is a technique for capturing the essential features of a physical system, even though it is understood that the actual system contains geometric complexities not simulated in the model. For example, Table 6-11 shows that the distribution of fracture spacings of mapped fractures is not uniform. However, the important spacing of interest for transport is the spacing 
of flowing fractures, which adds significant additional uncertainty. Given this situation, an appropriate assumption for the purpose of capturing the impact of matrix diffusion is to assume the model geometry of equally spaced flowing fractures.

Confirmation Status: This assumption does not require verification.

Where Used: Section 6.4.3

Assumption 3: Dispersion of both aqueous and colloidal species in the UZ can be approximated as consisting only of longitudinal dispersion, characterized by a constant value of the dispersivity $\alpha_{l}$.

Rationale: When dispersivity is used to model solute spreading in porous media, it is introduced to capture variability in the flow velocity existing at smaller scales than are modeled in the numerical grid. Large-scale spreading caused by features explicitly present in the flow simulation is captured directly, and is not considered to be dispersion in the sense being used here. Because the use of this model is to predict transport time distributions of radionuclides to the water table, longitudinal dispersion is potentially important to capture a dispersed solute front arriving at the water table. By contrast, transverse dispersion, omitted in this model, will tend to allow mass to migrate short distances in the horizontal direction. For example, as a rule of thumb, assume that a transverse dispersivity of one tenth the longitudinal dispersivity of $10 \mathrm{~m}$ (see Table 6-2), a value of $1 \mathrm{~m}$ is representative. The characteristic distance of spreading of a dispersing plume resulting from a point source is given by (Freeze and Cherry 1979 [DIRS 101173], p. 395) $\sqrt{2 D_{t} t}=\sqrt{2 \alpha_{t} v(L / v)}=\sqrt{2 \alpha_{t} L}$, where $D_{t}$ is the transverse dispersion coefficient, $\alpha_{t}$ is the transverse dispersivity, and $t$ is the characteristic time equal to the velocity, $v$, divided by the length, $L$. For a radionuclide point source traveling vertically to the water table $(L \approx 350 \mathrm{~m})$, the transverse spreading of the plume at the water table is approximately $\sqrt{2(1)(350)}=26 \mathrm{~m}$. This amount of lateral spreading is small compared to the width of the repository, or even the width of a grid block in the UZ model. Therefore, the velocity field encountered by the plume is not expected to be significantly different than if no transverse dispersion is assumed. On this basis, lateral transverse dispersion is insignificant and can be neglected. Finally, to a first approximation, this variability will act similarly on aqueous and colloidal components. As a result, the same dispersivity should be used for both.

Confirmation Status: This assumption does not require verification.

Where Used: Section 6.4.2

Assumption 4: Radionuclide releases at the location of the repository can be represented stochastically by identifying regions on the basis of the predicted water flux 
through the medium, and placing particles randomly within this region to represent the release.

Rationale: Water flux through the repository region is known to be a key factor controlling waste package degradation and waste mobilization. By partitioning the finite difference grid cells in the UZ model into groups based on flux, radionuclides will preferentially enter the system at locations where the flux is highest. This approach preserves this known relationship, and does not artificially introduce radionuclides into the model at locations where transport times are extremely long.

Confirmation Status: This assumption does not require verification.

\section{Where Used: Section 6.5.15}

Assumption 5: For the purposes of computing radionuclide transport, flow through the UZ can be approximated assuming that the system (rock mass and flow conditions) has not been influenced by repository waste heat effects or drift shadow effects. Durable changes to the rock mass hydrologic properties are also assumed to be negligible.

Rationale: Numerical modeling shows that the flow conditions around the repository will change after waste emplacement due to thermal-hydrologic effects, and these effects are expected to last for a few thousand years (BSC 2004 [DIRS 170338], Section 8.1). As long as the radionuclide releases occur after the main part of this perturbation takes place, the system should have bounced back to its ambient flow conditions. Regarding the potential for durable changes to the rock mass properties, a range of hydrologic flow conditions (in the form of different flow fields imported to the model) are assumed. It is assumed that this range will encompass the possibility of changes to the far-field rock conditions from repository waste heat.

Confirmation Status: This assumption does not require verification.

\section{Where Used: Section 6.5.1}

Assumption 6: Climate changes can be considered in an approximate way by imparting an instantaneous jump from one steady state flow field to another, with a corresponding rise or fall in the water table representing the bottom of the UZ model. Shorter-term transients (wet and dry years, individual storm events, etc.) are assumed to be adequately captured with a model that assumes such transients can be averaged to obtain a long-term, effective steady state.

Rationale: In simulations of system performance lasting 10,000 to 20,000 years, long-term changes in climatic conditions are expected to change the UZ flow field from its present-day condition. In the Yucca Mountain UZ, water transport times of hundreds to thousands of years through the entire system are likely, although this process is obviously uncertain. Assuming that the jump 
from one steady state flow field to another occurs instantaneously is a reasonable approximation, given the uncertainties and the inability to observe this process directly. When the climate changes from drier to wetter during the regulatory compliance period (BSC 2004 [DIRS 170002], Section 7), transport velocities will immediately be greater and the flow path length to the water table will be shorter; imposing both of these changes immediately will ensure that the approach will not artificially delay the imposition of the more rapid transport conditions. Regarding short-term transients, the relatively unfractured portions of the rock, such as the Paintbrush nonwelded vitric tuff (PTn), will dampen such transients, allowing a long-term steady state model to be used (BSC 2004 [DIRS 169861], Appendix G ).

Confirmation Status: This assumption does not require verification.

Where Used: Section 6.4.8 


\section{MODEL DISCUSSION}

\subsection{MODELING OBJECTIVES AND APPROACH}

This report documents the abstraction of UZ transport model to be used in TSPA-LA simulations. The UZ transport model studies the movement of radionuclides released from the EBS into the unsaturated fractured geological media downward to the water table. Radionuclide mass flux versus time exiting the UZ is transferred to the SZ model in the TSPA-LA system model.

Processes affecting radionuclide transport in the UZ include advection, dispersion, fracturematrix interaction, sorption, colloid-facilitated transport, climate change and water table rises, and radionuclide decay/ingrowth. The numerical representation of those processes is described in Section 6.4.

The pregenerated flow fields are simulated in the document by BSC (2004 [DIRS 169861]) and saved for TSPA-LA use. The use of pregenerated flow fields increases the efficiency of transport simulations.

In TSPA runs, GoldSim (BSC 2003 [DIRS 161572]) initiates a call to the FEHM external dynamic link library (dll) to start UZ transport simulations (Figure 6-1). GoldSim (BSC 2003 [DIRS 161572]) passes the following data to FEHM through the interface:

- Simulation time

- Flow fields to be used

- Coordinates for early failed packages and number of repository subregions

- Number of radionuclide species

- Radionuclide mass release from EBS to UZ in each designated subregion for each species.

At the end of each FEHM UZ transport run, FEHM passes the simulated mass output at the water table back for input to SZ. 


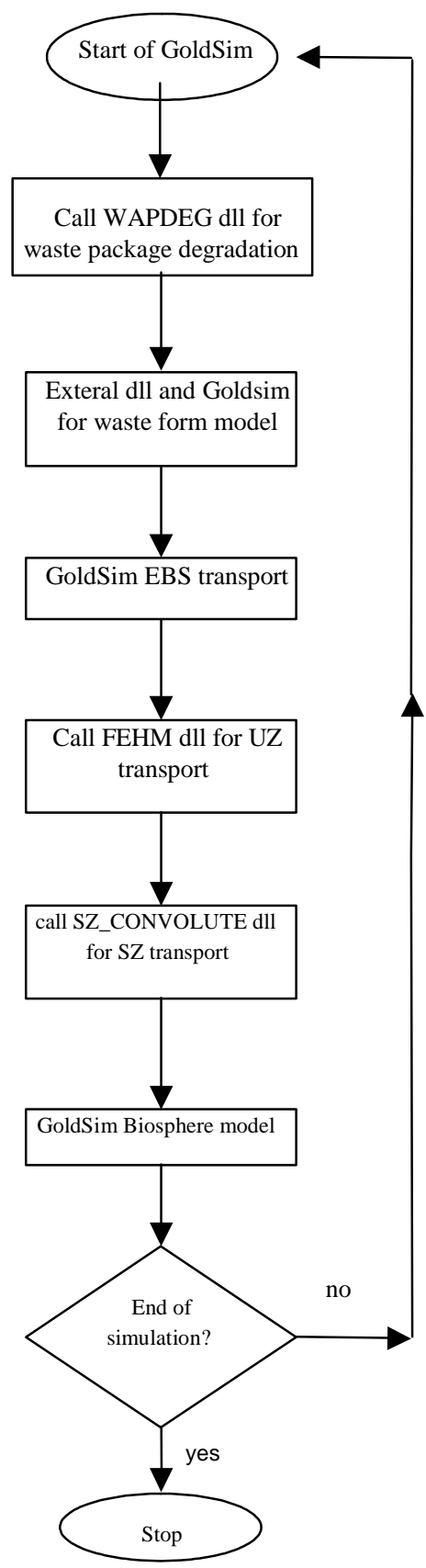

Figure 6-1. Schematic of the GoldSim-FEHM Coupling 


\subsection{FEATURES, EVENTS, AND PROCESSES INCLUDED IN THE MODEL}

The development of a comprehensive list of FEPs potentially relevant to postclosure performance of the Yucca Mountain repository is an ongoing, iterative process based on sitespecific information, design, and regulations. The list of FEPS relevant to this AMR was initially identified in the TWP (BSC 2004 [DIRS 171282]) and has been further refined based on subsequent review of the LA FEP List as documented in DTN: MO0407SEPFEPLA.000 [DIRS 170760]. The FEP 1.2.02.01.0A, Fractures, has been added to the list identified in the TWP (BSC 2004 [DIRS 171282]) because fractures are included in the UZ transport abstraction model that supports TSPA-LA. Table 6-1 provides a list of FEPs that are specifically addressed in this report and identifies the sections of this AMR that addresses those FEPs. The rationale for excluding a FEP from the TSPA-LA model is given in the Scientific Analysis Report, Features, Events, and Processes in UZ Flow and Transport (BSC 2004 [DIRS 170012]).

Table 6-1. Included FEPs for This Model Report and Their Disposition in the TSPA-LA

\begin{tabular}{|c|c|c|}
\hline FEP Number & FEP Name & Section Where FEP is Addressed* \\
\hline 1.2.02.01.0A & Fractures & Sections $6.4 .3,6.5 .1,6.5 .7$, and 6.6.2 \\
\hline 1.2.02.02.0A & Faults & Sections $6.5 .1,6.5 .7$, and 6.6.2. \\
\hline 1.3.01.00.0A & Climate change & Sections 6.4 .8 and 6.6 .2 \\
\hline 1.3.07.02.0B & Water table rise affects UZ & Section 6.4 .8 \\
\hline 1.4.01.01.0A & Climate modification increases recharge & Sections 6.5 .1 and 6.6 .2 \\
\hline 2.1.08.01.0A & Water influx at the repository & Section 6.5 .15 \\
\hline 2.2.03.01.0A & Stratigraphy & Section 6.5.1. \\
\hline 2.2.03.02.0A & Rock properties of host rock and other units & Sections 6.5.3, 6.5.7, and 6.6.2. \\
\hline 2.2.07.02.0A & Unsaturated groundwater flow in the geosphere & Sections 6.5 .1 and 6.6.2. \\
\hline 2.2.07.04.0A & Focusing of unsaturated flow (fingers, weeps) & Sections 6.5.1, 6.6.2, and C5. \\
\hline 2.2.07.06.0B & $\begin{array}{l}\text { Long-term release of radionuclides from the } \\
\text { repository }\end{array}$ & Sections 6.4 .6 and 6.4 .7 \\
\hline 2.2.07.07.0A & Perched water develops & Section 6.5 .1 \\
\hline 2.2.07.08.0A & Fracture flow in the UZ & Section 6.5 .1 \\
\hline 2.2.07.09.0A & Matrix imbibition in the UZ & Section 6.5.1 \\
\hline 2.2.07.15.0B & Advection and dispersion in the UZ & Sections 6.4.1, 6.4.2, 6.6.2, and 7.2.1.1. \\
\hline 2.2.08.01.0B & Chemical characteristics of groundwater in the UZ & Section 6.5 .4 \\
\hline 2.2.08.06.0B & Complexation in the UZ & Section 6.5 .4 \\
\hline 2.2.08.08.0B & Matrix diffusion in the $U Z$ & $\begin{array}{l}\text { Sections 6.4.3, 6.5.5, 6.6.2, 7.2.1.2, 7.2.1.3, } \\
\text { and Appendix C. }\end{array}$ \\
\hline 2.2.08.09.0B & Sorption in the UZ & $\begin{array}{l}\text { Sections 5., 6.4.3, 6.4.5, 6.5.4, 6.5.8, and } \\
6.6 .2 \text {. }\end{array}$ \\
\hline 2.2.08.10.0B & Colloidal transport in the UZ & $\begin{array}{l}\text { Sections } 6.4 .5,6.5 .9,6.5 .10,6.5 .11,6.5 .12 \text {, } \\
6.5 .13 \text {, and } 6.6 .2\end{array}$ \\
\hline 2.2.09.01.0B & Microbial activity in the UZ & Section 6.5 .4 \\
\hline 3.1.01.01.0A & Radioactive decay and ingrowth & Sections $6.4 .4,6.5 .14$, and 6.6 .2 \\
\hline
\end{tabular}


The following descriptions elaborate on several of the FEPs listed in Table 6-1. Those not included below do not require additional explanation.

- 1.2.02.01.0A-Elements of this FEP are implicitly included through the use of the pregenerated flow fields (Section 6.5.1. DTN: LB0305TSPA18FF.001 [DIRS 165625]).

- 1.2.02.02.0A-Elements of this FEP are implicitly included through the use of the pregenerated flow fields (Section 6.5.1; DTN: LB0305TSPA18FF.001 [DIRS 165625]).

- 1.3.01.00.0A-Elements of this FEP are implicitly included through the use of the pregenerated flow fields under different climates (DTN: LB0305TSPA18FF.001 [DIRS 165625]).

- 1.3.07.02.0B-Elements of this FEP are implicitly included through the use of the pregenerated flow fields under different climates, with water table rise built into the flow fields (DTN: LB0305TSPA18FF.001 [DIRS 165625]).

- 1.4.01.01.0A-Elements of this FEP are implicitly included through the use of the pregenerated flow fields under different climates (DTN: LB0305TSPA18FF.001 [DIRS 165625]).

- 2.2.03.01.0A-Elements of this FEP are implicitly included through the use of the pregenerated flow fields (Section 6.5.1; DTN: LB0305TSPA18FF.001 [DIRS 165625]).

- 2.2.07.02.0A-Elements of this FEP are implicitly included through the use of the pregenerated flow fields (Section 6.5.1; DTN: LB0305TSPA18FF.001 [DIRS 165625]).

- 2.2.07.04.0A-Elements of this FEP are implicitly included through the use of the pregenerated flow fields (Section 6.5.1; DTN: LB0305TSPA18FF.001 [DIRS 165625]). In addition, this FEP is more fully addressed in the model report UZ Flow Models and Submodels (BSC 2004 [DIRS 169861]).

- 2.2.07.07.0A-Elements of this FEP are implicitly included through the use of the pregenerated flow fields (Section 6.5.1; DTN: LB0305TSPA18FF.001 [DIRS 165625]). In addition, more detailed information on the treatment of perched water in the UZ can be found in the model report, UZ Flow Models and Submodels (BSC 2004 [DIRS 169861]).

- 2.2.07.08.0A-Elements of this FEP are implicitly included through the use of the pregenerated flow fields (Section 6.5.1; DTN: LB0305TSPA18FF.001 [DIRS 165625]) and implementation of the active fracture model in the transport abstraction. In addition, this FEP is more fully addressed in the model report UZ Flow Models and Submodels (BSC 2004 [DIRS 169861]).

- 2.2.07.09.0A-Elements of this FEP are implicitly included through the use of the pregenerated flow fields (Section 6.5.1; DTN: LB0305TSPA18FF.001 [DIRS 165625]). 
In addition, this FEP is more fully addressed in the model report UZ Flow Models and Submodels (BSC 2004 [DIRS 169861]).

- 2.2.09.01.0B - The parameter distributions for sorption coefficient were developed with microbial effects considered. See the process model report (BSC 2004 [DIRS 164500], Section 6.4.2) for a discussion of this issue.

\subsection{THE UZ TRANSPORT ABSTRACTION MODEL}

The UZ transport component of the total system model tracks the movement of radionuclides released from the EBS down to the water table (Figure 6-2).

The top boundary of the UZ flow model is the ground surface, with prescribed infiltration rates, and the bottom boundary is the water table, modeled with constant pressure. The side boundaries are no flow (BSC 2004 [DIRS 169861], Section 6.1.3).

The UZ flow fields are pregenerated and saved for use by FEHM. During TSPA simulation runs, the FEHM dll reads in the pregenerated flow fields and then carries out transport simulations. The impact of climate change is investigated by using the UZ flow fields corresponding to different climate scenarios. The FEHM-compatible flow field files developed for the TSPA-LA model are in DTN: LB0305TSPA18FF.001 [DIRS 165625].

The UZ transport model is based on the dual-k formulation for fluid flow, with additional transport considerations to incorporate the influence of sorption and fracture-matrix interactions on radionuclide transport. The influence of spatial variability is included through a threedimensional model that incorporates the appropriate geometry and geology.

For the UZ transport model, radionuclides are released at the repository where failed waste packages release radionuclides into the system. Any radionuclide that reaches the water table is removed from the UZ transport system and put into the SZ system.

Once a radionuclide particle is released from the EBS into the UZ, the particle is carried by water traveling through the fractured media downward to the water table. The following transport mechanisms can affect the movement of a radionuclide particle and are considered in the UZ transport model:

- Advection

- Dispersion

- Sorption

- Fracture-matrix interaction, including matrix diffusion

- Colloid-facilitated transport

- Radioactive decay/ingrowth

- Climate change and water table rise. 


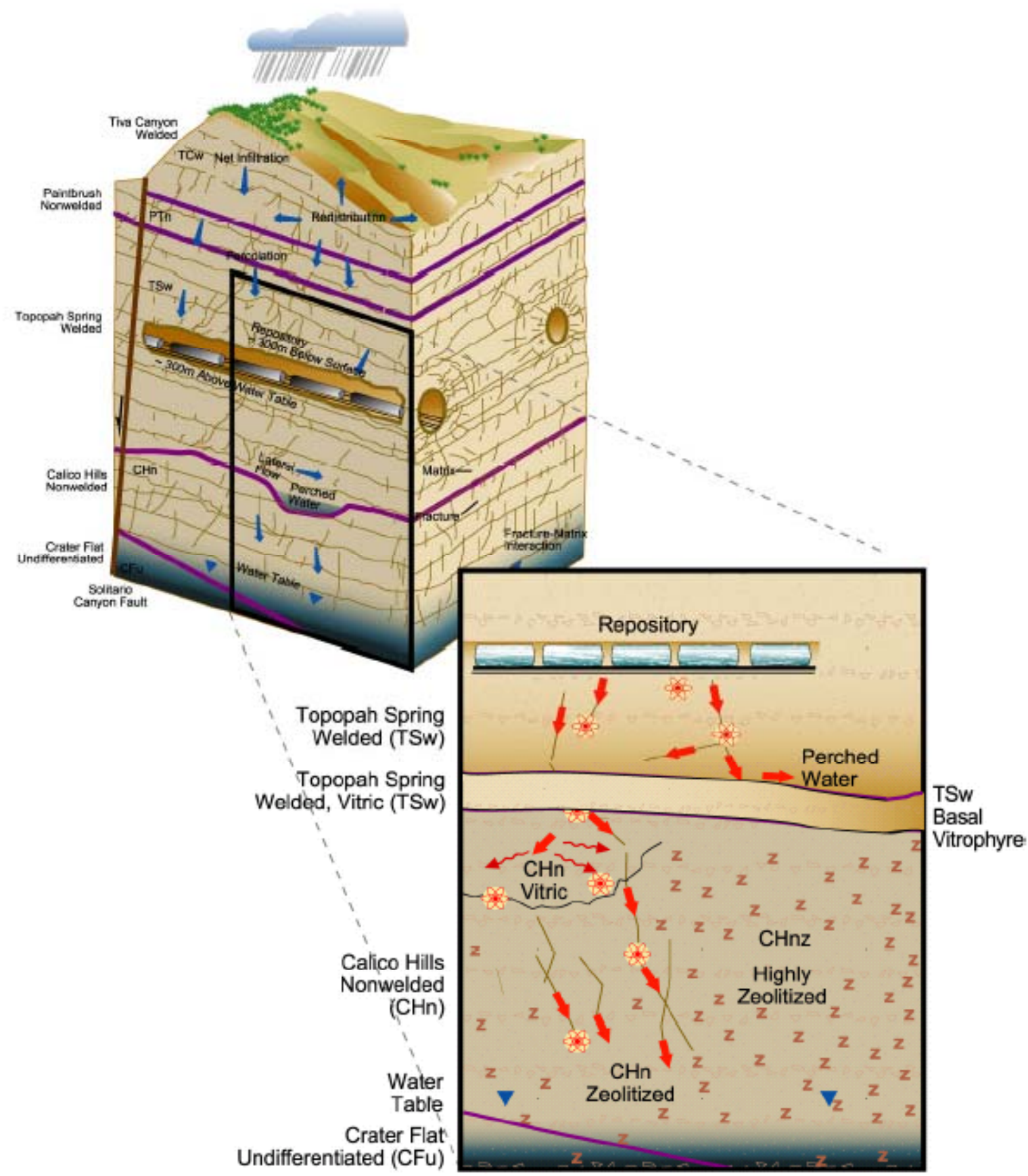

Figure 6-2. Schematic of Water Movement and Radionuclide Transport Through the UZ

Implementation of the above transport mechanisms inside FEHM are described in Section 6.4 of this report. The abstraction model is designed to facilitate parameter uncertainty analyses in TSPA. This is done by running multiple realizations with different parameter values based on parameter distributions. 
Performing multiple realizations (numbering in the hundreds) for such a complex system requires that the software used for simulating radionuclide transport in the system be efficient while also being able to handle complex physical and chemical processes with sufficient accuracy. FEHM (Zyvoloski et al. 1997 [DIRS 100615]) was selected for simulating radionuclide transport in the system because of the efficiency of the particle tracking method and its ability to handle advection, dispersion, sorption, matrix-diffusion, and multiple-species radionuclide decay/ingrowth in the system.

\subsection{THE NUMERICAL REPRESENTATION OF THE UZ TRANSPORT MODEL}

This section outlines the development of the general transport methods used for the RTTF particle-tracking model and issues specific to the use of this model to simulate radionuclide transport for the Yucca Mountain UZ.

Prediction of solute transport is a critical element of many groundwater flow studies, including contaminant transport and the movement of dissolved species in solution. Modeling efforts typically are motivated by the need to predict the movement of a pollutant or dissolved chemical in the subsurface to answer practical questions concerning the rate and direction of contaminant movement and the predicted concentration in solution. In a typical solute transport simulation, a dissolved chemical is introduced into a steady-state or time-varying flow field, and the fate of the chemical is tracked while undergoing physical and chemical processes such as advection, dispersion, chemical and biological reaction, or diffusion into dead-end pore space. Often, a concentration front is established that must be tracked accurately. In addition, many field investigations employ natural or introduced tracers to study the flow and transport system. These studies also require models to simulate the movement of dissolved species.

Traditional solutions to the advection-dispersion (AD) equation, such as those used in most finite-element or finite-difference flow and transport codes, are versatile and allow the simultaneous solution of multiple interacting species. One drawback of a finite-difference or finite-element solution to the $\mathrm{AD}$ equation is that significant numerical dispersion may arise in the portion of a computational domain occupied by a front of rapidly varying concentration. Reducing the numerical dispersion requires either increased grid resolution or higher-order approximation methods, both of which may lead to prohibitive computational costs. Numerical dispersion affects the migration of a contaminant in a manner similar to that of actual dispersion, so it is often difficult to separate numerical from actual dispersion in complex transport simulations.

Approaches to cope with this problem include front-tracking algorithms with multiple grids (e.g., Yeh 1990 [DIRS 101501]; Wolfsberg and Freyberg 1994 [DIRS 101498]), the method of characteristics (e.g., Chiang et al. 1989 [DIRS 101384]), hybrid Eulerian-Lagrangian solution techniques (Neuman 1984 [DIRS 101463]), and particle-tracking techniques (e.g., Tompson and Gelhar 1990 [DIRS 101490]). Front-tracking algorithms solve the AD equation in integrated form on a numerical grid while tailoring the mesh to increase the resolution of the calculation at fronts. In contrast, an Eulerian-Lagrangian technique casts the $\mathrm{AD}$ equation using the total derivative, so that the advection portion of transport can be solved accurately using particletracking techniques or the method of characteristics, while the dispersion component of transport is solved on a finite-difference or finite-element grid using standard techniques. 
Particle-tracking transport models take a fundamentally different approach. The trajectory of individual molecules or packets of fluid containing molecules are tracked through the model domain. When the fluid path lines are the model result of interest (Pollack 1988 [DIRS 101466]; Lu 1994 [DIRS 101413]), a relatively small number of particles can be used to trace the streamlines. Particle tracking is also used to simulate solute transport, such as the migration of a contaminant plume (Akindunni et al. 1995 [DIRS 101378]) or the prediction of breakthrough curves in interwell tracer experiments (Johnson et al. 1994 [DIRS 101400]). For these applications, a relatively large number of such particles must be used to obtain accurate solutions to the transport problem. Particle tracking has also been used to solve the advective portion of complex reactive transport models that simulate chemical reactions among multiple species (Fabriol et al. 1993 [DIRS 101387]).

In a typical particle-tracking algorithm, a particle is sent to a new position assuming that the magnitude and direction of the velocity vector are constant during a time step. If small enough time steps are taken, particle pathways can be tracked accurately. Dispersion is treated as a random process that diverts the particle a random distance from its dispersion-free, deterministic path. In these so-called "random walk" models (e.g., Kinzelbach 1988 [DIRS 101402]), dispersion is usually calculated stochastically, subject to a Gaussian model to reproduce the specified dispersion coefficient. The technique has also been extended by employing nonGaussian random walk functions to represent scale-dependent dispersion (Scheibe and Cole 1994 [DIRS 101477]). Linear equilibrium sorption can be handled through the use of a retardation factor to correct the magnitude of the particle velocity.

A crucial component of most random-walk particle-tracking algorithms developed to date is the need to accurately estimate the velocity at every position in the model domain. In the context of a finite-difference or finite-element numerical code, this means that velocities at positions other than the node points of the fluid flow grid must be computed using an interpolation scheme. Many studies have proposed and studied the accuracy of different interpolation schemes, including methods developed for regular, two-, or three-dimensional finite difference grids (Schafer-Perini and Wilson 1991 [DIRS 101476]; Zheng 1993 [DIRS 101502]), for two- and three-dimensional finite-element grids (Cordes and Kinzelbach 1992 [DIRS 101385]), and for codes that employ the boundary element method for computing fluid flow (Latinopoulos and Katsifarakis 1991 [DIRS 101408]). Special techniques have been developed to handle complexities such as point fluid sources and sinks, and abrupt changes in the conductivity of the medium (Zheng 1994 [DIRS 101503]).

Unfortunately, many of the velocity interpolation schemes used in conventional particle-tracking techniques are computationally intensive, thus limiting the number of particles that can practically be used. Another drawback to traditional particle-tracking approaches is that spatial and temporal discretization often results in numerical inaccuracy in the fluid flow solution upon which velocity determinations are based. Thus, precise and time-consuming velocity interpolation schemes may not be justified in finite-difference or finite-element models. Finally, and most important for the simulation of transport in the UZ at Yucca Mountain, dual-permeability models employ overlapping continua to represent fracture and matrix flow (Zyvoloski et al. 1992 [DIRS 101026]; Zimmerman et al. 1993 [DIRS 100614]). To develop a streamline-based particle-tracking method for dual-permeability models, velocity interpolations on each continuum would have to be coupled to a transfer term that allows particles to move 
from one medium to the other. This additional complexity, along with the inherent approximations associated with the dual-permeability method itself, may make precise velocity interpolation calculations of limited validity.

In this model, a particle-tracking technique is employed that can be used for transient, multidimensional finite-difference or finite-element codes. The algorithm is designed for computing solute concentration fields quickly and easily with structured or unstructured numerical grids of arbitrary complexity. Both continuum and dual-permeability formulations can be simulated. This flexibility is accomplished by extending the cell-based strategy of Desbarats (1990 [DIRS 101386]) for mapping out the path of the particle. In this method, the calculation of an "exact" pathline is replaced with a cell-to-cell migration of the particle. The mass flux from cell to cell is used directly, and no velocity interpolations are required. Since numerical solutions for fluid flow are typically mass-conservative (though not necessarily accurate) the particle-tracking method automatically conserves mass.

\subsubsection{Basic Methods}

The particle-tracking method developed in the present study views the fluid flow computational domain as an interconnected network of fluid storage volumes. Particles travel only from cell to cell, requiring no greater resolution of the particle pathways. In this sense, the method is similar to the node-to-node routing method of Desbarats (1990 [DIRS 101386], p. 156). This simple starting point has been extended to include many different transport submodels and complex flow domains. Even though some aspects of the development that follows would appear to be applicable for steady-state, single-porosity flow fields, the extensions to the method for treating transient flow systems and dual-porosity model formulations are discussed in Section 6.4.3. The two steps in the particle-tracking approach are: 1 ) determine the time a particle spends in a given cell; and 2) determine which cell the particle travels to next. These two steps are detailed below.

The residence time for a particle in a cell is governed by a transfer function describing the probability of the particle spending a given length of time in the cell. Thus, this particle-tracking approach is called the RTTF method (Robinson et al. 2003 [DIRS 171674]). The schematic plots shown in Figures 6-3 and 6-4 illustrate the basis of the RTTF approach. For a cumulative probability distribution function of particle residence times, the residence time of a particle in a cell is computed by generating a random number between 0 and 1 to determine the corresponding residence time from the distribution function. In the simplest case of advective transport through the cell, there is only one possible transport time through the cell, and the function is the Heaviside function (a unit step function). However, dispersion and diffusion give rise to a distribution of transport times through the cell that must be reproduced in order to simulate these mechanisms. In the example in Figure 6-4, the AD equation was used to generate the RTTF curve, but other transport mechanisms can be incorporated as well. 


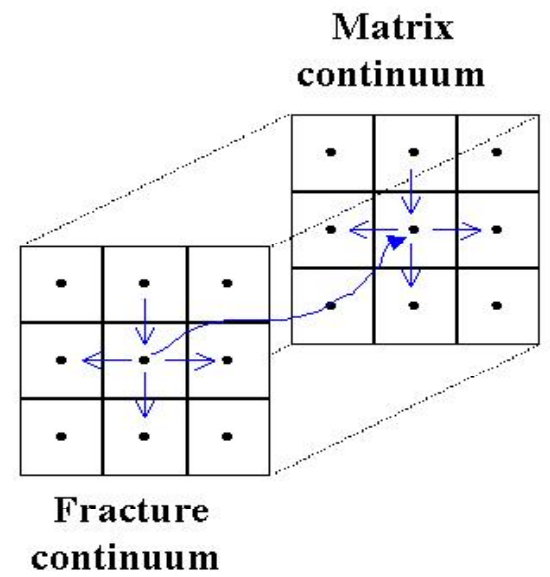

Figure 6-3. Schematic of the Cell-Based Particle-Tracking Technique

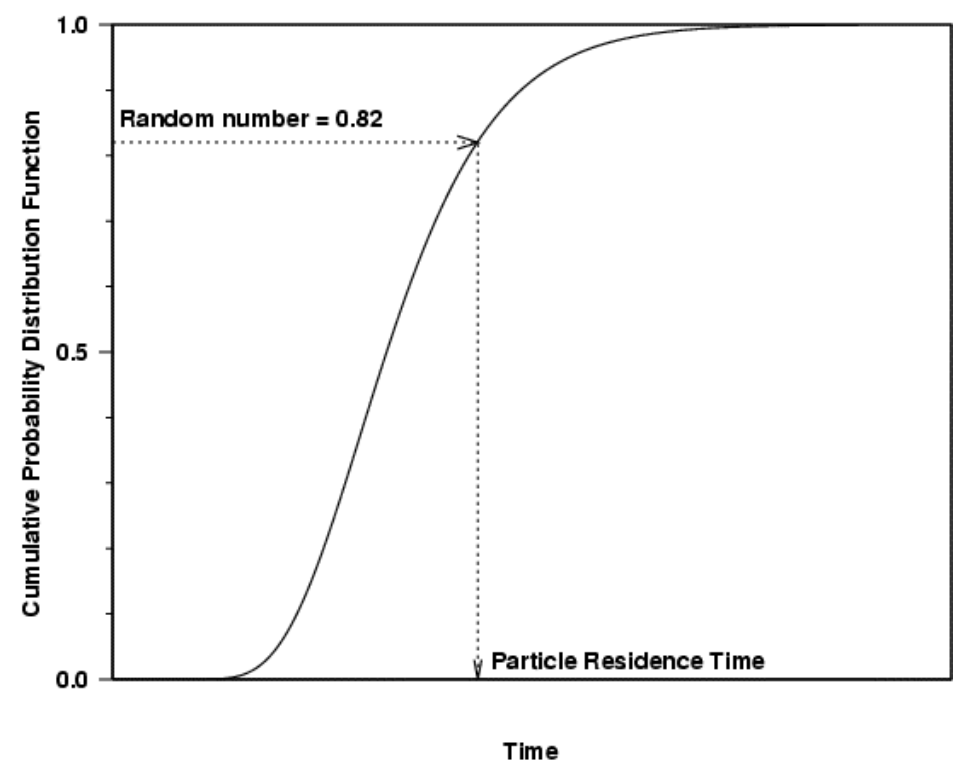

NOTE: The time axis represents the probabilistically determined residence time of a particle in the cell.

Figure 6-4. Schematic of the RTTF Technique for Determining Particle Residence Time in a Cell 
If a large number of particles pass through the cell, the cumulative residence time distribution of particles in the cell will be reproduced. Particle-tracking models of single-fracture transport (Yamashita and Kimura 1990 [DIRS 101499]) have employed this approach to simulate fracture transport with diffusion into the rock matrix. From the solution of the flow field in a numerical model, the mass of fluid in the computational cell and the mass flow rate to or from each adjacent cell is computed. In the simplest case, the residence time of a particle in a cell, $\tau_{\text {part }}$, is given by:

$$
\tau_{\text {part }}=\tau_{f l}=\frac{M_{f l}}{\sum \dot{m}_{\text {out }}}
$$

where $M_{f l}$ is the fluid mass in the cell and the summation term in the denominator refers to the outlet fluid mass flow rates from the cell to adjacent cells. In the absence of dispersion or other transport mechanisms, the transfer function describing the distribution of particle residence times is a Heaviside function (unit step function) that is unity at the fluid residence time $\tau_{f f}$, because for this simple case, particles entering the cell will possess this residence time. Equilibrium, linear sorption is included by correcting the particle residence time by a retardation factor $R$. Thus, $\tau_{\text {part }}=R \tau_{f f}$, and $R$ is given by:

$$
R=1+\frac{\rho_{b} K_{d}}{\theta_{f l}}
$$

where:

$K_{d}$ is the equilibrium sorption coefficient (mL fluid/g rock)

$\rho_{b}$ is the bulk rock density (g rock/mL total)

$\theta_{f l}$ is the volumetric water content ( $\mathrm{mL}$ fluid/mL total).

The use of a linear, equilibrium sorption model warrants further discussion. It is well-known that the effective sorption coefficient in porous media is a function of many factors, including mineralogy, groundwater aqueous chemistry (including redox conditions), and heterogeneity at scales smaller than are considered in numerical models. Furthermore, the kinetics of the sorption reaction must be considered to ensure that the reactions are effectively at equilibrium. Despite these limitations, the $\mathrm{K}_{\mathrm{d}}$ model is by far the most widely used sorption model in PA calculations due to its simplicity and ease of use. The factors listed above do not preclude the use of this model. However, they must be considered when establishing the parameter uncertainty distribution for $\mathrm{K}_{\mathrm{d}}$. As long as the range of sorption coefficients used in PA calculations takes into account uncertainties arising due to the factors listed here, then this approach is valid for the intended use of this model. As was the case for advection, in the particle tracking model formulation, in the absence of other transport processes, the transfer function for sorption is also a Heaviside function. Note that the method is applicable for either liquid or gas phase transport, so the generic term "fluid" is used in the definition above. However, in this report, only liquid phase transport is simulated. 
Before discussing more complex transfer functions for the RTTF method, the method for determining which cell a particle travels to after completing its stay at a given cell is discussed. The approach that is consistent with the RTTF method is that the probability of traveling to a neighboring cell is proportional to the mass flow rate to that cell. Only outflows are included in this calculation; the probability of traveling to an adjacent node is 0 if fluid flows from that node to the current node. In summary, the particle-tracking algorithm is: 1) compute the residence time of a particle at a cell using the RTTF method; and 2) at the end of its stay, send the particle to an adjacent cell randomly, with the probability of traveling to a given cell proportional to the mass flow rate to that cell.

\subsubsection{Dispersion}

Transport processes such as dispersion can be incorporated into the RTTF particle-tracking algorithm through the use of transfer functions. For dispersion, within a computational cell, the equation for one-dimensional, axial dispersion is applied. The solution desired is the concentration-time breakthrough curve at the outlet of the one-dimensional model for a unit step change in inlet concentration. This solution represents the cumulative distribution of transport times for transport with dispersion, which is what is desired for the transfer function. The transport equation and boundary conditions for the one-dimensional, advective-dispersion equation are (Freeze and Cherry 1979 [DIRS 101173], from equation 9.9):

$$
\begin{aligned}
& R \frac{\partial C}{\partial t}=D_{\text {eff }} \frac{\partial^{2} C}{\partial z^{2}}-v \frac{\partial C}{\partial z} \\
& C(z, t)=0, \quad t=0 \\
& C(z, t)=C_{0}, \quad z=0 \\
& C(z, t)=0, \quad z \rightarrow \infty
\end{aligned}
$$

where

$C$ is the concentration (moles $/ \mathrm{kg}$ fluid)

$C_{0}$ is the injection concentration (moles/kg fluid)

$v$ is the flow velocity $(\mathrm{m} / \mathrm{s})$

$D_{\text {eff }}$ is the effective dispersion coefficient $\left(\mathrm{m}^{2} / \mathrm{s}\right)$, given by $D_{\text {eff }}=\alpha v$, where $\alpha$ is the dispersivity of the medium (m).

Here the molecular diffusion coefficient is ignored, since in general it is much smaller than the flow dispersion component of $D_{\text {eff }}$. A nondimensional version of Equation 6-3 can be obtained by the following transformations: $\widehat{C}=C / C_{0}, \hat{z}=z / L$, and $\hat{t}=v t / R L$, where $L$ is the flow 
path length. The solution to Equations 6-3 to 6-6 is obtained after manipulation of Freeze and Cherry (1979 [DIRS 101173], p. 391, Equation 9.5), yielding:

$$
\widehat{C}=\frac{1}{2}\left[\operatorname{erfc}\left(\frac{\sqrt{P e}(1-\hat{t})}{2 \sqrt{\hat{t}}}\right)+e^{P e} \operatorname{erfc}\left(\frac{\sqrt{P e}(1+\hat{t})}{2 \sqrt{\hat{t}}}\right)\right]
$$

where $P e$ is the Peclet number (dimensionless), $P e=v L / D_{\text {eff }}=L / \alpha$. This solution was obtained from Freeze and Cherry by substituting the definitions of $P e$ and $\hat{t}$ into the corresponding terms of the Freeze and Cherry equation and performing the needed algebra.

The use of this solution in the RTTF particle-tracking method requires that the transport problem be advection-dominated, such that during the time spent in a computational cell, solute would not tend to spread a significant distance away from that cell. Then, the approximate use of a distribution of times within a single cell will be adequate. Quantitatively, the criterion for applicability is based on the grid Peclet number $P e_{g}=\Delta x / \alpha$, where $\Delta x$ is the characteristic length scale of the computational cell. Note that in contrast to conventional numerical solutions of the advective-dispersion equation, coarse spatial discretization is helpful for satisfying this criterion. Of course, the mesh spacing must still be small enough to provide an accurate flow solution. Highly dispersive transport invalidates the assumptions of the RTTF particle-tracking technique. When dispersion coefficients are large, accurate solutions to the advective-dispersion equation are easily obtained by conventional finite-difference or finite-element techniques, so these techniques should be used instead under these circumstances.

For multidimensional flow systems, the dispersion model developed for one-dimensional systems can be extended to include dispersion coefficient values aligned with the coordinate axes. For this case, the flow direction is determined by the vector drawn from the nodal position of the previous cell to the current cell, and the dispersivity for this flow direction is computed from the equation for an ellipsoid:

$$
\alpha=\frac{L}{\sqrt{\Delta x^{2} / \alpha_{x}^{2}+\Delta y^{2} / \alpha_{y}^{2}+\Delta z^{2} / \alpha_{z}^{2}}}
$$

where $L$ now represents the distance from the previous cell to the current cell, $\Delta x, \Delta y$, and $\Delta z$ are the distances from one grid point to the other in the three coordinate directions, and $\alpha_{x}, \alpha_{y}$, and $\alpha_{z}$ are the longitudinal dispersivities in the three coordinate directions. The RTTF particletracking technique cannot be simply formulated with a longitudinal and transverse dispersion coefficient model with the tensor aligned with the flow direction because the flow rates between cells are defined rather than the actual flow velocity at a position. For a dispersion model aligned with the flow direction, a random-walk particle-tracking method such as that of Tompson and Gelhar (1990 [DIRS 101490]), also implemented in the SZ particle-tracking algorithm of FEHM, or a conventional finite-element or finite-difference solution to the AD equation, such as the reactive transport solution module in FEHM, should be used instead. 
The numerical implementation of this technique requires the determination of the dimensionless time $\hat{t}$ in Equation 6-7 for a randomly determined value of the dimensionless concentration $\hat{C}$. This determination is accomplished numerically in the particle-tracking code by fitting Equation 6-7 at selected values of $P e$ between 1 and 1,000 using a piecewise continuous series of straight lines spanning the entire range of values. Then, the value of $\hat{t}$ at an arbitrary value of $P e$ is computed by linear interpolation between values determined at the Peclet numbers that bracket the actual value. This technique, involving a simple search for the correct type curves, followed by the calculation of two values of $\hat{t}$ and an interpolation, is much more computationally efficient (about a factor of two in CPU time) and robust than an iterative approach to the exact solution using Newton's method. Solutions of adequate accuracy (less than 1 percent root mean squared error: see LANL 2003 [DIRS 166306], tests titled "Tests of Cell-Based Particle Tracking Model”) are easily obtained using this linear-interpolation method. This error is trivial compared to the uncertainties being propagated through the model. Therefore, this implementation is adequate for the purposes of the model.

\subsubsection{Fracture/Matrix Interaction Submodel}

In a dual-permeability system, the transfer of solute mass between fractures and matrix can occur via advection, where fluid movement carries solute from one medium to the other, and matrix diffusion, where molecular diffusion transports mass. Matrix diffusion has been recognized as an important transport mechanism in fractured porous media (e.g., Neretnieks 1980 [DIRS 101148]; Robinson 1994 [DIRS 101154]). For many hydrologic flow systems, fluid flow is dominated by fractures because of the orders-of-magnitude larger permeabilities in the fractures compared to the surrounding rock matrix. However, even when fluid in the matrix is completely stagnant, solute can migrate into the matrix via molecular diffusion, resulting in a physical retardation of solute compared to pure fracture transport. This effect has recently been demonstrated on the laboratory scale by Reimus (1995 [DIRS 101474]) and on the field scale both by Maloszewski and Zuber (1991 [DIRS 146957]) and in the SZ at Yucca Mountain by Reimus et al. (1999 [DIRS 126243]). In the UZ at Yucca Mountain, dual-permeability models allow fluid to migrate in both fractures and the matrix. An additional process that allows solute to transport between the continua is molecular diffusion. The distribution of transport times through such a system is a complex function of the relative velocities in the two media, the advective flux between the media, the spacing between flowing fractures, matrix diffusion coefficients, and sorption. This section describes the submodel developed to obtain transfer functions suitable for use in dual-permeability systems.

For transport in a dual-permeability system at the field scale, it is important to recognize that the flow model consists of one matrix grid cell for each fracture cell. However, important processes associated with flow and transport occur at scales smaller than those considered in the mountainscale UZ model, particularly in the immediate region of the matrix adjacent to each flowing fracture. Therefore, the incorporation of fracture-matrix interactions into the model is in essence an upscaling problem. The goal of this development is to utilize a suitable idealized system that captures, at the small scale, important transport processes, and allows this small-scale behavior to be simply upscaled for inclusion in the large-scale model. This model report will demonstrate that this upscaling method will allow testing of ACMs for the $\mathrm{f} / \mathrm{m}$ interaction model for transport. 
To accomplish the upscaling within the particle tracking transport model, the transfer function approach is used to construct an idealized transport model at the small scale that allows the transfer functions to be tabulated. In a dual-permeability system, transport behavior is vastly different depending on whether solute starts in the fracture or in the matrix. Therefore, the transfer function method is adapted in the UZ transport model to accommodate dual-permeability behavior. The approach consists of using transfer functions to determine both the residence time in a cell, and to determine whether the particle enters the next cell in the fractures or the matrix. In this way, the combined fracture and matrix system will be treated as a unified medium in which there is a distribution of transport times depending on whether the particle enters the cells in the fracture versus the matrix. The transfer functions themselves (described below and in Appendix C) are computed based on an idealized $\mathrm{f} / \mathrm{m}$ transport model with parallel flow in the fractures and matrix. The choice of a parallel fracture model for developing the matrix diffusion submodel is for convenience and due to the fact that information does not exist to warrant more complex fracture geometries. The steps of the algorithm are as follows (note that the algorithm starts with a known particle location, either in the fracture or matrix continuum):

Step 1. Determine probabilistically whether the particle should move to the other medium due to advective flux to that medium

Step 2. Determine probabilistically whether the particle will leave this cell via the current medium or the other medium

Step 3. Use the conditional transfer function to determine probabilistically the residence time of the particle

Step 4. Determine probabilistically using the relative total flux to adjacent nodes which cell the particle moves to next (whether it starts in the fracture or matrix continuum in the next cell has been determined previously in Step 2).

This approach handles the combined fracture and matrix continua as a single porous medium through which mass travels, and apportions the particles to each continuum according to the diffusive and advective fluxes defined by the flow field and the transport parameters. In the most general case, the dual-permeability flow model at the mountain scale prescribes a net flow through the fracture continuum, a net flow through the matrix continuum, and a fracture to matrix (or matrix to fracture) fluid flux. To implement this algorithm and allow the transfer function to be computed readily, Step 1 takes the fracture-matrix advective flux term and applies it immediately when the particle enters the cell. Then, after potentially shifting the particle from one medium to the other via advection (with no increase to the transport time), the subsequent transfer functions are based on parallel flow in the two continua with no flux between the continua. This approach, which amounts to a form of upwinding of the fracture-matrix fluid flux term, simplifies the transfer function process by eliminating the need for an additional variable, the fracture-matrix advective flux, in the construction of the transfer function curves. Instead, a probability $p_{f m}$ of the particle transferring to the other medium (Step 1) is assigned:

$p_{f m}=0$ if the fracture-matrix flux term $f_{f m}$ is into the medium in which the particle already resides, or 
$p_{f m}=f_{f m} /\left(f_{f m}+f_{i n}\right)$, where $f_{\text {in }}$ is the total flux into the continuum in which the particle currently resides.

Step 2 accounts for the fact that there is a finite probability that, due to matrix diffusion, the particle will leave the cell through the other medium regardless of where it starts. In the transfer function approach, solute mass is introduced in the model system (the two-dimensional) in either the fracture fluid or the matrix fluid. For the general case of water flow through both the fracture and matrix, mass leaves the DFM via either medium. Therefore, conditional transfer functions must be generated to obtain the probabilities in Step 2. That is, for mass injected with the fracture fluid entering the discrete fracture submodel, there is a breakthrough curve for mass leaving the model via the fracture fluid, and a similar breakthrough curve for mass leaving via the matrix fluid. Similarly, there are two breakthrough curves for mass injected with the matrix fluid. The plateau values attained for a given transfer function curve represents the probability of leaving via a particular medium in Step 2. In other words, the probability of a particle leaving via a given continuum equals the steady state solute mass flux (the plateau of the transfer function curve) divided by the total mass flux through the DFM. This step provides a way to assign probabilities for moving particles between the media via diffusion in a system in which water flows through both continua.

Once Step 2 is completed using the steady state solute mass flux derived from the conditional transfer functions, the selection of the transfer function to apply to obtain the residence time for Step 3 is also determined. This part of the method is identical to that described previously, which is to generate a random number between 0 and 1 and determine the particle residence time from the transfer function.

Finally, Step 4 routes the particle to the appropriate connecting cell in the finite volume domain, as described earlier. If the particle is determined to enter an adjoining cell via the fracture continuum, then the internodal fluxes associated with the fractures are used to define the probabilities of traveling to each connected fracture cell. Similarly, for transport to an adjoining matrix cell, matrix fluxes are used.

The process employed in this model to obtain the transfer functions for the dual-k transport submodel consists of a series of numerical simulations on the idealized model system shown in Figure 6-5. Because each grid block in the mountain-scale model possesses different hydrologic and transport parameters, a procedure for deriving a nondimensional form of the submodel is required to make the method practical. Appendix $\mathrm{C}$ presents the derivation of the nondimensional model, and presents the method for generating the transfer function curves. In summary, there are three nondimensional groups that, if specified, fully capture the range of behavior of the submodel:

$$
p_{1}=\frac{D_{m} \tau_{f} R_{f}}{B^{2} R_{m}}
$$




$$
\begin{aligned}
& p_{2}=\frac{D_{m} \tau_{f} \theta_{m}}{b B \theta_{f}} \\
& p_{3}=\frac{\tau_{f} R_{f}}{\tau_{m} R_{m}}
\end{aligned}
$$

In these equations, $D_{m}$ is the effective diffusion coefficient; $\tau_{f}$ and $\tau_{m}$ are the fluid transport times in the fracture and matrix, respectively; $R_{f}$ and $R_{m}$ are the retardation factors in the fracture and matrix, respectively; $B$ is the half-spacing between flowing fractures; $b$ is the fracture half-aperture; and $\theta_{f}$ and $\theta_{m}$ are the volumetric water contents of the fracture and matrix, respectively. For a given parameter vector $\left(p_{1}, p_{2}, p_{3}\right)$, there is a unique set of conditional transfer function curves of the form $\hat{C}$ versus $\hat{t}$, where $\hat{C}$ is the normalized breakthrough curve for the nondimensional time $\hat{t}$ given by

$$
\hat{t}=\frac{t}{R_{f} \tau_{f}}
$$

The set of conditional transfer function curves consists of a total of four normalized curves for each $\left(p_{1}, p_{2}, p_{3}\right)$ : mass input in fracture, output in fracture; mass input in fracture, output in matrix; mass input in matrix, output in fracture; and mass input in matrix, output in matrix. This capability for sampling conditional transfer functions associated with the fracture-matrix interaction dual-k submodel of the UZ transport abstraction model has been implemented and documented in FEHM V2.21 (LANL 2003 [DIRS 165741]). For details on the generation of the transfer function curves and other important implementation details, see Appendix C.

The final issue associated with implementing the transfer function approach is the means by which the idealized model of Figure 6-5 is simulated. In this abstraction model, two ACMs are implemented to simulate different types of $\mathrm{f} / \mathrm{m}$ interaction conceptualizations. In the first ACM, called the DFM formulation, a two-dimensional numerical grid is used with fine discretization in the matrix close to the fracture. This allows sharp gradients in concentration close to the fracture to be captured. The second ACM, called the dual-k formulation, uses a numerical grid with one finite volume cell that is paired with each fracture grid cell. This type of discretization is identical to that used in the dual-k transport formulation of the T2R3D process model. It could be argued that the DFM formulation more accurately captures the small-scale transport processes. However, the dual-k formulation has the advantage of consistency with the model formulation on which the flow simulations are based. Furthermore, as a practical matter, the three-dimensional process model uses a dual-k formulation for transport, so, for benchmarking purposes, the dual-k approach is more likely to yield comparable results. 


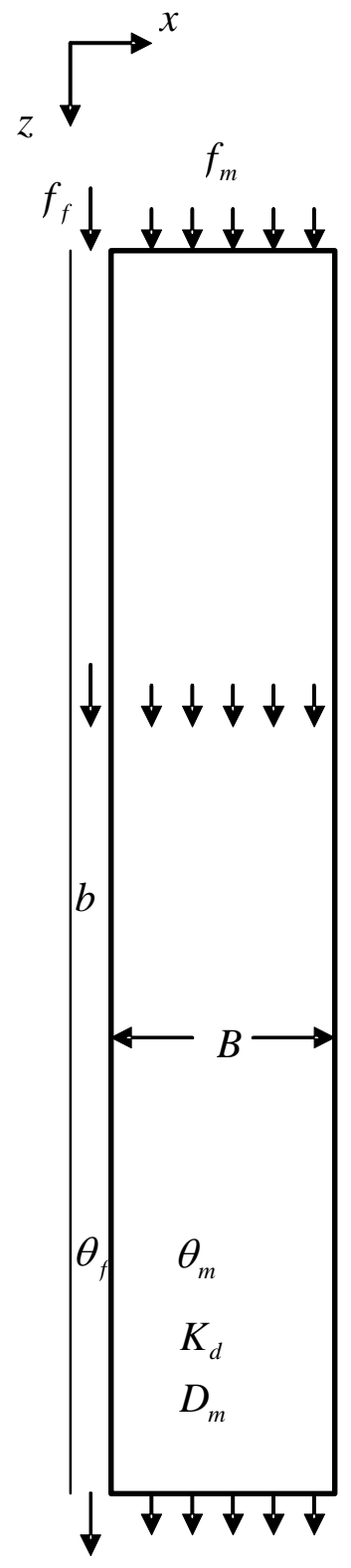

Figure 6-5. Schematic of the Fracture Transport Submodel

The advantage of the transfer function approach used in the particle tracking abstraction model is that both conceptualizations can be implemented easily by using either the DFM or dual-k model grid to generate the transfer function curves. Then, when running the abstraction model, the user selects one or the other set of transfer function curves, and all other input remains the same. However, due to the fact that process model validation activities were performed based on a dual-k model, the dual-k transfer functions should be used in TSPA analyses. Additional details on the behavior of these two $\mathrm{f} / \mathrm{m}$ interaction submodels are presented in Appendix C. 


\subsubsection{Multiple Radionuclides with Decay/Ingrowth}

The FEHM code (Zyvoloski et al. 1997 [DIRS 100615]) allows particles to decay with or without the production of the daughter product. For multiple species with decay chains, the code uses the approach outlined below to determine the number of decayed particles, and the code performs the bookkeeping needed to keep track of the locations and numbers of each type of radionuclide. These multiple species can each have their own transport parameters such as sorption and diffusion coefficients.

For decay-ingrowth simulations with time-dependent release of tracer particles, the computational burden increases dramatically with the number of particles in the field. For example, the decay-ingrowth calculation for species $i$ decaying into species $j$ at a decay rate $\lambda$ is:

$$
N_{j}=\sum_{m=1}^{N_{i}}\left\{1-\exp \left[-\lambda\left(t-t_{m}\right)\right]\right\}
$$

where $N_{j}$ is the number of particles of species $j$ decayed from species $i, N_{i}$ is the number of particles of species $i$, and $t_{m}$ is the time at which the $m$ th particle is injected into the system. If 500,000 particles of species $i$ are injected into the system, then at each time step, the number of mathematical operations for ingrowth calculations alone are around 2.5 million. For a simulation time period of 1 million years, the typical calculation requires about 100 time steps. Therefore, the total number of operations for ingrowth calculations will reach 0.25 billion, and for site-scale simulations, the use of Equation 6-13 would be extremely inefficient.

To reduce the computational burden in simulations, the decay-ingrowth calculation in Equation 6-13 is approximated with an integral by assuming that particles are injected into the system uniformly in time domain. Multiplying both sides of Equation 6-13 by $\Delta t$, the average injection time interval between particles, and approximating Equation 6-13 with respect to $t-t_{m}$ :

$$
N_{j} \approx\left\{\left(\tau_{1}-\tau_{2}\right)+\frac{1}{\lambda} \bullet\left[\exp \left(-\lambda \tau_{1}\right)-\exp \left(-\lambda \tau_{2}\right)\right]\right\} / \Delta t
$$

where $\tau_{1}=t-t_{1}$ and $\tau_{2}=t-t_{N i}, t_{1}$ is the time at which particle injection starts, $t_{N i}$ is the time of the Nth injected particle, and $t$ is the time at which the decay-ingrowth calculation is carried out. The use of Equation 6-14 reduces the number of operations within one time step from millions of operations to just 10, which greatly increases the speed of simulations. Validity of this approach is demonstrated in Figure 6-6.

The accuracy of the integral approach depends on the number of particles and their release history. In general, the use of a greater number of particles increases the accuracy. With respect to release, for the same number of particles, a simulation with a constant release rate will exhibit less error than a time-varying release such as a shorter pulse. If the release rate changes with time, the release period is divided into segments so that within each segment the release rate can be treated as a constant. 
Validity of this approach was demonstrated in detail by LANL (2003 [DIRS 166306]). A FEHM test run from the cited document is summarized in this report to demonstrate the capability of FEHM decay-ingrowth model. Simulation results from the FEHM particle-tracking model with decay and ingrowth were verified against results from a semi-analytical solutions for a 4 species chain decay-ingrowth model, CHAIN (van Genuchten 1985 [DIRS 146961]). The method of comparison for the run is a visual comparison of the plotted results.

For all comparisons of FEHM with the semi-analytical solution for decay-ingrowth simulations, a flow system was developed with the following attributes (LANL 2003 [DIRS 166306]):

- Saturated steady state flow in a one-dimensional system

- Porosity of 0.3

- Average pore-water velocity was $1.05192 \times 10^{-4} \mathrm{~m} /$ year

- Solute with constant injection concentration of $1.0 \mathrm{~mol} / \mathrm{L}$ released from 0 to 5,000 years at origin $x=0$. Breakthrough data were collected at $x=1 \mathrm{~m}$ down stream

- FEHM grid resolution: $0.005 \mathrm{~m}$

- Longitudinal dispersivity of $0.005 \mathrm{~m}$.

In the test case, a pseudo sequential decay chain is simulated with species $1 \rightarrow 2 \rightarrow 3 \rightarrow 4$, with half lives for species 1 through species 4 of 10,000,3,000, 10,000, and 4,000 years, respectively. The transport process was dominated by advection and dispersion only with a grid Peclet number of 1.0. In the FEHM simulations, the 5,000 year release period was divided into 50 segments so that each segment corresponds to 100 years. Within each segment, 10,000 particles were injected into the system uniformly over the 100 year period for species 1 . There was no source release for the other species, which are generated by the decay-ingrowth model. The retardation factors for species 1 through species 4 were 1.0, 1.0, 1.9, and 1.001, respectively.

The FEHM and CHAIN breakthrough curves are plotted in Figure 6-6. In general, good agreement was observed between FEHM and CHAIN curves. Combined with the suite of validation runs documented in Section 7 of this report, this simulation demonstrates that the particle tracking model accurately handles decay chains and, thus, is suitable for use in simulating multiple radionuclides in the UZ transport model. 


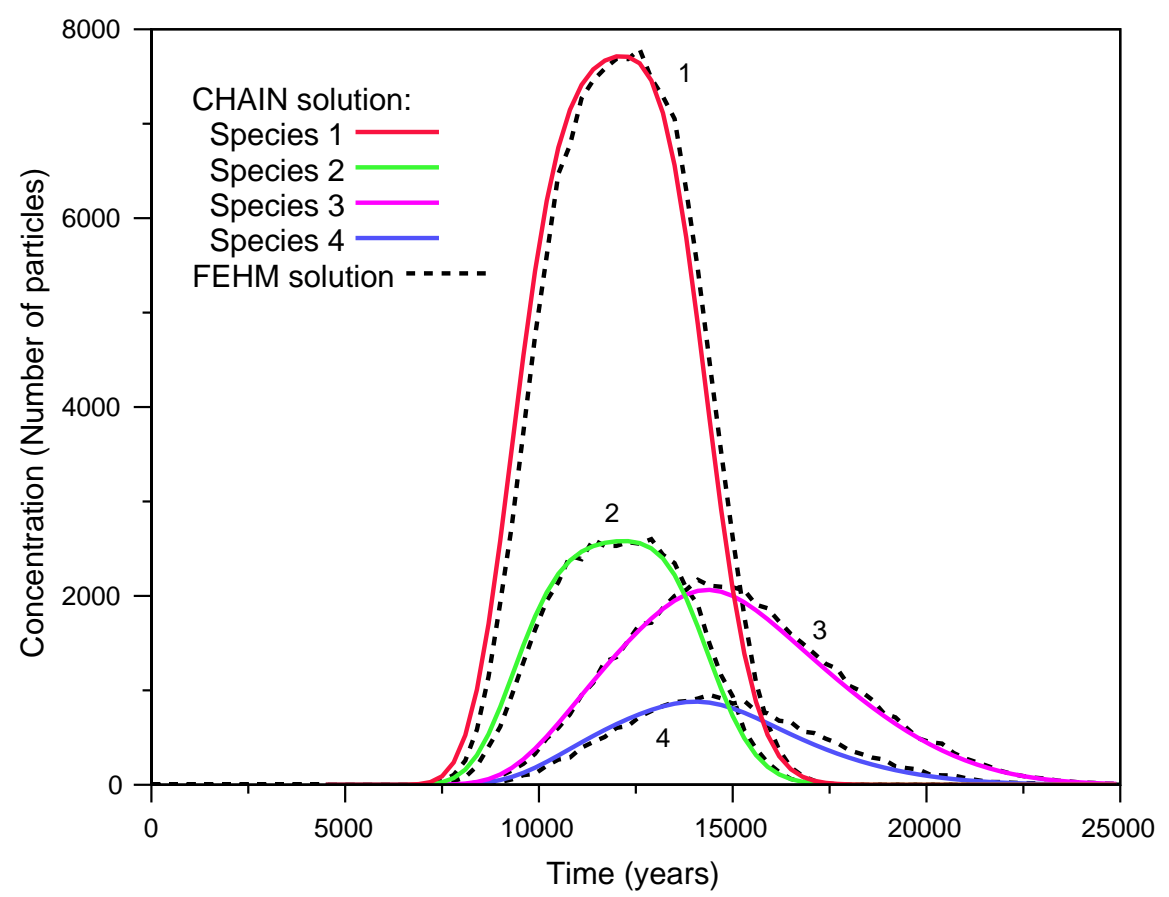

NOTE: $\quad$ Peclet Number $=1.0$ (used for comparative purposes only; taken from Figure 59 in the report by LANL (2003 [DIRS 166306]).

Figure 6-6. Comparison of Software CHAIN and FEHM Transport Results for a Case with a 4-Member Decay-Ingrowth CHAIN and a Retardation Factor of 1.9 for Species 3

\subsubsection{Colloid Transport}

Colloids are divided into three basic types: true colloids, primary colloids, and pseudocolloids:

True colloids originate from the hydrolysis and polymerization of actinide ions dissolved in solution. Degradation of commercial SNF may form true colloids (e.g., plutonium oxides and hydroxides) consisting of americium, plutonium, and rare earths, but these are anticipated to sorb to iron oxide/oxyhydroxides, forming a "pseudocolloid". However, the solution chemistry and temperature in the waste package and EBS prevents significant introduction of true colloids to the environment (BSC 2004 [DIRS 170025], Section 6.3.1).

Waste form colloids originate from the nucleation of corrosion products of defense high level glass waste. These colloids are composed of smectite (clay) and have plutonium and americium embedded in the colloid structure (BSC 2004 [DIRS 170025], Section 6.3.1). Colloids with embedded radionuclides will be termed "irreversible colloids" for the purposes of radionuclide transport due to the strong, permanent association between the colloid and the radionuclides.

Pseudocolloids consist of nonradioactive particles that may sorb radionuclides. Colloids with radionuclides sorbed to their surfaces will be called "reversible colloids" for the purposes of radionuclide transport because the radionuclides can attach and detach from the colloid. Note that clay colloids formed from defense high-level waste glass may interact with radionuclides as irreversible and/or reversible colloids. Pseudocolloids are distinguished as either natural 
groundwater colloids or corrosion product colloids. Corrosion product colloids originate from the corrosion of steel components in the engineered barrier system and defense high-level waste glass. Colloids formed from steel corrosion products are composed of a mixture of hydrous ferric oxides that are modeled as hematite (BSC 2004 [DIRS 170025], Section 6.3.1). Defense high-level waste glass corrosion produces colloidal smectite, as discussed for waste form colloids. Natural groundwater colloids are generated by natural geochemical processes in the rock that transform rock minerals into clay minerals. For the purposes of modeling colloid transport, these clays are treated as smectite (BSC 2004 [DIRS 170025], Section 6.3.1).

Irreversible colloids are treated in the UZ transport abstraction model as a particle with zero diffusion (discussed below and in Section 6.5.5). In addition, due to colloid size, these particles preferentially move through fractures as a result of the size exclusion model (see below and Section 6.5.10). Because the radionuclides are permanently attached to the colloids, colloid filtration effectively removes the associated radionuclides from the system (see below and Section 6.5.9). Transport of these colloids in the fractures are retarded as a result of colloid interactions with the rock which is described with a retardation factor (see below and Section 6.5.13). Finally, a fraction of the irreversible colloid component will not be retarded; this fraction is termed the "irreversible fast colloids" (Section 6.5.13). Isotopes of plutonium and americium are affected by irreversible colloid transport (BSC 2004 [DIRS 170025], Section 6.3.1).

Reversible colloids differ from irreversible colloids in the UZ transport abstraction model because the radionuclide may detach from a colloid, becoming an aqueous species, and subsequently may reattach to a different colloid. Because of this, colloid filtration and retardation are not included in the processes affecting reversible colloids. As for irreversible colloids, reversible colloids have zero diffusion and preferentially move through the fractures due to size exclusion. The effective strength of radionuclide associations with reversible colloids is a function of both the intrinsic sorptive capacity of a given radionuclide on a colloid surface, expressed as a sorption coefficient, and the mass density of colloids in the water (see below and Section 6.5.12). Isotopes of plutonium, americium, thorium, protactinium, and cesium are affected by reversible colloid transport (BSC 2004 [DIRS 170025], Section 6.3.3.1).

For colloid-facilitated transport, the transport equations for matrix diffusion, with either the semi-infinite or finite fracture spacings, can be simply revised. The expression for transport for contaminant on colloids is analogous to Equation 6-3 earlier (Freeze and Cherry 1979 [DIRS 101173], from equation 9.9):

$$
R_{\text {coll }} \frac{\partial C_{\text {coll }}}{\partial t}=D_{\text {eff }} \frac{\partial^{2} C_{\text {coll }}}{\partial z^{2}}-v \frac{\partial C_{\text {coll }}}{\partial z}
$$

where $D_{\text {eff }}$ is the same as for an aqueous solute and $R_{\text {coll }}$ is the colloid retardation factor. The basis for not including colloid matrix diffusion is that the estimated values for diffusion coefficient of colloids from Table 6-8 in the report by BSC (2004 [DIRS 164500]) are significantly lower than values for aqueous species presented in Section 6.5.5 of this report. Rather than incorporating an additional parameter in the model, it is conservatively assumed that colloids travel via advection, without matrix diffusion. 
To estimate retardation of colloids in the fracture continuum, field experiments at the C-wells complex near Yucca Mountain were examined, in which transport of microspheres was used as an analogue for colloids. The microsphere breakthrough curves were fit to forward and reverse filtration rates (DTN: LA0002PR831231.003 [DIRS 144462]). These rate constants were then used to calculate a retardation factor for colloid transport through saturated fractured rock (BSC 2004 [DIRS 170006]; DTN: LA0303HV831352.002 [DIRS 163558]). For compatibility with this analysis of field data, this approach is adopted in the numerical model as well. The governing equation for the corresponding dissolved contaminant moving in fractures with interactions with matrix blocks but without decay can be derived from Equation (1) of Sudicky and Frind (1982 [DIRS 105043]) and re-written as:

$$
R_{f} \frac{\partial C}{\partial t}=D_{e f f} \frac{\partial^{2} C}{\partial z^{2}}-v \frac{\partial C}{\partial z}-\frac{q}{b}
$$

where $R_{f}$ is the retardation factor of the dissolved contaminant, $b$ is half of the fracture aperture, and $q$ (mass per time per unit area) is the mass exchange rate through fracture-matrix interface.

At this stage, a relation between $C_{\text {coll }}$ and $C$ is required. Most measurements of sorption onto bulk rock and colloids are interpreted using an equilibrium sorption model. For compatibility with the data collected on sorption, this approach is adopted in the numerical model as well. Therefore, the parameter used in the model to capture this behavior is the equilibrium sorption parameter $K_{c}=C_{\text {coll }} / C_{\text {fluid }}$, where $C_{\text {coll }}$ is the radionuclide concentration residing on the colloids (moles radionuclide on colloid per kg fluid), and $C_{\text {fluid }}$ is the corresponding concentration in the fluid phase (moles aqueous radionuclide per kg fluid). Combining Equations 6-15 and 6-15a, and making use of the relation $K_{c}=C_{\text {coll }} / C$ :

$$
\left(\frac{R_{f}+K_{c} R_{\text {coll }}}{1+K_{c}}\right) \frac{\partial C}{\partial t}=D_{\text {eff }} \frac{\partial^{2} C}{\partial z^{2}}-v \frac{\partial C}{\partial z}-\frac{q}{b\left(1+K_{c}\right)}
$$

This equation can be recognized as being analogous to the matrix diffusion model of Sudicky and Frind (1982 [DIRS 105043], Eq. 1), with the exception of a different term preceding the time derivative and a modified denominator of the term involving diffusive flux $q$. Mathematically, this implies that the transport equation for matrix diffusion can be revised to include colloid facilitated transport by replacing the half-aperture $b$ by:

$$
b_{\text {coll }}=\left(1+K_{c}\right) b
$$

and the retardation factor in the fracture by:

$$
R_{f, \text { coll }}=\frac{R_{f}+K_{c} R_{\text {coll }}}{1+K_{c}}
$$


These relationships are built into the FEHM particle-tracking code, so that the additional terms $K_{c}$ and $R_{\text {coll }}$ are provided as inputs. Note that to simulate a radionuclide irreversibly attached to colloids, one should set a large value of $K_{c}$ (say, $10^{20}$ ). In general, either a retarded or unretarded colloidally bound radionuclide may be simulated by setting $R_{\text {coll }}$ to a number greater than or equal to 1 . However, colloid retardation factors greater than 1 are only implemented for irreversible colloids (Section 6.5.13)

In addition to the transport of radionuclides bound to colloids, there are several mechanisms related to the migration of the colloids themselves that can be simulated in the model. Above, the retardation factor for colloid migration $R_{\text {coll }}$ was introduced. In addition, the model parameterization provides a means for accounting for colloid size and surface charge effects. When the colloid size and/or surface properties preclude their transport into a porous medium, size exclusion and/or filtration can occur. In the particle-tracking module, models have been implemented for these processes. For advective flow from fracture to matrix in the dualpermeability model, a size-exclusion model is implemented whereby colloids can remain in the fracture in proportions greater than the relative flow rate entering the matrix. A size exclusion parameter $f_{\text {coll }} \leq 1$ is defined such that the probability of particles entering the matrix due to advective transport is multiplied by this factor. Therefore, complete exclusion from the matrix is obtained by setting $f_{\text {coll }}=0$, whereas aqueous solute behavior is retained by setting $f_{\text {coll }}=1$. Filtration, resulting in complete immobilization of the particle, can also be simulated at specified interfaces within either the fracture or matrix continua. To invoke this mechanism, a filtration factor $f_{\text {filt }}$ at an interface (the finite element connections between two specified zones in an FEHM simulation) is defined. If a particle is slated to pass from one zone to the other via advective transport, $f_{\text {filt }}$ is the probability the particle continues moving, $\left(1-f_{\text {filt }}\right)$ is the probability that it is irreversibly removed by filtration.

When using the filtration option, a word of caution is warranted. Colloid simulations are typically used to provide a mechanism for radionuclides to travel in the water bound to colloids. Filtration renders the colloids immobile, which, in reality, only renders the radionuclide immobile if it is irreversibly bound to the colloid. When the radionuclide is only weakly sorbed to the colloid, the filtration option will artificially remove radionuclide mass from the system, resulting in a nonconservative simulation. Therefore, the filtration option should only be invoked for irreversibly bound radionuclides or when simulating colloid tracer experiments.

\subsubsection{Particle Sources and Sinks}

There are two methods for introducing particles into the flow system: particles are (1) either injected with the source fluid entering the model domain or (2) released at a particular cell or set of cells. The first method is used to track source fluid as it passes through the system. The number of particles entering with the source fluid at each cell is proportional to the source flow rate at that cell, which is equivalent to injecting fluid with a constant solute concentration. For Method 2, an arbitrary number of particles are released at each specified cell, regardless of the source flow rate. In the present application, Method 2 is used to input particles, which are used to represent radionuclide mass into the system at the repository level. 
Within Method 2, there are various ways to input a time-varying source of particles. For stand-alone simulations, the particles are inserted at a constant rate for a specified duration. There is also an option, used when the FEHM code is coupled with GoldSim (BSC 2003 [DIRS 161572]), to input a time-varying and spatially varying source mass flux into the model. The details of the method for accepting complex sources of multiple radionuclides from the EBS model are discussed in the next section.

When fluid exits the model domain at a sink, the model treats this flow as another outlet flow from the cell. The decision of whether the particle leaves the system or travels to an adjacent cell is then made on a probabilistic basis, just as though the fluid sink were another connected cell. Thus, the complexities discussed by Zheng (1994 [DIRS 101503]) for handling a so-called weak sink are avoided in the RTTF particle-tracking model.

\subsubsection{EBS Random Release Model for Radionuclide Source Terms}

This section discusses the implementation of the interface between the EBS and the UZ transport models, describing the way in which released radionuclide mass from the EBS enters the UZ. In broad overview, the radionuclides that are released from the EBS are represented in the FEHM abstraction model as particles. Each particle introduced in FEHM represents a given mass. FEHM converts the mass from the GoldSim EBS abstraction model to a specific number of particles, with a mass conversion factor that allows for the translation from mass to particles. When a particle leaves the UZ, it is converted back to radionuclide mass before being returned to GoldSim. In this way, mass is conserved exactly at the EBS-UZ and UZ-SZ interfaces of the TSPA-LA model. The algorithm for determining the conversion factor is based input that the user adjusts to effectively use the available memory on a particular computer. Details on the inputs available to adjust the memory utilization are presented in the report by LANL (2003 [DIRS 165741]).

The remainder of this section describes the algorithm for apportioning the particles to different locations within the repository domain to simulate the spatial and temporal distribution of radionuclide releases from the EBS. The development of "bins" of similar release behavior for the TSPA-LA model is presented in Section 6.5.15. If waste packages containing high-level radionuclide material in the repository eventually fail due to corrosion, the process will almost certainly be variable in both space and time. At early times, a few packages may fail, releasing radionuclides into the UZ. At later times, a greater number of packages may fail. In Viability Assessment calculations (DOE 1998 [DIRS 100547], Figure 4-10), releases from the EBS to UZ were spread over the entire repository subregions. Such treatment of the EBS release could result in significant artificial dilution of the UZ transport source term. In reality, waste packages may not fail uniformly in space and time. Rather, a few waste packages may fail at early times, while others may fail gradually over longer time periods. An EBS random release model was developed in FEHM to allow the model to simulate early failed packages and time- and spatiallyvariable radionuclide releases.

To begin, a repository is defined consisting of N_large subregions. Each subregion contains certain number of waste packages. Initially, M_fine packages fail at locations designated by package $\mathrm{x}-\mathrm{y}$ locations $(\mathrm{x}, \mathrm{y})$. The $\mathrm{M}$-fine failed packages release radionuclides at a mass flow rate of $M \_f l u x \_i$, where $i$ is the $i^{\text {th }}$ failed package. 
With time, packages fail in the subregions of the repository. At each time step, there are a certain number of failed packages in each subregion i. The mass flux released from those packages is denoted as N_large_flux for the $i^{\text {th }}$ subregion. In this model, the release nodes in the numerical grid for the failed packages are randomly selected from the available repository nodes within that subregion to mimic the failure process of the waste packages. The mass release of M_fine packages is separated from those of the other failed packages.

To simulate the impact of the EBS random release on system performance at the Yucca Mountain site, the FEHM EBS random release model was developed to perform the following tasks:

- Locate the M_fine early failed package nodes in repository subregions based on given failed package coordinates. If no node matches a given coordinate, then select the nearest node to the given coordinate. Note that in the current version of the TSPA-LA model, the M_fine user option is not used. However, because it is still in the code, the GoldSim (BSC 2003 [DIRS 161572]) calling program passes M_fine = 0 to FEHM. This situation (where the M_fine option is not used) is discussed in more detail in the following paragraphs.

- Randomly select the failed package nodes in the designated subregion i.

- Release particle into the selected fracture or matrix nodes based on the fracture flow fraction data passed from EBS.

For a species, a particle can be released into a fracture node or a matrix node. The probability of the particle being released into the fracture node is proportional to the fracture fractional flow data from EBS. At run time, a random number is generated for each particle, if the random number is smaller than the fracture fractional flow data, then the particle will be released into the selected fracture node. Otherwise, the particle will be injected into the matrix node corresponding to the selected fracture node.

From FEHM particle-tracking subroutine part_track, subroutine getrip is called to determine the particle release locations. First, the subroutine obtains information passed by GoldSim (BSC 2003 [DIRS 161572]) in an input one-dimensional array called in[ ]. The structure of the in[ ] array is shown in Figure 6-7.

\begin{tabular}{|c|c|c|c|c|c|c|c|c|c|c|c|c|}
\hline$\stackrel{\oplus}{\underline{E}}$ & 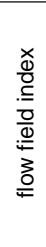 & 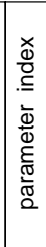 & 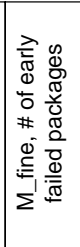 & 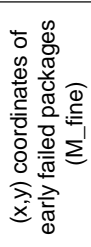 & 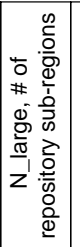 & 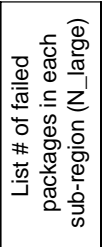 & 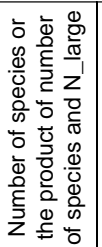 & $\begin{array}{l}\text { Optional input } \\
\text { default value: } 1 . \\
\text { Fracture fractional } \\
\text { flow data for each } \\
\text { species (N_large x } \\
\text { \#_of_species) }\end{array}$ & 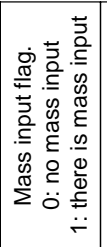 & 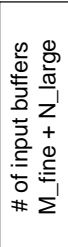 & 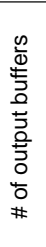 & $\begin{array}{l}\text { Mass release for each species during the current } \\
\text { time step. Values are passed first for the early } \\
\text { failed packages for all species from the first } \\
\text { releasing node to the M_fine th node. Then, from } \\
\text { the first sub-region in the N_large th sub-region } \\
\text { (M_fine + N_large) } x \text { number_of_species. }\end{array}$ \\
\hline
\end{tabular}

Figure 6-7. The Structure of the in[ ] Array Passed to FEHM from GoldSim

The algorithm used in FEHM EBS random release model is summarized in Figure 6-8, the flow chart of the EBS random release model. 


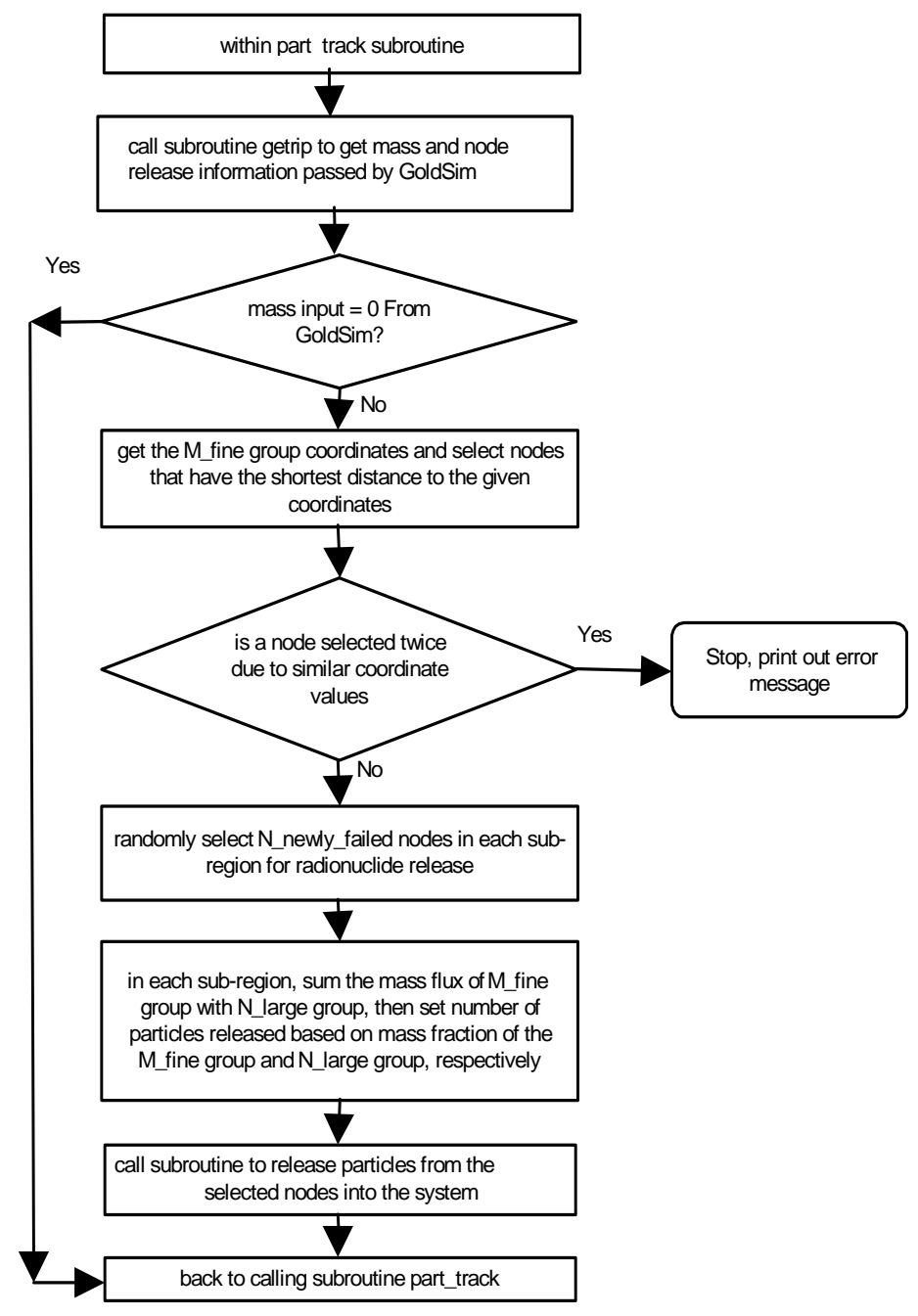

Figure 6-8. Flow Chart of EBS Random Release Model

Starting with the M_fine early failed packages, getrip extracts the $(\mathrm{x}, \mathrm{y})$ coordinates of the early failed packages and loops through each repository subregion node to select the one that is closest to the given coordinates. To prevent a node being selected more than once for two or more given coordinates, getrip checks the selected nodes for overlapping. If overlapping is found, getrip prints out error messages to the error file fehmn.err, then stops the program.

When the selection of M_fine nodes is complete, getrip extracts the number of failed packages in each subregion for the N_large subregions. The number of failed packages at the current time step is compared with the values at the previous time step to determine the number of newly failed packages, N_newly_failed, within the current time step in each subregion. Then, getrip randomly selects N_newly_failed nodes within the corresponding subregion. The selected failed nodes are stored in the memory for use in releasing radionuclides and are removed from the base of available repository nodes. If the number of failed packages is larger than the number of nodes in a subregion, then radionuclides will be released from all nodes within the subregion. Once all nodes of failed packages are determined, getrip allocates the number of released 
particles proportionally to the mass flux values of each failed package. Then, subroutine setmptr is called to inject particles into the system for each species.

When the locations/coordinates of M_fine early failed packages are unknown, the user can simulate the effect of early failed packages on UZ transport by passing the number of early failed packages in the N_large subregions to FEHM. FEHM then randomly selects the locations of the early failed packages and releases particles into the UZ as described in the paragraph above. Using this option, the user will pass $M_{-}$fine $=0$ to $F E H M$ and omit the coordinates of the early failed packages (the 5th data block in Figure 6-7 is not needed).

To investigate the influence of matrix diffusion on UZ transport behavior, a radionuclide can be released from either a fracture node or a matrix node. The probability of the particle to be released from a fracture node is proportional to the fracture fractional flow data passed from GoldSim to FEHM in the input array in[ ] (Figure 6-7). At run time, a random number is generated; when the generated random number is smaller than the given fracture fraction flow, the particle is released from a selected fracture node. Otherwise, the particle is released through a selected matrix node.

In the case of radionuclide release as gas phase and transport through geosphere, TSPA treats the released mass as aqueous phase. This is expected to bound any dose effects of gas-phase release due to the large dilution of gas-phase release in the atmosphere (Features, Events, and Processes in UZ Flow and Transport, BSC 2004 [DIRS 170012]).

\subsubsection{Climate Change and Water Table Rise}

One important factor that could affect the performance of the repository is future climate changes. As it is difficult and time consuming to simulate the transition of flow fields from one climate to another, in TSPA several pregenerated flow fields are used to represent the corresponding climates. These flow fields are developed in the report by BSC (2004 [DIRS 169861]), and are converted to FEHM-compatible flow fields in DTN: LB0305TSPA18FF.001 [DIRS 165625]. This approach treats flow in the system as a sequence of steady states. For TSPA simulations, those pregenerated flow fields are read in by FEHM at run time and whenever the GoldSim (BSC 2003 [DIRS 161572]) model signals to FEHM that the climate is changing. From that point until the climate changes again, the flow field is taken to be steady. The following discussion details the numerical approach for handling varying flow fields.

The RTTF particle-tracking method for a time-varying fluid flow system as compared with a steady flow system is more complex but still tractable. Consider a numerical simulation in which a discrete time step is taken at time $t$ and a new fluid flow field is computed. In this model, the new fluid flow time $t_{\text {new }}=t+\Delta t$ is treated as an intermediate time at which the particle-tracking calculation must stop. The time is intermediate because if the flow field is at steady state, there is no reason to stop at any time before the end of the simulation except to record particle information for output or processing purposes. The fate of all particles is tracked from time $t$ to time $t_{\text {new }}$; assuming that the flow field is constant over this time interval. When the simulation reaches $t_{\text {new }}$, the position (cell number) of the particle is recorded, along with its 
fractional time remaining at the cell and the randomly generated y-coordinate of the transfer function used for that particle in the cell. When the new fluid flow solution is established, the remaining residence time for a particle is determined from the following steps:

1. Compute a new fluid residence time ${ }^{\tau_{f}}$.

2. Using the y-coordinate of the transfer function previously computed and the new transfer function, calculate a new particle residence time.

3. Multiply this time by the fractional time remaining in the cell to obtain the remaining time in the cell.

This method approximates the behavior in a transient system, while reducing to the behavior that would be obtained in an unchanging flow field had the calculation not been forced to stop at the intermediate time.

Another transient effect that must be considered is that the sum of the outlet mass flow rates $\sum \dot{m}_{\text {out }}$ in Equation 6-1 does not necessarily equal the sum of the inlet mass flow rates. When there is net fluid flow into a cell, the particle-tracking algorithm uses the sum of the inlet flow rates in Equation 6-1, whereas Equation 6-1 itself is used when there is net outflow from a cell. Finally, with respect to the transfer function methodology outlined in Section 6.4.3, when the climate changes, the code redefines the parameters in Equations 6-9, 6-10, and 6-11, and uses these parameters and the new flow field to continue the transport simulation.

It is expected that the water table will be higher in future climates. One issue related to climate change is water table rise. In the UZ transport model abstraction, water table is switched instantaneously from one climate to another when climate changes. Any radionuclides (in the form of particles in the particle tracking model) below the new water table are immediately removed from the UZ and sent to SZ. This approach is conservative as both the flow field and water table are immediately switched to the wetter climate at time of climate change, which not only accelerates the movement of radionuclides in the system but also tends to result in instantaneous pulses of radionuclides into the SZ.

To set the water table elevation to a higher value than that used for the development of the flow fields in DTN: LB0305TSPA18FF.001 [DIRS 165625], the flow field files must be postprocessed using the software WTRISE (LBNL 2003 [DIRS 163453]). This has not been done in this abstraction model because the calculations presented are being compared to process model results that assumed the present-day water table for the future climate modeling. For TSPA-LA model calculations, this processing step has been performed for all flow fields of future, wetter climates. The use of WTRISE requires the specification of a water table elevation under the future climate scenarios. The code adjusts the flow field for all grid blocks beneath this elevation to force particles to immediately leave when reaching any of these grid blocks. Therefore, an elevation for the higher water table must be selected.

The magnitude of the rise in the water table beneath the repository at Yucca Mountain under previous glacial-transition climatic conditions is uncertain, but estimates are available from 
several independent lines of evidence (Forester et al. 1999 [DIRS 109425], pp. 56 and 57). Early groundwater flow modeling of the response to a doubling of the mean annual precipitation indicated a maximum increase of $130 \mathrm{~m}$ of the water table in the vicinity of Yucca Mountain (Czarnecki 1984 [DIRS 101043], p. 21). Analysis of mineralogic alteration (zeolitization and tridymite distribution) in the UZ at Yucca Mountain showed that the water table has probably not risen more than $60 \mathrm{~m}$ above its present position in the geologic past (Levy 1991 [DIRS 100053], p. 477). Analyses of ${ }^{87} \mathrm{Sr} /{ }^{86} \mathrm{Sr}$ ratios in calcite veins of the UZs and SZs at Yucca Mountain indicated previous water table positions of $85 \mathrm{~m}$ higher than present (Marshall et al. 1993 [DIRS 101142], p. 1948). Groundwater flow modeling of the regional flow system under projected future climate conditions simulated water levels of $60 \mathrm{~m}$ to $150 \mathrm{~m}$ higher than present beneath Yucca Mountain (D’Agnese et al. 1999 [DIRS 120425], p. 2).

Given this set of estimates from multiple, independent sources, Forester et al. (1999 [DIRS 109425], p. 56) suggests that site data are consistent with past water table elevations up to $120 \mathrm{~m}$ higher than present day elevations. This value of $120 \mathrm{~m}$ is therefore adopted in this report for the purpose of establishing the water table under future, wetter climates. Because the water table is not flat, a nominal elevation for the present-day water table must be selected and the future water table must then be based on that selection. For the typical water table elevation under present day conditions beneath the repository of $730 \mathrm{~m}$ (BSC 2004 [DIRS 170037], Section 6.4.5.1), a rise of $120 \mathrm{~m}$ results in an elevation of $850 \mathrm{~m}$. As a comparison, BSC (2004 [DIRS 170037], Section 6.4.5.1) performed an analysis in which the water table was assumed to be $100 \mathrm{~m}$ higher than present-day, but processed the water table to parallel the present-day water table. Figure 6-11 in the document by BSC (2004 [DIRS 170037]) shows that for the future water table analysis used to investigate the impact on SZ processes, the $850 \mathrm{~m}$ elevation contours passes through the repository footprint. Therefore, choosing an elevation of $850 \mathrm{~m}$ for processing the UZ flow fields for the future climate cases is consistent with available site data, and is consistent with SZ studies. Furthermore, since there is no site data or numerical modeling available to form a basis for selecting different water table elevations for the various future climate states, the $850 \mathrm{~m}$ elevation is used for future climate flow fields. With respect to UZ transport to the water table, this approximation should be conservative because a reasonable maximum elevation, resulting in a minimum for the UZ flow path length, is used for future climates, even though some of the site data mentioned above yielded estimates of smaller water table rise. The flow fields processed to incorporate the higher water table for the future, wetter climates are available in DTN: LB0312TSPA06FF.001 [DIRS 166671].

\subsubsection{Interface with GoldSim}

The interface between GoldSim and FEHM establishes a protocol for defining the radionuclide sources to the UZ transport model provided by GoldSim (BSC 2003 [DIRS 161572]), the definition of a particular flow field for FEHM to use, and exit mass fluxes of radionuclides from the UZ model (from FEHM to GoldSim based on the particle-tracking simulation). This protocol is quite flexible, allowing an arbitrary number of source regions, radionuclides, exit regions, and flow fields to be defined and passed between GoldSim and FEHM through the FEHM subroutine call statement. Figure 6-9 shows a simplified flow chart of the GoldSimFEHM coupling. 


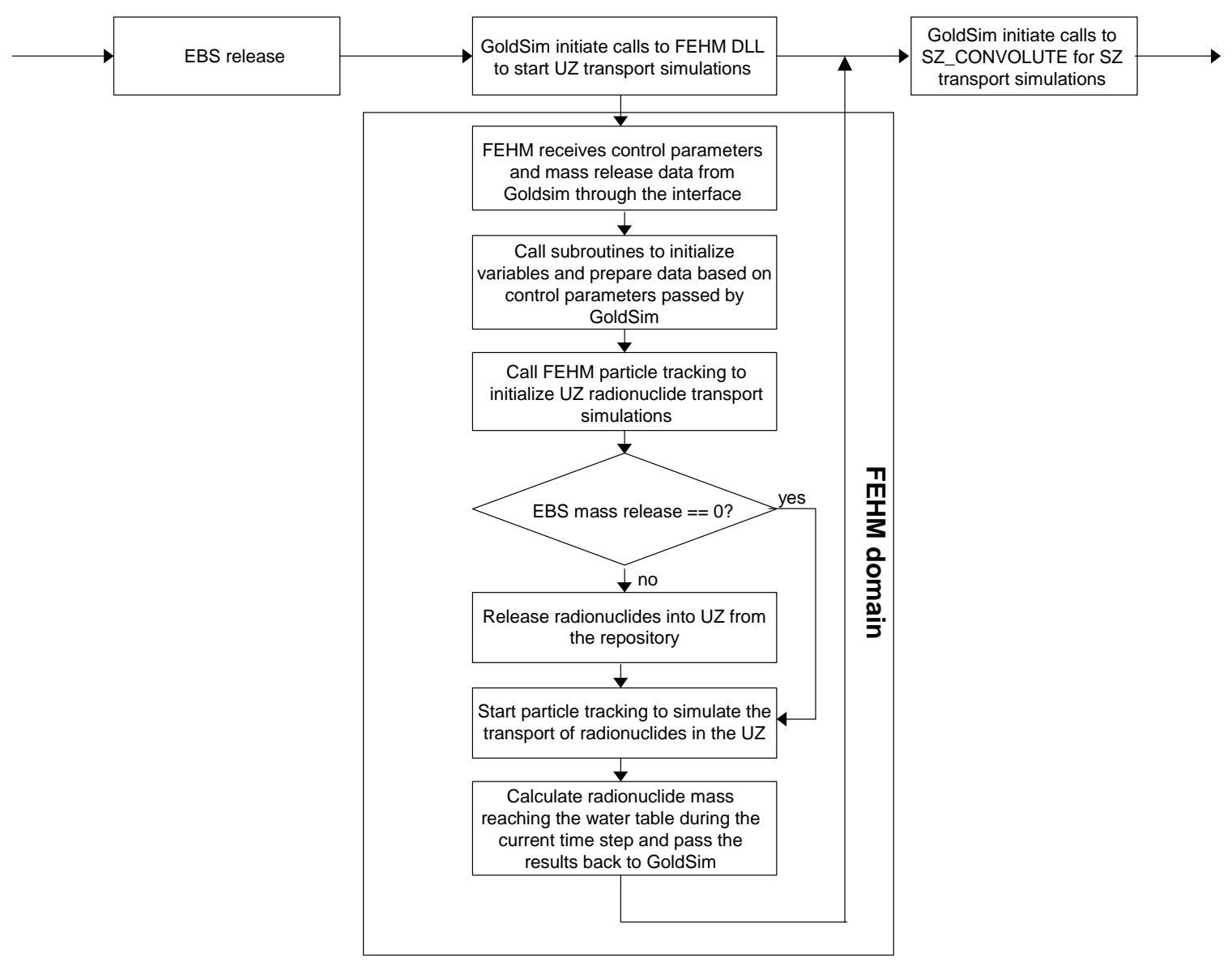

Figure 6-9. Schematic Flow Chart of GoldSim-FEHM Coupling

During a GoldSim simulation, FEHM cedes control of the time step to GoldSim. At each time, GoldSim provides a flag defining the flow field and the mass flux inputs of radionuclides. By changing the flow field during a simulation, the model can simulate the impact of a climate-induced change in the UZ system. When this occurs, FEHM reads in the new flow field and proceeds with the transport simulation (see Section 6.4.8). Since each flow field is a steady state flow field, the implicit assumption is a quasi-steady one, that is, the system establishes a new steady state rapidly in comparison to transport velocities through the UZ. At the end of each time step, FEHM passes back to GoldSim the exiting mass flux values from the UZ model.

\subsection{TRANSPORT MODEL INPUTS}

This section describes the input parameters and their uncertainties. The importance of different transport mechanisms depends on the values of the corresponding parameters that are inputs to the transport model. Parameters read in by the FEHM abstraction as input to the transport model include

- Dispersivity (m)

- Matrix porosity and rock density $\left(\mathrm{kg} / \mathrm{m}^{3}\right)$

- Matrix sorption coefficient (mL/g) 
- Matrix diffusion coefficient $\left(\mathrm{m}^{2} / \mathrm{sec}\right)$

- Fracture residual saturation and fracture gamma parameters (unitless)

- Fracture porosity, fracture spacing (m), and fracture aperture (m)

- Fracture surface retardation factor (unitless)

- Colloid size distribution, colloid $\mathrm{K}_{\mathrm{c}}$, colloid $\mathrm{R}_{\text {coll }}$, and colloid filtration factor

- Radionuclide half lives (years) and daughter products.

For layers above the repository, placeholder values for these transport parameters are used in the input files for the model, but these values are not germane to the model results because radionuclide particles do not pass through these units. Beyond the transport parameters, at run time, FEHM also reads in the pregenerated flow fields and property zone data. Those data are inputs from UZ flow model to the transport model. Finally, boundary and initial conditions comprise the remaining model inputs required to perform a transport simulation. In this model, the top boundary is the repository, where radionuclides are released from the EBS into the system. The strength of the source release varies with time and depends on the failure rate of the waste packages. At the bottom boundary (the water table), radionuclides are removed from the UZ system and become the source term for the SZ model. The side boundaries of the transport model are no-flow boundaries defined as the outer surfaces of the model domain. Finally, the initial condition of the transport model is set to a concentration of zero for all radionuclides because the model simulations are initiated before any radionuclides have escaped the EBS.

Note that for some parameters, such as longitudinal dispersivity, colloid transport parameters, and matrix diffusion parameters, different values and ranges are developed in this report when compared to the process model report by BSC (2004 [DIRS 164500]). The values and ranges developed in the sections below are the values to be used in TSPA calculations, whereas in the report by BSC (2004 [DIRS 164500]) the parameters are set to explore the sensitivity of the model to the parameter uncertainties. Therefore, all transport parameter feeds to TSPA are through this report, in the sections presented below. It is also important to note that for the purposes of comparing the process and abstraction models in Section 7, consistent parameters were used.

The sub-sections below give a more detailed discussion about each parameter.

\subsubsection{Pre-generated Flow Fields}

In TSPA runs, a total of 9 base case flow fields corresponding to 9 climate scenarios, present day [low, mean, and high], glacial transition [low, mean, and high], and monsoon [low, mean, and high], are pregenerated and fed into FEHM.

The flow fields are based on the dual-k model formulation that allows water flow in both fractures and the corresponding matrix blocks. A total of 120,711 physical nodes are used to discretize the Yucca Mountain Project site. For the dual-k model, at any physical node, there is a fracture node and a corresponding matrix node. Thus, the flow model has a total of 241,422 flow nodes (DTN: LB0305TSPA18FF.001 [DIRS 165625]).

The UZ flow model is characterized by potential lateral flow in the PTn unit, the occurrence of perched water within low-permeability zeolites in the Calico Hills nonwelded unit or the densely 
welded basal vitrophyre of the Topopah Spring welded (TSw) unit, and the effects of faults on the UZ flow system (BSC 2004 [DIRS 169861]).

In TSPA-LA runs, the 9 base case flow fields will be used in the corresponding climates. The name of the flow fields and corresponding files are listed in Table 4-1.

\subsubsection{Dispersivity}

The site-scale UZ flow model has indicated that flow in the fractured rock system is dominated by fracture flow. In such a system, radionuclide transport is primarily advection dominated, and the influence of dispersion on radionuclide transport is not expected to be important. The reason for this is that when compared to the spreading of radionuclides due to matrix diffusion effects, the impact on transport times of longitudinal dispersion is likely to be small.

There are few data available on dispersivity distributions at Yucca Mountain site. Neuman 1990 [DIRS 101464] showed that field dispersivity varied with the scale of study. Field tracer tests at the C-holes at Yucca Mountain also showed that on a 100-m scale, field dispersivity had a range of approximately 3 to 63 m (BSC 2004 [DIRS 170010], Table 6.3-3).

In the UZ transport abstraction model, the fracture dispersivity is set at $10 \mathrm{~m}$. This is toward the lower end of the value from field studies (BSC 2004 [DIRS 170010], Table 6.3-3). Although the impact of dispersivity should be very small, the value chosen should be conservative, as higher dispersivity tends to spread the radionuclide plume and reduce the peak concentration. While it can be argued that for a decaying species, higher dispersivity can allow a greater fraction of the mass to arrive downstream before decaying, the point here is that in comparison to diffusion and large scale heterogeneities, dispersivity effects have a very small influence on the breakthrough curves. This justifies the use of a fixed value for dispersivity rather than treating it as a stochastic parameter (Table 6-2).

Table 6-2. Dispersivity Used in UZ Transport Abstraction Model

\begin{tabular}{|l|l|l|l|l|}
\hline \multicolumn{1}{|l|}{ Input Name } & \multicolumn{1}{|c|}{ Input Description } & \multicolumn{1}{c|}{$\begin{array}{c}\text { Type of } \\
\text { Input Sources }\end{array}$} & \multicolumn{1}{c|}{$\begin{array}{c}\text { Value (Units) } \\
\text { Uncertainty }\end{array}$} \\
\hline $\begin{array}{l}\text { Fracture } \\
\text { dispersivity }\end{array}$ & $\begin{array}{l}\text { Input to FEHM for simulating } \\
\text { dispersion effect }\end{array}$ & $\begin{array}{l}\text { BSC 2003 [DIRS 170010], } \\
\text { Table 6.3-3 } \\
\text { Saturated Zone In-Situ Testing }\end{array}$ & $10 \mathrm{~m}$ & Fixed value \\
\hline
\end{tabular}

FEHM=finite element heat and mass (model)

Because the dual-k abstraction model treats the combined fracture-matrix system as a unified continuum, this dispersivity applies to the medium as a whole. Therefore, the model does not distinguish between fracture dispersivity and matrix dispersivity.

\subsubsection{Matrix Porosity and Rock Density}

Matrix porosity is used to calculate the matrix pore volume associated with each matrix block. The pore volume data are then multiplied by the corresponding water saturation data to determine the fluid volume in a cell. 
Matrix porosity and rock density values combined with rock sorption coefficient and water saturation are used for calculating matrix retardation factors used in simulating the sorption effect on radionuclide transport.

Values of matrix porosity are from the Technical Data Management System (TDMS) (DTN: LB0210THRMLPRP.001 [DIRS 160799]) and listed in Table 6-3.

Table 6-3. Matrix Porosities Used in the Transport Model

\begin{tabular}{|c|c|c|c|c|}
\hline Matrix Layer & $\begin{array}{c}\text { Matrix } \\
\text { Porosity }\end{array}$ & Input Description & Input Source & Type of Uncertainty \\
\hline tcwm1 & 1.18E-01 & \multirow{37}{*}{$\begin{array}{l}\text { Matrix porosity values are } \\
\text { used in determining matrix } \\
\text { pore volume, simulating } \\
\text { matrix diffusion effects, and } \\
\text { calculating matrix sorption } \\
\text { retardation factors. }\end{array}$} & \multirow{37}{*}{$\begin{array}{l}\text { LB0210THRMLPRP.001 } \\
\text { [DIRS 160799] } \\
\text { "Thermal Properties of UZ } \\
\text { Model Layers: Data } \\
\text { Summary" }\end{array}$} & \multirow{37}{*}{$\begin{array}{l}\text { Fixed values for each } \\
\text { layer but varies from } \\
\text { layer to layer }\end{array}$} \\
\hline tcwm2 & 1.18E-01 & & & \\
\hline tcwm3 & 4.57E-02 & & & \\
\hline ptnm1 & 3.54E-01 & & & \\
\hline ptnm2 & 3.54E-01 & & & \\
\hline ptnm3 & 3.54E-01 & & & \\
\hline ptnm4 & 3.54E-01 & & & \\
\hline ptnm5 & 3.54E-01 & & & \\
\hline ptnm6 & 2.51E-01 & & & \\
\hline tswm1 & 4.57E-02 & & & \\
\hline tswm2 & 1.18E-01 & & & \\
\hline tswm3 & 1.43E-01 & & & \\
\hline tswm4 & 1.29E-01 & & & \\
\hline tswm5 & 1.49E-01 & & & \\
\hline tswm6 & 1.06E-01 & & & \\
\hline tswm7 & 1.06E-01 & & & \\
\hline tswm8 & 4.57E-02 & & & \\
\hline tswmv & 4.57E-02 & & & \\
\hline tswmz & 4.57E-02 & & & \\
\hline ch1mv & 3.54E-01 & & & \\
\hline ch2mv & $3.28 \mathrm{E}-01$ & & & \\
\hline $\operatorname{ch} 3 m v$ & $3.28 E-01$ & & & \\
\hline ch4mv & $3.28 \mathrm{E}-01$ & & & \\
\hline ch5mv & 3.28E-01 & & & \\
\hline ch6mv & $3.28 \mathrm{E}-01$ & & & \\
\hline $\operatorname{ch} 1 \mathrm{mz}$ & 3.54E-01 & & & \\
\hline $\operatorname{ch} 2 \mathrm{mz}$ & 3.28E-01 & & & \\
\hline ch3mz & $3.28 \mathrm{E}-01$ & & & \\
\hline ch4mz & $3.28 \mathrm{E}-01$ & & & \\
\hline $\operatorname{ch} 5 \mathrm{mz}$ & 3.28E-01 & & & \\
\hline ch6mz & 3.28E-01 & & & \\
\hline pp4mz & 2.97E-01 & & & \\
\hline pp3md & 2.97E-01 & & & \\
\hline pp2md & 2.33E-01 & & & \\
\hline pp1mz & $2.73 \mathrm{E}-01$ & & & \\
\hline bf3md & $1.88 \mathrm{E}-01$ & & & \\
\hline bf2mz & $2.62 E-01$ & & & \\
\hline
\end{tabular}


Table 6-3. Matrix Porosities Used in the Transport Model (Continued)

\begin{tabular}{|c|c|c|c|c|}
\hline Matrix Layer & $\begin{array}{c}\text { Matrix } \\
\text { Porosity }\end{array}$ & Input Description & Input Source & Type of Uncertainty \\
\hline tr3md & 2.80E-01 & \multirow{9}{*}{$\begin{array}{l}\text { Matrix porosity values are } \\
\text { used in determining matrix } \\
\text { pore volume, simulating } \\
\text { matrix diffusion effects, and } \\
\text { calculating matrix sorption } \\
\text { retardation factors. }\end{array}$} & \multirow{9}{*}{$\begin{array}{l}\text { LB0210THRMLPRP.001 } \\
\text { [DIRS 160799] } \\
\text { "Thermal Properties of UZ } \\
\text { Model Layers: Data } \\
\text { Summary" }\end{array}$} & \multirow{9}{*}{$\begin{array}{l}\text { Fixed values for each } \\
\text { layer but varies from } \\
\text { layer to layer }\end{array}$} \\
\hline $\operatorname{tr} 2 \mathrm{mz}$ & 3.35E-01 & & & \\
\hline pcm38 & 4.57E-02 & & & \\
\hline pcm39 & 4.57E-02 & & & \\
\hline pcm1z & 3.54E-01 & & & \\
\hline pcm2z & 3.28E-01 & & & \\
\hline pcm5z & 3.28E-01 & & & \\
\hline pcm6z & $3.28 \mathrm{E}-01$ & & & \\
\hline pcm4p & 2.97E-01 & & & \\
\hline
\end{tabular}

NOTE: Layers defining the perched water units are assigned porosity values that are the same as those of the corresponding geologic unit in which they reside.

Rock density values are from the TDMS (DTN: LB0210THRMLPRP.001 [DIRS 160799]) and are listed in Table 6-4 below. These densities are bulk rock densities, obtained from the grain density in the cited DTN, multiplied by one minus the porosity, using the porosities listed in Table 6-3.

Table 6-4. Matrix Rock Density Values

\begin{tabular}{|c|c|c|c|c|}
\hline Matrix Layer & $\begin{array}{c}\text { Rock } \\
\text { Density } \\
\left(\mathbf{k g} / \mathrm{m}^{3}\right)\end{array}$ & Input Description & Input Source & Type of Uncertainty \\
\hline Tcwm1 & $2.217 E+03$ & \multirow{22}{*}{$\begin{array}{l}\text { Rock density data are } \\
\text { used by FEHM in the } \\
\text { calculation of matrix } \\
\text { sorption retardation } \\
\text { factors. These } \\
\text { densities are bulk rock } \\
\text { densities obtained from } \\
\text { the grain density in the } \\
\text { cited DTN, multiplied } \\
\text { by one minus the } \\
\text { porosity, using the } \\
\text { porosities listed in } \\
\text { Table 6-3. }\end{array}$} & \multirow{22}{*}{$\begin{array}{l}\text { LB0210THRMLPRP.001 } \\
\text { [DIRS 160799] } \\
\text { "Thermal Properties of } \\
\text { UZ Model Layers: Data } \\
\text { Summary" }\end{array}$} & \multirow{22}{*}{$\begin{array}{l}\text { Fixed values for each } \\
\text { layer but varies from } \\
\text { layer to layer }\end{array}$} \\
\hline Tcwm2 & $2.217 E+03$ & & & \\
\hline Tcwm3 & $2.170 \mathrm{E}+03$ & & & \\
\hline ptnm1 & $1.478 \mathrm{E}+03$ & & & \\
\hline ptnm2 & $1.478 \mathrm{E}+03$ & & & \\
\hline ptnm3 & $1.478 \mathrm{E}+03$ & & & \\
\hline ptnm4 & $1.478 \mathrm{E}+03$ & & & \\
\hline ptnm5 & $1.478 E+03$ & & & \\
\hline ptnm6 & $1.709 \mathrm{E}+03$ & & & \\
\hline Tswm1 & $2.170 E+03$ & & & \\
\hline Tswm2 & $2.217 E+03$ & & & \\
\hline Tswm3 & $2.022 E+03$ & & & \\
\hline Tswm4 & 2.149 E+03 & & & \\
\hline Tswm5 & $1.980 \mathrm{E}+03$ & & & \\
\hline Tswm6 & $2.211 E+03$ & & & \\
\hline tswm7 & $2.211 E+03$ & & & \\
\hline tswm8/pcm38 & $2.170 \mathrm{E}+03$ & & & \\
\hline $\begin{array}{l}\text { tswm9/pcm39/t } \\
\text { swmv/tswmz }\end{array}$ & $2.170 \mathrm{E}+03$ & & & \\
\hline ch1mv & $1.478 \mathrm{E}+03$ & & & \\
\hline ch2mv & $1.516 E+03$ & & & \\
\hline ch3mv & $1.516 E+03$ & & & \\
\hline ch4mv & $1.516 E+03$ & & & \\
\hline
\end{tabular}


Table 6-4. Matrix Rock Density Values (Continued)

\begin{tabular}{|c|c|c|c|c|}
\hline Matrix Layer & $\begin{array}{c}\text { Rock } \\
\text { Density } \\
\left(\mathrm{kg} / \mathrm{m}^{3}\right) \\
\end{array}$ & Input Description & Input Source & Type of Uncertainty \\
\hline ch5mv & $1.516 \mathrm{E}+03$ & \multirow{21}{*}{$\begin{array}{l}\text { Rock density data are } \\
\text { used by FEHM in the } \\
\text { calculation of matrix } \\
\text { sorption retardation } \\
\text { factors. These } \\
\text { densities are bulk rock } \\
\text { densities obtained from } \\
\text { the grain density in the } \\
\text { cited DTN, multiplied } \\
\text { by one minus the } \\
\text { porosity, using the } \\
\text { porosities listed in } \\
\text { Table } 6-3 \text {. }\end{array}$} & \multirow{21}{*}{$\begin{array}{l}\text { LB0210THRMLPRP.001 } \\
\text { [DIRS 160799] } \\
\text { "Thermal Properties of } \\
\text { UZ Model Layers: Data } \\
\text { Summary" }\end{array}$} & \multirow{21}{*}{$\begin{array}{l}\text { Fixed values for each } \\
\text { layer but varies from } \\
\text { layer to layer }\end{array}$} \\
\hline ch6mv* & $1.516 E+03$ & & & \\
\hline ch1mz/pcm1z & $1.478 E+03$ & & & \\
\hline ch2mz/pcm2z & $1.516 \mathrm{E}+03$ & & & \\
\hline ch3mz & $1.516 \mathrm{E}+03$ & & & \\
\hline $\operatorname{ch} 4 \mathrm{mz}$ & $1.516 \mathrm{E}+03$ & & & \\
\hline ch5mz/pcm5z & $1.516 \mathrm{E}+03$ & & & \\
\hline ch6mz/pcm6z & $1.516 \mathrm{E}+03$ & & & \\
\hline pp4mz/pcm4p & $1.478 E+03$ & & & \\
\hline pp3md & $1.478 \mathrm{E}+03$ & & & \\
\hline pp2md & $1.829 E+03$ & & & \\
\hline pp1mz & $1.481 \mathrm{E}+03$ & & & \\
\hline bf3md & $1.709 \mathrm{E}+03$ & & & \\
\hline bf2mz & $1.486 E+03$ & & & \\
\hline tr3md & $1.707 \mathrm{E}+03$ & & & \\
\hline $\operatorname{tr} 2 \mathrm{mz}$ & $1.478 \mathrm{E}+03$ & & & \\
\hline \multicolumn{2}{|c|}{ Fault Zone Rock Density Data } & & & \\
\hline tcw & $2.198 E+03$ & & & \\
\hline ptn & $1.577 \mathrm{E}+03$ & & & \\
\hline tsw & $2.125 E+03$ & & & \\
\hline chn & $1.550 \mathrm{E}+03$ & & & \\
\hline
\end{tabular}

NOTE: Layers defining the perched water units (not listed in the table) are assigned porosity values that are the same as those of the corresponding geologic unit in which they reside.

${ }^{*}$ Rock density not given for layer ch6mv in the cited DTN. Value taken to be the same as ch5mv.

DTN=data tracking number; FEHM=finite element heat and mass (model)

\subsubsection{Matrix Sorption Coefficient $(\mathrm{mL} / \mathrm{g})$}

Dissolved radionuclide waste traveling through the matrix can be retarded due to sorption on to the surface of the porous matrix material. In TSPA-LA runs, the linear sorption model is used to describe the partitioning of radionuclides between the solute and the matrix through the UZ system. Matrix sorption coefficients can be read in by FEHM at run time. The values are then used to calculate matrix rock retardation factors of different radionuclides. The validity of the linear equilibrium model and the derivation of sorption coefficient distributions based on laboratory experiment data are documented in model report, Radionuclide Transport Models Under Ambient Conditions (BSC 2004 [DIRS 164500]).

The strength of matrix sorption depends on the properties of the rock material, aqueous composition, and the radionuclides. Matrix sorption coefficients for different rock types (zeolitic, devitrified, and vitric) are taken from the TDMS (DTN: LA0408AM831341.001 [DIRS 171584]). Values of the sorption coefficient are divided into three groups based on rock type (e.g., devitrified, vitric, and zeolitic). Table 6-5 lists the statistical distribution of matrix sorption coefficient for different radionuclide types. 
To address the influence of the sorption coefficient uncertainty on system performance, the matrix sorption coefficients of each species are presampled for each rock type (based on the listed distribution values in Table 6-5) for each TSPA realization. For a discussion on the method of correlating sorption coefficients to one another in the stochastic sampling of parameters, see Appendix B of the report by BSC (2004 [DIRS 164500]).

Table 6-5. Sorption-Coefficient Distributions for Unsaturated Zone Units

\begin{tabular}{|c|c|c|c|c|}
\hline Species & $\begin{array}{l}\text { Rock } \\
\text { Type }\end{array}$ & $\begin{array}{c}\text { Type of Uncertainty } \\
\text { Distribution }\end{array}$ & $\begin{array}{c}\text { Coefficients Describing Distribution (Kd: } \\
\mathrm{mL} / \mathrm{g})\end{array}$ & Input Description \\
\hline \multirow[b]{3}{*}{$U$} & Zeolitic & Cumulative & (Kd value, probability) $(0,0)(0.5,0.5)(30,1.0)$ & \multirow{27}{*}{$\begin{array}{l}\text { The matrix sorption } \\
\text { coefficient data are read in } \\
\text { at runtime by FEHM for } \\
\text { simulating the effect of } \\
\text { matrix sorption on } \\
\text { radionuclide transport. }\end{array}$} \\
\hline & Devitrified & Cumulative & (Kd value, probability) $(0,0)(0.2,0.5)(4 ., 1.0)$ & \\
\hline & Vitric & Cumulative & (Kd value, probability) $(0,0)(0.2,0.5)(3 ., 1.0)$ & \\
\hline \multirow[b]{3}{*}{$\mathrm{Np}$} & Zeolitic & Cumulative & (Kd value, probability) $(0,0)(0.5,0.5)(6 ., 1.0)$ & \\
\hline & Devitrified & Cumulative & (Kd value, probability) $(0,0)(0.5,0.5)(6 ., 1.0)$ & \\
\hline & Vitric & Cumulative & (Kd value, probability) $(0,0)(1.0,0.5)(3 ., 1.0)$ & \\
\hline \multirow{3}{*}{$\mathrm{Pu}$} & Zeolitic & Cumulative & $\begin{array}{l}\text { (Kd value, probability) }(10 ., 0)(100 ., 0.5)(200 ., \\
1.0)\end{array}$ & \\
\hline & Devitrified & Cumulative & $\begin{array}{l}\text { (Kd value, probability) }(10 ., 0)(70 ., 0.5)(200 ., \\
1.0)\end{array}$ & \\
\hline & Vitric & Cumulative & $\begin{array}{l}\text { (Kd value, probability) }(10 ., 0)(100 ., 0.5)(200 ., \\
1.0)\end{array}$ & \\
\hline \multirow{3}{*}{ Am } & Zeolitic & Truncated Normal & $\begin{array}{l}\text { Range }=1000-10000 \text { Mean=5500 Std } \\
\text { Dev }=1500\end{array}$ & \\
\hline & Devitrified & Truncated Normal & $\begin{array}{l}\text { Range }=1000-10000 \text { Mean }=5500 \text { Std } \\
\text { Dev }=1500\end{array}$ & \\
\hline & Vitric & Cumulative & $\begin{array}{l}\text { (Kd value, probability) }(100 ., 0)(400 ., 0.5) \\
(1000 ., 1.0)\end{array}$ & \\
\hline \multirow{3}{*}{$\mathrm{Pa}$} & Zeolitic & Truncated Normal & $\begin{array}{l}\text { Range }=1000-10000 \text { Mean }=5500 \text { Std } \\
\text { Dev }=1500\end{array}$ & \\
\hline & Devitrified & Truncated Normal & $\begin{array}{l}\text { Range }=1000-10000 \text { Mean }=5500 \text { Std } \\
\text { Dev }=1500\end{array}$ & \\
\hline & Vitric & Truncated Normal & $\begin{array}{l}\text { Range }=1000-10000 \text { Mean }=5500 \text { Std } \\
\text { Dev }=1500\end{array}$ & \\
\hline \multirow{3}{*}{ Cs } & Zeolitic & Cumulative & $\begin{array}{l}\text { (Kd value, probability) }(425 ., 0)(5000 ., 0.5) \\
(20000 ., 1.0)\end{array}$ & \\
\hline & Devitrified & Uniform & Range $=1-15$ & \\
\hline & Vitric & Cumulative & (Kd value, probability) $(0 ., 0)(2 ., 0.5)(100 ., 1.0)$ & \\
\hline \multirow{3}{*}{$\mathrm{Sr}$} & Zeolitic & Uniform & Range $=50-2000$ & \\
\hline & Devitrified & Uniform & Range $=10-70$ & \\
\hline & Vitric & Uniform & Range $=0-50$ & \\
\hline \multirow{3}{*}{$\mathrm{Ra}$} & Zeolitic & Uniform & Range $=1000-5000$ & \\
\hline & Devitrified & Uniform & Range $=100-1000$ & \\
\hline & Vitric & Uniform & Range $=50-600$ & \\
\hline \multirow{3}{*}{ Th } & Zeolitic & Uniform & Range $=1000-30000$ & \\
\hline & Devitrified & Uniform & Range $=1000-10000$ & \\
\hline & Vitric & Uniform & Range $=1000-10000$ & \\
\hline
\end{tabular}

DTN: LA0408AM831341.001 [DIRS 171584]

FEHM=finite element heat and mass (model) 


\subsubsection{Matrix Diffusion Coefficient $\left(\mathrm{m}^{2} / \mathrm{sec}\right)$}

It has been shown that matrix diffusion combined with matrix sorption can play an important role in slowing the movement of radionuclides in fractured rocks (Sudicky and Frind 1982 [DIRS 105043]).

A matrix diffusion coefficient is used in FEHM for simulating the effect of matrix diffusion on radionuclide transport in the fractured media. Values of matrix diffusion coefficient affect the strength of fracture-matrix interaction due to diffusion of radionuclides.

In the radionuclide transport process model documented by BSC (2004 [DIRS 164500]), the diffusive flux is defined in terms of the concentration gradient and the effective diffusion coefficient, which is the product of the free diffusion coefficient and the tortuosity. BSC (2004 [DIRS 164500]) shows, based on work by Grathwohl (2000 [DIRS 141512]), that it is a reasonable approximation to set tortuosity equal to the matrix porosity. The abstraction model calls for the effective diffusion coefficient as a direct parameter input, rather than separately defining tortuosity and free diffusion coefficient. In the development below, correlations between effective diffusion coefficient, water content, and matrix permeability are proposed based on available experimental data. The end result of this development is a range of effective diffusion coefficients that in effect capture the uncertainty in the mechanisms associated with diffusion through tortuous pore spaces. Therefore, even though the tortuosity is not a direct model input, its impact on matrix diffusion, and the correlation between diffusion and matrix porosity, is implicitly captured in the abstraction model.

In current TSPA simulations, unsaturated matrix diffusion coefficients are based on the correlation between matrix diffusion, porosity, and saturated permeability developed for the SZ (Reimus et al. 2002 [DIRS 163008]). To adapt the relationship for the UZ, the porosity is replaced with water content and the permeability is replaced with effective permeability. The equation is re-written as:

$$
\log \left(D_{m}\right)=-3.49+1.38 \theta_{m}+0.165 \log \left(k_{m}\right)
$$

where $D_{m}$ is the matrix diffusion coefficient in $\mathrm{cm}^{2} / \mathrm{s}, \theta_{m}$ is the matrix water content, and $k_{m}$ is the effective permeability to water in $\mathrm{m}^{2}$.

The data from Reimus et al. (2002 [DIRS 163008]) suggests that the range of diffusion coefficients for tritium, bicarbonate, and pertechnetate individually are roughly similar to the range of mean values for each. This suggests that a single broad distribution scaled by the range of values between cations and anions from DTN: LA0003JC831362.001 [DIRS 149557] would provide a better representation of the uncertainty in matrix diffusion. To capture this with the correlation given by Reimus et al. (2002 [DIRS 163008]), consider the following transformation:

$$
X=\log \left(\frac{D_{0}}{D_{m}}\right)
$$


where $D_{0}$ is the limiting upper value for $D_{m}$. This value is given in DTN: LA0003JC831362.001 [DIRS 149557] as $10^{-9} \mathrm{~m}^{2} / \mathrm{s}$. The average for $X$ is

$$
\mu_{X}=\log \left(D_{0}\right)-\overline{\log \left(D_{m}\right)}
$$

where the second term on the right hand side is the mean of $\log \left(D_{m}\right)$. Stipulating that the variable $X$ ranges from 0 to infinity, $D_{m}$ is constrained to be less than $10^{-9} \mathrm{~m}^{2} / \mathrm{s}$.

Given the semi-infinite range for $X$, it can be sampled as a lognormal distribution. This introduces the second logarithmic transformation, $Y$,

$$
Y=\ln (X)
$$

the mean for $Y$ is taken to be

$$
\mu_{Y}=\ln \left(\mu_{X}\right)
$$

such that the mean for the Reimus correlation is unchanged by the transformation to a lognormal distribution. In this case, note that $\mu_{\mathrm{x}}$ is the median of $\mathrm{X}$, not the mean. Distribution parameters may be obtained by setting $\overline{\log \left(D_{m}\right)}$ to be the $\log$ of the geometric mean of the mean values in DTN: LA0003JC831362.001 [DIRS 149557] and then adjust the standard deviation for $Y$ such that it covers the range of values represented by cations and anions in DTN: LA0003JC831362.001 [DIRS 149557]. The standard deviation of 0.3 for $Y$ results in a spread for the distribution that is representative of the spread of values in DTN: LA0003JC831362.001 [DIRS 149557], as shown in Figure 6-10.

The range of values for the UZ may be examined using 5th and 95th percentile values for water content and effective matrix permeability. Doing this, the "low" distribution may be computed based on the Reimus correlation (Reimus et al. 2002 [DIRS 163008]) by assigning the mean using the 5th percentile water content and effective matrix permeability and a "high" distribution based on the 95th percentile of values of these quantities. The results are shown in Figure 6-11.

Figure 6-11 shows that most of the matrix diffusion coefficients estimated using Equation 6-19 will fall within the range of the "Reimus low" and "Reimus high" curves. The data used to develop the distributions in DTN: LA0003JC831362.001 [DIRS 149557] were from diffusion measurements under saturated conditions. Therefore, the generally lower values represented by the Reimus distributions are expected. The comparison with measured diffusion coefficients for tritium, technetium, and carbon is given in Figure 6-12. Again, the correlations for the UZ are lower than the measured values, which were performed under saturated conditions.

The groups of model units for sampling matrix diffusion shown in Table 6-6 were selected based on similarity in properties of porosity, permeability, and water content. Distributions for the water content and $(\log )$ effective permeability to water for each group are derived from the 9 flow fields used for TSPA calculations (BSC 2004 [DIRS 169861]; DTN: LB03023DSSCP9I.001 [DIRS 163044]). 


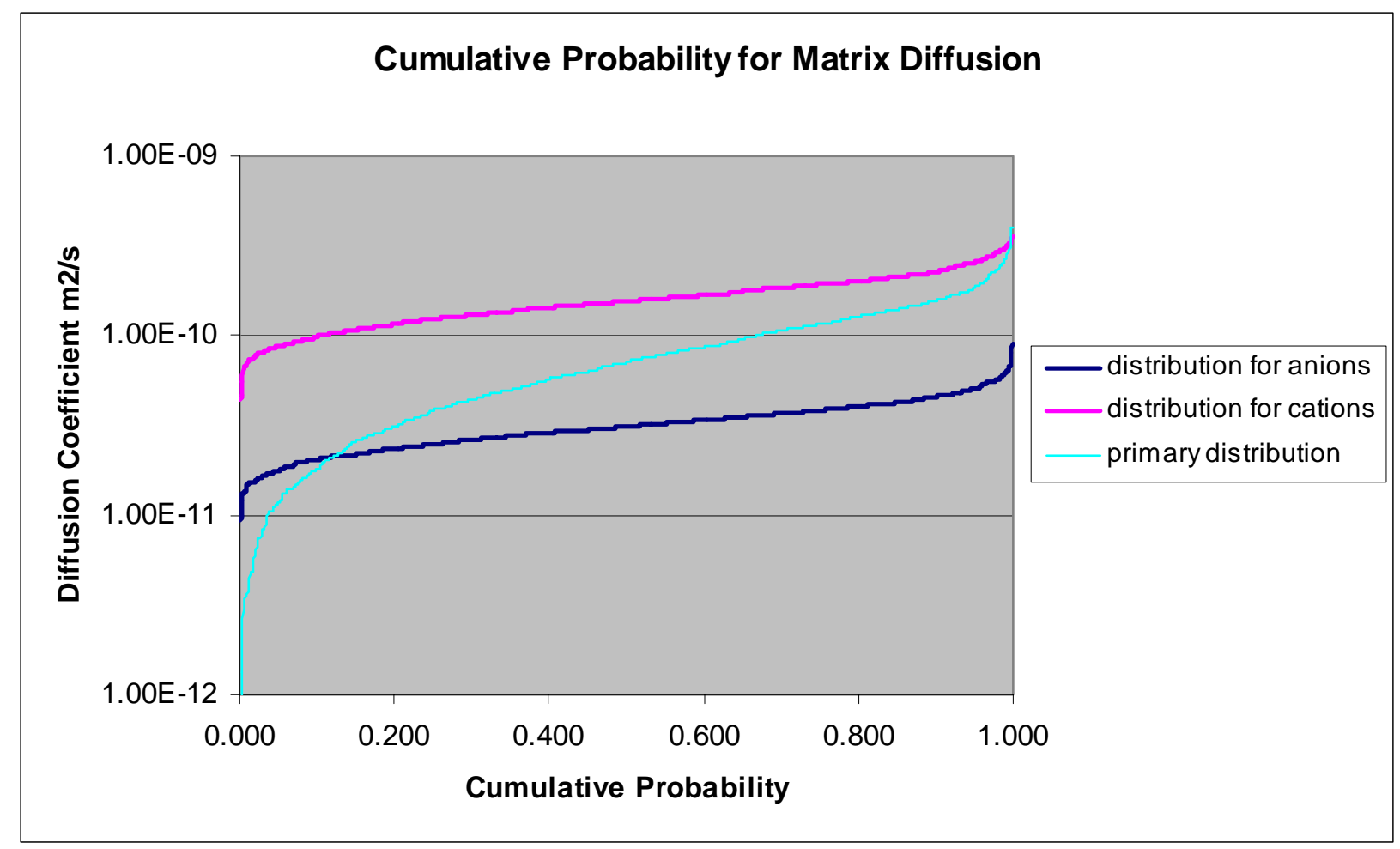

Output DTN: LA0407BR831371.001.

Figure 6-10. Cumulative Probability for Matrix Diffusion Under Saturated Conditions 


\section{Cumulative Probability for Matrix Diffusion}

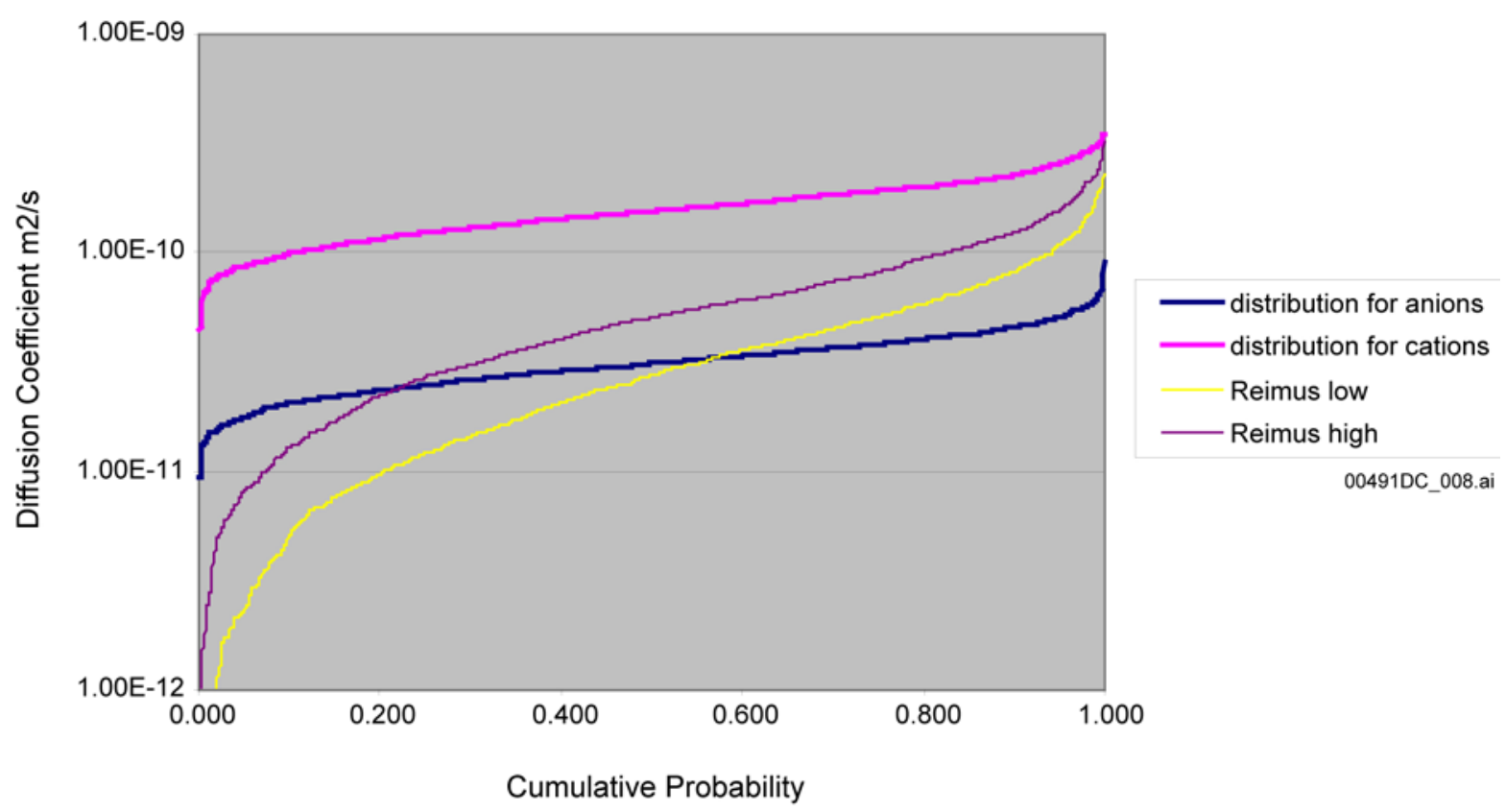

Output DTN: LA0407BR831371.001.

Figure 6-11. Comparison of Cation/Anion Distributions with Reimus High/Low Distributions for Unsaturated Conditions

The influence of matrix diffusion coefficient uncertainty on radionuclide transport is investigated by independently sampling water content and permeability for each rock group (Table 6-6; techniques for deriving the numerical values are presented in Appendix A). The water content and (log) effective permeability are independently sampled from these cumulative distributions. A matrix diffusion coefficient is then computed from Equation 6-19.

In all TSPA simulations, colloid matrix diffusion (diffusion of a colloid from the fracture to the matrix) is neglected because of lack of data and because diffusion coefficients for colloidal particles are expected to be small. This is conservative with respect to the TSPA calculation of transport times through the UZ. 


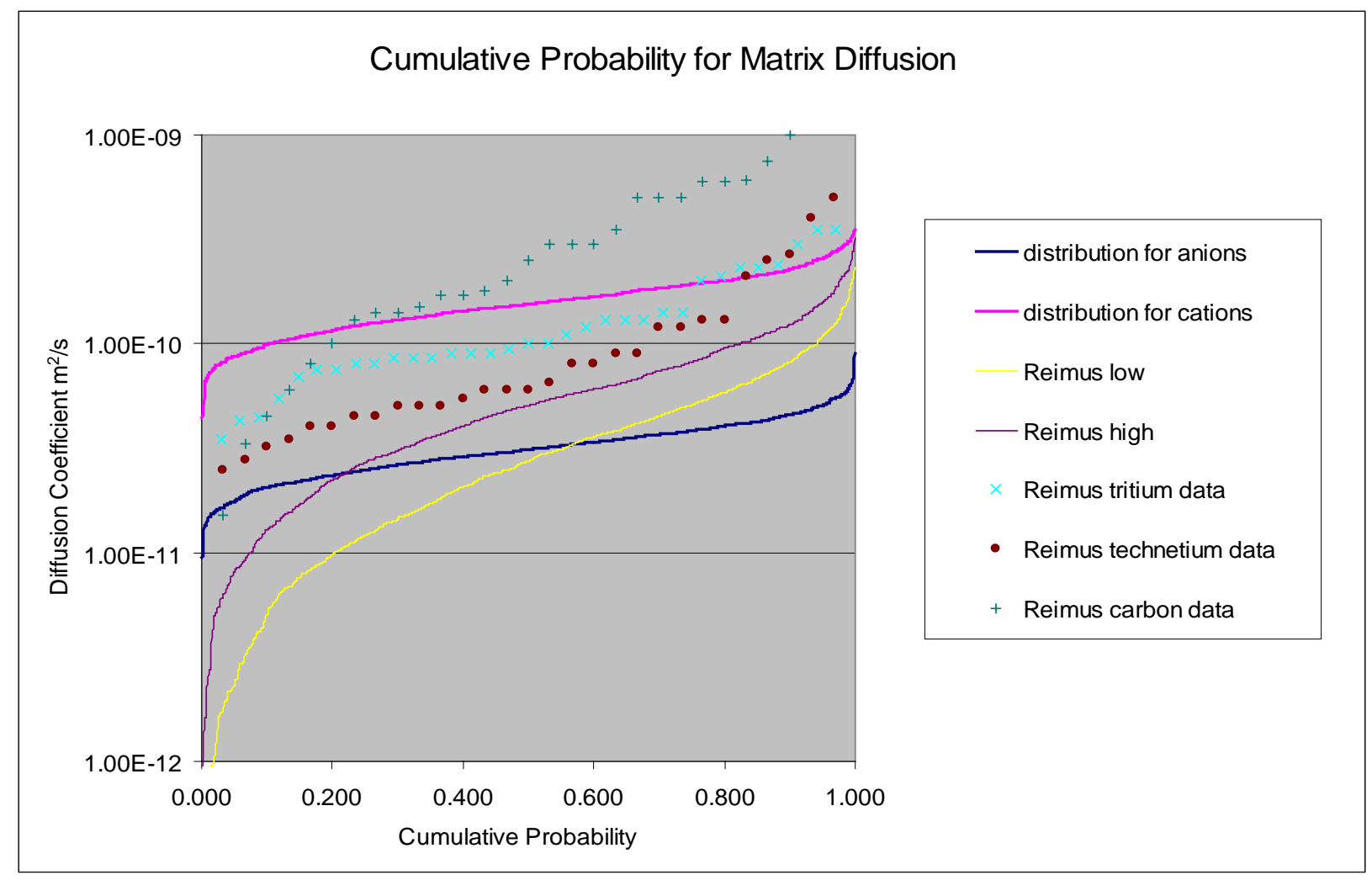

Output DTN: LA0407BR831371.001.

Figure 6-12. Comparison of the Distributions with Diffusion Data

\subsubsection{Fracture Residual Saturation and Active Fracture Model Gamma Parameters (Unitless)}

Fracture residual saturation and fracture $\gamma$ parameter values are used by FEHM to calculate the fracture spacing based on the AFM (Liu et al. 1998 [DIRS 105729]).

In TSPA-LA, a constant fracture residual saturation of 0.01 is used for all layers (DTN: LB0302UZDSCPUI.002 [DIRS 161787]). Note that this DTN also lists values for the matrix. These are not directly used in the transport model. Currently, there are no data from Yucca Mountain that could be used to assess the uncertainty in residual fracture saturation (Table 6-7). 
Table 6-6. Distribution of Water Content and Effective Permeability

\begin{tabular}{|c|c|c|c|c|c|c|c|c|}
\hline $\begin{array}{l}\text { Group } \\
\text { Index }\end{array}$ & Unit & $\begin{array}{c}\text { Mean Water } \\
\text { Content (-) }\end{array}$ & $\begin{array}{c}\text { Standard } \\
\text { Deviation } \\
\text { Water } \\
\text { Content }\end{array}$ & $\begin{array}{c}\text { Maximum } \\
\text { Water } \\
\text { Content }\end{array}$ & \begin{tabular}{|c|} 
Minimum \\
Water \\
Content
\end{tabular} & $\begin{array}{l}\text { Mean Log } \\
\text { Effective } \\
\text { Permeability } \\
\left(\mathrm{m}^{2}\right)\end{array}$ & \begin{tabular}{|c|} 
Standard \\
Deviation \\
Log \\
Effective \\
Permeability \\
$\left(\mathrm{m}^{2}\right)$ \\
\end{tabular} & $\begin{array}{c}D_{m} \\
\text { Calculated } \\
\text { Using } \\
\text { Listed } \\
\text { Mean } \\
\text { Values and } \\
\text { Eq. 6-19 } \\
\left(\mathrm{m}^{2} / \mathrm{s}\right) \\
\end{array}$ \\
\hline 1 & \begin{tabular}{|l} 
bf2mz, ch1mz, \\
ch[1,2,3,4,5, \\
6]mv, tswmv, \\
tswmz, , pp3Md, \\
pp2Md, pp1Mz, \\
pp4Mz, bf3Md, \\
tr3Md \\
\end{tabular} & 2.06E-01 & 8.41E-02 & 5.33E-01 & $6.81 \mathrm{E}-03$ & $-1.62 E+01$ & 5.50E-01 & 1.33E-10 \\
\hline 2 & $\begin{array}{l}\operatorname{ch}[2,3,4,5,6] \mathrm{mz}, \\
\text { pcm[1,2,5,6]mz, } \\
\text { pcm39, pcm4p }\end{array}$ & 3.00E-01 & 5.12E-02 & 5.78E-01 & 7.73E-02 & $-1.83 E+01$ & 4.20E-01 & 8.10E-11 \\
\hline 3 & $\begin{array}{l}\operatorname{tswm}[3,4,5,6,7,8], \\
\text { pcM38 }\end{array}$ & 1.12E-01 & 3.43E-02 & 3.19E-01 & $7.75 \mathrm{E}-5$ & $-1.89 E+01$ & 4.62E-01 & 3.47E-11 \\
\hline
\end{tabular}

Output DTN: LA0407BR831371.001.

NOTE: A beta distribution was used for the matrix water content, and a lognormal distribution was used for the matrix effective permeability.

Table 6-7. Fracture Residual Saturation Values

\begin{tabular}{|c|c|c|c|c|}
\hline Input Name & Input Value & Input Description & Input Source & Type of Uncertainty \\
\hline $\begin{array}{c}\text { Fracture } \\
\text { residual } \\
\text { saturation }\end{array}$ & 0.01 & $\begin{array}{c}\text { Fracture residual saturation } \\
\text { is used to calculate active } \\
\text { fracture spacing }\end{array}$ & $\begin{array}{c}\text { LB0302UZDSCPUI.002 } \\
\text { [DIRS 161787] }\end{array}$ & $\begin{array}{c}\text { Fixed value. The } \\
\text { fracture residual } \\
\text { saturation is constant } \\
\text { over all layers and does } \\
\text { not change with } \\
\text { climate. }\end{array}$ \\
\hline
\end{tabular}

Values of fracture $\gamma$ parameter vary with infiltration rates in each rock layer. Tables 6-8 through 6-10 list the fracture $\gamma$ parameter values used in TSPA-LA for different infiltration scenarios (DTN: LB0305TSPA18FF.001 [DIRS 165625]). Note that according to Tables 6-8, 6-9, and 6-10 of the report by BSC (2004 [DIRS 169857]), the flow models were developed assuming that there is no fracture flow in the vitric Calico Hills units; instead, matrix flow is assumed. In these units, the $\gamma$ value of 0.25 is used as a placeholder in the abstraction model. The value used is immaterial because the flow occurs only in the matrix, and the transport reverts to a matrixonly transport model for this situation.

The influence of $\gamma$ parameter uncertainty on radionuclide transport is investigated using sensitivity analyses in Section 6.8 of BSC (2004 [DIRS 169861]) and Section 7.2.3.3 of this report. 
Table 6-8. Fracture $\gamma$ Parameter for Lower-Bound Infiltration Scenario

\begin{tabular}{|c|c|c|c|c|c|c|}
\hline $\begin{array}{l}\text { Rock } \\
\text { Layer }\end{array}$ & Fracture $\gamma$ & $\begin{array}{l}\text { Rock } \\
\text { Layer }\end{array}$ & Fracture $\gamma$ & Input Description & Input Source & $\begin{array}{c}\text { Type of } \\
\text { Uncertainty }\end{array}$ \\
\hline tcwf1 & 0.4834 & ch1fz & 2.759 E-01 & \multirow{25}{*}{$\begin{array}{l}\text { This value is read } \\
\text { in by FEHM and } \\
\text { used in calculating } \\
\text { fracture spacing } \\
\text { values based on } \\
\text { the active fracture } \\
\text { model. }\end{array}$} & \multirow{25}{*}{$\begin{array}{l}\text { LB0208UZDSCPLI.002 } \\
\text { [DIRS 161788] } \\
\text { LB0305TSPA18FF.001 } \\
\text { [DIRS 165625] } \\
\text { "Eighteen 3-D Site } \\
\text { Scale UZ Flow Fields } \\
\text { Converted from } \\
\text { TOUGH2 to T2FEHM } \\
\text { Format." File: } \\
\text { glaq_IA.dat. }\end{array}$} & \multirow{25}{*}{$\begin{array}{l}\text { Fixed value } \\
\text { for each layer } \\
\text { but varies } \\
\text { from layer to } \\
\text { layer. The } \\
\text { values also } \\
\text { depend on } \\
\text { climate. }\end{array}$} \\
\hline tcwf2 & 0.4834 & $\operatorname{ch} 2 f z$ & 2.759 E-01 & & & \\
\hline tcwf3 & 0.4834 & $\operatorname{ch} 3 f z$ & 2.759 E-01 & & & \\
\hline ptnf1 & $0.1032 E-01$ & $\operatorname{ch} 4 \mathrm{fz}$ & 2.759 E-01 & & & \\
\hline ptnf2 & $0.1032 \mathrm{E}-01$ & $\operatorname{ch} 5 f z$ & 2.759 E-01 & & & \\
\hline ptnf3 & $0.1032 \mathrm{E}-01$ & ch6fz & 2.759 E-01 & & & \\
\hline ptnf4 & $0.1032 E-01$ & $\mathrm{pp} 4 \mathrm{fz}$ & $2.759 \mathrm{E}-01$ & & & \\
\hline ptnf5 & $0.1032 \mathrm{E}-01$ & pp3fd & 2.476 E-01 & & & \\
\hline ptnf6 & $0.1032 \mathrm{E}-01$ & pp2fd & $2.476 \mathrm{E}-01$ & & & \\
\hline tswf1 & $0.3741 \mathrm{E}-01$ & pp1fz & 2.759 E-01 & & & \\
\hline tswf2 & 0.5284 & bf3fd & 2.476 E-01 & & & \\
\hline tswf3 & 0.5284 & bf $2 f z$ & 2.759 E-01 & & & \\
\hline tswf4 & 0.4764 & $\operatorname{tr} 3 f d$ & $2.476 \mathrm{E}-01$ & & & \\
\hline tswf5 & 0.4764 & $\operatorname{tr} 2 f z$ & $2.759 \mathrm{E}-01$ & & & \\
\hline tswf6 & 0.4764 & pcf38 & 0.000 E-01 & & & \\
\hline tswf7 & 0.4764 & pcf39 & 0.000 E-01 & & & \\
\hline tswf8 & 0.4764 & Pc1fz & 0.000 E-01 & & & \\
\hline tswfz & 0.2759 & Pc2fz & 0.000 E-01 & & & \\
\hline tswfv & 0.2500 & Pc5fz & 0.000 E-01 & & & \\
\hline ch1fv & 0.2500 & Pc6fz & 0.000 E-01 & & & \\
\hline ch2fv & 0.2500 & pc4fp & 0.000 E-01 & & & \\
\hline ch3fv & 0.2500 & $\begin{array}{l}\text { tcwff } \\
\text { (fault) }\end{array}$ & 4.000 E-01 & & & \\
\hline ch4fv & 0.2500 & $\begin{array}{l}\text { ptnff } \\
\text { (fault) }\end{array}$ & 1.138 E-01 & & & \\
\hline ch5fv & 0.2500 & $\begin{array}{l}\text { tswff } \\
\text { (fault) }\end{array}$ & 3.000 E-01 & & & \\
\hline ch6fv & 0.2500 & $\begin{array}{l}\text { chnff } \\
\text { (fault) }\end{array}$ & 3.000 E-01 & & & \\
\hline
\end{tabular}

3-D=three-dimensional; FEHM=finite element heat and mass (model); UZ-unsaturated zone 
Table 6-9. Fracture $\gamma$ Parameter for Mean Infiltration Scenario

\begin{tabular}{|c|c|c|c|c|c|c|}
\hline $\begin{array}{l}\text { Rock } \\
\text { Layer }\end{array}$ & Fracture $\gamma$ & $\begin{array}{l}\text { Rock } \\
\text { Layer }\end{array}$ & Fracture $\gamma$ & Input Description & Input Source & $\begin{array}{c}\text { Type of } \\
\text { Uncertainty }\end{array}$ \\
\hline tcwf1 & 0.5866 & ch1fz & 3.704 E-01 & \multirow{25}{*}{$\begin{array}{l}\text { This value is read } \\
\text { in by FEHM and } \\
\text { used in calculating } \\
\text { fracture spacing } \\
\text { values based on } \\
\text { the active fracture } \\
\text { model. }\end{array}$} & \multirow{25}{*}{$\begin{array}{l}\text { LB0208UZDSCPMI.002 } \\
\text { [DIRS 161243] } \\
\text { LB0305TSPA18FF.001 } \\
\text { [DIRS 165625] } \\
\text { "Eighteen 3-D Site } \\
\text { Scale UZ Flow Fields } \\
\text { Converted from } \\
\text { TOUGH2 to T2FEHM } \\
\text { Format”. File: } \\
\text { glaq_mA.dat. }\end{array}$} & \multirow{25}{*}{$\begin{array}{l}\text { Fixed value } \\
\text { for each } \\
\text { layer but } \\
\text { varies from } \\
\text { layer to } \\
\text { layer. The } \\
\text { values also } \\
\text { depend on } \\
\text { climate. }\end{array}$} \\
\hline Tcwf2 & 0.5866 & $\operatorname{ch} 2 f z$ & 3.704 E-01 & & & \\
\hline tcwf3 & 0.5866 & $\operatorname{ch} 3 f z$ & 3.704 E-01 & & & \\
\hline ptnf1 & 0.9051E-01 & $\operatorname{ch} 4 \mathrm{fz}$ & 3.704 E-01 & & & \\
\hline ptnf2 & 0.9051E-01 & $\operatorname{ch} 5 f z$ & 3.704 E-01 & & & \\
\hline ptnf3 & 0.9051E-01 & $\operatorname{ch} 6 f z$ & 3.704 E-01 & & & \\
\hline ptnf4 & 0.9051E-01 & $\mathrm{pp} 4 \mathrm{fz}$ & 3.704 E-01 & & & \\
\hline ptnf5 & 0.9051E-01 & pp3fd & 1.989 E-01 & & & \\
\hline ptnf6 & 0.9051E-01 & $\mathrm{pp} 2 \mathrm{fd}$ & 1.989 E-01 & & & \\
\hline tswf1 & 0.1289 & pp1fz & 3.704 E-01 & & & \\
\hline tswf2 & 0.6000 & bf3fd & 1.989 E-01 & & & \\
\hline tswf3 & 0.6000 & bf2fz & 3.704 E-01 & & & \\
\hline tswf4 & 0.5686 & $\operatorname{tr} 3 \mathrm{fd}$ & $1.989 \mathrm{E}-01$ & & & \\
\hline tswf5 & 0.5686 & $\operatorname{tr} 2 f z$ & 3.704 E-01 & & & \\
\hline tswf6 & 0.5686 & pcf38 & 0.000 E-01 & & & \\
\hline tswf7 & 0.5686 & pcf39 & 0.000 E-01 & & & \\
\hline tswf8 & 0.5686 & pcf1z & 0.000 E-01 & & & \\
\hline tswfz & 0.3704 & pcf2z & 0.000 E-01 & & & \\
\hline tswfv & 0.2500 & pcf5z & 0.000 E-01 & & & \\
\hline ch1fv & 0.2500 & pcf6z & 0.000 E-01 & & & \\
\hline ch2fv & 0.2500 & pcf4p & $0.000 \mathrm{E}-01$ & & & \\
\hline ch3fv & 0.2500 & $\begin{array}{l}\text { tcwff } \\
\text { (fault) }\end{array}$ & 4.000 E-01 & & & \\
\hline ch4fv & 0.2500 & $\begin{array}{l}\text { ptnff } \\
\text { (fault) }\end{array}$ & 1.138 E-01 & & & \\
\hline ch5fv & 0.2500 & $\begin{array}{l}\text { tswff } \\
\text { (fault) }\end{array}$ & 3.000 E-01 & & & \\
\hline ch6fv & 0.2500 & $\begin{array}{l}\text { chnff } \\
\text { (fault) }\end{array}$ & 3.000 E-01 & & & \\
\hline
\end{tabular}

3-D=three-dimensional; FEHM=finite element heat and mass (model); UZ=unsaturated zone

\subsubsection{Fracture Porosity, Fracture Spacing (m), and Fracture Aperture (m)}

Fracture porosity is used in FEHM to calculate the fracture pore volume of the corresponding fracture node block for determining the resident time of radionuclides within each fracture cell.

Fracture spacing and aperture data are used by FEHM in estimating the effect of matrix diffusion on radionuclide transport. In the abstraction model, aperture and spacing based on geometric considerations are adjusted before use in the transport calculations to conform to the assumptions of the AFM of Liu et al. (1998 [DIRS 105729]). This section describes the geometric parameters. For a discussion of how the model implements the AFM for transport, see Appendix C, Section C5. 
Table 6-10. Fracture $\gamma$ Parameter for Upper-Bound Infiltration Scenario

\begin{tabular}{|c|c|c|c|c|c|c|}
\hline $\begin{array}{l}\text { Rock } \\
\text { Layer }\end{array}$ & Fracture $\gamma$ & $\begin{array}{l}\text { Rock } \\
\text { Layer }\end{array}$ & Fracture $\gamma$ & Input Description & Input Source & $\begin{array}{c}\text { Type of } \\
\text { Uncertainty }\end{array}$ \\
\hline tcwf1 & 0.5000 & $\operatorname{ch} 1 \mathrm{fz}$ & 5.000 E-01 & \multirow{25}{*}{$\begin{array}{l}\text { This value is read } \\
\text { in by FEHM and } \\
\text { used in calculating } \\
\text { fracture spacing } \\
\text { values based on } \\
\text { the active fracture } \\
\text { model. }\end{array}$} & \multirow{25}{*}{$\begin{array}{l}\text { LB0302UZDSCPUI.002 } \\
\text { [DIRS 161787] } \\
\text { LB0305TSPA18FF.001 } \\
\text { [DIRS 165625] } \\
\text { "Eighteen 3-D Site } \\
\text { Scale UZ Flow Fields } \\
\text { Converted from } \\
\text { TOUGH2 to T2FEHM } \\
\text { Format." File: } \\
\text { glaq_uA.dat. }\end{array}$} & \multirow{25}{*}{$\begin{array}{l}\text { Fixed value } \\
\text { for each } \\
\text { layer but } \\
\text { varies from } \\
\text { layer to } \\
\text { layer. The } \\
\text { values also } \\
\text { depend on } \\
\text { climate. }\end{array}$} \\
\hline Tcwf2 & 0.5000 & $\operatorname{ch} 2 \mathrm{fz}$ & 5.000 E-01 & & & \\
\hline tcwf3 & 0.5000 & $\operatorname{ch} 3 f z$ & 5.000 E-01 & & & \\
\hline ptnf1 & 0.8319E-01 & ch4fz & 5.000 E-01 & & & \\
\hline ptnf2 & 0.8319E-01 & $\operatorname{ch} 5 f z$ & 5.000 E-01 & & & \\
\hline ptnf3 & 0.8319E-01 & ch6fz & 5.000 E-01 & & & \\
\hline ptnf4 & 0.8319E-01 & pp4fz & 5.000 E-01 & & & \\
\hline ptnf5 & 0.8319E-01 & pp3fd & 5.000 E-01 & & & \\
\hline ptnf6 & $0.8319 \mathrm{E}-01$ & $\mathrm{pp} 2 \mathrm{fd}$ & 5.000 E-01 & & & \\
\hline tswf1 & 0.1000 & pp1fz & 5.000 E-01 & & & \\
\hline tswf2 & 0.5606 & bf3fd & 5.000 E-01 & & & \\
\hline tswf3 & 0.5606 & bf2fz & 5000 E-01 & & & \\
\hline tswf4 & 0.5700 & $\operatorname{tr} 3 \mathrm{fd}$ & 5.000 E-01 & & & \\
\hline Tswf5 & 0.5700 & $\operatorname{tr} 2 f z$ & 5.000 E-01 & & & \\
\hline Tswf6 & 0.5700 & pcf38 & 0.000 E-01 & & & \\
\hline Tswf7 & 0.5700 & pcf39 & 0.000 E-01 & & & \\
\hline Tswf8 & 0.5700 & pcf1z & 0.000 E-01 & & & \\
\hline tswfz & 0.5000 & pcf2z & 0.000 E-01 & & & \\
\hline tswfv & 0.2500 & pcf5z & 0.000 E-01 & & & \\
\hline ch1fv & 0.2500 & pcf6z & $0.000 \mathrm{E}-01$ & & & \\
\hline $\operatorname{ch} 2 f v$ & 0.2500 & pcf4p & 0.000 E-01 & & & \\
\hline ch3fv & 0.2500 & $\begin{array}{l}\text { tcwff } \\
\text { (fault) }\end{array}$ & 4.000 E-01 & & & \\
\hline $\operatorname{ch} 4 \mathrm{fv}$ & 0.2500 & $\begin{array}{l}\text { ptnff } \\
\text { (fault) }\end{array}$ & 1.138 E-01 & & & \\
\hline $\operatorname{ch} 5 f v$ & 0.2500 & $\begin{array}{l}\text { tswff } \\
\text { (fault) }\end{array}$ & 3.000 E-01 & & & \\
\hline ch6fv & 0.2500 & $\begin{array}{l}\text { chnff } \\
\text { (fault) }\end{array}$ & 3.000 E-01 & & & \\
\hline
\end{tabular}

3-D=three-dimensional; FEHM=finite element heat and mass (model); UZ=unsaturated zone

The fracture porosity and fracture spacing data are sampled to address the uncertainty of fracture properties on radionuclide transport in TSPA calculations. The data sets (DTN: LB0205REVUZPRP.001 [DIRS 159525] and DTN: LB0207REVUZPRP.001 [DIRS 159526]) list fracture spacing data in terms of fracture frequency, defined as the inverse of fracture spacing. Thus, the fracture frequency is first sampled, and the inverse of the sampled data are taken to derive sampled fracture spacing data.

Table 6-11 lists the uncalibrated fracture porosity and frequency data based on field information. Among them, data for the fault zone are from DTN: LB0207REVUZPRP.001 [DIRS 159526]. Those are the uncalibrated properties as developed in the report by BSC (2004 [DIRS 169857]). However, fracture porosity and frequency data are not subject to adjustment in the calibration in the report by BSC (2004 [DIRS 169857]), therefore, these properties are carried forward into the calibrated property set without modification. 
Among the listed geological rock layers, only those below the repository (tswf3 and below) could affect the transport of radionuclides downward toward the water table. Therefore, the sampling of properties in TSPA-LA is limited to these layers. Rock layers below the repository are grouped together based on similarity in the fracture porosity and frequency characteristics. The nine groups identified are shown in Table 6-12. For groups with multiple units having different parameter values, an arithmetic average value is used for the group. An arithmetic average is sufficient because the variation of mean values between members of any group are insignificant relative to the standard deviation, as can be seen from Tables 6-12 and 6-13. There is only one standard deviation for fracture porosity, so the other groups are assigned a fracture porosity standard deviation such that the ratio of the standard deviation to the mean is constant for all the groups. Group 9 (tswf3) has its own standard deviation for fracture frequency, which is used. For the other groups, the standard deviation is set equal to 0.831 times the mean. This is based on the relationship between fracture frequency and the standard deviation of fracture frequency found for model units above the proposed repository (see Figure 6-13). In this way, the mean and standard deviation for each parameter in each group were computed.

As porosity must lie within the finite range of 0 to 1 , a beta distribution with these bounds is suitable for studying the influence of porosity uncertainty on radionuclide transport. Table 6-13 lists the distribution data for fracture porosity.

Given that fracture frequency can theoretically span values from zero to infinity, the lognormal distribution is suitable. The mean and standard deviation for $\ln (f)$ are given in terms of the mean and standard deviation for $f$ by the following relationships from the document by Hogg and Craig (1978 [DIRS 163236], pp. 180 and 432):

$$
\begin{gathered}
\mu_{\ln (f)}=\ln \left(\mu_{f}\right)-\frac{1}{2} \ln \left(1+\frac{\sigma_{f}^{2}}{\mu_{f}^{2}}\right) \\
\sigma_{\ln (f)}=\sqrt{\ln \left(1+\frac{\sigma_{f}^{2}}{\mu_{f}^{2}}\right)}
\end{gathered}
$$

For further information on this derivation, see Appendices A and K in the report by BSC (2004 [DIRS 170040]), Equations A-1, A-2, and K-4 through K-7. Values for $\mu_{\ln (f)}$ and $\sigma_{\ln (f)}$ are given in Table 6-13. 
Table 6-11. Fracture Porosity and Frequency Data

\begin{tabular}{|c|c|c|c|c|c|c|c|}
\hline Rock Layer & $\phi_{f}$ & Std. Dev. & $\begin{array}{c}f \\
(1 / \mathrm{m})\end{array}$ & $\sigma_{f}$ & Input Description & Input Source & $\begin{array}{c}\text { Type of } \\
\text { Uncertainty }\end{array}$ \\
\hline tcwf1 & $2.4 \mathrm{E}-2$ & - & 0.92 & 0.94 & \multirow{43}{*}{$\begin{array}{l}\phi_{f} \text { is the fracture } \\
\text { porosity and } f \text { is } \\
\text { fracture frequency. } \sigma_{f} \\
\text { is the standard } \\
\text { deviation for the } \\
\text { fracture frequency. } \\
\text { Data are uncalibrated. } \\
\text { However, the fracture } \\
\text { porosity and fracture } \\
\text { frequency data are } \\
\text { not subject to } \\
\text { adjustment in } \\
\text { calibration; therefore, } \\
\text { those properties are } \\
\text { carried forward into } \\
\text { the calibrated } \\
\text { property set without } \\
\text { modification. }\end{array}$} & \multirow{43}{*}{$\begin{array}{l}\text { LB0205REVUZPRP.001 } \\
\text { [DIRS 159525] } \\
\text { Fault zone fracture } \\
\text { porosity data are from } \\
\text { LB0207REVUZPRP.001 } \\
\text { [DIRS 159526]. }\end{array}$} & \multirow{43}{*}{$\begin{array}{l}\text { As porosity } \\
\text { must fall in } \\
\text { the range of } \\
0 \text { and } 1, a \\
\text { beta } \\
\text { distribution } \\
\text { is suitable to } \\
\text { describe the } \\
\text { uncertainty } \\
\text { of the } \\
\text { porosity } \\
\text { values. }\end{array}$} \\
\hline tcwf2 & 1.7E-2 & - & 1.91 & 2.09 & & & \\
\hline tcwf3 & 1.3E-2 & - & 2.79 & 1.43 & & & \\
\hline ptnf1 & $9.2 \mathrm{E}-3$ & - & 0.67 & 0.92 & & & \\
\hline ptnf2 & 1.0E-2 & - & 0.46 & - & & & \\
\hline ptnf3 & $2.1 \mathrm{E}-3$ & - & 0.57 & - & & & \\
\hline ptnf4 & $1.0 \mathrm{E}-2$ & - & 0.46 & 0.45 & & & \\
\hline ptnf5 & $5.5 \mathrm{E}-3$ & - & 0.52 & 0.6 & & & \\
\hline ptnf6 & $3.1 \mathrm{E}-3$ & - & 0.97 & 0.84 & & & \\
\hline tswf1 & $5.0 \mathrm{E}-3$ & - & 2.17 & 2.37 & & & \\
\hline tswf2 & 8.3E-3 & - & 1.12 & 1.09 & & & \\
\hline tswf3 & $5.8 \mathrm{E}-3$ & - & 0.81 & 1.03 & & & \\
\hline tswf4 & 8.5E-3 & 2.50E-03 & 4.32 & 3.42 & & & \\
\hline tswf5 & $9.6 \mathrm{E}-3$ & - & 3.16 & - & & & \\
\hline tswf6 & 1.3E-2 & - & 4.02 & - & & & \\
\hline tswf7 & 1.3E-2 & - & 4.02 & - & & & \\
\hline tswf8/pcf38 & $1.1 \mathrm{E}-2$ & - & 4.36 & - & & & \\
\hline $\begin{array}{l}\text { tswf9/pcf39/ } \\
\text { tswfz/tswfv }\end{array}$ & 4.3E-3 & - & 0.96 & - & & & \\
\hline $\operatorname{ch} 1 \mathrm{fv}$ & $6.1 \mathrm{E}-4$ & - & 0.10 & - & & & \\
\hline ch2fv & 7.7E-4 & - & 0.14 & - & & & \\
\hline ch3fv & 7.7E-4 & - & 0.14 & - & & & \\
\hline ch4fv & 7.7E-4 & - & 0.14 & - & & & \\
\hline ch5fv & 7.7E-4 & - & 0.14 & - & & & \\
\hline ch6fv & 7.7E-4 & - & 0.14 & - & & & \\
\hline ch1fz/pcf1z & $1.6 \mathrm{E}-4$ & - & 0.04 & - & & & \\
\hline $\operatorname{ch} 2 f z / p c f 2 z$ & 3.7E-4 & - & 0.14 & - & & & \\
\hline $\operatorname{ch} 3 f z$ & 3.7E-4 & - & 0.14 & - & & & \\
\hline $\operatorname{ch} 3 f z$ & 3.7E-4 & - & 0.14 & - & & & \\
\hline $\operatorname{ch} 4 \mathrm{fz}$ & 3.7E-4 & - & 0.14 & - & & & \\
\hline ch5fz/pcf5z & $3.7 \mathrm{E}-4$ & - & 0.14 & - & & & \\
\hline ch6fz/pcf6z & $1.6 \mathrm{E}-4$ & - & 0.04 & - & & & \\
\hline pp4f/pcf4p & 3.7E-4 & - & 0.14 & - & & & \\
\hline pp3f & 9.7E-4 & - & 0.20 & - & & & \\
\hline pp2f & $9.7 \mathrm{E}-4$ & - & 0.20 & - & & & \\
\hline pp1f & 3.7E-4 & - & 0.14 & - & & & \\
\hline bf3f & 9.7E-4 & - & 0.20 & - & & & \\
\hline bf2f & 3.7E-4 & - & 0.14 & - & & & \\
\hline tr3f & 9.7E-4 & - & 0.20 & - & & & \\
\hline tr2f & $3.7 \mathrm{E}-4$ & - & 0.14 & - & & & \\
\hline tcw fault & $2.9 \mathrm{E}-2$ & - & 1.90 & - & & & \\
\hline ptn fault & $1.1 \mathrm{E}-2$ & - & 0.54 & - & & & \\
\hline tsw fault & $2.5 \mathrm{E}-2$ & - & 1.70 & - & & & \\
\hline chn fault & $1.0 \mathrm{E}-3$ & - & 0.13 & - & & & \\
\hline
\end{tabular}


Table 6-12. Grouping of Rock Layers Below the Repository

\begin{tabular}{|c|c|c|c|}
\hline Group & Units & Porosity & Frequency $\left(\mathrm{m}^{-1}\right)$ \\
\hline 1 & chnf & $1.0 \mathrm{E}-3$ & 0.13 \\
\hline 2 & tswf & $2.5 \mathrm{E}-2$ & 1.7 \\
\hline \multirow[t]{6}{*}{3} & $\operatorname{ch}[2,3,4,5] \mathrm{fz}$ & 3.7E-4 & 0.14 \\
\hline & $\mathrm{pc}[2,5] \mathrm{fz}$ & 3.7E-4 & 0.14 \\
\hline & $\mathrm{pp} 4 \mathrm{fz} / \mathrm{pcf} 4 \mathrm{p}$ & 3.7E-4 & 0.14 \\
\hline & pp1fz & 3.7E-4 & 0.14 \\
\hline & $b f 2 f z$ & $3.7 \mathrm{E}-4$ & 0.14 \\
\hline & $\operatorname{tr} 2 \mathrm{fz}$ & $3.7 \mathrm{E}-4$ & 0.14 \\
\hline \multirow[t]{4}{*}{4} & pp3fd & $9.7 \mathrm{E}-4$ & 0.20 \\
\hline & $\mathrm{pp} 2 \mathrm{fd}$ & $9.7 \mathrm{E}-4$ & 0.20 \\
\hline & bf3fd & $9.7 \mathrm{E}-4$ & 0.20 \\
\hline & $\operatorname{tr} 3 f d$ & $9.7 \mathrm{E}-4$ & 0.20 \\
\hline \multirow[t]{2}{*}{5} & ch1fz/pcf1z & 1.6E-4 & 0.04 \\
\hline & ch6fz/pcf6z & $1.6 \mathrm{E}-4$ & 0.04 \\
\hline \multirow[t]{2}{*}{6} & ch1fv & $6.1 \mathrm{E}-4$ & 0.10 \\
\hline & $\operatorname{ch}[2,3,4,5,6] \mathrm{fv}$ & 7.7E-4 & 0.14 \\
\hline 7 & $\begin{array}{l}\text { tswf9/pcf39/ } \\
\text { tswfz/tswfv }\end{array}$ & 4.3E-3 & 0.96 \\
\hline \multirow[t]{4}{*}{8} & tswf4 & $8.5 \mathrm{E}-3$ & 4.32 \\
\hline & tswf5 & $9.6 \mathrm{E}-3$ & 3.16 \\
\hline & tswf $[6,7]$ & 1.3E-2 & 4.02 \\
\hline & tswf8/pcf38 & 1.1E-2 & 4.36 \\
\hline 9 & tswf3 & $5.8 \mathrm{E}-3$ & 0.81 \\
\hline
\end{tabular}

DTNs: LB0205REVUZPRP.001 [DIRS 159525]; LB0207REVUZPRP.001 [DIRS 159526].

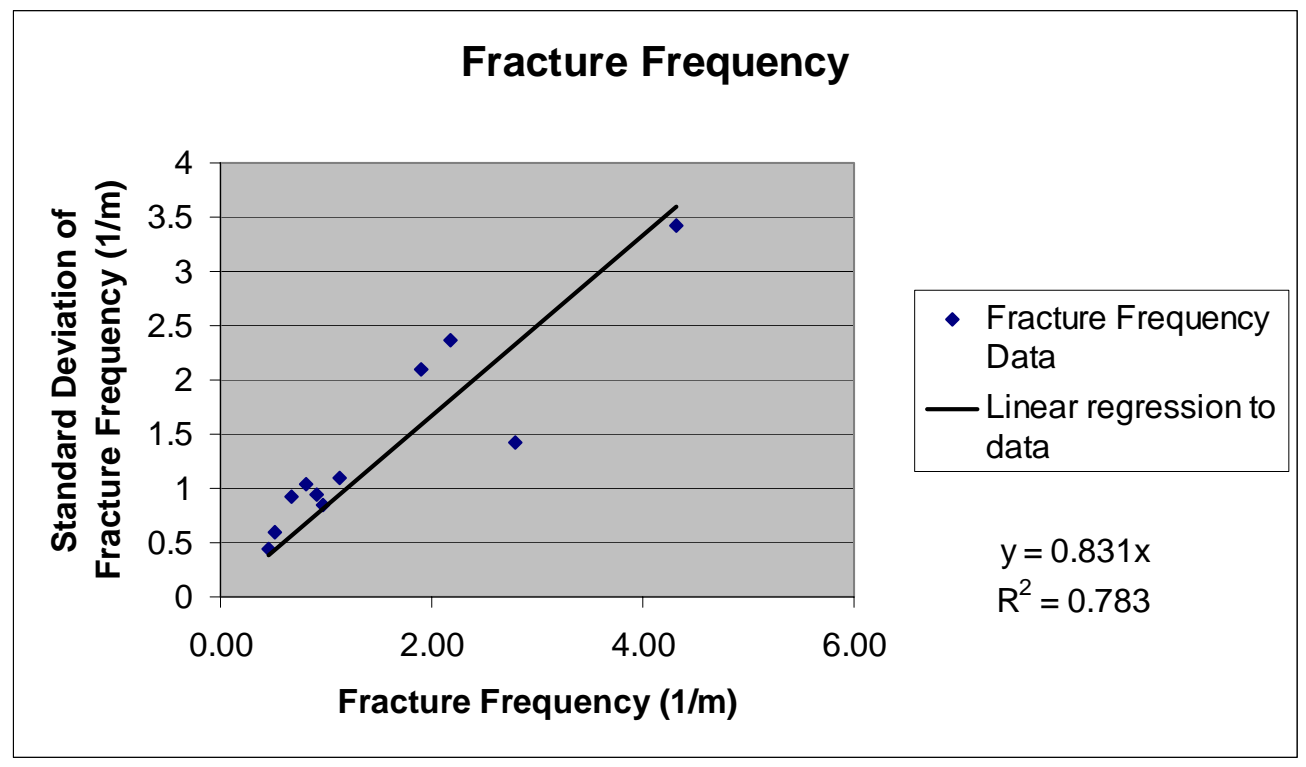

Output DTN: LA0407BR831371.001.

Figure 6-13. Relationship Between Fracture Frequency and Standard Deviation 
Table 6-13. Fracture Porosity and Frequency Distribution Data

\begin{tabular}{|c|c|c|c|c|c|c|c|c|}
\hline \multirow[b]{3}{*}{ Group } & \multirow[b]{3}{*}{ Units } & \multirow{2}{*}{\multicolumn{2}{|c|}{$\begin{array}{c}\text { Porosity (-) } \\
\text { Beta Distribution } \\
\min =0 ; \max =1\end{array}$}} & \multirow{2}{*}{\multicolumn{2}{|c|}{$\begin{array}{l}\text { Fracture Frequency } \\
\qquad\left(\mathrm{m}^{-1}\right)\end{array}$}} & \multicolumn{2}{|c|}{$\begin{array}{l}\text { Fracture Frequency }\left(\mathrm{m}^{-1}\right) \\
\text { Lognormal Distribution }\end{array}$} & \multirow{3}{*}{$\begin{array}{c}\text { Aperture (m) } \\
\qquad \mathbf{2 b} \\
\text { Derived from } \\
\text { Eq. 6-26: } \\
2 b=\frac{\phi_{f}}{f}\end{array}$} \\
\hline & & & & & & \multirow{2}{*}{$\begin{array}{c}\text { Mean } \\
\text { For } \ln (\mathbf{f})\end{array}$} & \multirow{2}{*}{$\begin{array}{l}\text { Std Dev } \\
\text { For In (f) }\end{array}$} & \\
\hline & & Mean & Std Dev & Mean & Std Dev & & & \\
\hline 1 & Chnf & 1.0E-03 & 3.09E-04 & 1.26E-01 & 1.05E-01 & $-2.33 E+00$ & 7.24E-01 & 7.94E-03 \\
\hline 2 & Tswf & 2.5E-02 & 7.25E-03 & $1.75 \mathrm{E}+00$ & $1.45 \mathrm{E}+00$ & 2.96E-01 & 7.24E-01 & 1.43E-02 \\
\hline \multirow[t]{6}{*}{3} & $\operatorname{ch}[2,3,4,5] \mathrm{fz}$ & \multirow[t]{6}{*}{$3.7 \mathrm{E}-4$} & \multirow[t]{6}{*}{ 1.09E-04 } & \multirow[t]{6}{*}{ 1.40E-01 } & \multirow[t]{6}{*}{ 1.16E-01 } & \multirow[t]{6}{*}{$-2.23 E+00$} & \multirow[t]{6}{*}{ 7.24E-01 } & \multirow[t]{6}{*}{ 2.64E-03 } \\
\hline & $\operatorname{pcf}[2,5] z$ & & & & & & & \\
\hline & pp4fz & & & & & & & \\
\hline & pp1fz & & & & & & & \\
\hline & bf2fz & & & & & & & \\
\hline & $\operatorname{tr} 2 f z$ & & & & & & & \\
\hline \multirow[t]{4}{*}{4} & pp3fd & \multirow[t]{4}{*}{ 9.7E-4 } & \multirow[t]{4}{*}{ 2.85E-04 } & \multirow[t]{4}{*}{ 2.00E-01 } & \multirow[t]{4}{*}{ 1.66E-01 } & \multirow[t]{4}{*}{-1.87E+00 } & \multirow[t]{4}{*}{ 7.24E-01 } & \multirow[t]{4}{*}{ 4.85E-03 } \\
\hline & pp2fd & & & & & & & \\
\hline & bf3fd & & & & & & & \\
\hline & $\operatorname{tr} 3 f d$ & & & & & & & \\
\hline 5 & $\begin{array}{l}\text { ch1fz/pcf1z } \\
\text { ch6fz/pcf6z }\end{array}$ & $1.6 \mathrm{E}-4$ & 4.71E-05 & 4.00E-02 & 3.32E-02 & $-3.48 E+00$ & 7.24E-01 & 4.00E-03 \\
\hline 6 & $\operatorname{ch}[1,2,3,4,5,6] f \mathrm{fv}$ & $6.9 \mathrm{E}-4$ & 2.03E-04 & 1.20E-01 & 9.96E-02 & $-2.38 \mathrm{E}+00$ & 7.24E-01 & $5.75 \mathrm{E}-03$ \\
\hline 7 & $\begin{array}{l}\text { tswf9/pcf39 } \\
\text { /tswfv/tswfz }\end{array}$ & 4.3E-3 & 1.26E-03 & 9.60E-01 & 7.97E-01 & $-3.03 E-01$ & 7.24E-01 & 4.48E-03 \\
\hline \multirow[t]{3}{*}{8} & Tswf $[4,5]$ & \multirow[t]{3}{*}{ 1.05E-02 } & \multirow[t]{3}{*}{ 3.10E-03 } & \multirow[t]{3}{*}{$3.97 \mathrm{E}+00$} & \multirow[t]{3}{*}{$3.29 \mathrm{E}+00$} & \multirow[t]{3}{*}{$1.12 \mathrm{E}+00$} & \multirow[t]{3}{*}{ 7.24E-01 } & \multirow[t]{3}{*}{ 2.64E-03 } \\
\hline & tswf[6,7] & & & & & & & \\
\hline & tswf8/pcf38 & & & & & & & \\
\hline 9 & tswf3 & 5.8E-3 & 1.71E-03 & 8.10E-01 & $1.03 E+00$ & $-6.92 \mathrm{E}-01$ & 9.81E-01 & 7.16E-03 \\
\hline
\end{tabular}

Output DTN: LA0407BR831371.001.

In TSPA-LA calculations, the fracture porosity and fracture frequency are sampled independently. The basis for this approximation is that there is only a very weak correlation between fracture porosity and frequency (Figure 6-14). Therefore, correlating these two parameters is not warranted.

The sampled fracture porosity and frequency data are used in deriving the fracture spacing and aperture based on the following relationship:

$$
\phi_{f}=(2 b) f
$$

where $2 b$ is the fracture aperture $(\mathrm{m}), f$ is the fracture frequency $\left(\mathrm{m}^{-1}\right)$, and $\phi_{f}$ is the fracture porosity (-). Fracture frequency is the inverse of the fracture spacing. 


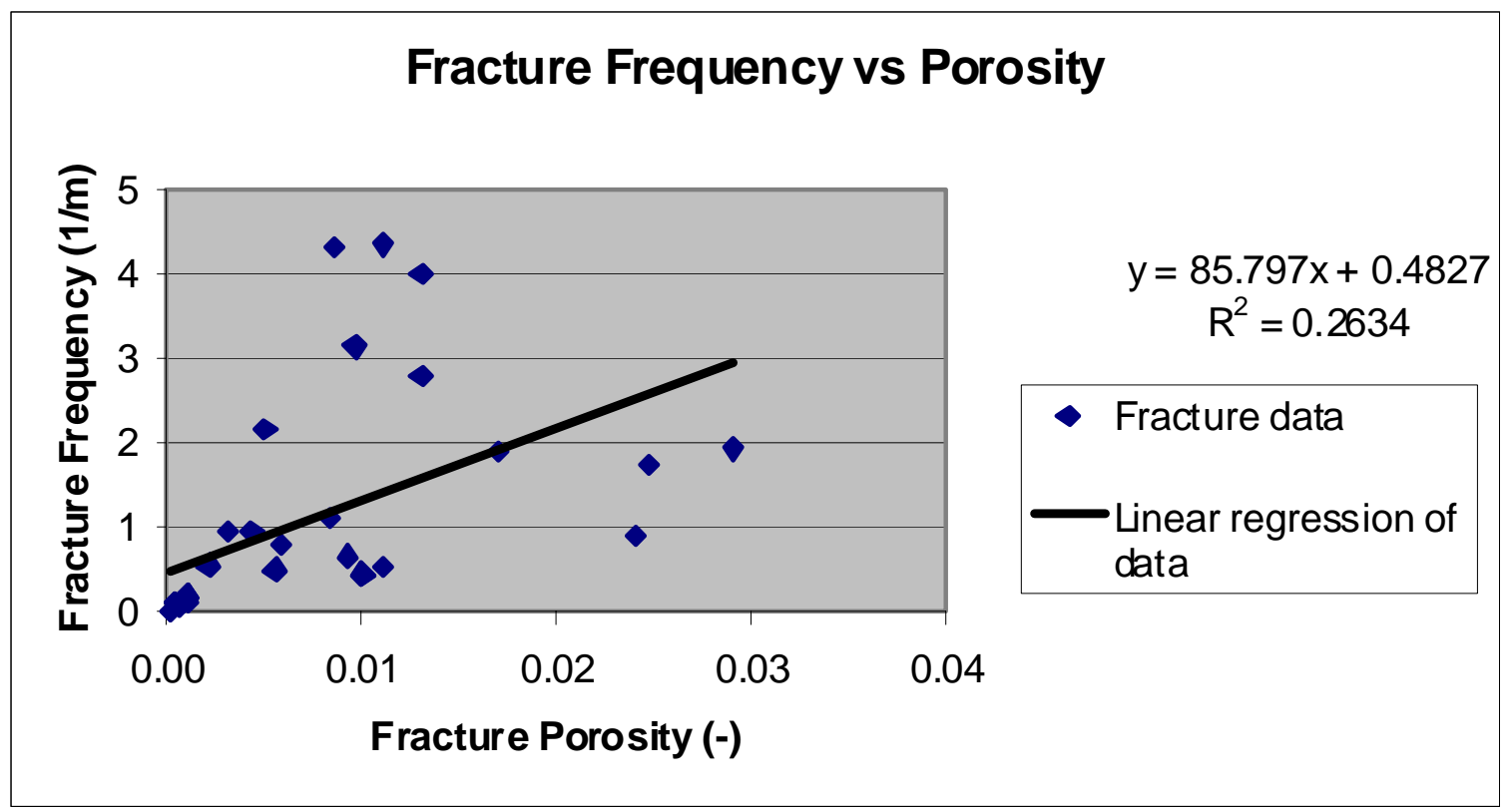

Output DTN: LA0407BR831371.001.

Figure 6-14. Relationship Between Fracture Porosity and Frequency

\subsubsection{Fracture Surface Retardation Factor (Unitless)}

Because few data are available on fracture surface retardation factors, no fracture surface retardation is simulated in the TSPA-LA model. In current TSPA simulations, the fracture surface retardation factors are set to 1.0 (no fracture surface retardation) to be conservative. Values of fracture surface retardation factors are included in FEHM input data file and are read in at run time (Table 6-14).

Table 6-14. Fracture Surface Retardation Factor

\begin{tabular}{|c|c|c|c|c|}
\hline $\begin{array}{c}\text { Rock } \\
\text { Layers }\end{array}$ & $\begin{array}{l}\text { Fracture Surface } \\
\text { Retardation Factor }\end{array}$ & Input Description & Input Source & $\begin{array}{c}\text { Type of } \\
\text { Uncertainty }\end{array}$ \\
\hline All layers & 1.0 & $\begin{array}{l}\text { Parameter used to simulate the effect } \\
\text { of fracture surface retardation on } \\
\text { radionuclide transport. }\end{array}$ & $\begin{array}{l}\mathrm{N} / \mathrm{A}-\text { conservative } \\
\text { assumption used to } \\
\text { assign this } \\
\text { parameter }\end{array}$ & Fixed value \\
\hline
\end{tabular}

N/A=not applicable

\subsubsection{Colloid Filtration at Matrix Interface}

Matrix pore size distribution combined with colloid size distribution is used in FEHM for determining colloid filtration at the interfaces between matrix units. Each time step at a matrix unit interface FEHM compares a colloid's size against the sampled pore size of the matrix unit it 
is entering. If the colloid size is bigger than the pore size, then the colloid cannot enter the matrix and is removed from the simulation (permanently filtered). In TSPA simulations the cumulative probabilities for colloid transport between one matrix unit and another are taken from DTN: LA0003MCG12213.002 [DIRS 147285] and listed in Table 6-15 (only colloid size data beneath the repository level are listed). In FEHM the matrix pore size data are sampled based on the cumulative colloid transport probability data in Table 6-15 and the sampled data are used in simulating colloid filtration at matrix interfaces.

Table 6-15. Cumulative Probabilities for Colloid Transport at Matrix Interfaces

\begin{tabular}{|c|c|c|c|c|c|c|c|}
\hline \multirow[b]{2}{*}{ Units } & \multicolumn{7}{|c|}{ Colloid Size $(\mathrm{nm})$} \\
\hline & 2000 & 1000 & 450 & 200 & 100 & 50 & 6 \\
\hline TMN/TSW4 & 1.00 & 0.92 & 0.87 & 0.81 & 0.71 & 0.55 & 0.31 \\
\hline TLL /TSW5 & 1.00 & 0.80 & 0.79 & 0.70 & 0.61 & 0.51 & 0.19 \\
\hline TM2/TSW6 & 1.00 & 0.94 & 0.90 & 0.82 & 0.65 & 0.51 & 0.21 \\
\hline TMN1/TSW7 & 1.00 & 0.99 & 0.99 & 0.99 & 0.93 & 0.68 & 0.36 \\
\hline PV3 /TSW8 & 1.00 & 0.98 & 0.96 & 0.94 & 0.90 & 0.89 & 0.68 \\
\hline PV2/TSW9 & 1.00 & 0.72 & 0.57 & 0.47 & 0.39 & 0.35 & 0.22 \\
\hline $\mathrm{BT} 1 \mathrm{a} / \mathrm{CH} 1$ & 1.00 & 0.91 & 0.89 & 0.87 & 0.85 & 0.83 & 0.53 \\
\hline $\mathrm{CHV}$ & 1.00 & 0.58 & 0.49 & 0.43 & 0.39 & 0.36 & 0.07 \\
\hline $\mathrm{CHZ}$ & 1.00 & 0.79 & 0.76 & 0.73 & 0.68 & 0.56 & 0.30 \\
\hline $\mathrm{BT} / \mathrm{CH} 6$ & 1.00 & 0.95 & 0.94 & 0.92 & 0.92 & 0.85 & 0.40 \\
\hline PP1 & 1.00 & 0.79 & 0.68 & 0.63 & 0.57 & 0.48 & 0.21 \\
\hline PP2 & 1.00 & 0.91 & 0.86 & 0.81 & 0.65 & 0.53 & 0.22 \\
\hline PP3 & 1.00 & 0.49 & 0.34 & 0.26 & 0.21 & 0.16 & 0.07 \\
\hline PP4 & 1.00 & 0.99 & 0.99 & 0.98 & 0.98 & 0.96 & 0.32 \\
\hline BF2 & 1.00 & 0.98 & 0.97 & 0.96 & 0.96 & 0.83 & 0.25 \\
\hline $\mathrm{BF} 3$ & 1.00 & 0.97 & 0.94 & 0.83 & 0.74 & 0.66 & 0.14 \\
\hline $\begin{array}{l}\text { Type of } \\
\text { Uncertainty }\end{array}$ & \multicolumn{7}{|c|}{ Fixed values. } \\
\hline $\begin{array}{l}\text { Input } \\
\text { Description }\end{array}$ & \multicolumn{7}{|c|}{$\begin{array}{l}\text { Data are used by FEHM in combination with colloid size distribution data for simulating the } \\
\text { effect of colloid filtration at matrix interface. }\end{array}$} \\
\hline
\end{tabular}

Input Source: DTN: LA0003MCG12213.002 [DIRS 147285].

FEHM=finite element heat and mass (model)

\subsubsection{Colloid Size Exclusion}

Due to flow exchange between fractures and the corresponding matrix block, colloids may be carried into matrix from fractures by advection. The amount of colloids that can enter into matrix depends on the size of the colloids and the size of the matrix pores. At the fracture-matrix interface, when a colloid's size is larger than the matrix pore size, this colloid will stay in the fracture. On the other hand, when a particle size is smaller than the matrix pore size, the colloid will enter into the matrix through advection. The colloid size exclusion effect in the current FEHM model is simulated with a size exclusion factor $f_{c}$ based on the percentage of the pores that are greater than the expected colloid size of $100 \mathrm{~nm}$ (DTN: LA0003MCG12213.002 [DIRS 147285]). Table 6-16 lists the values used in FEHM. There is no site-specific transport data available to validate this aspect of the colloid transport model. The incorporation of this 
feature is intended to avoid a nonphysical situation in which colloids are allowed to enter the matrix even when they are larger than the typical pore size. This aspect of the model is conservative, in that it will tend to exclude some colloids from the slower moving matrix fluid and keep them in the fractures.

Table 6-16. Colloid Size Exclusion Factor Used in FEHM

\begin{tabular}{|c|c|c|c|c|}
\hline Rock Units & $\begin{array}{l}\text { Size Exclusion } \\
\text { Factor }\end{array}$ & Input Description & Input Source & Type of Uncertainty \\
\hline TMN (TSW4) & 0.29 & \multirow{16}{*}{$\begin{array}{l}\text { Parameters are used by } \\
\text { FEHM for simulating } \\
\text { the effect of colloid size } \\
\text { exclusion on } \\
\text { radionuclide transport } \\
\text { at the fracture-matrix } \\
\text { interface. }\end{array}$} & \multirow{16}{*}{$\begin{array}{l}\text { LA0003MCG12213.002 } \\
\text { [DIRS 147285] }\end{array}$} & \multirow{16}{*}{$\begin{array}{l}\text { Fixed value. In } \\
\text { TSPA-LA simulations, } \\
\text { a random number } \\
\text { generator is used to } \\
\text { determine the } \\
\text { probability of a colloid } \\
\text { entering into matrix } \\
\text { from the } \\
\text { corresponding } \\
\text { fractures. }\end{array}$} \\
\hline TLL (TSW5) & 0.39 & & & \\
\hline TM2 (TSW6) & 0.35 & & & \\
\hline TMN1 (TSW7) & 0.07 & & & \\
\hline PV3 (TSW8) & 0.10 & & & \\
\hline PV2 (TSW9) & 0.61 & & & \\
\hline BT1a (CH1) & 0.15 & & & \\
\hline $\mathrm{CHV}$ & 0.61 & & & \\
\hline $\mathrm{CHZ}$ & 0.27 & & & \\
\hline $\mathrm{BT}(\mathrm{CH} 6)$ & 0.08 & & & \\
\hline PP4 & 0.02 & & & \\
\hline PP3 & 0.79 & & & \\
\hline PP2 & 0.35 & & & \\
\hline PP1 & 0.43 & & & \\
\hline BF3 & 0.26 & & & \\
\hline $\mathrm{BF} 2$ & 0.04 & & & \\
\hline
\end{tabular}

FEHM=finite element heat and mass (model); TSPA-LA=Total System Performance Assessment for the License Application.

\subsubsection{Colloid Size Distribution}

A colloid size distribution is used by FEHM to get the interpolated colloid size of each colloid particle. The colloid size information is then combined with pore size data to simulate filtration effects at matrix unit interfaces.

The colloid size range of $6 \mathrm{~nm}$ to $450 \mathrm{~nm}$ is based on the document by CRWMS M\&O (2001 [DIRS 154071], Section 6.3); DTN: LL000122051021.116 [DIRS 142973]. However, because a specific distribution was not available, the following distribution (Table 6-17) was chosen (not developed) to be consistent with Figure 23 in the report by CRWMS M\&O (2001 [DIRS 154071]).

The same colloid size distribution data are used in this abstraction model. FEHM data files contain the colloid size input data under the macro "size."

\subsubsection{Colloid Concentration and Colloid $K_{c}$}

The colloid equilibrium sorption parameter $K_{c}$ is defined as $K_{c}=C_{\text {coll }} / C_{\text {fluid, }}$, where $C_{\text {coll }}$ is the radionuclide concentration residing on colloids and $C_{\text {fluid }}$ is the radionuclide concentration in 
fluid. Colloid $K_{c}$ is used in FEHM as an input parameter for calculating the retardation factors for colloid facilitated radionuclide transport in the media.

Radionuclide sorption to colloids can be categorized into reversible and irreversible categories. When sorption to colloids is treated as an irreversible process, a very large number (1.0E20) is assigned for $K_{c}$ (see Table 6-18).

Table 6-17. Colloid Size Distribution

\begin{tabular}{|c|c|c|c|c|}
\hline $\begin{array}{l}\text { Colloid } \\
\text { Size (nm) }\end{array}$ & $\begin{array}{l}\text { Cumulative } \\
\text { Probability }\end{array}$ & Input Description & Input Source & Type of Uncertainty \\
\hline 1 & 0 & \multirow{6}{*}{$\begin{array}{l}\text { Colloid size distribution } \\
\text { data are used in } \\
\text { simulating colloid } \\
\text { filtration effect at matrix } \\
\text { interface. }\end{array}$} & \multirow{6}{*}{$\begin{array}{l}\text { LL000122051021.116 } \\
\text { [DIRS 142973] }\end{array}$} & \multirow{6}{*}{$\begin{array}{l}\text { FEHM read in the cumulative } \\
\text { distribution data at run time. } \\
\text { Random colloid size data are } \\
\text { generated on the fly to address } \\
\text { the effect of colloid size } \\
\text { uncertainty on filtration. }\end{array}$} \\
\hline 6 & 0.2 & & & \\
\hline 50 & 0.4 & & & \\
\hline 100 & 0.6 & & & \\
\hline 200 & 0.8 & & & \\
\hline 450 & 1.0 & & & \\
\hline
\end{tabular}

FEHM=finite element heat and mass (model)

Table 6-18. $\mathrm{K}_{\mathrm{c}}$ for Irreversible Colloid

\begin{tabular}{|l|c|l|l|l|}
\hline $\begin{array}{c}\text { Irreversible } \\
\text { Colloids }\end{array}$ & $\mathbf{K}_{\mathbf{c}}$ & \multicolumn{1}{c|}{ Input Description } & \multicolumn{1}{c|}{$\begin{array}{c}\text { Type of } \\
\text { Input Source }\end{array}$} \\
\hline $\begin{array}{l}\text { Irreversible } \\
\text { colloids }\end{array}$ & $1.0 \mathrm{E} 20$ & $\begin{array}{l}\text { Simulating the effect of } \\
\text { irreversible sorption to colloid }\end{array}$ & $\begin{array}{l}\text { A large value that ensures the sorption } \\
\text { process to colloids be irreversible }\end{array}$ & Fixed value \\
\hline
\end{tabular}
NOTE: This input value is not data; rather, it is a recommended input value to allow irreversible sorption to
colloids to be simulated in the abstraction model.

In TSPA-LA calculations, to reflect the influence of reversible colloid facilitated radionuclide transport on system performance, colloid $K_{d}$ values $K_{d \text {,coll }}$ are sampled at run time and used in the calculation of $K_{c}$. The sampled radionuclide sorption coefficients are then multiplied by the colloid concentration $C_{\text {coll }}$ to calculate the colloid $K_{c}$ values:

$$
K_{c}=C_{\text {coll }} K_{d, \text { coll }}
$$

Field data and laboratory experiments have shown that colloid concentration in groundwater can vary several order of magnitudes and is also a function of ionic strength and groundwater $\mathrm{pH}$ (BSC 2004 [DIRS 170025]; DTN: SN0306T0504103.005 [DIRS 164132]). To address the uncertainty of colloid concentration on colloid facilitated radionuclide transport, in TSPA-LA, the colloid concentration is sampled at run time and provided to FEHM for the calculation of reversible colloid $K_{c}$. Table 6-19 lists the distribution of colloid concentration used in TSPA-LA. As shown in the table, a cumulative distribution with values ranging from 0.001 to $200 \mathrm{mg} / \mathrm{L}$ is used if the ionic strength of the fluid is low $(<0.05 \mathrm{M})$. However, to account for the fact that high ionic strength results in colloid flocculation, and, hence, low colloid concentrations, a value of $1 . \mathrm{E}-6 \mathrm{mg} / \mathrm{L}$ is used for high ionic strength fluids (>=0.05 M). 
Table 6-19. Colloid Concentration Distribution

\begin{tabular}{|c|c|c|c|c|}
\hline $\begin{array}{c}\text { Colloid } \\
\text { Concentration } \\
(\mathrm{mg} / \mathrm{L})\end{array}$ & $\begin{array}{l}\text { Cumulative } \\
\text { Probability }\end{array}$ & Input Description & Input Source & Type of Uncertainty \\
\hline 0.001 to 0.1 & 50 & \multirow{5}{*}{$\begin{array}{l}\text { Ionic strength less than } \\
0.05 \text {. Data are used in } \\
\text { the estimation of } \\
\text { reversible colloid } K_{c} \text {. }\end{array}$} & \multirow{6}{*}{$\begin{array}{l}\text { BSC } 2004 \\
\text { [DIRS 170025], } \\
\text { Section 6.3.2.4, } \\
\text { Table 6-4. } \\
\text { SN0306T0504103.005 } \\
\text { [DIRS 164132] }\end{array}$} & \multirow{6}{*}{$\begin{array}{l}\text { The cumulative distribution } \\
\text { data listed in this table will } \\
\text { be used to generate random } \\
\text { colloid concentrations at } \\
\text { TSPA-LA runtime to address } \\
\text { the influence of colloid } \\
\text { concentration uncertainty of } \\
\text { radionuclide transport. }\end{array}$} \\
\hline 0.1 to 1.0 & 75 & & & \\
\hline 1.0 to 10 & 90 & & & \\
\hline 10 to 50 & 98 & & & \\
\hline 50 to 200 & 100 & & & \\
\hline 1.E-6 & 100 & Ionic strength $>=0.05$ & & \\
\hline
\end{tabular}

NOTE: The probability of occurrence values listed in the source Table 6-4 are summed up to generate the cumulative probability in this table.

TSPA-LA=Total System Performance Assessment for the License Application.

The strength of radionuclide sorption onto colloid is determined by the sorption coefficient $K_{d}$. In TSPA-LA, the following $K_{d}$ distribution is used (Table 6-20). Among them, $K_{d}$ ranges and distributions for Th and $\mathrm{Pa}$ are assumed to be those of Am primarily because of limited data on Th and Pa (BSC 2004 [DIRS 170025]; DTN: SN0306T0504103.006 [DIRS 164131]).

Table 6-20. Radionuclide Sorption Coefficient ( $\mathrm{mL} / \mathrm{g})$ onto Colloids

\begin{tabular}{|c|c|c|c|c|c|}
\hline $\begin{array}{l}\text { Radio- } \\
\text { nuclide }\end{array}$ & Colloid & Values (-) & $K_{d}$ Value Intervals & $\begin{array}{c}\mathrm{K}_{\mathrm{d}} \text { Value Interval } \\
\text { Probability of } \\
\text { Occurrence }\end{array}$ & $\begin{array}{c}\mathrm{K}_{\mathrm{d}} \text { Value Interval } \\
\text { Cumulative } \\
\text { Probability of } \\
\text { Occurrence }\end{array}$ \\
\hline \multirow[t]{6}{*}{$\mathrm{Pu}$} & \multirow{6}{*}{$\begin{array}{l}\text { Iron- } \\
\text { (hydr)oxide }\end{array}$} & \multirow[t]{6}{*}{$10^{4}$ to $10^{6}$} & $<1 \times 10^{4}$ & 0 & 0 \\
\hline & & & $1 \times 10^{4}$ to $5 \times 10^{4}$ & 0.15 & 0.15 \\
\hline & & & $5 \times 10^{4}$ to $1 \times 10^{5}$ & 0.20 & 0.35 \\
\hline & & & $1 \times 10^{5}$ to $5 \times 10^{5}$ & 0.50 & 0.85 \\
\hline & & & $5 \times 10^{5}$ to $1 \times 10^{6}$ & 0.15 & 1.00 \\
\hline & & & $>1 \times 10^{6}$ & 0. & \\
\hline \multirow[t]{8}{*}{$\mathrm{Pu}$} & \multirow[t]{8}{*}{ Smectite } & \multirow[t]{8}{*}{$10^{3}$ to $10^{6}$} & $<1 \times 10^{3}$ & 0. & 0. \\
\hline & & & $1 \times 10^{3}$ to $5 \times 10^{3}$ & 0.04 & 0.04 \\
\hline & & & $5 \times 10^{3}$ to $1 \times 10^{4}$ & 0.08 & 0.12 \\
\hline & & & $1 \times 10^{4}$ to $5 \times 10^{4}$ & 0.25 & 0.37 \\
\hline & & & $5 \times 10^{4}$ to $1 \times 10^{5}$ & 0.20 & 0.57 \\
\hline & & & $1 \times 10^{5}$ to $5 \times 10^{5}$ & 0.35 & 0.92 \\
\hline & & & $5 \times 10^{5}$ to $1 \times 10^{6}$ & 0.08 & 1.00 \\
\hline & & & $>1 \times 10^{6}$ & 0. & \\
\hline
\end{tabular}


Table 6-20. Radionuclide Sorption Coefficient $(\mathrm{mL} / \mathrm{g})$ onto Colloids (Continued)

\begin{tabular}{|c|c|c|c|c|c|}
\hline $\begin{array}{l}\text { Radio- } \\
\text { nuclide }\end{array}$ & Colloid & Values (-) & $K_{d}$ Value Intervals & $\begin{array}{c}\mathrm{K}_{\mathrm{d}} \text { Value Interval } \\
\text { Probability of } \\
\text { Occurrence }\end{array}$ & $\begin{array}{c}\mathrm{K}_{\mathrm{d}} \text { Value Interval } \\
\text { Cumulative } \\
\text { Probability of } \\
\text { Occurrence }\end{array}$ \\
\hline \multirow{14}{*}{$\begin{array}{l}\mathrm{Am}, \mathrm{Th}, \\
\mathrm{Pa}\end{array}$} & \multirow{6}{*}{$\begin{array}{l}\text { Iron- } \\
\text { (hydr)oxide }\end{array}$} & \multirow[t]{6}{*}{$10^{5}$ to $10^{7}$} & $<1 \times 10^{5}$ & 0. & 0. \\
\hline & & & $1 \times 10^{5}$ to $5 \times 10^{5}$ & 0.15 & 0.15 \\
\hline & & & $5 \times 10^{5}$ to $1 \times 10^{6}$ & 0.20 & 0.35 \\
\hline & & & $1 \times 10^{6}$ to $5 \times 10^{6}$ & 0.55 & 0.90 \\
\hline & & & $5 \times 10^{6}$ to $1 \times 10^{7}$ & 0.10 & 1.00 \\
\hline & & & $>1 \times 10^{7}$ & 0. & \\
\hline & \multirow[t]{8}{*}{ Smectite } & \multirow[t]{8}{*}{$10^{4}$ to $10^{7}$} & $<1 \times 10^{4}$ & 0. & 0. \\
\hline & & & $1 \times 10^{4}$ to $5 \times 10^{4}$ & 0.07 & 0.07 \\
\hline & & & $5 \times 10^{4}$ to $1 \times 10^{5}$ & 0.10 & 0.17 \\
\hline & & & $1 \times 10^{5}$ to $5 \times 10^{5}$ & 0.23 & 0.40 \\
\hline & & & $5 \times 10^{5}$ to $1 \times 10^{6}$ & 0.20 & 0.60 \\
\hline & & & $1 \times 10^{6}$ to $5 \times 10^{6}$ & 0.32 & 0.92 \\
\hline & & & $5 \times 10^{6}$ to $1 \times 10^{7}$ & 0.08 & 1.00 \\
\hline & & & $>1 \times 10^{7}$ & 0. & \\
\hline \multirow[t]{12}{*}{$\mathrm{Cs}$} & \multirow{6}{*}{$\begin{array}{l}\text { Iron- } \\
\text { (hydr)oxide }\end{array}$} & \multirow[t]{6}{*}{$10^{1}$ to $10^{3}$} & $<1 \times 10^{1}$ & 0. & 0. \\
\hline & & & $1 \times 10^{1}$ to $5 \times 10^{1}$ & 0.13 & 0.13 \\
\hline & & & $5 \times 10^{1}$ to $1 \times 10^{2}$ & 0.22 & 0.35 \\
\hline & & & $1 \times 10^{2}$ to $5 \times 10^{2}$ & 0.55 & 0.90 \\
\hline & & & $5 \times 10^{2}$ to $1 \times 10^{3}$ & 0.10 & 1.00 \\
\hline & & & $>1 \times 10^{3}$ & 0. & \\
\hline & \multirow[t]{6}{*}{ Smectite } & \multirow[t]{6}{*}{$10^{2}$ to $10^{4}$} & $<1 \times 10^{2}$ & 0. & 0. \\
\hline & & & $1 \times 10^{2}$ to $5 \times 10^{2}$ & 0.20 & 0.20 \\
\hline & & & $5 \times 10^{2}$ to $1 \times 10^{3}$ & 0.25 & 0.45 \\
\hline & & & $1 \times 10^{3}$ to $5 \times 10^{3}$ & 0.50 & 0.95 \\
\hline & & & $5 \times 10^{3}$ to $1 \times 10^{4}$ & 0.05 & 1.00 \\
\hline & & & $>1 \times 10^{4}$ & 0. & \\
\hline
\end{tabular}

Source: BSC 2004 [DIRS 170025], Section 6.3.3.1, Table 6-6.

\subsubsection{Fractions of Colloids Traveling Unretarded and Colloid Retardation Factor}

Colloid retardation factor, $R_{c}$, is used in FEHM to study the impact of colloid retardation in the fractured media on irreversibly sorbed radionuclide transport. Field experiments have shown that a small percentage of colloids transport through the groundwater system essentially without retardation (BSC 2004 [DIRS 170006]). The fractions of unretarded colloids have been developed based on field data and are listed in Table 6-21.

This table, derived in the report by BSC (2004 [DIRS 170006]), postulates that the fraction of colloids escaping retardation due to physical and chemical processes is a function of the residence time of the colloid: progressively fewer colloids migrate unretarded with time. This poses a difficulty in simulating transport for the unretarded colloids - the transport times of the 
combined UZ and SZ system are not known a priori. Therefore, it is recommended that the fraction be chosen for a transport time that can be reasonably expected to be conservative, such as 100 years for the combined system. Therefore, from Table 6-21, the fraction of colloids traveling unretarded should be set at $1.68 \mathrm{E}-03$. If simulations suggest that a different residence time is more representative, then this time should be changed, and a new unretarded fraction should be selected from Table 6-21. It should be noted that this aspect of the colloid transport model is relatively uncertain, so parameter sensitivity studies are advisable if it is determined that a colloidal radionuclide may be important to performance. Nevertheless, using the transport time of 100 years as the basis for the fraction of colloids traveling unretarded will result in a conservative model that provides an upper bound on rapid colloid transport.

Colloids traveling unretarded will be given a colloid retardation factor of 1 .

Table 6-21. Fractions of Colloids Traveling Unretarded

\begin{tabular}{|c|c|c|c|c|}
\hline $\begin{array}{c}\text { Transport } \\
\text { Time (Years) }\end{array}$ & $\begin{array}{c}\text { Fraction of } \\
\text { Colloids Unretarded }\end{array}$ & Input Description & Input Source & $\begin{array}{c}\text { Type of } \\
\text { Uncertainty }\end{array}$ \\
\hline 1 & $1.10 \mathrm{E}-02$ & \multirow{15}{*}{$\begin{array}{l}\text { This parameter is used in } \\
\text { determining fractions of } \\
\text { colloids traveling } \\
\text { unretarded in the UZ. }\end{array}$} & \multirow{15}{*}{$\begin{array}{l}\text { BSC } 2004 \text { [DIRS 170006]; } \\
\text { DTN: LA0303HV831352.003 } \\
\text { [DIRS 165624] }\end{array}$} & \multirow[t]{15}{*}{ Fixed value } \\
\hline 5 & $5.70 \mathrm{E}-03$ & & & \\
\hline 10 & $4.30 \mathrm{E}-03$ & & & \\
\hline 20 & 3.24 E-03 & & & \\
\hline 30 & 2.74 E-03 & & & \\
\hline 40 & $2.44 \mathrm{E}-03$ & & & \\
\hline 50 & $2.23 \mathrm{E}-03$ & & & \\
\hline 75 & $1.89 \mathrm{E}-03$ & & & \\
\hline 100 & $1.68 \mathrm{E}-03$ & & & \\
\hline 300 & 1.07 E-03 & & & \\
\hline 600 & $8.08 \mathrm{E}-04$ & & & \\
\hline 1,000 & $6.56 \mathrm{E}-04$ & & & \\
\hline 2,000 & $4.94 \mathrm{E}-04$ & & & \\
\hline 5,000 & 3.40 E-04 & & & \\
\hline 10,000 & $2.56 \mathrm{E}-04$ & & & \\
\hline
\end{tabular}

UZ=unsaturated zone

For colloids that are delayed relative to a conservative species, the retardation of colloids in groundwater system depends on colloid type; colloid size; groundwater $\mathrm{pH}$, Eh, and ionic strength; and rock properties, etc. Field tests at the C-wells complex near Yucca Mountain and Nevada Test Site and laboratory experiments were carried out under saturated conditions to estimate colloid retardation factors (BSC 2004 [DIRS 170006]). Although these experimental studies were performed under saturated conditions, their use in the UZ model is justified based on the fact that the fundamental fluid flow conditions at the scale of the filtration processes should be similar. In particular, the C-wells experiments were carried out in fractured tuffs, and the colloid retardation process in the UZ is also expected to be taking place within fractures. To account for the relatively large uncertainty associated with these processes, a broad distribution of colloid retardation factors is warranted. Table 6-22 lists the cumulative distribution data of colloid retardation factors. 
Table 6-22. Colloid Retardation Factors

\begin{tabular}{|c|c|c|c|c|}
\hline $\begin{array}{c}\text { Colloid } \\
\text { Retardation } \\
\text { Factor }\end{array}$ & $\begin{array}{l}\text { Cumulative } \\
\text { Probability }\end{array}$ & Input Description & Input Source & Type of Uncertainty \\
\hline 6.00 & 0 & \multirow{6}{*}{$\begin{array}{l}\text { Colloid retardation factor } \\
\text { is used by FEHM in } \\
\text { simulation of the effects of } \\
\text { colloid retardation in } \\
\text { fractured rock on colloid } \\
\text { facilitated radionuclide } \\
\text { transport. }\end{array}$} & \multirow{6}{*}{$\begin{array}{l}\text { Section } 6.4 .3 \text { of BSC } 2004 \\
\text { [DIRS 170006]; } \\
\text { LA0303HV831352.002 } \\
\text { [DIRS 163558] }\end{array}$} & \multirow{6}{*}{$\begin{array}{l}\text { A cumulative distribution } \\
\text { is used to describe the } \\
\text { distribution of colloid } \\
\text { retardation factor. In } \\
\text { TSPA-LA, the colloid } \\
\text { retardation factor will be } \\
\text { sampled at runtime and } \\
\text { used by FEHM in TSPA- } \\
\text { LA calculations. }\end{array}$} \\
\hline 6.00 & 0.15 & & & \\
\hline 10.23 & 0.25 & & & \\
\hline 26.00 & 0.50 & & & \\
\hline 59.98 & 0.80 & & & \\
\hline 800. & 1.00 & & & \\
\hline
\end{tabular}

FEHM=finite element heat and mass (model); TSPA-LA=Total System Performance Assessment for the License Application

In TSPA-LA calculations, to investigate the uncertainty of colloid retardation factors on radionuclide transport, colloid retardation factors are sampled for each realization at run time based on the given cumulative distribution in Table 6-22.

\subsubsection{Radionuclide Half Lives (Years) and Daughter Products}

FEHM needs the radionuclide half life and daughter products information to simulate the influence of radionuclide decay and ingrowth on system performance. The radionuclide half life and daughter products for the following species are used in FEHM as input parameters (see Table 6-23).

\subsubsection{Repository Radionuclide Release Bins}

Radionuclides will be released from nodes corresponding to the repository location. These nodes were grouped into bins (zones) that shared common infiltration ranges, to be compatible with a conceptual model for radionuclide release in which releases are a strong function of the percolation rates at the repository horizon. This would help to categorize release points according to high or low percolation rates. Five bins were chosen based on the cumulative probability of percolation for the glacial-transition climate period. The glacial-transition period was selected to perform this binning because the majority of the simulation is performed under this climate state. The definition of the 5 bins is listed in Table 6-24.

Node coordinates within each bin are given in the multiscale thermal-hydrologic model (DTN: LL030610323122.029 [DIRS 164513]). As the grid resolution of the thermal-hydrologic model is much finer (file: NEVADA_SMT_percolation_BIN_ma.txt. DTN: LL030610323122.029 [DIRS 164513]) than the site scale FEHM transport model, the node coordinates of the thermal-hydrologic model are mapped onto the FEHM grid to derive the corresponding FEHM nodes. 
Table 6-23. Radionuclide Half-Lives and Daughter Products Used in the TSPA-LA

\begin{tabular}{|c|c|c|c|c|c|}
\hline Radionuclide & Half-Life (yr) & $\begin{array}{c}\text { Daughter } \\
\text { Product }\end{array}$ & Input Description & Input Source & $\begin{array}{c}\text { Type of } \\
\text { Uncertainty }\end{array}$ \\
\hline $\mathrm{C}^{14}$ & $5.715 E+03$ & & \multirow{24}{*}{$\begin{array}{l}\text { Radionuclide half-lives } \\
\text { and daughter products. } \\
\text { Those data will be } \\
\text { used by FEHM in } \\
\text { radionuclide decay and } \\
\text { ingrowth calculations. }\end{array}$} & \multirow{24}{*}{$\begin{array}{l}\text { Parrington et al. } 1996 \\
\text { [DIRS 103896] } \\
\text { DTN: N/A established fact }\end{array}$} & \multirow{24}{*}{ Fixed values } \\
\hline $\mathrm{Cs}^{135}$ & 2.3E6 & & & & \\
\hline $\mathrm{Cs}^{137}$ & $3.007 \mathrm{E}+1$ & & & & \\
\hline $1^{129}$ & $1.57 \mathrm{E}+7$ & & & & \\
\hline $\mathrm{Sr}^{90}$ & $2.878 \mathrm{E}+1$ & & & & \\
\hline $\mathrm{Tc}^{99}$ & $2.13 \mathrm{E}+5$ & & & & \\
\hline $\mathrm{Am}^{243}$ & $7.37 \mathrm{E}+3$ & $\mathrm{Pu}^{239}$ & & & \\
\hline $\mathrm{Pu}^{239}$ & $2.410 \mathrm{E}+4$ & $\mathrm{U}^{235}$ & & & \\
\hline $\mathrm{U}^{235}$ & $7.04 \mathrm{E}+8$ & $\mathrm{~Pa}^{231}$ & & & \\
\hline $\mathrm{Pa}^{231}$ & $3.28 \mathrm{E}+04$ & & & & \\
\hline $\mathrm{Am}^{241}$ & $4.327 \mathrm{E}+2$ & $\mathrm{~Np}^{237}$ & & & \\
\hline $\mathrm{Np}^{237}$ & $2.14 \mathrm{E}+06$ & $U^{233}$ & & & \\
\hline $\mathrm{U}^{233}$ & $1.592 \mathrm{E}+5$ & $\mathrm{Th}^{229}$ & & & \\
\hline $\mathrm{Th}^{229}$ & $7.3 \mathrm{E}+3$ & & & & \\
\hline $\mathrm{Pu}^{240}$ & $6.56 \mathrm{E}+3$ & $\mathrm{U}^{236}$ & & & \\
\hline $\mathrm{U}^{236}$ & $2.342 \mathrm{E}+7$ & $\mathrm{Th}^{232}$ & & & \\
\hline $\mathrm{Th}^{232}$ & $1.40 \mathrm{E}+10$ & & & & \\
\hline $\mathrm{U}^{232}$ & $6.98 \mathrm{E}+1$ & & & & \\
\hline $\mathrm{Pu}^{242}$ & $3.75 E+5$ & $\mathrm{U}^{238}$ & & & \\
\hline $\mathrm{Pu}^{238}$ & $8.77 \mathrm{E}+1$ & $\mathrm{U}^{234}$ & & & \\
\hline $\mathrm{U}^{238}$ & $4.47 \mathrm{E}+9$ & $U^{234}$ & & & \\
\hline $\mathrm{U}^{234}$ & $2.46 \mathrm{E}+5$ & $\mathrm{Th}^{230}$ & & & \\
\hline $\mathrm{Th}^{230}$ & $7.54 \mathrm{E}+4$ & $\mathrm{Ra}^{226}$ & & & \\
\hline $\mathrm{Ra}^{226}$ & $1.599 \mathrm{E}+3$ & & & & \\
\hline
\end{tabular}

FEHM=finite element heat and mass (model); N/A=not applicable

NOTE: Irreversible and reversible colloid facilitated radionuclide has the same half-life and daughter products as corresponding dissolved species.

Table 6-24. Definition of Repository Release Bins

\begin{tabular}{|l|l|c|c|c|c|}
\hline & \multicolumn{1}{|c|}{$\operatorname{Bin} \mathbf{1}$} & $\operatorname{Bin} \mathbf{2}$ & $\operatorname{Bin} \mathbf{3}$ & $\operatorname{Bin} \mathbf{4}$ & $\operatorname{Bin} \mathbf{5}$ \\
\hline $\begin{array}{l}\text { Range of Cumulative } \\
\text { Probability }\end{array}$ & $0-0.05$ & $0.05-0.30$ & $0.30-0.70$ & $0.70-0.95$ & $0.95-1.00$ \\
\hline $\begin{array}{l}\text { Range of Percolation for } \\
\text { Glacial-Transition Climate } \\
\text { (mm/year) }\end{array}$ & $0.73-6.71$ & $6.71-11.77$ & $11.77-21.22$ & $21.22-38.48$ & $38.48-76.67$ \\
\hline
\end{tabular}

Source: BSC 2004 [DIRS 169565], Appendix VIII, "Binning Calculations."

The mapping was done using FEHM V2.21 (LANL 2003 [DIRS 165741]) and Microsoft Excel. The smeared-sources mountain-scale thermal model (SMT) node coordinates from the thermalhydrologic model were read in by FEHM using the "zone” macro. FEHM did a search to find the closest node to a given SMT coordinate. Once FEHM nodes corresponding to the given 
SMT coordinates were found, Excel was used to get the frequency of FEHM node within each bin (data to be submitted). The following rules are applied during the mapping using Excel.

- As the FEHM grid is coarser than the thermal-hydrologic model grid, it is possible that some nodes in the thermal-hydrologic model within different bins may map onto a single FEHM node in the corresponding bins. In this case, the FEHM node with the most frequent appearance prevails. For example, FEHM 36189 appeared two times in bin 1 and four times in bin 4. Based on the rule, FEHM node 36189 was assigned to bin 4.

- When an FEHM node appears an equal number of times in different bins, this node will be assigned to the highest bin number. For example, FEHM node 39316 appeared three times in bin 2 and bin 3, respectively. Thus, node 39316 was assigned to bin 3 .

A file containing a listing of these bins and the associated nodes was created and named repository_bins. The bin data are incorporated into FEHM zone files in TSPA simulations and used to release radionuclides from the repository.

Figures 6-15 and 6-16 are plots showing the location of SMT repository release nodes and the transformed FEHM repository release nodes, respectively. It is clear that the transformed FEHM release nodes corresponding to the SMT release nodes closely. But, because of the much coarser FEHM grid and the lack of a one-to-one transformation from one grid to the other, the FEHM repository release nodes does not capture the detail depicted in the SMT grid. Nevertheless, the transformation is sufficient for the purposes of depicting the role of percolation variability on radionuclide releases and transport.

\subsubsection{Radionuclide Collecting Bins at UZ/SZ Interface}

For the UZ/SZ interface, all nodes at (or below) the highest potential water table elevation of $850 \mathrm{~m}$ in the UZ model were grouped into four regions (or bins). The purpose of this process is for increased resolution to be captured in the TSPA-LA model with respect to the arrival location and its impact on transport times in the SZ. Radionuclide mass reaching the water table in one location may have a different SZ travel path and transport time than mass arriving at some other location. The collecting bins are the means by which this potentially significant feature of the system can be quantified. As discussed in Section 6.5.2.13 of the report by BSC (2004 [DIRS 170042]), these source regions were selected to be compatible with the overall repository extent and on the general pattern of groundwater flow within the UZ model domain. Then, within the SZ transport simulations in the document by BSC (2004 [DIRS 170042]), the total radionuclide mass flow rate in each of these four bins will be focused at a random point (within each of the four bins), which is appropriate for a single leaking waste package or for highly focused groundwater flow along a fault or single fracture in the UZ. A more diffuse source of radionuclides at the water table may be more physically realistic for later times when numerous leaking waste packages occur, however, the use of a point source in the SZ is an approach that overestimates the concentration of radionuclides near the source (BSC 2004 [DIRS 170042], Section 6.5.2.13). The four regions (Figure 6-17) are defined by an east-west boundary at a Universal Transverse Mercator (UTM) easting coordinate of 548500 and a north-south boundary at a UTM northing coordinate at 4078630 m (BSC 2004 [DIRS 170042], Table 6-8). 


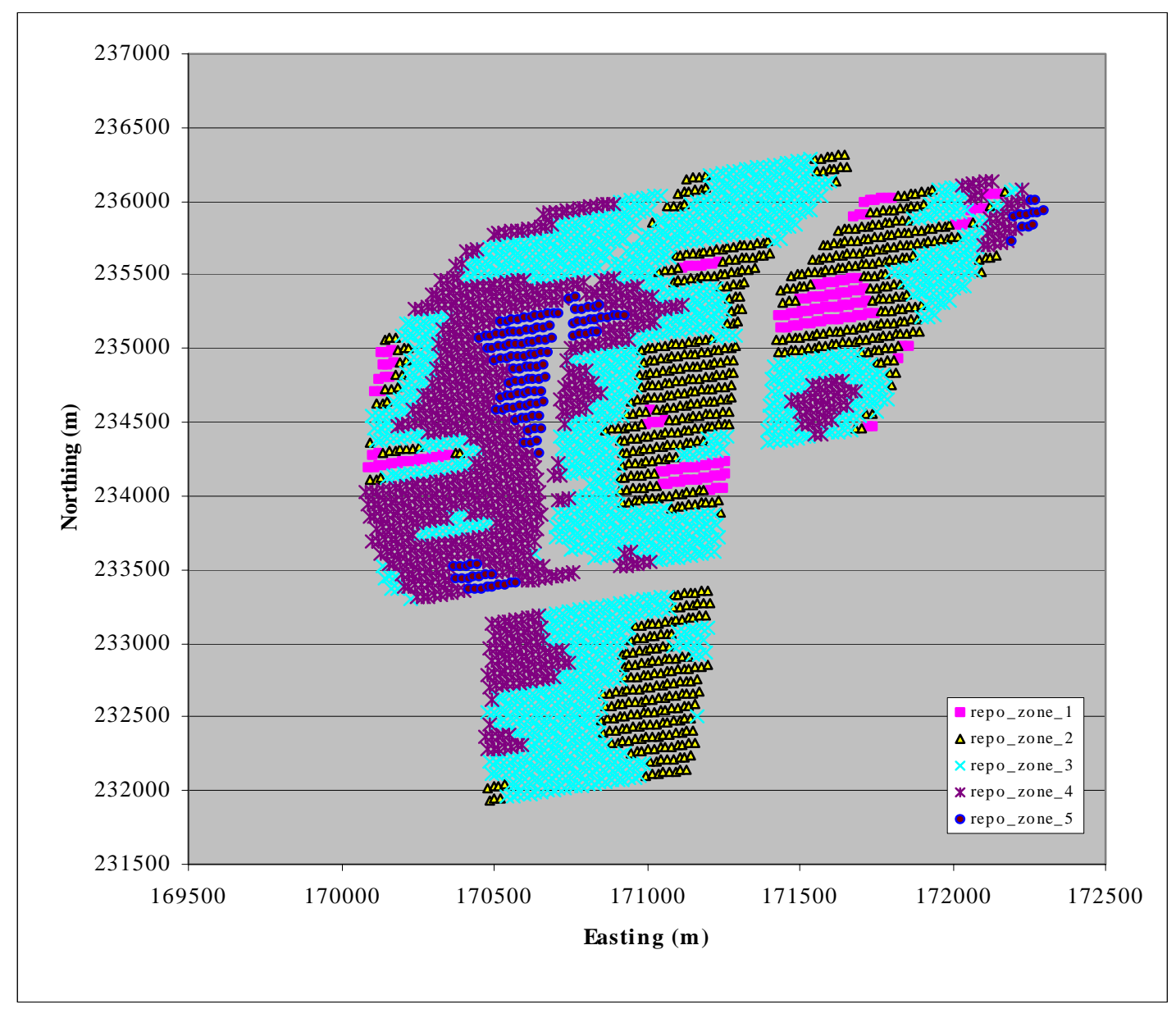

Output DTN: LA0407BR831371.001.

Figure 6-15. SMT Repository Release Nodes

All nodes at or beneath the water table in the UZ transport abstraction model were grouped into one of the four regions based on data listed in Table 6-8 in the report by BSC (2004 [DIRS 170042]). All particles falling into each FEHM water table collecting bin are used to compute the input to the appropriate SZ source release bin. Since the FEHM water table collecting bins are larger than the SZ source release bins (defined in Figure 6-17), it is assured that no particles fall outside of the four SZ release zones and go uncounted. The FEHM water table collecting bin nodes were extracted from the ELEME data from TOUGH2 site scale flow model package (DTN: LB0323DSSCP9I.001 [DIRS 163044]). The data contain the cell name and coordinates for each node in the site scale UZ flow model. As the UZ transport model uses the Nevada State Plane coordinates, the given UTM coordinates are converted into Nevada State Plane coordinates during the extraction of the water table collect bins. The extraction was done in an Excel spreadsheet through several conditional if statements (See Appendix B for details). 


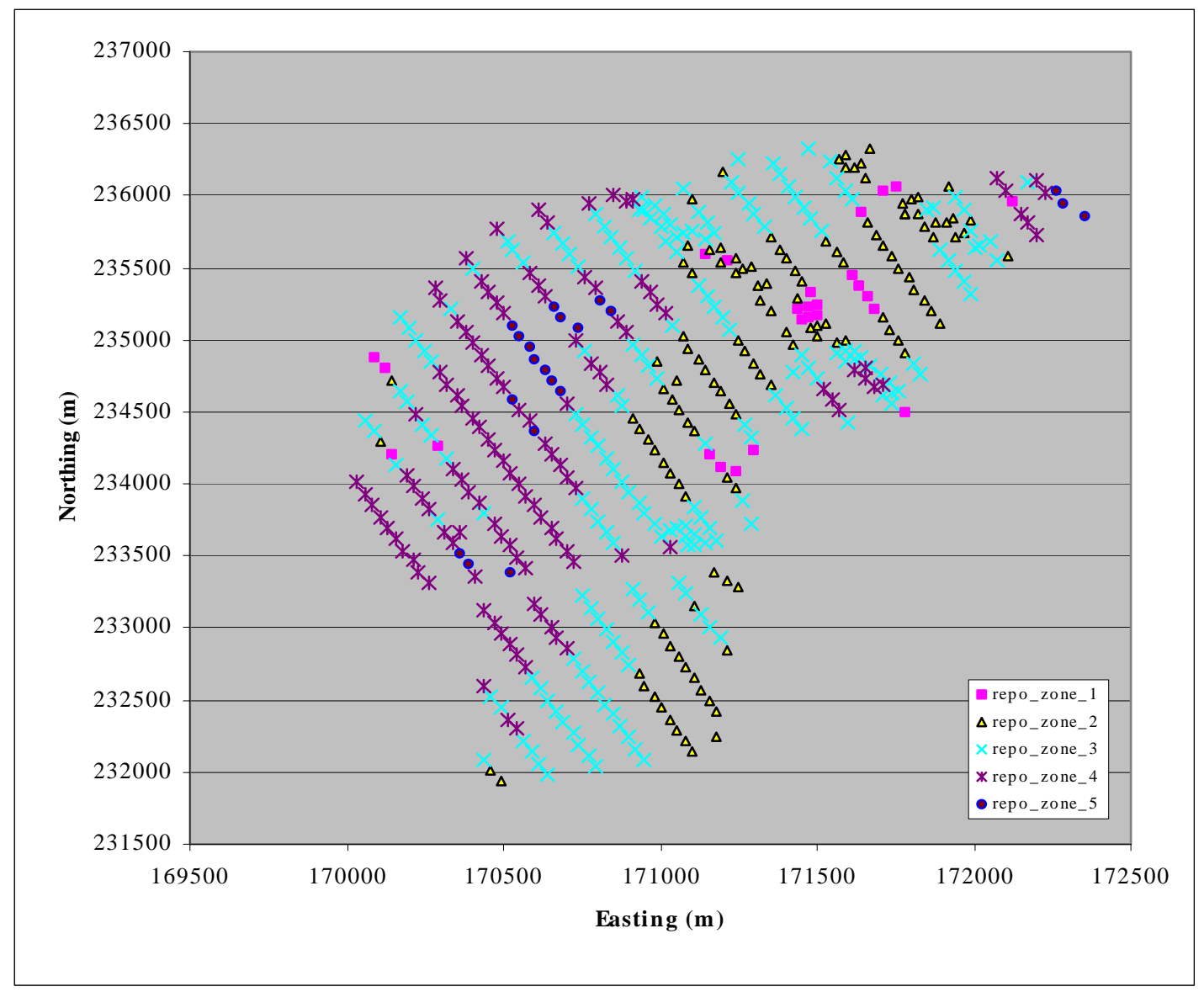

Output DTN: LA0407BR831371.001.

Figure 6-16. FEHM Repository Release Nodes Transformed Based on SMT Release Nodes (Shown in Figure 6-15)

The four collecting bins in FEHM are named 701, 702, 703, and 704, containing SZ source release regions $1,2,3$, and 4, respectively. Among them, zone 701 contains all nodes beneath the water table with a UTM easting coordinate less than $548500 \mathrm{~m}$ (NSP: $171189.79 \mathrm{~m}$ ) and a UTM northing coordinate greater than 4078630 m (NSP: $233459.87 \mathrm{~m}$ ); zone 702 contains all water table nodes with a UTM easting coordinate greater than $548500 \mathrm{~m}$ (NSP: $171189.79 \mathrm{~m}$ ) and a UTM northing coordinate greater than $4078630 \mathrm{~m}$ (NSP: $233459.87 \mathrm{~m}$ ); zone 703 contains all water table nodes with a UTM easting coordinate less than $548500 \mathrm{~m}$ (NSP: $171189.79 \mathrm{~m}$ ) and a UTM northing coordinate less than $4078630 \mathrm{~m}$ (NSP: $233459.87 \mathrm{~m}$ ); and zone 704 contains water table nodes with a UTM easting coordinate greater than $548500 \mathrm{~m}$ (NSP: $171189.79 \mathrm{~m}$ ) and a UTM northing coordinate less than $4078630 \mathrm{~m}$ (NSP: $233459.87 \mathrm{~m}$ ). 


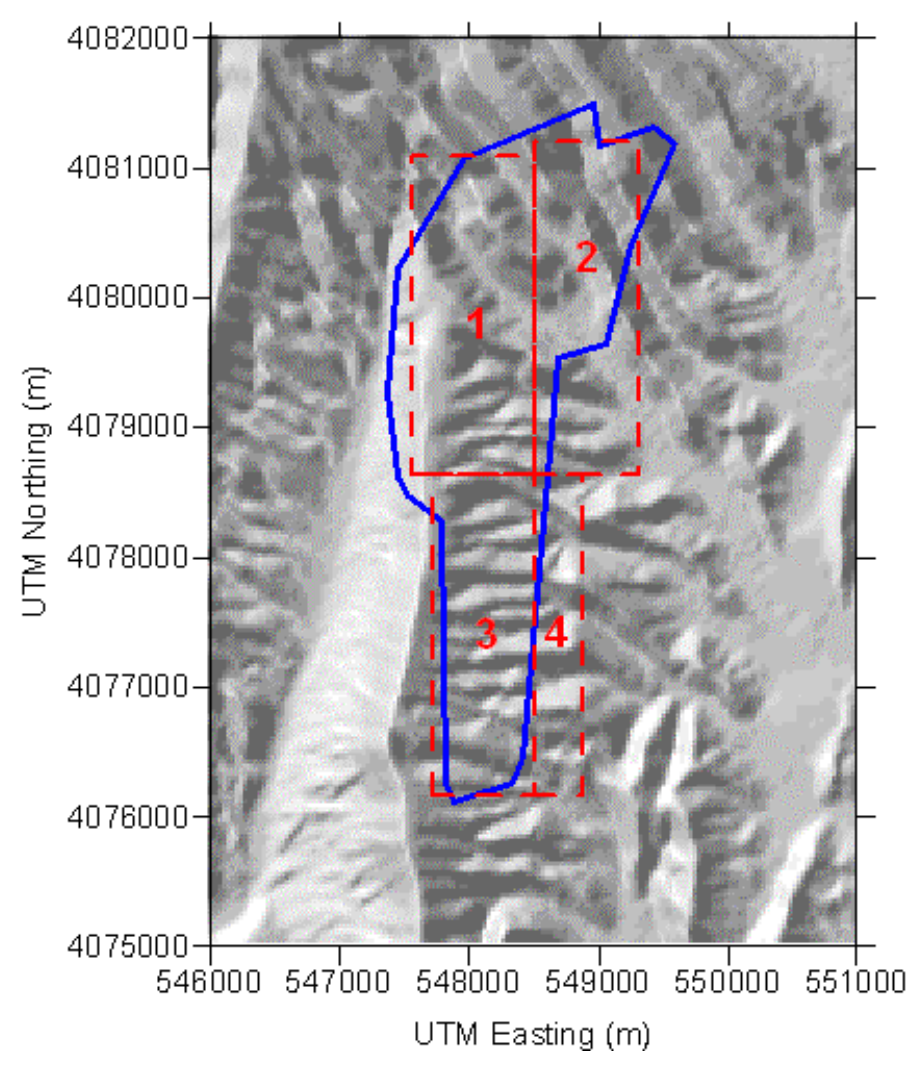

Source: BSC 2004 [DIRS 170042], Figure 6-27.

NOTE: Dashed lines represent the boundaries of the SZ release regions and the solid lines represent the boundary of the repository release region.

Figure 6-17. Source Regions for Radionuclide Release in the SZ Transport Abstraction Model

Nodes contained in each of the collection bins were stored in file wt.zone and defined in the corresponding FEHM zone file. These nodes are contained in the output DTN: LA0407BR831371.001. Once a particle reaches the water table, the particle is removed from the UZ transport system. Inside FEHM, the code records mass leaving the system within each bin/zone (FEHM V2.21 Users Manual, LANL 2003 [DIRS 165741]). As climate change can cause water table rise or fall, the defined collection bins/zones contain all nodes between the lowest and the highest water tables, up to an elevation of $850 \mathrm{~m}$ (see Section 6.4.8 for details). Note that for the simulations in this report, the present day water table is used for all simulation results to maintain consistency and allow comparison to the process model simulation results.

At the end of each simulation time step, FEHM collects the total radionuclide mass leaving each water table collection bin/zone and then passes the data to GoldSim (BSC 2003 [DIRS 161572]) for use as input for SZ transport simulations.

\subsection{BASE-CASE MODEL}

In this report, the base case is taken to be a case using mean radionuclide transport parameters and present day mean infiltration or glacial-transition mean infiltration. The results from this run will not be used by TSPA. This simulation activity illustrates the possible transport behavior of 
radionuclides within the UZ under the conditions of present-day or glacial-transition mean infiltration condition and mean transport parameter values. In TSPA-LA, the abstracted model will be used with different parameter combinations to study the uncertainty of parameters and flow fields on radionuclide transport through the UZ and its impacts on system performance. In addition, it should be noted that in a few instances, values for certain parameters are slightly different than those cited in the tables of Section 6.5. These differences are a result of parameter changes precipitated by reviews performed subsequent to running these example simulations. Because the changes are not expected to result in qualitatively different simulation results, and because the model runs presented below are for illustrative purposes only, it was decided that these models need not be rerun. Therefore, although the results are generally reflective of the TSPA-LA abstraction model, the intent is that these results are for illustrative purposes only, and should not be used to draw quantitative conclusions regarding the behavior of the TSPA-LA abstraction model for UZ transport. The exact parameter values used for the calculations presented below are given in the output DTN: LA0407BR831371.001.

\subsubsection{Overview}

The simulations were carried out using FEHM V2.21 (LANL 2003 [DIRS 165741]). Data used in this simulations are the mean parameter values listed in Section 6.5 Transport Model Inputs. The flow fields used in the simulations were for present-day or glacial-transition mean infiltration.

The objective of this run is to study the movement of radionuclides released from EBS into unsaturated fractured geological media downward to the water table as stated in Section 6.1.

A total of 36 species (Table 6-25) were simulated to study the transport of radionuclides in the UZ. This list of radionuclides is modified from the list given in BSC (2004 [DIRS 170022], Table 7-1). The list in Table 6-25 does not include radionuclides Ac-227, Cl-36, Cm-245, $\mathrm{Pb}-210$, Pu-241, Ra-228, Se-79, and Sn-126 identified in Table 7-1 of BSC (2004 [DIRS 170022]). Cl-36, Pb-210, Se-79, and Sn-126 are identified in Table 7-1 of BSC (2004 [DIRS 170022]) as being included only for potential use in longer-term performance assessment calculations beyond the 10,000-year regulatory period. The half-life of Ac-227 is only 22 years (BSC 2002 [DIRS 160059], Table 2). Therefore, if released from the repository, this radionuclide will decay substantially before reaching the accessible environment. Ac-227 is only included as a decay product in secular equilibrium with Pa-231 in TSPA. Cm-245, Pu-241, and Ra-228 were screened out (BSC 2002 [DIRS 160059], Table 13) and were only included as part of the radionuclide inventory to allow for ingrowth of decay products in the inventory.

As shown in Table 6-25, the decay products associated with irreversible colloids are treated as either remaining with the colloid or entering the aqueous phase. If the decay product is a radionuclide associated with irreversible colloids, i.e. isotopes of $\mathrm{Am}$ and $\mathrm{Pu}$, then the decay product remains associated with an irreversible colloid. If the decay product is a radionuclide not associated with irreversible colloids, i.e. isotopes of $U$ and $\mathrm{Np}$, then the decay product enters the aqueous phase. 
Table 6-25. Radionuclides Simulated in Base-Case Run

\begin{tabular}{|c|c|c|c|}
\hline Index & Species_Name & Half-Life (days) & $\begin{array}{c}\text { Daughter } \\
\text { Species }\end{array}$ \\
\hline 1 & C14 & $2.09 E+06$ & Simple decay \\
\hline 2 & Cs135 & $8.4 \mathrm{E}+08$ & Simple decay \\
\hline 3 & Cs137 & $1.10 \mathrm{E}+04$ & Simple decay \\
\hline 4 & I129 & $5.73 E+09$ & Simple decay \\
\hline 5 & Sr90 & $1.05 E+04$ & Simple decay \\
\hline 6 & Tc99 & $7.78 \mathrm{E}+07$ & Simple decay \\
\hline 7 & Am243 & $2.69 \mathrm{E}+06$ & 10 \\
\hline 8 & Ic243 & $2.69 E+06$ & 11 \\
\hline 9 & If 243 & $2.69 \mathrm{E}+06$ & 12 \\
\hline 10 & Pu239 & $8.80 E+06$ & 13 \\
\hline 11 & Ic239 & $8.80 E+06$ & 13 \\
\hline 12 & If239 & $8.80 \mathrm{E}+06$ & 13 \\
\hline 13 & U235 & $2.57 E+11$ & 14 \\
\hline 14 & $\mathrm{~Pa} 231$ & $1.20 \mathrm{E}+07$ & Simple decay \\
\hline 15 & Am241 & $1.58 \mathrm{E}+05$ & 18 \\
\hline 16 & Ic241 & $1.58 \mathrm{E}+05$ & 18 \\
\hline 17 & If 241 & $1.58 \mathrm{E}+05$ & 18 \\
\hline 18 & Np237 & $7.82 E+08$ & 19 \\
\hline 19 & U233 & $5.81 \mathrm{E}+07$ & 20 \\
\hline 20 & Th229 & 2.7E+06 & Simple decay \\
\hline 21 & Pu240 & $2.40 \mathrm{E}+06$ & 24 \\
\hline 22 & Ic240 & $2.40 \mathrm{E}+06$ & 24 \\
\hline 23 & If 240 & $2.40 \mathrm{E}+06$ & 24 \\
\hline 24 & U236 & $8.55 E+09$ & 25 \\
\hline 25 & Th232 & $5.11 E+12$ & Simple decay \\
\hline 26 & U232 & $2.55 E+04$ & Simple decay \\
\hline 27 & Pu242 & $1.37 \mathrm{E}+08$ & 33 \\
\hline 28 & Ic242 & $1.37 \mathrm{E}+08$ & 33 \\
\hline 29 & If242 & $1.37 \mathrm{E}+08$ & 33 \\
\hline 30 & Pu238 & $3.20 E+04$ & 34 \\
\hline 31 & Ic238 & $3.20 \mathrm{E}+04$ & 34 \\
\hline 32 & If238 & $3.20 E+04$ & 34 \\
\hline 33 & U238 & $1.63 \mathrm{E}+12$ & 34 \\
\hline 34 & U234 & $8.99 E+07$ & 35 \\
\hline 35 & Th230 & $2.75 \mathrm{E}+07$ & 36 \\
\hline 36 & Ra226 & $5.84 \mathrm{E}+05$ & Simple decay \\
\hline
\end{tabular}

Source: BSC 2004 [DIRS 170022], Table 7-1.

NOTE: Half-life data are from Table 6-23. The second column shows the species name of the radionuclides. Species with names beginning with Icxxx represent irreversible colloids traveling retarded. Species with names beginning with Ifxxx represent irreversible colloids traveling unretarded. 


\subsubsection{Base-Case Model Results}

Figure 6-18 shows the normalized cumulative breakthrough curves at water table for the 36 species simulated under the present-day mean infiltration condition, and Figure 6-19 shows the same simulation results for the glacial-transition mean infiltration condition. In these figures and others in which the term "normalized" is used, the simulation consists of a pulse input of particles, and the plot is the cumulative number of particles reaching the water table. Therefore, if all particles released from the repository reach the water table, the value will reach unity. Under the conditions of steady state flow, this integral plot represents the mass flux (normalized by the input mass flux) that would have been obtained if a constant mass flux had been input, even though the actual input was a pulse. For breakthrough curves that exceed unity, a source input at the repository is augmented by mass produced by ingrowth from the decay of a parent species. Note that for the colloid simulations, colloid filtration at matrix interfaces (Section 6.5.9) was not included in these calculations. The process model does not have this particular feature, so it was decided that, in order to make comparison with the process model results simpler, the calculations presented here should omit this process as well. However, this mechanism should be included in the TSPA-LA model.

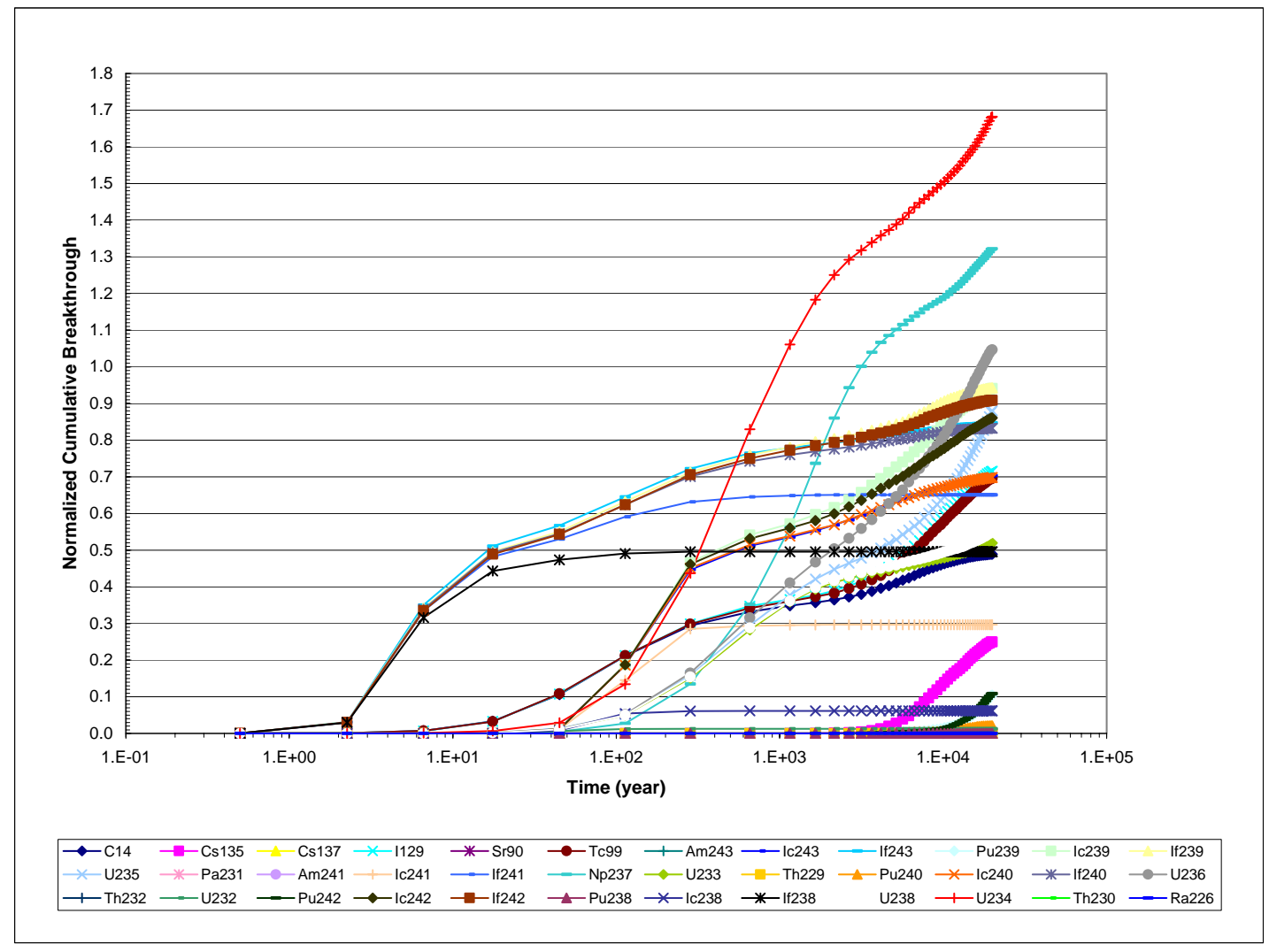

Output DTN: LA0407BR831371.001.

NOTE: These results are for comparison purposes only. Actual radionuclide mass flux reaching the water table will depend on release rates and locations, and will be simulated in the TSPA-LA model.

Figure 6-18. Base-Case Model Normalized Mass Flux at the Water Table for 36 Radionuclide Species, Present-Day Mean Infiltration Scenario, Representative Parameter Values, and PresentDay Water Table 


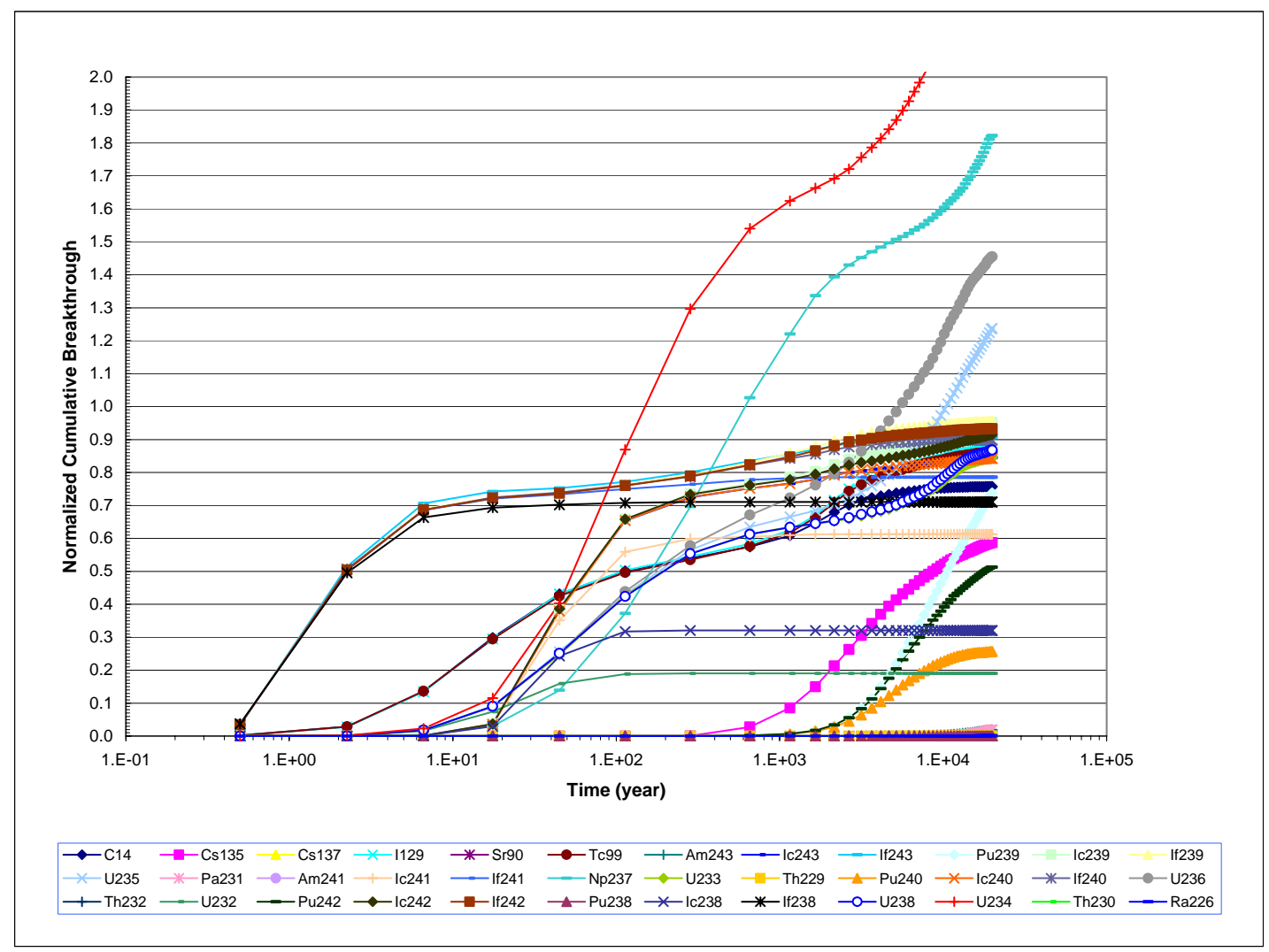

Output DTN: LA0407BR831371.001

NOTE: These results are for comparison purposes only. Actual radionuclide mass flux reaching the water table will depend on release rates and locations, and will be simulated in the TSPA-LA model.

Figure 6-19. Base-Case Model Normalized Mass Flux at the Water Table for 36 Radionuclide Species, Glacial-Transition Mean Infiltration Scenario, Representative Parameter Values, and Present-Day Water Table

For the detailed discussion of these results, the glacial-transition climate case is used to illustrate the type of transport mechanism most influencing the behavior. Beginning with colloidal species, the simulation results reveal that irreversible fast colloids (Pu-239, Am-241, Pu-242, and Am-243 in curves labeled If239, If241, If242, and If243, respectively) which are not affected by matrix diffusion and retardation, have the shortest breakthrough times and the greatest breakthrough quantities. Within a time period of less than 100 years, over 50 percent of the irreversible fast colloids traveled through the UZ.

Irreversible slow colloids which undergo retardation move more slowly than their corresponding fast colloids but faster than their corresponding dissolved species. The transport time of the irreversible slow colloids depends on their retardation factor. In TSPA-LA simulations, the retardation factors of the slow colloids will be sampled and its impact on system performance will be evaluated. For illustrative purposes, Figure 6-20 shows the combined breakthrough of the colloidal species that transport via either the "fast" or "slow" mechanisms. These results were obtained by applying the fraction of irreversible fast colloids of 1.68 E-03 (derived in Section 6.5.13), and assuming that the remaining fraction (9.98 E-01) travels via the slow 
mechanism. In the context of the regulatory time period of 10,000 years, both types of colloids travel rapidly through the UZ.

Dissolved species have longer breakthrough times than either irreversible fast colloids or irreversible slow colloids due to matrix diffusion and matrix sorption. The results (Figure 6-21) show that for nonsorbing species, like Tc-99, C-14, and I-129, about 50 percent of the mass travels through fast flow paths and arrives at the water table within roughly 100 years. The remainder of the mass traveled at much lower velocities due to matrix diffusion. Dissolved species with moderate matrix sorption, like Np-237 and the isotopes of uranium (Figure 6-22), travel more slowly through the UZ than the nonsorbing species Tc-99, C-14, and I-129. For example, within the first 100 years under the glacial-transition mean infiltration conditions, about 40 percent of the total U-233 mass passed through the UZ. U-234 exhibits a relatively fast transport process with higher mass output than the other dissolved uranium radionuclides because it is produced by the decay of a colloid facilitated species (Pu-238). Strongly sorbing species like $\mathrm{Pu}-242$ (median $\mathrm{K}_{\mathrm{d}}$ of $100 \mathrm{~mL} / \mathrm{g}$ in zeolitic, $70 \mathrm{~mL} / \mathrm{g}$ in devitrified, and $100 \mathrm{~mL} / \mathrm{g}$ in vitric layers) exhibit transport of roughly 50 percent of the input through the UZ within the 20,000 year simulation period (Figure 6-23). The most strongly sorbing species (Figures 6-24 and 6-25) such as Th-230 (mean $\mathrm{K}_{\mathrm{d}}$ of $15500 \mathrm{~mL} / \mathrm{g}$ in zeolitic, $5500 \mathrm{~mL} / \mathrm{g}$ in devitrified, and $5500 \mathrm{~mL} / \mathrm{g}$ in vitric layers) do not break through the UZ within the 20,000 year period. Finally, note that U-234 and Np-237 have normalized cumulative breakthrough values greater than 1 at 20,000 years due to the decay of Pu-238 (Pu238, If238, and Ic238) and Am-241 (Am241, If241, and Ic241), respectively. For completeness, several species not presented in other plots are also shown in Figure 6-25.

For comparison, the case run under the present-day mean infiltration condition (Figure 6-19) reveals that, for example, significantly less Tc-99 breaks through at the water table under the present-day infiltration condition. This indicates that fast water flow under wetter infiltration conditions reduces the effect of matrix diffusion and transport radionuclides through the UZ within the simulation time period of 20,000 years, whereas transport times are expected to be longer under present-day conditions.

With regard to colloid transport, the simulation results suggest that colloids can play an important role in accelerating the transport of radionuclides in the UZ, especially the irreversible fast colloids. Of course, if the quantity of colloids is low, the impact on dose would not be expected to be important. In TSPA-LA calculations, a conservative percentage of colloids will be selected to study its impact on dose. For irreversible slow colloids, the retardation factor should be sampled to investigate parameter uncertainty on system performance.

Matrix diffusion and matrix sorption can play an important role in retarding the movement of dissolved radionuclides and could significantly impact dose predictions. The strength of fracture-matrix interaction due to matrix diffusion and sorption depends on matrix diffusion coefficient, matrix sorption coefficient, fracture spacing, and fracture aperture. In TSPA-LA calculations, those parameters will be sampled based on uncertainty distributions, and the impact on system performance of these uncertainties will be quantified. Another important factor that controls the transport process is infiltration rate. The impact of climate changes on system performance will be investigated using different flow fields developed in the report by BSC (2004 [DIRS 169861]) and DTN: LB0305TSPA18FF.001 [DIRS 165625]. These flow fields 
have different amounts of fracture and matrix flow, and water table elevation changes will also be included (see Section 6.4.8). Based on the results presented here, under the wetter climate conditions, radionuclide transport velocities will increase during the wetter climates due to increased infiltration, greater fracture flow, and less pervasive matrix diffusion.

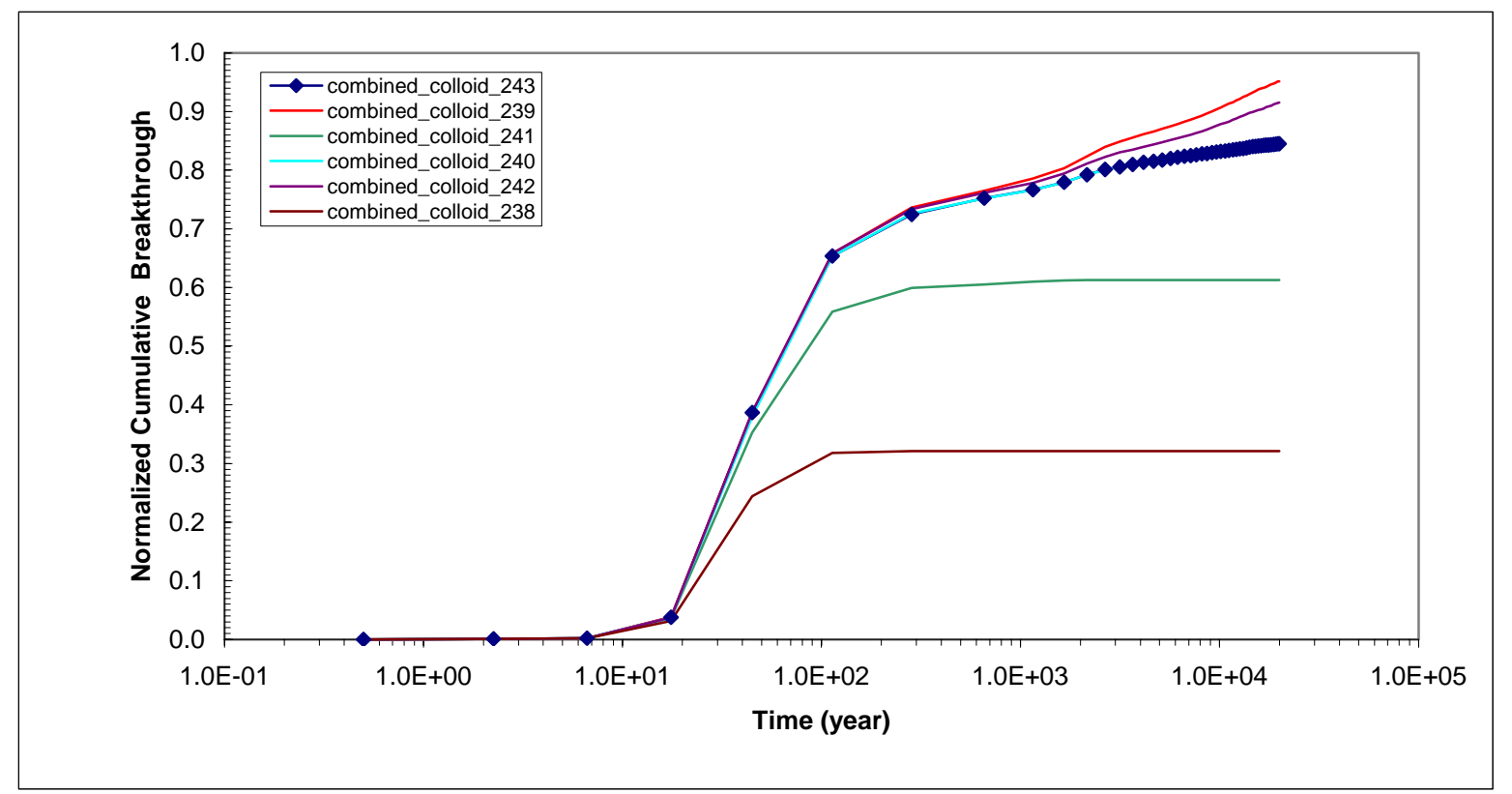

Output DTN: LA0407BR831371.001.

NOTE: These results are for comparison purposes only. Actual radionuclide mass flux reaching the water table will depend on release rates and locations, and will be simulated in the TSPA-LA model.

Figure 6-20. Base-Case Model Normalized Mass Flux at the Water Table for Combined Irreversible Fast and Irreversible Slow Colloids, Glacial-Transition Mean Infiltration Scenario, Representative Parameter Values, and Present-Day Water Table 


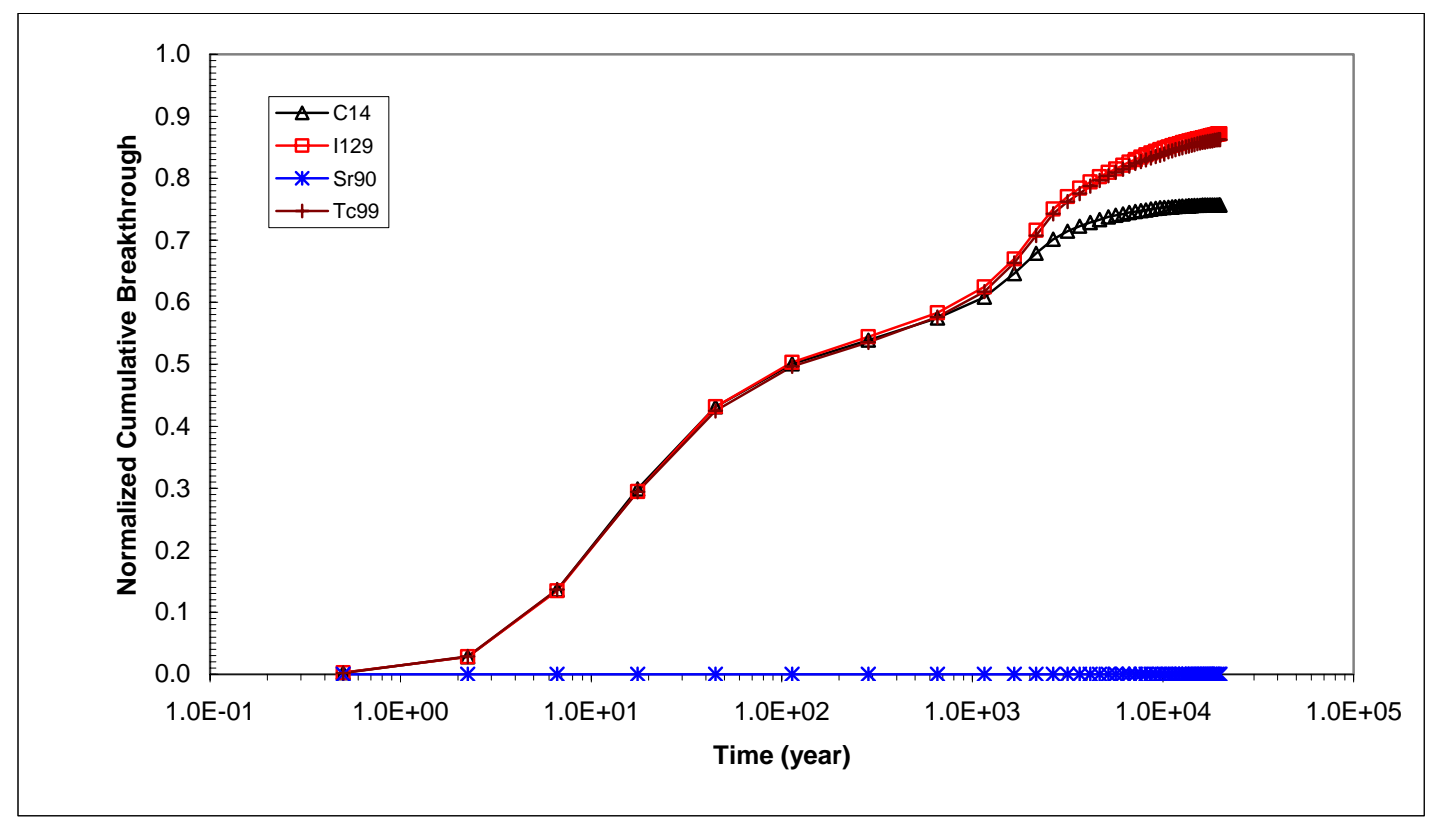

Output DTN: LA0407BR831371.001.

NOTE: These results are for comparison purposes only. Actual radionuclide mass flux reaching the water table will depend on release rates and locations, and will be simulated in the TSPA-LA model.

Figure 6-21. Base-Case Model Normalized Mass Flux at the Water Table for Conservative Radionuclides and Sr-90, Glacial-Transition Mean Infiltration Scenario, Representative Parameter Values, and Present-Day Water Table 


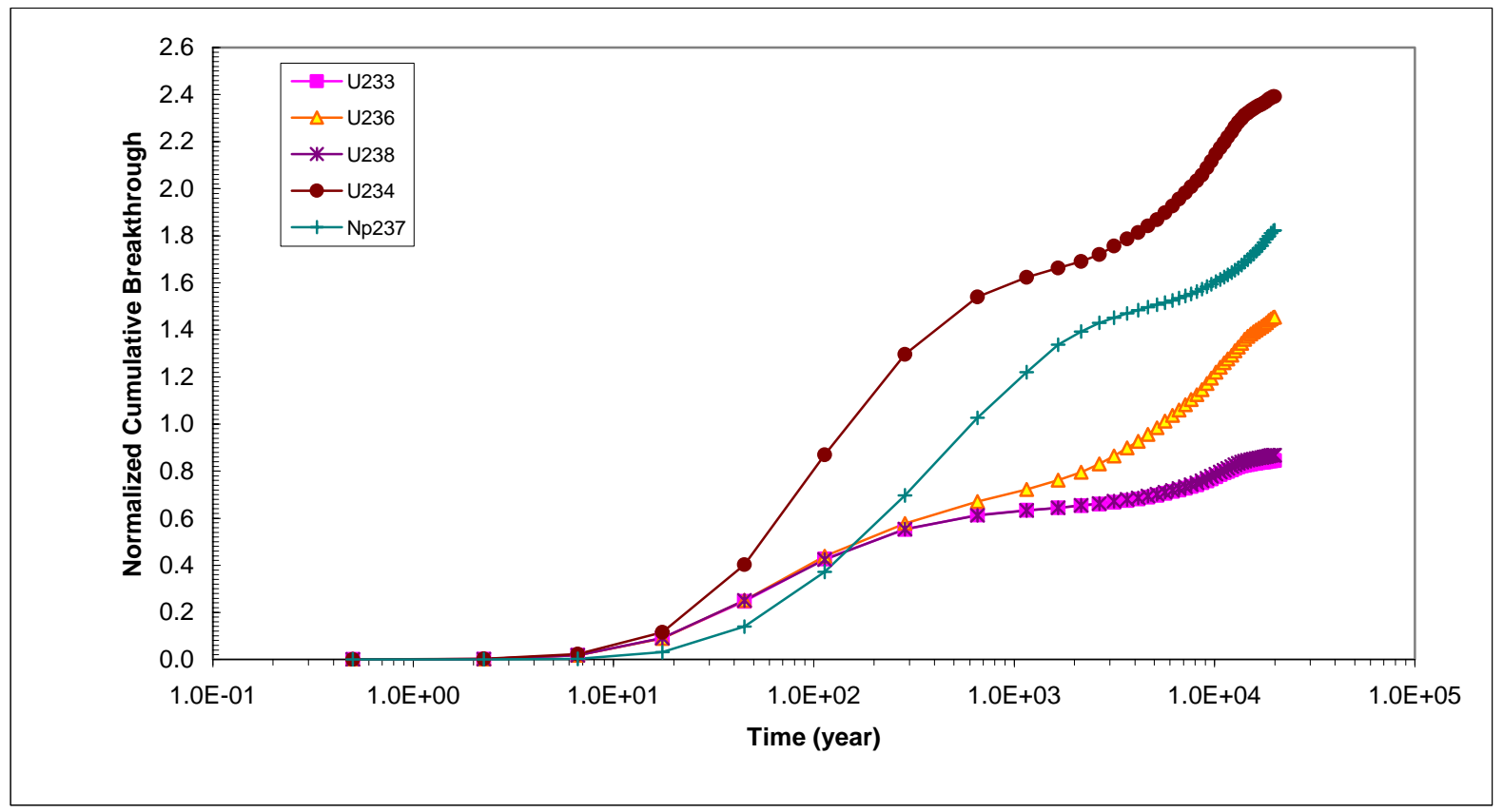

\section{Output DTN: LA0407BR831371.001.}

NOTE: These results are for comparison purposes only. Actual radionuclide mass flux reaching the water table will depend on release rates and locations, and will be simulated in the TSPA-LA model.

Figure 6-22. Base-Case Model Normalized Mass Flux at the Water Table for Moderately Sorbing Radionuclides, Glacial-Transition Mean Infiltration Scenario, Representative Parameter Values, and Present-Day Water Table 


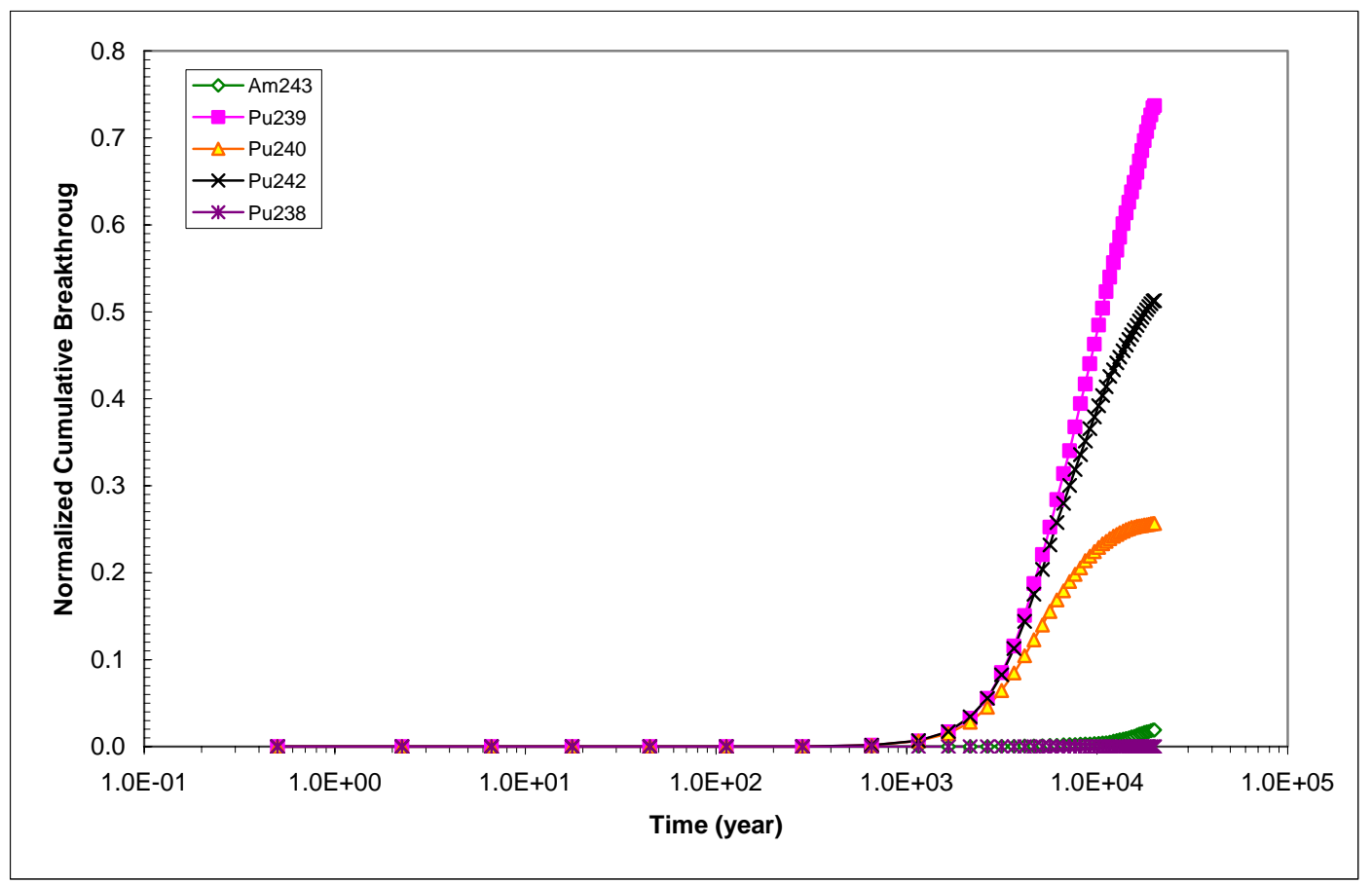

Output DTN: LA0407BR831371.001.

NOTE: These results are for comparison purposes only. Actual radionuclide mass flux reaching the water table will depend on release rates and locations, and will be simulated in the TSPA-LA model.

Figure 6-23. Base-Case Model Normalized Mass Flux at the Water Table for Aqueous Species of Americium and Plutonium, Glacial-Transition Mean Infiltration Scenario, Representative Parameter Values, and Present-Day Water Table 


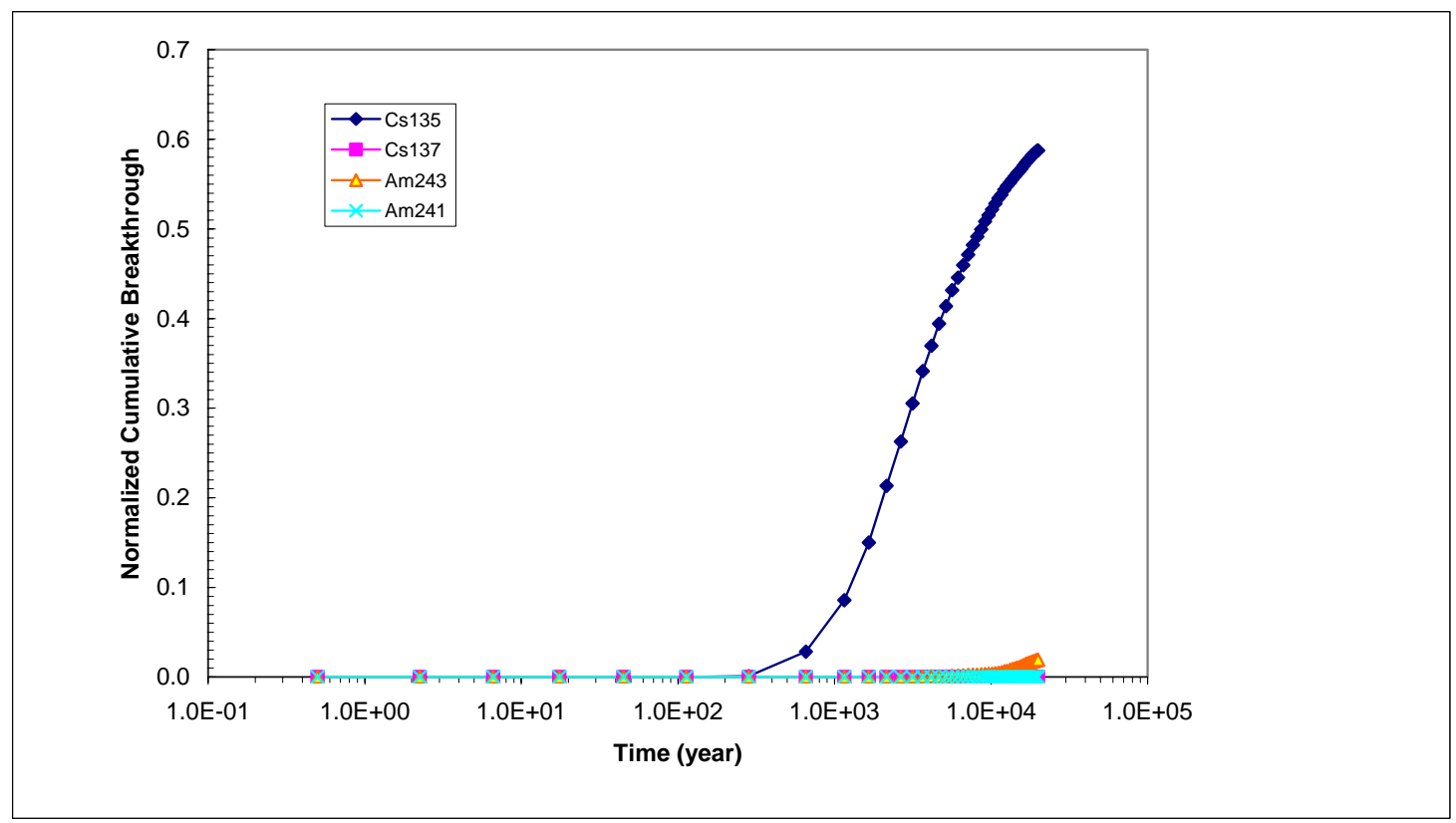

Output DTN: LA0407BR831371.001.

NOTE: These results are for comparison purposes only. Actual radionuclide mass flux reaching the water table will depend on release rates and locations, and will be simulated in the TSPA-LA model.

Figure 6-24. Base-Case Model Normalized Mass Flux at the Water Table for Aqueous Species of Cesium and Americium, Glacial-Transition Mean Infiltration Scenario, Representative Parameter Values, and Present-Day Water Table 


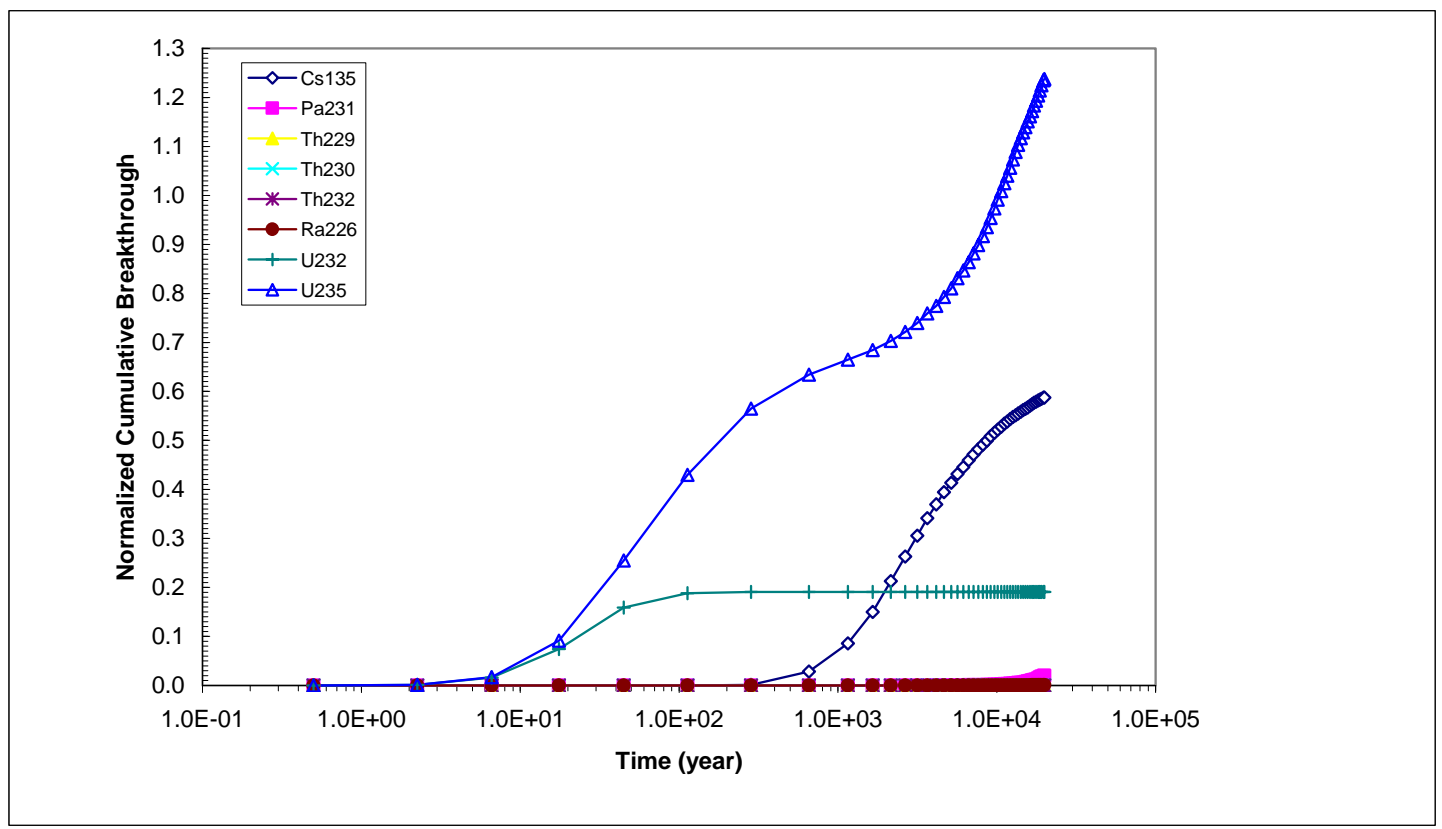

Output DTN: LA0407BR831371.001.

NOTE: These results are for comparison purposes only. Actual radionuclide mass flux reaching the water table will depend on release rates and locations, and will be simulated in the TSPA-LA model.

Figure 6-25. Base-Case Model Normalized Mass Flux at the Water Table for Various Moderately to Strongly Sorbing Radionuclides, Glacial-Transition Mean Infiltration Scenario, Representative Parameter Values, and Present-Day Water Table 


\subsection{EVALUATION OF ALTERNATIVE MODELS AND MODEL UNCERTAINTY}

Geological, hydrological, and geochemical data have been used to support parameters, used in conceptual models, process-level models, and alternative conceptual models, considered in the abstraction of radionuclide transport in the UZ. These traceable, well-documented data have been used to support the technical bases for FEPs that have been included in the abstraction of radionuclide transport in the UZ (Table 6-1). As discussed in the radionuclide transport process model (BSC 2004 [DIRS 164500]) on which this abstraction model is based, a conservative model approach has been used to address conceptual model or processes uncertainty (Table 6-26). The selected conceptual model of radionuclide transport in the UZ is conservative, and supported by available data and current scientific understanding.

Radionuclide Transport Models Under Ambient Conditions (2004 [DIRS 164500]) discusses alternative conceptual radionuclide transport models involving:

- Different representations of the matrix-fracture system - multiple interactive continua, (MINC) versus dual-k systems

- Different conceptual methods of describing the transport problem (Particle tracking versus conventional representation in control-volume finite element codes).

In the MINC method, the steep gradients at the matrix fracture surface are resolved by including additional grids in the matrix in an appropriate number of nested shells. This is based on the concept that rapid changes at the fracture-matrix interface will propagate rapidly through the fracture system, while invading the tight matrix comparatively slowly (steep gradient to the inside of matrix block). The MINC behavior results in later breakthrough times (as the enhanced $\mathrm{f} / \mathrm{m}$ interaction allows for increased diffusion), longer contact times, and more effective sorption (in sorbing media/solute systems). In the report by BSC (2004 [DIRS 164500]), the MINC model response [using both T2R3D V1.4 (LBNL 1999 [DIRS 146654]) and TOUGH2 V1.11 MEOS9nTV1.0 (LBNL 1999 [DIRS 113943]) was compared to UZ transport models employing a particle-tracking-based numerical method, Dual Continuum Particle Tracking Computer Code (DCPT) V2.0 (LBNL 2002 [DIRS 154342]). The results of those simulations are presented in Section 7 (Figure 7-7). The result with the MINC grid conforms to expectations, resulting in later breakthrough times, when matrix diffusion is significant. However, despite its conceptual appeal, the application of the MINC concept to the three-dimensional UZ site-scale model would incur a large computational burden because it necessitates replacement of the single matrix block in the current dual-k system with several MINC subdomains. The validation conducted in Section 7 shows that the FEHM particle-tracking code replicates behavior similar to that of the MINC model when transfer functions developed using a DFM are used. By contrast, when transfer functions are developed with a dual-k formulation, behavior similar to that of the dual-k process model are obtained. Therefore, these ACMs can both be examined at the total-system level using the UZ transport abstraction model.

Table 6-26 gives a summary of alternative conceptual models and processes, and the recommended disposition for the TSPA-LA transport abstraction. 
Table 6-26. Summary of Alternative Conceptual Model Processes and Their Dispositions for the TSPA-LA

\begin{tabular}{|c|c|c|c|}
\hline $\begin{array}{c}\text { Alternative Conceptual } \\
\text { Model }\end{array}$ & Key Assumptions & $\begin{array}{c}\text { Summary of Subsystem } \\
\text { Evaluation }\end{array}$ & $\begin{array}{c}\text { Recommend TSPA } \\
\text { Evaluation }\end{array}$ \\
\hline $\begin{array}{l}\text { MINC model of UZ matrix, } \\
\text { alternative to single matrix } \\
\text { dual permeability model. }\end{array}$ & $\begin{array}{l}\text { More accurate models } \\
\text { concentration gradient } \\
\text { at fracture-matrix } \\
\text { interface, resulting in a } \\
\text { more accurate model of } \\
\text { matrix diffusion. }\end{array}$ & $\begin{array}{l}\text { Results in later break- } \\
\text { through times when matrix } \\
\text { diffusion is significant for } \\
\text { long-lived radionuclides. } \\
\text { MINC models not directly } \\
\text { handled by particle tracking } \\
\text { codes. }\end{array}$ & $\begin{array}{l}\text { MINC not directly used in } \\
\text { TSPA because of large } \\
\text { computation burden, but } \\
\text { FEHM particle tracking } \\
\text { transport abstraction } \\
\text { model reproduces the } \\
\text { results predicted by MINC } \\
\text { and discrete fracture } \\
\text { models. }\end{array}$ \\
\hline $\begin{array}{l}\text { Finite difference numerical } \\
\text { models EOS9nT, T2R3D, } \\
\text { and DCPT particle } \\
\text { tracking, alternative to } \\
\text { FEHM particle tracking. }\end{array}$ & $\begin{array}{l}\text { Provide a basis for } \\
\text { modeling coupled flow } \\
\text { and transport of single } \\
\text { (T2R3D) or multiple } \\
\text { radionuclides } \\
\text { (EOS9nT). }\end{array}$ & $\begin{array}{l}\text { Used primarily to provide } \\
\text { validated models of UZ } \\
\text { transport processes that } \\
\text { form the basis for the } \\
\text { abstraction models. These } \\
\text { are calibrated against a } \\
\text { variety of experimental and } \\
\text { analytical models. }\end{array}$ & $\begin{array}{l}\text { Large computational } \\
\text { burden limits use for } \\
\text { multiple realizations that } \\
\text { can provide uncertainty } \\
\text { estimates. FEHM particle } \\
\text { tracking transport } \\
\text { abstraction model can } \\
\text { reproduce the results } \\
\text { predicted by dual-k models } \\
\text { by using transfer functions } \\
\text { developed using a dual-k } \\
\text { formulation. }\end{array}$ \\
\hline $\begin{array}{l}\text { Lateral flow diversion in UZ } \\
\text { above repository, } \\
\text { alternative to no PTn } \\
\text { lateral diversion model flow } \\
\text { fields. }\end{array}$ & $\begin{array}{l}\text { Lateral flow in the PTn } \\
\text { will divert percolating } \\
\text { water to the faults and } \\
\text { reduce percolation flux } \\
\text { at repository. }\end{array}$ & $\begin{array}{l}\text { Used in UZ flow model to } \\
\text { provide evaluation of the } \\
\text { impact of lateral flow on UZ } \\
\text { flux. The steady state flow } \\
\text { fields provide basis for } \\
\text { transport simulations. }\end{array}$ & $\begin{array}{l}\text { The base case flow fields } \\
\text { used provide a basis. } \\
\text { Lateral diversion is not } \\
\text { significant at infiltrations } \\
\text { greater than } 1 \mathrm{~mm} / \text { year } \\
\text { and may be important only } \\
\text { at lower bounds of } \\
\text { infiltration ranges or in } \\
\text { areas with low infiltration. }\end{array}$ \\
\hline $\begin{array}{l}\text { No radionuclide release } \\
\text { into faults, alternative to } \\
\text { radionuclide release into } \\
\text { all repository level nodes } \\
\text { including faults. }\end{array}$ & $\begin{array}{l}\text { High fault permeability } \\
\text { leads to fast advective } \\
\text { transport of } \\
\text { radionuclide directly } \\
\text { released into faults to } \\
\text { top of TSw and to } \\
\text { water table. }\end{array}$ & $\begin{array}{l}\text { No significant effects on } \\
\text { overall transport to water } \\
\text { table even for non-sorbing } \\
\text { tracers, except for Np and } \\
\text { Pu (which already has a } \\
\text { high } \mathrm{t}_{10} \text {, the time at which } \\
10 \% \text { of the mass arrives at } \\
\text { the water table). There is } \\
\text { no effect on } \mathrm{t}_{50} \text { (the time for } \\
50 \% \text { arrival), because } \\
\text { lateral diversion redirects } \\
\text { advective flow to faults and } \\
\text { other fast flow pathways }\end{array}$ & $\begin{array}{l}\text { Conservative estimate of } \\
\text { transport times, but has } \\
\text { substantial effect on } \\
\text { radionuclide arrival at top } \\
\text { of } \mathrm{CHn} \text { (TSw39). TSPA } \\
\text { models should consider no } \\
\text { release into faults by } \\
\text { limiting the nodes into } \\
\text { which radionuclides are } \\
\text { released. }\end{array}$ \\
\hline $\begin{array}{l}\text { Include drift shadow, a } \\
\text { capillary diversion, } \\
\text { alternative to no drift } \\
\text { shadow effects. }\end{array}$ & $\begin{array}{l}\text { Capillary diversion } \\
\text { even under ambient } \\
\text { conditions may result in } \\
\text { low fracture saturation } \\
\text { below the drift (drift } \\
\text { shadow) that may } \\
\text { persist for years. }\end{array}$ & $\begin{array}{l}\text { Drift shadow may develop } \\
\text { and remain only under low } \\
\text { infiltration. Seepage } \\
\text { through fractures may be } \\
\text { significant after climate } \\
\text { change. }\end{array}$ & $\begin{array}{l}\text { Ignoring drift shadow is a } \\
\text { conservative assumption } \\
\text { of transport in the UZ. }\end{array}$ \\
\hline
\end{tabular}


Table 6-26. Summary of Alternative Conceptual Model Processes and Their Dispositions for the TSPA-LA (Continued)

\begin{tabular}{|l|l|l|l|}
\hline \multicolumn{1}{|c|}{$\begin{array}{c}\text { Alternative Conceptual } \\
\text { Model }\end{array}$} & \multicolumn{1}{|c|}{ Key Assumptions } & $\begin{array}{l}\text { Summary of Subsystem } \\
\text { Evaluation }\end{array}$ & \multicolumn{1}{|c|}{$\begin{array}{c}\text { Recommend TSPA } \\
\text { Evaluation }\end{array}$} \\
\hline $\begin{array}{l}\text { Perched water } \\
\text { permeability barrier zones } \\
\text { below the repository, } \\
\text { alternative to no perched } \\
\text { water permeability barrier } \\
\text { (continuous and well- } \\
\text { connected fractures). }\end{array}$ & $\begin{array}{l}\text { Perched water will } \\
\text { delay and dilute } \\
\text { radionuclide } \\
\text { concentration and } \\
\text { reduce advective } \\
\text { transport. }\end{array}$ & $\begin{array}{l}\text { Continuous well connected } \\
\text { fractures are used to model } \\
\text { transport processes using } \\
\text { the particle tracking } \\
\text { method. The flow fields } \\
\text { from the UZ account for } \\
\text { perched water effects. }\end{array}$ & $\begin{array}{l}\text { Perched water may only } \\
\text { be present in the northern } \\
\text { part of the repository. } \\
\text { Ignoring perched water is a } \\
\text { conservative treatment. }\end{array}$ \\
\hline $\begin{array}{l}\text { Include TH, THC, and } \\
\text { THM effects on UZ on flow } \\
\text { and transport. }\end{array}$ & $\begin{array}{l}\text { Vaporization due to } \\
\text { repository heat will } \\
\text { maintain the drift dry for } \\
\text { several hundreds to a } \\
\text { few thousand years. } \\
\text { THC and THM effects } \\
\text { may alter flow and } \\
\text { transport properties of } \\
\text { UZ rocks. }\end{array}$ & $\begin{array}{l}\text { TH, THC, and THM effects } \\
\text { are insignificant after } \\
\text { change to Glacial-Transition } \\
\text { climate, the period during } \\
\text { which transport processes } \\
\text { are dominant, following } \\
\text { release of radionuclides by } \\
\text { corrosion processes. }\end{array}$ & $\begin{array}{l}\text { Ignoring TH, THC, and } \\
\text { THM effects is a } \\
\text { conservative assumption. }\end{array}$ \\
\end{tabular}

Source: BSC 2004 [DIRS 169861].

$\mathrm{CHn}=$ Calico Hills nonwelded hydrogeologic; DCPT=Dual Continuum Particle Tracking Computer Code; FEHM=finite element heat and mass (model); MINC=matrix-fracture system - multiple interactive continua; $\mathrm{TH}=$ thermal-hydrologic; THC=thermal-hydrologic-chemical; THM=thermal-hydrologic-mechanical; TSPA=total system performance assessment; TSw=Topopah Spring welded unit; UZ=unsaturated zone

\subsection{DESCRIPTION OF BARRIER CAPABILITY}

The UZ units below the repository are barriers that delay and limit radionuclide movement to the water table due to a variety of natural processes influenced by local hydrological, the intrinsic characteristics of the rocks, and by the repository design. A full treatment of the barrier capability is presented in the report by BSC (2004 [DIRS 164500]); a condensed summary is given below. The major large-scale processes included in this TSPA abstraction model are:

1. The limited and low rate of flow of water through the UZ, which limits the rate at which radionuclides can move by advection out of the repository: included through the use of UZ model flow and transport properties and steady state flow fields (Section 6.5.1).

2. Sorption, which chemically binds radionuclides to minerals in the rock matrix: included by explicit modeling of sorption processes (Section 6.5.4).

3. Matrix diffusion, which physically traps and delays radionuclides within the rock matrix: included by explicit modeling of molecular and colloidal diffusion in the abstraction of transport (Section 6.5.5).

Other processes that operate at a more local scale also contribute to UZ ability to limit water movement and radionuclide transport. Examples include the diversion of flowing water around drift openings in the UZ by capillary suction and the dryout zone of the region surrounding 
repository drifts by heat associated with emplacement waste. These processes are beyond the scope of this report, which treats only mountain-scale radionuclide transport.

On the other hand, colloidal transport of radionuclides has the potential to offset the effectiveness of both sorption and matrix diffusion by providing a mechanism for transport of radionuclides that have very low solubility limits. Radionuclides can be transported as intrinsic (true) colloids (fine particles 1 to 10,000 nm) of elemental particles e.g., Plutonium. They can also be transported as pseudo colloids i.e., bound to naturally occurring fine particles. The size of the colloids determines their ability to be excluded or filtered by matrix pores, and transported by fracture advection and dispersion processes. The effect of colloidal transport is discussed in the document by BSC (2004 [DIRS 164500]) and is accounted for in this TSPA abstraction of UZ transport (Sections 6.5.9 to 6.5.13).

\subsubsection{Analyses of Barrier Capability}

The breakthrough times provide a quantitative assessment of the ability of the UZ to delay (retard) the transport of radionuclides to the accessible environment. An example set of calculations from the UZ transport process model (BSC 2004 [DIRS 164500]) is reproduced in Tables 6-27, 6-28, and 6-29 for aqueous and colloidal radionuclide species. The sorption and diffusion parameters used in these simulations are given in Tables 6-3 and 6-4 in the report by BSC (2004 [DIRS 164500]). The $t_{10}$ (time for 10 percent arrival) and $t_{50}$ (time for 50 percent arrival) values for solute and colloidal transport, are presented for representative radionuclides, and combinations of three climate states, three infiltration cases, and the two release scenarios (instantaneous and continuous). At repository closure, short lived radionuclides such as strontium-90 and cesium-137 will be reduced to a small fraction of their initial inventory long before they could be transported through the UZ. For long lived radionuclides, models provide a means for assessing the effectiveness of the UZ to delay and retard (by slow advection, sorption and diffusion) their transport through the UZ. For strongly sorbing radionuclides like plutonium-239, the rate of movement is retarded so much that there is virtually no breakthrough before 10,000 years for the mean infiltration case. For weakly sorbing radionuclides such as neptunium-237, radionuclide transport is retarded for at least 1,000 years. For the long-lived

nonsorbing radionuclides like ${ }^{99} \mathrm{Tc}$, the rate of transport is dictated by matrix diffusion and advective transport. However, even these require 3,000 to 4,000 years to move through the UZ (BSC 2004 [DIRS 164500]). 
Table 6-27. Radionuclide Transport Times in Years to the Water Table for Instantaneous Release

\begin{tabular}{|c|c|c|c|c|c|c|c|}
\hline \multirow[b]{2}{*}{ Radionuclide } & \multirow{2}{*}{$\begin{array}{c}\begin{array}{c}\text { Climatel } \\
\text { Infiltration }\end{array} \\
\text { Case }\end{array}$} & \multicolumn{2}{|c|}{ Present-Day } & \multicolumn{2}{|c|}{ Monsoon } & \multicolumn{2}{|c|}{ Glacial-Transition } \\
\hline & & $\begin{array}{c}T_{10} \\
\text { (Years) }\end{array}$ & $T_{50}$ (Years) & $T_{10}$ (Years) & $T_{50}$ (Years) & $T_{10}$ (Years) & $T_{50}$ (Years) \\
\hline \multirow[t]{3}{*}{${ }^{241} \mathrm{Am}$} & Lower & - & - & - & - & - & - \\
\hline & Mean & - & - & - & - & - & - \\
\hline & Upper & 12 & - & 3 & - & 1 & - \\
\hline \multirow[t]{3}{*}{${ }^{237} \mathrm{~Np}$} & Lower & 33,800 & $>1,000,000$ & 15 & 6,160 & 185 & 34,400 \\
\hline & Mean & 410 & 25,400 & 8 & 2,120 & 4 & 1,070 \\
\hline & Upper & 4 & 1,600 & 2 & 714 & 1 & 336 \\
\hline \multirow[t]{3}{*}{${ }^{231} \mathrm{~Pa}$} & Lower & - & - & - & - & - & - \\
\hline & Mean & - & - & - & - & - & - \\
\hline & Upper & 13 & - & 4 & - & 2 & - \\
\hline \multirow[t]{3}{*}{${ }^{239} \mathrm{Pu}$} & Lower & - & - & 86,000 & - & - & - \\
\hline & Mean & - & - & 10,400 & - & 3,710 & - \\
\hline & Upper & 1,530 & - & 4 & - & 2 & - \\
\hline \multirow[t]{3}{*}{${ }^{226} \mathrm{Ra}$} & Lower & - & - & - & - & - & - \\
\hline & Mean & - & - & - & - & - & - \\
\hline & Upper & - & - & - & - & 3 & - \\
\hline \multirow[t]{3}{*}{${ }^{90} \mathrm{Sr}$} & Lower & - & - & - & - & - & - \\
\hline & Mean & - & - & - & - & - & - \\
\hline & Upper & - & - & - & - & 3 & - \\
\hline \multirow[t]{3}{*}{${ }^{99} \mathrm{Tc}$} & Lower & 13,900 & $>1,000,000$ & 22 & 1,310 & 102 & 8,140 \\
\hline & Mean & 83 & 6,640 & 9 & 417 & 6 & 164 \\
\hline & Upper & 6 & 230 & 2 & 92 & 1 & 42 \\
\hline \multirow[t]{3}{*}{${ }^{229} \mathrm{Th}$} & Lower & - & - & - & - & - & - \\
\hline & Mean & - & - & - & - & - & - \\
\hline & Upper & - & - & 4 & - & 2 & - \\
\hline \multirow[t]{3}{*}{${ }^{233} \mathrm{U}$} & Lower & 65,200 & $>1,000,000$ & 103 & 6,730 & 549 & 36,900 \\
\hline & Mean & 433 & 29,100 & 34 & 2,130 & 16 & 893 \\
\hline & Upper & 12 & 1,120 & 3 & 458 & 2 & 208 \\
\hline \multirow[t]{3}{*}{${ }^{235} U$} & Lower & 55,300 & $>1,000,000$ & 101 & 6,480 & 540 & 32,600 \\
\hline & Mean & 430 & 26,500 & 34 & 2,080 & 15 & 882 \\
\hline & Upper & 12 & 1,100 & 3 & 450 & 2 & 206 \\
\hline \multirow[t]{3}{*}{${ }^{135} \mathrm{Cs}$} & Lower & $>1,000,000$ & $>1,000,000$ & 22,400 & $>1,000,000$ & 150,000 & $>1,000,000$ \\
\hline & Mean & 52,500 & $>1,000,000$ & 4,690 & 309,000 & 2,460 & 120,000 \\
\hline & Upper & 2,170 & 71,200 & 753 & 24,500 & 305 & 990 \\
\hline
\end{tabular}

DTN: LB0307MR0060R1.007 [DIRS 164752].

Source: BSC 2004 [DIRS 164500].

NOTE: Symbol "-" indicates breakthrough at this relative arrival (i.e., either 10 percent or 50 percent) was never achieved in simulations. 
Table 6-28. Radionuclide Transport Times in Years to the Water Table for Continuous Release

\begin{tabular}{|l|l|c|c|}
\hline $\begin{array}{c}\text { Case } \\
\text { (Mean Infiltration/ } \\
\text { Present-Day Climate) }\end{array}$ & \multicolumn{1}{c|}{ Species } & $\boldsymbol{t}_{\mathbf{1 0}}$ (years) & $\boldsymbol{t}_{\mathbf{5 0}}$ (years) \\
\hline \multirow{2}{*}{ Three-Parents } & ${ }^{99} \mathrm{Tc}$ & 74 & 3,901 \\
\cline { 2 - 4 } & ${ }^{237} \mathrm{~Np}$ & 781 & 22,940 \\
\cline { 2 - 4 } & ${ }^{235} \mathrm{Pu}$ & - & - \\
\hline${ }^{239} \mathrm{Pu}-$ Chain & ${ }^{239} \mathrm{Pu}+{ }^{235} \mathrm{U}+{ }^{231} \mathrm{~Pa}$ & $319^{*}$ & $33,660^{*}$ \\
\hline${ }^{241} \mathrm{Am}-$ Chain & ${ }^{241} \mathrm{Am}+{ }^{237} \mathrm{~Np}+{ }^{233} \mathrm{U}+{ }^{229} \mathrm{Th}$ & $1,027^{*}$ & $23,450^{*}$ \\
\hline
\end{tabular}

DTN: LB0307MR0060R1.007 [DIRS 164752].

Source: BSC 2004 [DIRS 164500].

${ }^{*}$ Corresponds to the sum of the chain members.

NOTE: Symbol "-" indicates breakthrough at this relative arrival (i.e., either 10 percent or 50 percent) was never achieved in simulations.

Table 6-29. Colloid Transport Times in Years to the Water Table for Continuous Release

\begin{tabular}{|c|c|c|c|}
\hline $\begin{array}{c}\text { Case } \\
\text { (Mean Infiltration/Present- } \\
\text { Day Climate) }\end{array}$ & $\begin{array}{c}\text { Colloid Size } \\
\text { (nm) }\end{array}$ & $t_{10}$ (years) & $t_{50}$ (years) \\
\hline \multirow{4}{*}{$\begin{array}{l}1 \\
\text { (no declogging, in which } \\
\text { colloids, once filtered, do } \\
\text { not detach from the } \\
\text { pore/fracture walls) }\end{array}$} & 450 & 4.35 & - \\
\hline & 200 & 4.39 & - \\
\hline & 100 & 4.53 & - \\
\hline & 6 & - & - \\
\hline \multirow{4}{*}{$\begin{array}{l}2 \\
\text { (strong kinetic declogging, } \\
\text { providing an estimate of } \\
\text { maximum colloidal transport) }\end{array}$} & 450 & 4.35 & - \\
\hline & 200 & 4.39 & - \\
\hline & 100 & 4.53 & - \\
\hline & 6 & - & - \\
\hline \multirow{4}{*}{$\begin{array}{l}\mathbf{3} \\
\text { (weak kinetic declogging, } \\
\text { approaching equilibrium } \\
\text { filtration behavior) }\end{array}$} & 450 & 4.35 & - \\
\hline & 200 & 4.39 & - \\
\hline & 100 & 4.52 & - \\
\hline & 6 & - & - \\
\hline \multirow{4}{*}{$\begin{array}{l}4 \\
\text { (same as Case 2, but the } \\
\text { fractures have the same } \\
\text { colloidal transport properties } \\
\text { as the corresponding matrix; } \\
\text { provides an estimate of the } \\
\text { importance of fractures in the } \\
\text { transport of colloids) }\end{array}$} & 450 & 32.4 & 243 \\
\hline & 200 & 27.8 & 251 \\
\hline & 100 & 27.6 & - \\
\hline & 6 & - & - \\
\hline
\end{tabular}

DTN: LB0307MR0060R1.007 [DIRS 164752].

Source: BSC 2004 [DIRS 164500].

Symbol "-" indicates breakthrough at this relative arrival (i.e. either 10 percent or 50 percent) was never achieved in simulations. 


\subsubsection{Summary of Barrier Capability}

The radionuclide transport processes model (BSC 2004 [DIRS 164500]) demonstrates that even under the conservative approach in the three-dimensional site-scale models, the UZ of Yucca Mountain is an effective barrier to the transport of the strongly sorbing radionuclides $\left({ }^{90} \mathrm{Sr},{ }^{226} \mathrm{Ra}\right.$, ${ }^{229} \mathrm{Th},{ }^{241} \mathrm{Am},{ }^{221} \mathrm{~Pa}$ and ${ }^{239} \mathrm{Pu}$ ). The variably sorbing ${ }^{135} \mathrm{Cs}$ (strongly on zeolites, much less on other rocks), the mildly sorbing ${ }^{233} \mathrm{U},{ }^{235} \mathrm{U},{ }^{237} \mathrm{~Np}$, and the nonsorbing ${ }^{99} \mathrm{Tc}$ arrive at the water table at times that are fractions of their respective half-lives. However, this is not necessarily an indication of a breached or ineffective UZ barrier, but can be a direct consequence of the conceptual model of UZ flow and of the conservative approach taken to model transport. Eliminating potential sources from the vicinity of the fault fractures appears to have a small effect on transport and arrivals at the water table. For instantaneous release, the breakthrough curves show a small increase in $t_{10}$, but $t_{50}$ is practically unchanged.

Figures 6-26 and 6-27 are plots of normalized cumulative breakthrough curves for the same 11 species listed in Table 6-27, which were simulated using the base-case abstraction model in this report. A comparison between the base-case results of this report (Figures 6-18 and 6-19) and results from the process model (Table 6-27) reveals similar behavior for radionuclide transport through the UZ. The abstraction model shows that for the base-case model it takes the colloids far less time to travel through the UZ than the corresponding dissolved species. Due to matrix diffusion, the transport process for even nonsorbing species, like Tc-99, are retarded. Under the present day mean infiltration condition, only about 10 percent of the total mass travels through the UZ within the first 40 years. By 6,000 years, about 50 percent of the Tc-99 arrives at the water table. Under the glacial-transition infiltration scenario, where the matrix diffusion effect is reduced by the fast flow in the fractures, ten percent of the Tc-99 travels through the UZ in the first 5 years, and 50 percent arrives at the water table within slightly greater than 100 years. These transport times are qualitatively similar to those for the process model presented in Table 6-27. The weakly adsorbed Np-237 had a relatively higher breakthrough value than Tc-99 due to the decay of Am-241 traveling in the form of dissolved species (Am-241), colloids with irreversible sorption but retardation (Ic241), and colloids traveling unretarded (If241). Species with short half-life (Sr-90 and Am-241) did not appear within the 10,000 year period. Clearly, these results are similar to the conclusions reached in the report by BSC (2004 [DIRS 164500]), providing further confirmation that the abstraction model is in substantial agreement with the process model.

The abstraction model results indicate that the UZ can act as an effective barrier to transport of the dissolved radionuclide species because of matrix diffusion and sorption. Fast fracture flow in the UZ can weaken the UZ barrier's capability by reducing the effectiveness of matrix diffusion. Given the current model assumptions, the UZ system is a weak barrier for the fraction of the radionuclide inventory that travels via colloid facilitated radionuclide transport, especially under the high-infiltration scenarios. Ultimately, the quality of the barrier with respect to colloids will depend on the quantity of colloids in groundwater, the sorption coefficient, matrix diffusion coefficient, and geological properties of rock layers. Monte Carlo simulations to address the uncertainty of transport process on system performance are intended to be implemented in the TSPA-LA model. 


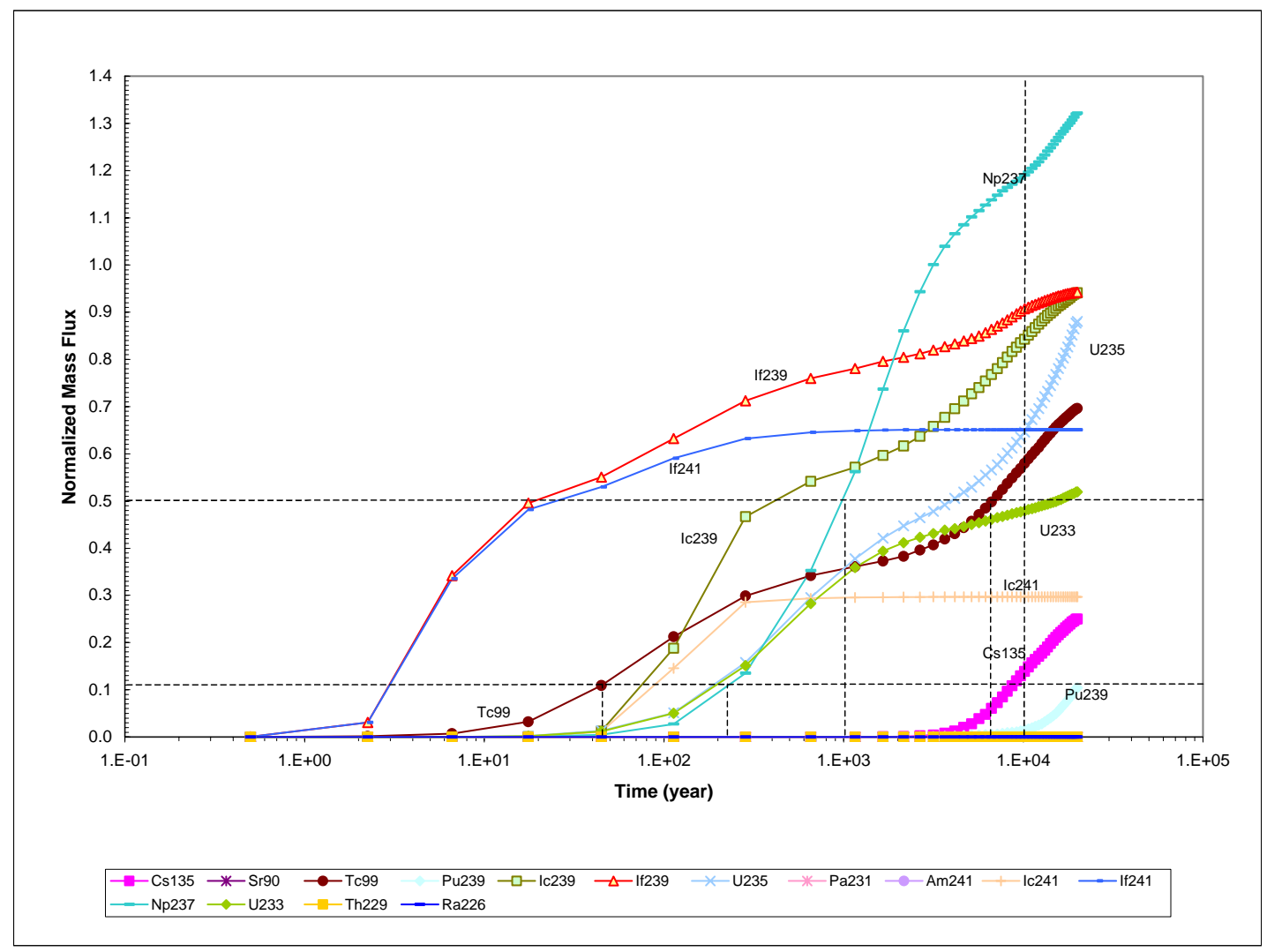

Output DTN: LA0407BR831371.001.

NOTE: $\quad$ Also shown are four breakthrough curves of colloidal forms of Pu-239 and Am-241. Ic239 and If239 are colloid species of Pu-239, and Ic241 and If241 are colloid species of Am-241.

Figure 6-26. Normalized Cumulative Breakthrough Curves of the 11 Radionuclides Under Present-Day Mean Infiltration Condition, Representative Parameter Values, and Present-Day Water Table 


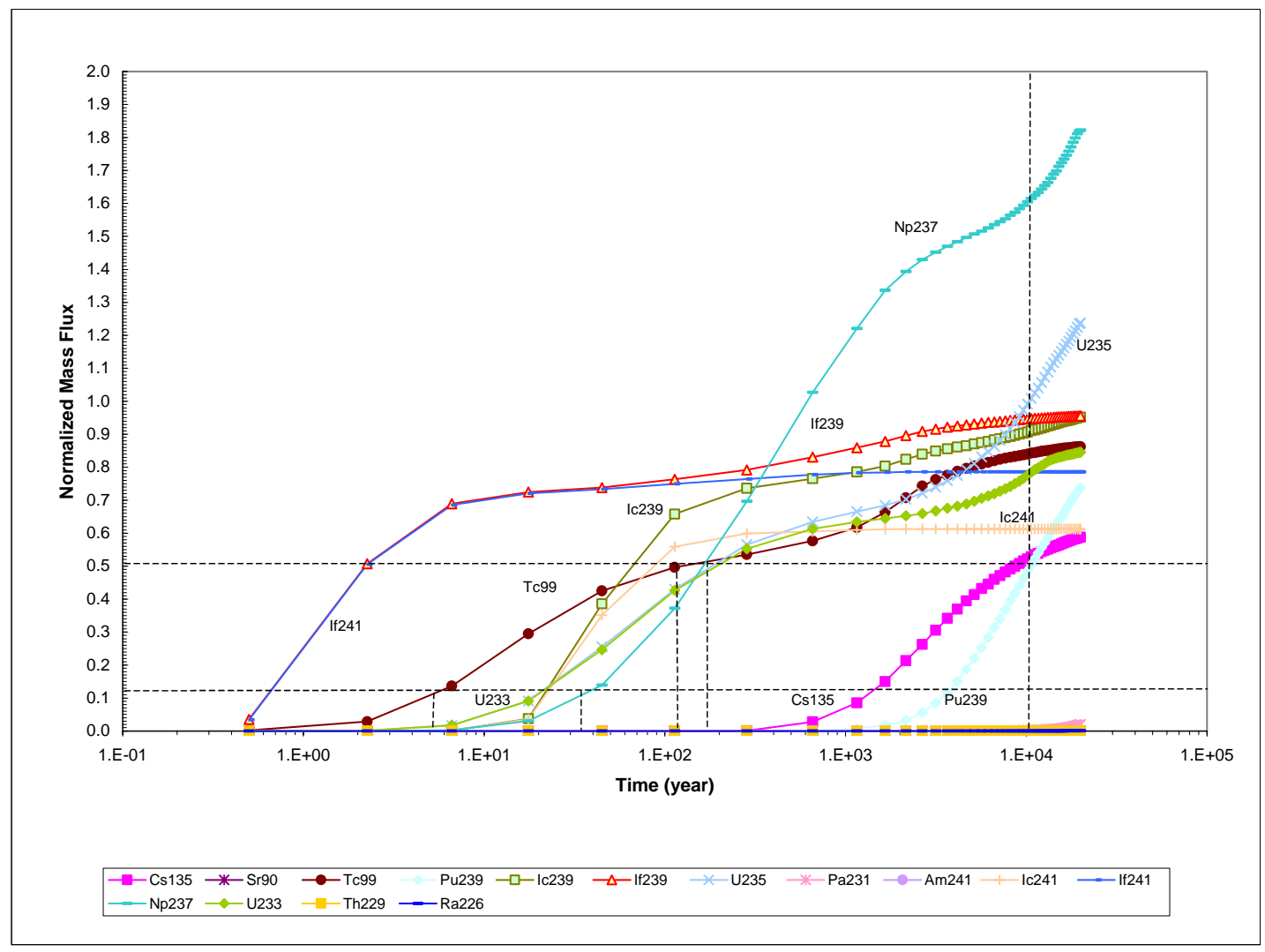

Output DTN: LA0407BR831371.001.

NOTE: $\quad$ Also shown are four breakthrough curves of colloidal forms of Pu-239 and Am-241. Ic239 and If239 are colloid species of Pu-239, and Ic241 and If241 are colloid species of Am-241.

Figure 6-27. Normalized Cumulative Breakthrough Curves of the 11 Species of Radionuclides Under Glacial-Transition Mean Infiltration Condition, Representative Parameter Values, and Present-Day Water Table 


\section{INTENTIONALLY LEFT BLANK}




\section{VALIDATION}

This section describes the validation of the UZ radionuclide transport abstraction model. This model is intended to support TSPA calculations of radionuclide transport in the UZ. AP-2.27Q, Planning for Science Activities (Attachment 3, Table 1) requires Level II validation for models supporting that TSPA component. The criteria for confidence building during model development are given in Technical Work Plan for: Unsaturated Zone Transport Model Report Integration (BSC 2004 [DIRS 171282], Section 2.2.3; BSC 2002 [DIRS 160819], Section I-2-21), consistent with AP-SIII.10Q, Models, Paragraph 5.3.2b). The general criteria for post-model development validation are given in AP-SIII.10Q, Models, Paragraph 5.3.2c). As specified in Attachment 3 of AP-2.27Q, the Level II post-development model validation must implement a single, appropriate method from this list. Section 7.1 discusses confidence building during model development which establishes the reasons for confidence in the UZ radionuclide transport abstraction model. Section 7.2 provides a detailed discussion of post-development validation activities based on corroboration with alternative models. Section 7.3 summarizes the model validation activities.

\subsection{CONFIDENCE BUILDING DURING MODEL DEVELOPMENT TO ESTABLISH THE SCIENTIFIC BASIS AND ACCURACY FOR INTENDED USE}

For confidence building during model development, Section 5.3.2(b) of AP-SIII.10Q specifies the following validation steps. Additional steps are listed in Attachment 3 of AP-2.27Q, Planning for Science Activities. The development of the UZ transport abstraction model has been conducted according to these specifications, as follows:

1. Selection of input parameters and/or input data, and a discussion of how the selection process builds confidence in the model.

[AP-SIII.10Q 5.3.2(b) (1) and AP-2.27Q Attachment Level I (a)].

The input parameters used in the abstraction process have been carefully selected from appropriate transport process models and from field and laboratory testing; they are reasonable and consistent with the data. Process model and parameter inputs to the abstraction have been discussed and evaluated in Sections 4.1 and 6.5. The process models supporting this abstraction have all been validated, typically in comparison with experimental data and through corroboration with alternative conceptual models. The boundary conditions and inputs used are appropriate; they sufficiently cover the expected conditions and ranges at Yucca Mountain, including temporal changes and spatial variability of processes and properties. Uncertainty in input parameters for this abstraction have been represented using appropriate probability distributions (Section 6.5). Percolation flux are provided through the results of the UZ Flow Model, where uncertainty is propagated through the lower, mean, and upper scenarios for each climate.

2. Description of calibration activities, and/or initial boundary condition runs, and/or run convergences, simulation conditions set up to span the range of intended use and avoid inconsistent outputs, and a discussion of how the activity or activities build confidence in the model. Inclusion of a discussion of impacts of any non-convergence runs. [(AP-SIII.10Q 5.3.2(b)(2) and AP-2.27Q Attachment 3 Level I (e)]. 
The fracture-matrix interaction submodel is developed through transfer functions that scale-up transport processes at the local scale such that they can be represented in the mountain-scale UZ transport abstraction (Section 6.4.3). This scale-up of processes helps build confidence in the model by incorporating finer-scale effects into the model results than can be directly represented in the processes operating on the mountain-scale grid. The particle tracking method is absolutely stable, so run nonconvergences are not applicable.

3. Discussion of the impacts of uncertainties to the model results including how the model results represent the range of possible outcomes consistent with important uncertainties. [AP-SIII.10Q 5.3.2(b)(3) and AP-2.27Q Attachment 3 Level 1 (d) and (f)].

Relevant sources of uncertainty related to transport parameters and flow simulation results have been characterized in and propagated through the UZ transport model abstraction (Section 6.5). Uncertainty in parameter values was identified and incorporated in the abstraction by use of probability distributions, including uncertainty identified in the upstream sources. For example, uncertainty in matrix diffusion is explicitly included by random sampling of the hydrologic characteristics that affect matrix diffusion as well as the uncorrelated uncertainty observed in measurements, while uncertainty in the future climates and percolation fluxes is accounted for by three different climate scenarios.

\section{Formulation of defensible assumptions and simplifications.} [AP-2.27Q Attachment 3 Level I (b)].

Discussion of assumptions and simplifications are provided in Section 5 and Section 6.4. The simplifications made are consistent with the purpose of this Model Report, i.e., to develop an abstraction model that simplifies the complex process of radionuclide transport in the UZ for incorporation into the TSPA-LA. These simplifications are adequate and defensible.

5. Consistency with physical principles, such as conservation of mass, energy, and momentum. [AP-2.27Q Attachment 3 Level I (c)].

The process models that provide inputs to the abstraction have been discussed and evaluated in Sections 4.1 and 6.5. Results from these upstream models and the UZ transport abstraction model presented here are consistent with physical principles, such as conservation of mass.

\subsection{POST-DEVELOPMENT MODEL VALIDATION TO SUPPORT THE SCIENTIFIC BASIS OF THE MODEL}

Requirements and criteria for post-development model validation of the UZ transport abstraction model have been developed in the TWP by BSC (2004 [DIRS 171282]), and discussed in general terms in Section 4.2, Acceptance Criterion 5. In essence, validation of this abstraction model consists of a series of visual comparisons of model results with both simple models and a full process model of the UZ. There are exceptions from the TWP (BSC 2004 [DIRS 171282], Section 2.2.3 and predecessors) in that it states that comparisons to the computer code DCPT V2.0 (LBNL 2002 [DIRS 154342]) and the analytical solution of Sudicky and Frind (1982 [DIRS 105043]) will be made. These comparisons are not included because it was determined that very similar comparisons could be made more efficiently that satisfy the criteria for validation. Therefore, the specific comparisons mentioned in the TWP (BSC 2004 
[DIRS 171282] and predecessors) are in effect satisfied in this validation by performing comparisons equivalent to the ones cited in the TWP. In particular, the requirement of a comparison to the solution of Sudicky and Frind (1982 [DIRS 105043]) is satisfied by the comparison to the DFM in Section 7.2.1.1 below, and the requirement to compare to DCPT V2.0 (LBNL 2002 [DIRS 154342]) is satisfied in the comparisons to the process model in Sections 7.2.2 and 7.2.3. These simulations are designed to summarize and augment the code verification checks that have been performed and documented in the qualification of FEHM V2.21 (see verification and validation documentation of this code: LANL 2003 [DIRS 166306]), as well as the individual tests reported in other sections of this report (for example, the decay-chain example of Section 6.4.4). Tests in the verification and validation documentation but not reproduced here include additional tests for dispersion and matrix diffusion. Validation runs under the more complex situations of interest to TSPA, namely Two-dimensional and threedimensional model domains for which process model simulations are available, are also carried out in this report. This strategy of model validation conforms with that required for Level II validation of models supporting the TSPA component (BSC 2004 [DIRS 171282], Section 2.2.1).

Three classes of comparisons are made in this validation section. The first, presented in Section 7.2.1, is a series of comparisons of the particle tracking model and a DFM. This comparison focuses on the ability of the model to adequately capture transport in a dualpermeability system under a variety of parameterizations. The series of tests is designed to demonstrate the validity of the underlying particle tracking method on a simple system. Simulations for this suite of runs can be thought of as representing the behavior of transport through an individual layer containing a small number of cells with uniform transport properties. Second, complexity is increased by comparing the particle-tracking model with simulations in a two-dimensional cross sectional model. For comparison purposes, results are available on this cross section from the report by BSC (2004 [DIRS 164500]) (DTN: LB03093RADTRNS.002 [DIRS 166071]), assuming both a dual-k and a MINC formulation to capture fracture-matrix interactions. The conceptual model for the $\mathrm{f} / \mathrm{m}$ interactions has an impact on the predicted behavior, especially for the fastest traveling portion of the solute. By using different transfer function representations (the dual-k and discrete fracture conceptual models), the model is shown to replicate the behavior of the process models employing similar conceptualizations (dual-k and MINC, respectively). Finally, the third class of comparisons uses the full three-dimensional transport model being used in TSPA-LA, thereby representing the full complexity of the UZ in terms of heterogeneities in fluid flow conditions and properties. The radionuclide Tc-99 is released at the repository horizon, and the breakthrough at the water table is recorded and compared to results from T2R3D, documented by BSC (2004 [DIRS 164500]) (DTN: LB0307MR0060R1.007 [DIRS 164752]). Results are available at the process model level only for the dual-k f/m interaction conceptualization, so direct comparisons to the particle tracking model are made for the dual-k transfer functions. Despite the fact that the dual-k formulation is ultimately recommended for use in the TSPA-LA model, the use of the DFM conceptualization in these validation studies allows a wider variety of benchmarking problems to be performed, thereby providing a more robust set of validation runs. In addition, if the DFM conceptualization is used at a later date in the TSPA model, this suite of tests confirms that the model is valid for those calculations. Finally, a sensitivity analysis shows the effect of employing the DFM conceptualization in the particle tracking model, and some qualitative tests of the implementation of the AFM in this abstraction model are presented. 
In summary, for an abstraction model, the sole activity that applies for model validation is that the model reproduces the results of other models and the process model. Therefore, the benchmarking presented below constitutes proof of the correct functioning of the model.

\subsubsection{COMPARISONS WITH DISCRETE FRACTURE MODEL}

A DFM, in which transport in a dual-permeability medium is simulated directly, is an excellent test case of the computationally simpler transport model employed in the UZ abstraction model. In the most general case, water moves in both media, as well as between the media, and solute communicates between the media as it moves through the system via molecular diffusion and advection. First, a test case for the advective movement between the fracture and matrix in such a system is presented. Then, parallel flow and transport in the two media is tested, with solute introduced into either the fracture or the matrix. To investigate the ability of the model to span a range of hydrologic conditions, a fracture-dominated flow situation (essentially 100 percent fracture flow) and a case with a 60/40 f/m flow split are used for testing. Figure 6-5 represents the model system simulated with a DFM. Transport between the media occurs via molecular diffusion, so that the breakthrough curve at the outlet of such a model is a function of the relative and absolute velocities, and the degree of diffusive communication of solute between the media. Geometric, flow, and transport parameters, listed in Table 7-1 for this suite of tests, are selected to be representative of transport conditions in the UZ at Yucca Mountain, but do not constitute an actual model of the system, merely a testing setup to enable comparisons to be made. Therefore, data sources for these values are not required. Nevertheless, because the parameters are in general in the range likely to be encountered in TSPA-LA model analyses, the model comparisons provide a good test of the correct functioning of the model.

Table 7-1. Parameter Values for Discrete Fracture Model Test Suite

\begin{tabular}{|c|c|c|c|}
\hline \multirow[b]{2}{*}{ Parameter } & \multirow[b]{2}{*}{ Symbol } & \multicolumn{2}{|c|}{ Value } \\
\hline & & Case 2 (Sect. 7.2.1.2) & Case 3 (Sect. 7.2.1.3) \\
\hline Flow Path length $(\mathrm{m})$ & $\mathrm{L}$ & 300 & 300 \\
\hline Fracture Half-Spacing $(\mathrm{m})$ & $\mathrm{B}$ & 0.5 & 0.5 \\
\hline Fracture Half-Aperture $(\mathrm{m})$ & $\mathrm{b}$ & $0.5 e-3$ & $0.5 e-3$ \\
\hline Fracture Saturation (unitless) & $\theta_{f}$ & 0.2 & 0.2 \\
\hline Matrix Water Content (unitless) & $\theta_{m}$ & 0.4 & 0.4 \\
\hline Fracture water flux (kg/s) & $f_{f}$ & $1.583 e-5$ (99\% of total) & $9.49 \mathrm{e}-6(60 \%$ of total $)$ \\
\hline Matrix water flux $(\mathrm{kg} / \mathrm{s})$ & $f_{m}$ & $1.583 e-7$ ( $1 \%$ of total) & $6.336 \mathrm{e}-6(40 \%$ of total $)$ \\
\hline Diffusion Coefficient $\left(\mathrm{m}^{2} / \mathrm{s}\right)$ & $D_{m}$ & $\begin{array}{l}\text { 1.e-30, 1.e-12, 1.e-11, 1.e- } \\
\text { 10, 1.e-9 }\end{array}$ & $\begin{array}{l}\text { 1.e-30, 1.e-12, 1.e-11, 1.e- } \\
10,1 . e-9\end{array}$ \\
\hline Matrix sorption coefficient $(\mathrm{mL} / \mathrm{g})$ & $K_{d}$ & 0 & 0 or 5 \\
\hline
\end{tabular}

For this entire set of simulations, a two-dimensional DFM with these parameters was simulated using FEHM V2.21 (LANL 2003 [DIRS 165741]) in a manner similar to that used to generate the transfer functions (see Appendix $\mathrm{C}$ ), and the resulting breakthrough curves at the outlet were processed using the software routine discrete_tf V1.1 (LANL 2003 [DIRS 165742]). For the 
simulations using the particle tracking model, a simple one-dimensional pathway is constructed consisting of ten dual-permeability cells (twenty total). The flow conditions (water contents, volumes, flow rates, etc.) were built into an FEHM restart flow field file by hand. These conditions, along with the grid files and the main FEHM input file, are read directly into the code and the transport particle tracking solution is obtained for the input flow field. This process was chosen to make this test as similar as possible to the way the code is to be used in TSPA calculations, in which flow fields are read in directly and transport is computed. Results are then postprocessed using software routine ppptrk V1.0 (LANL 2003 [DIRS 165753]).

\subsubsection{Test of Advective Transport Between Continua}

The initial test case (CASE 1) examines a situation with parallel flow in the two media, but with 90 percent fracture flux, 10 percent matrix flux for the first half of the flow path, transitioning abruptly to 60 percent fracture flux, 40 percent matrix flux for the second half of the path. Other geometric and storage parameters are the same as those listed in Table 7-1. Solute mass is input into the fracture. By turning off diffusion (which is tested separately in runs discussed later), it is trivial to determine the arrival times that the particle tracking code should produce. The early arrival represents mass that stays in the fracture, and later arrival represents the fracture transport for half of the path, and matrix transport for the remainder. In the results plotted in Figure 7-1, the vertical lines are the theoretical arrival times that the code should reproduce, and the horizontal line (at $2 / 3$, or 0.67 ) is the theoretically determined proportion of mass that should take the fracture pathways all the way through the model. The particle tracking code reproduces the theoretical behavior for advective movement between the media, thereby confirming that the code correctly routes particles on the basis of advective flow between the fracture and matrix continua. The two simulation curves in the figure are: a simulation with the diffusion model turned off completely, and a simulation with the diffusion model invoked, but the diffusion coefficient set to a low value. Despite the fact that both means for performing the simulation yield acceptable results, it is advisable to completely turn off the diffusion model if the intention is to model a solute with no diffusion. Nevertheless, this result indicates that if diffusion coefficient is set low, the model yields the correct behavior.

\subsubsection{Comparisons with Diffusion for Fracture-Dominated Flow}

Figure 7-2 (Case 2) shows the results of simulations representative of fracture-dominated flow, with 99 percent of the flow occurring in the fracture. Solute is introduced into the fracture, and the breakthrough at the end of the model is simulated. The particle tracking simulations in this and the next subsection use the DFM formulation so that the direct comparison to the DFM can be made. The description of how those transfer functions are generated is described in Section 6.4.3 and Appendix C. The simulations show that over the range from fracture-dominated transport ( $\left.\mathrm{D}=1 . \mathrm{e}-30 \mathrm{~m}^{2} / \mathrm{s}\right)$ to conditions corresponding to complete diffusive interchange between the two media ( $D=1 . e-9 \mathrm{~m}^{2} / \mathrm{s}$ ), the particle tracking model provides very close agreement with the DFM of the same system. Although it is tempting to assume that the model is simply reproducing the same curve that was provided as input in the form of a transfer function, this is not the case. In the particle-tracking model, the code executes a transfer function operation for each of the ten cells of the flow path. Each cell has a fracture transport time of one-tenth the total, meaning that the code correctly seeks the appropriate transfer function for that cell, and then predicts the overall breakthrough curve for a pathway consisting of multiple nodes. 
Deviations between the particle tracking model and the discrete fracture solution are due to the fact that the exact transfer functions for the test case are not available, and the model must find the curve with parameters closest to the desired values. This approach is therefore approximate, and relies on the code being supplied a family of transfer functions that covers the range of parameters encountered in a given simulation. Despite this limitation, this test demonstrates that the basic process for determining the transport times of individual particles through a series of connected cells is properly implemented. It also demonstrates the ability of the model to simulate the behavior for an important end-member condition, that of fracture-dominated flow.

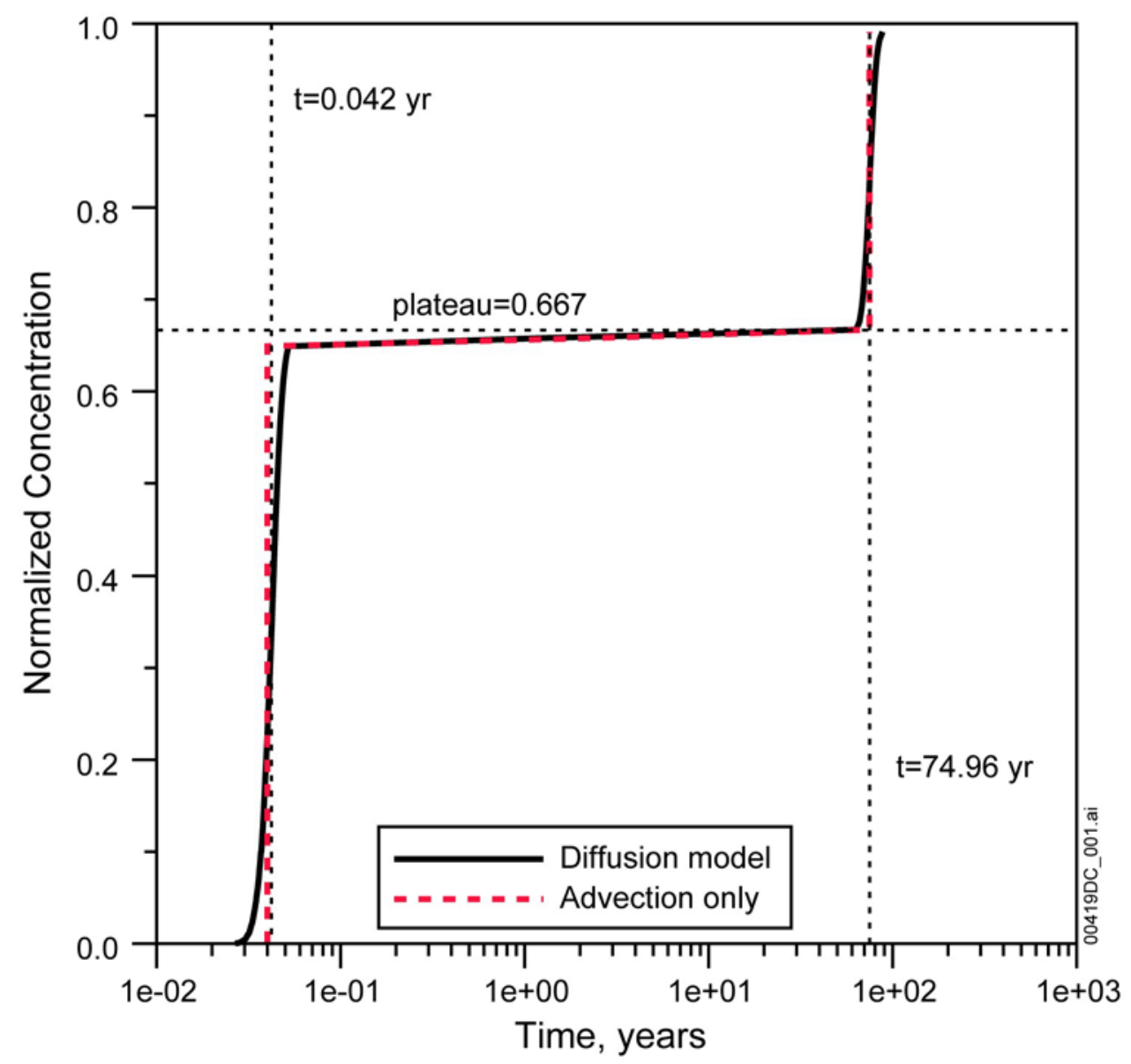

Output DTN: LA0311BR831371.001.

Figure 7-1. Particle-Tracking Abstraction Model Behavior for Advective Transport Between the Fracture and Matrix Continua: No Diffusion or Sorption, Solute Injected into the Fracture, Compared to Theoretical Results 
Nonsorbing, $D_{m}=1 . e-9,1 . e-10,1 . e-11,1 . e-12,1 . e-30$

Solute Injection into Fracture

Black - Particle Tracking; Red - Discrete Fracture Model

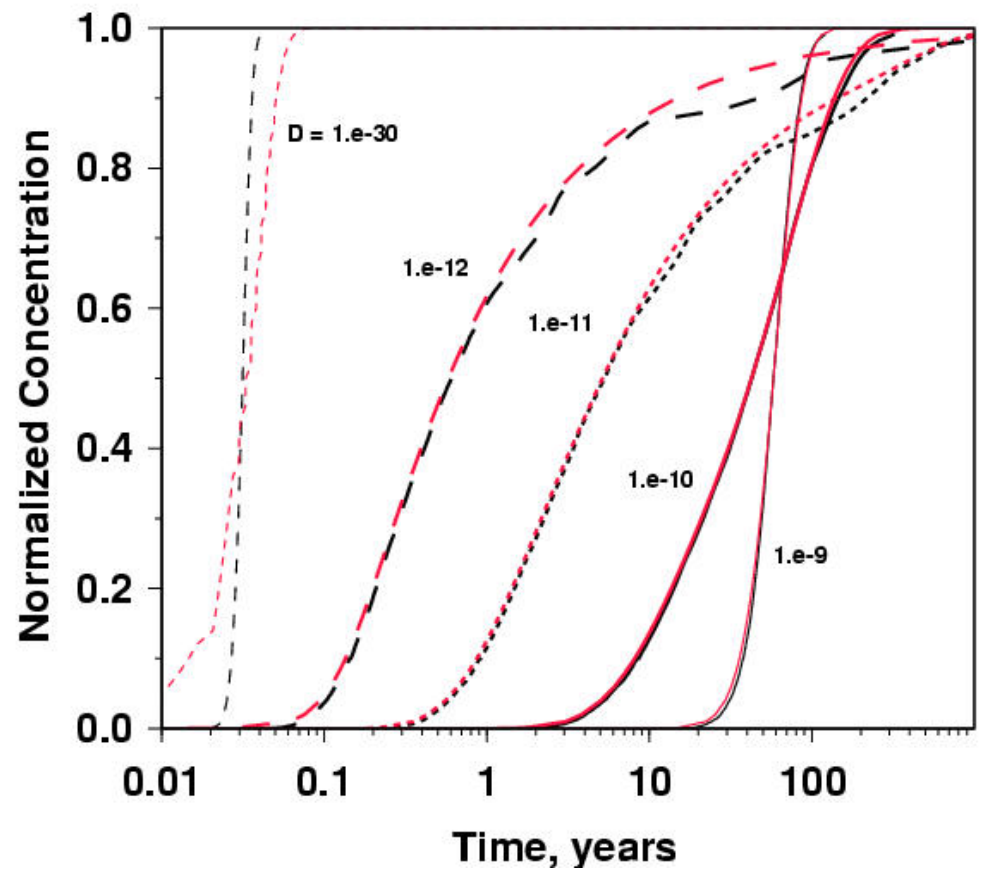

Output DTN: LA0311BR831371.001.

Figure 7-2. Comparison of Discrete Fracture Model and Particle-Tracking Abstraction Model: Non-Sorbing Solute Injected into the Fracture for Different Values of Diffusion Coefficient, $f_{f}=0.99$

\subsubsection{Comparisons with Diffusion and Sorption for Intermediate Flow Case}

Figure 7-3 (Case 3) compares the DFM and the particle tracking model for the case of more evenly divided flow in the two media (60/40 f/m flow split). Different diffusion coefficients are used, spanning the range from fracture-dominated transport to a diffusive regime in which the system is essentially behaving as a single continuum. The particle tracking model replicates the behavior adequately over the entire range of parameters. At the lower diffusion coefficients (1.e11 and 1.e-12 $\mathrm{m}^{2} / \mathrm{s}$ ), there is a slight distortion in the breakthrough curve of the particle tracking model at later times caused by the process by which particles are probabilistically shifted from one medium to the other due to the diffusive process. This is explained as follows. Consider the case in which a particle that enters a cell via the fracture is instructed by the algorithm to leave that cell via the matrix. This can occur in a low-diffusion regime for some of the solute mass. When the particle is placed in the matrix in the next cell, it is implicitly assumed to be randomly placed along the width of the matrix. In reality, for low diffusion, solute mass will reside preferentially near the fracture, so that the assumption of it being randomly placed along the matrix width is in error. This results in longer transport times for mass that shifts from fracture to matrix. The result is a tendency to predict longer transport times than is expected from a DFM. Despite this error, the initial breakthrough is captured very well, and the overall trends of the DFM are reproduced. At higher diffusion coefficients, this problem does not occur because 
the assumption of randomly distributed solute mass along the matrix width is a good one. Therefore, the important end-member of single-continuum behavior, with breakthrough times controlled by the matrix storage volume, is reproduced as well. Finally, this phenomenon is less pronounced for the fracture-dominated flow case of the previous section because fewer particles leave via the matrix for the case of low matrix flow. Although this error is reasonably small compared to the robust fashion in which the model captures the transport behavior over orders of magnitude ranges in diffusion coefficient, and the error is fairly small for either fracturedominated flow or highly diffusive transport, additional tests are conducted at the end of this section to investigate the nature of this error and document its magnitude.

Nonsorbing, $D_{m}=1 . e-9,1 . e-10,1 . e-11,1 . e-12,1 . e-30$

Solute Injection into Fracture

Black - Particle Tracking; Red - Discrete Fracture Model

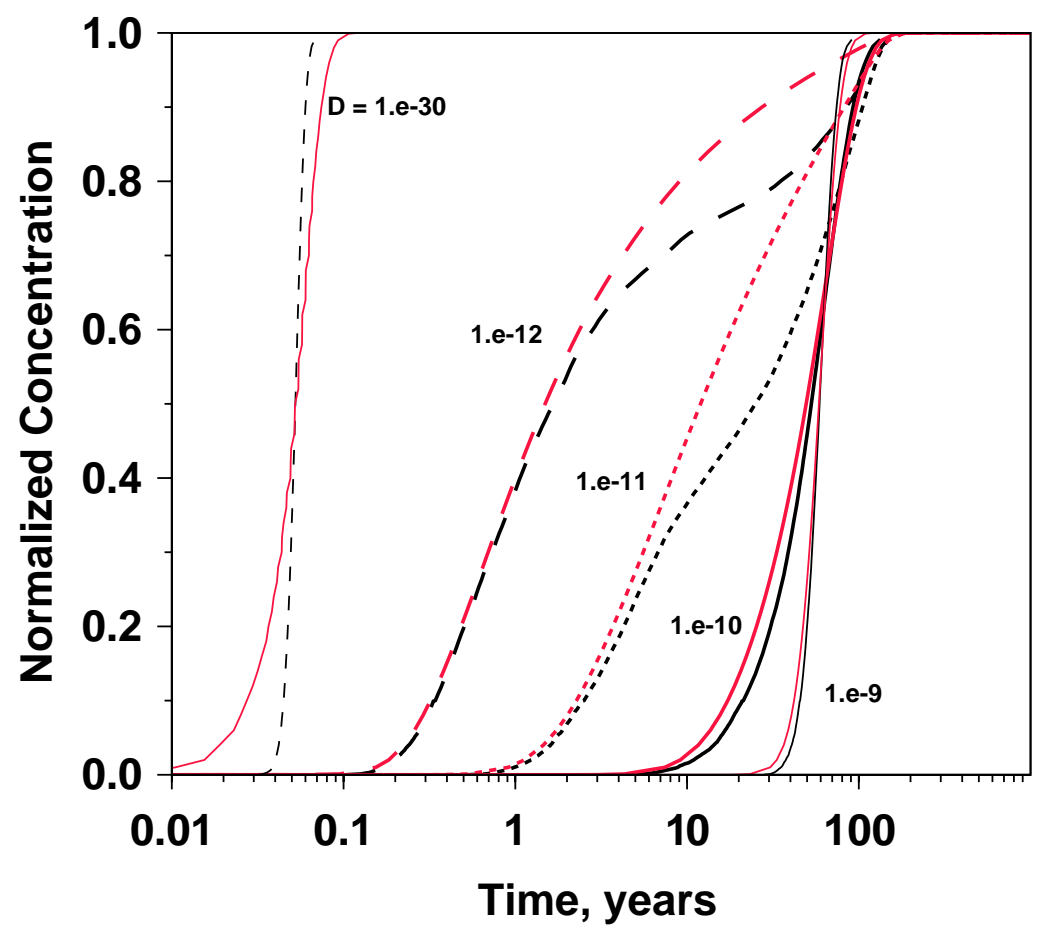

Output DTN: LA0311BR831371.001.

Figure 7-3. Comparison of Discrete Fracture Model and Particle-Tracking Abstraction Model: Non-Sorbing Solute Injected into the Fracture for Different Values of Diffusion Coefficient, $f_{f}=0.6$ 
Figure 7-4 shows a set of breakthrough curves for Case 2 with a sorbing solute of $K_{d}=5 \mathrm{cc} / \mathrm{g}$. Similar behavior is observed, with longer transport times caused by sorption of the mass that diffuses into the matrix. Similar to the nonsorbing solute comparisons, these comparisons illustrate that the model adequately captures the impact of sorption on the matrix rock. Differences similar to those observed in the nonsorbing cases are present, but the particle tracking model replicates the fracture-matrix interactions in the dual-k model over a broad range of diffusion coefficients with sorption included. Further verification of the correct implementation of the model for sorption is shown in Figures 7-5 and 7-6, which show the comparisons to the DFM for high values of $K_{d}$. At a diffusion coefficient of 1.e-11 (Figure 7-5) or 1.e-10 (Figure 7-6), the application of high values of $K_{d}$ in the model are shown to reproduce the expected behavior for the DFM.

Next, Figure 7-7 replicates the conditions of the nonsorbing simulations, except that the solute mass is introduced into the matrix. Very important features of the transport behavior predicted by the DFM are replicated quite closely in these runs. The generally longer transport times are due to the introduction of mass into the slower moving matrix flow. The nature of these results in terms of first arrivals and mean behavior can be understood as follows. When diffusion is finite but relatively low, the small portion of the solute introduced close to the fracture can diffuse into the fracture and travel rapidly to the outlet, yielding a leading edge of the breakthrough curve at short times. This important aspect of the behavior for releases into the matrix is reproduced very accurately by the particle tracking code, as evidenced by the comparison to the DFM. This leading edge is not present for higher diffusion coefficients because mass diffuses readily between the continua, making the probability of rapid transport along the entire length of the model negligibly small. However, the rise in the breakthrough curve representing the bulk of the mass arrival occurs earlier for the high-diffusion case. This can be understood by recognizing that when diffusion is large enough to allow migration of solute over distances comparable to $B$, the system becomes essentially a composite medium with an effective flow rate equal to the sum of the fracture and matrix fluxes. By contrast, at low diffusion coefficients, transport times through the matrix are governed by the matrix flux, which in this example is only 40 percent of the total. Hence, arrival times for the matrix release case and low diffusion is later than for the high-diffusion case.

Of note in these comparisons is that the particle tracking model reproduces these features quite well, with the following caveats. At later arrival times, the particle tracking and DFMs diverge, with particle tracking breakthroughs occurring earlier than the DFM breakthrough. The explanation described when explaining the differences for fracture releases applies in reverse for solute releases into the matrix. Nevertheless, the particle tracking simulations compare well overall with the DFM results, capturing the key features and the transport times for matrix releases. This comparison provides important assurance that the mass that enters the UZ transport model via EBS diffusive releases into the matrix will be properly simulated. 
Sorbing, $K_{d}=5, D_{m}=1 . e-10,1 . e-11,1 . e-12$

Solute Injection into Fracture

Black - Particle Tracking; Red - Discrete Fracture Model

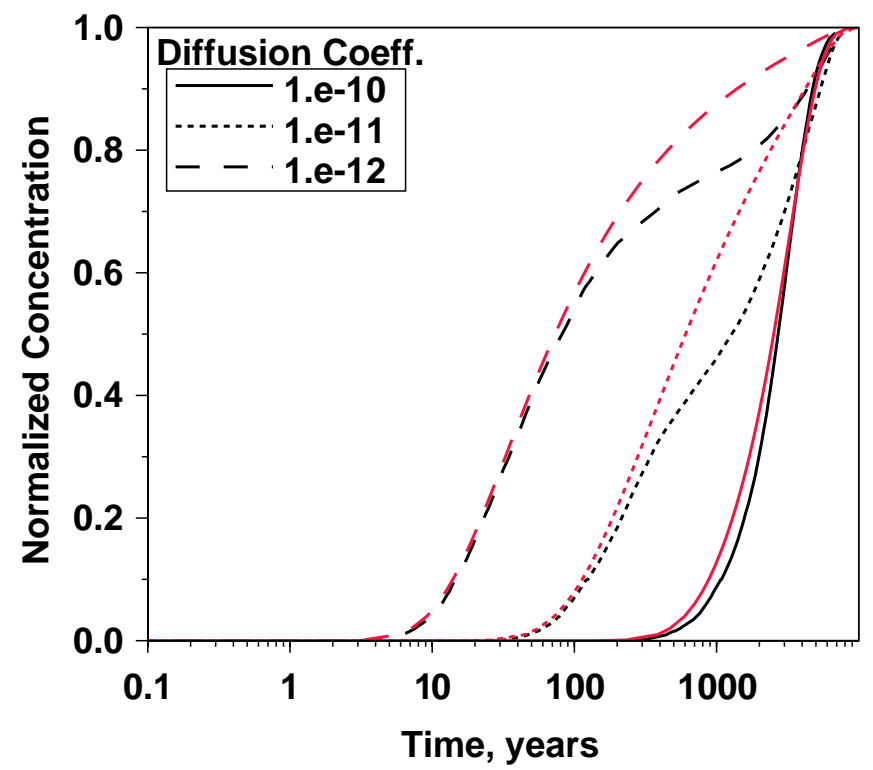

Output DTN: LA0311BR831371.001.

Figure 7-4. Comparison of Discrete Fracture Model and Particle-Tracking Abstraction Model: Sorbing Solute Injected into the Fracture for Different Values of Diffusion Coefficient

Sorbing, $K_{d}=0$ to $10000, D_{m}=1 . e-11$

Solute Injection into Fracture

Black - Particle Tracking; Red - Discrete Fracture Model

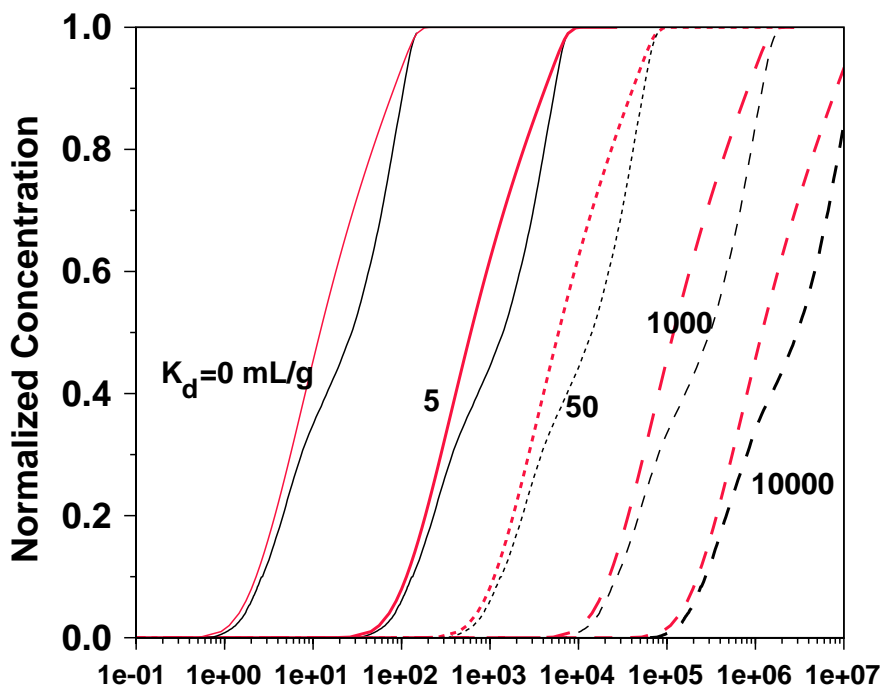

Time, years

Output DTN: LA0311BR831371.001.

Figure 7-5. Comparison of Discrete Fracture Model and Particle-Tracking Abstraction Model: Solute Injected into the Fracture for Different Values of Sorption Coefficient, $D_{m}=1$.e-11 
Sorbing, various $K_{d}, D_{m}=1 . e-10$

Solute Injection into Fracture

Black - Particle Tracking; Red - Discrete Fracture Model

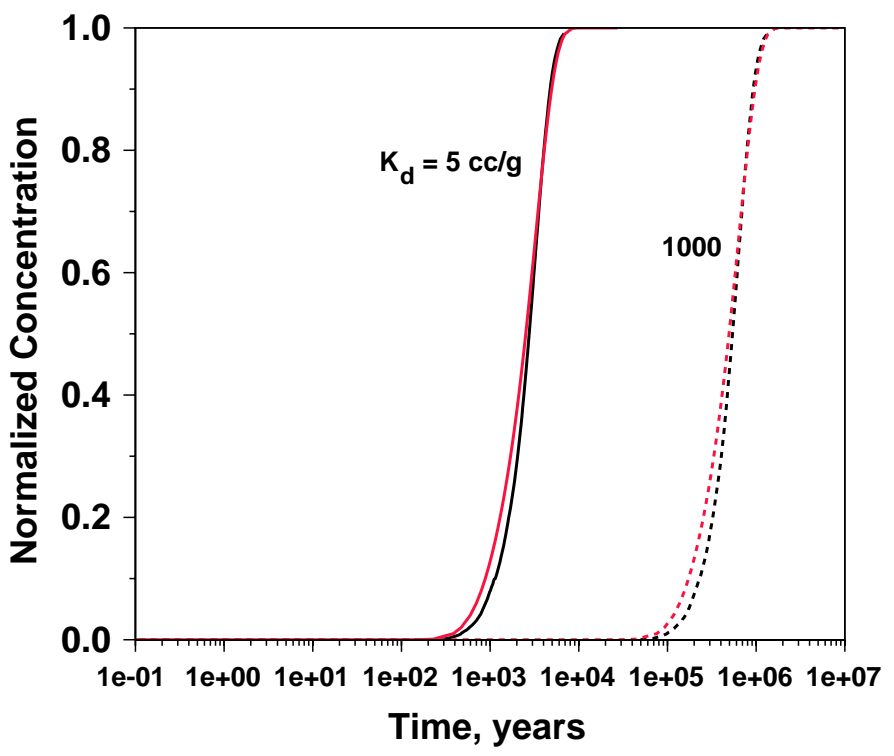

Output DTN: LA0311BR831371.001.

Figure 7-6. Comparison of Discrete Fracture Model and Particle-Tracking Abstraction Model: Solute Injected into the Fracture for Different Values of Sorption Coefficient, $D_{m}=1 . \mathrm{e}-10$

Nonsorbing, $D_{m}=1 . e-10,1 . e-11,1 . e-12$

Solute Injection into Matrix

Black - Particle Tracking; Red - Discrete Fracture Model

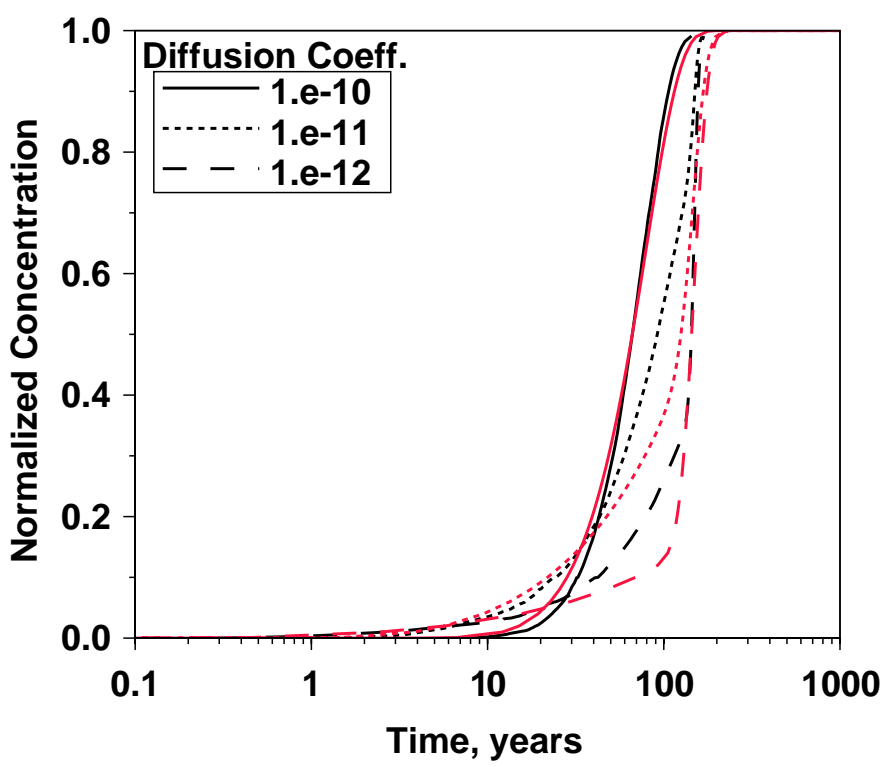

Output DTN: LA0311BR831371.001.

Figure 7-7. Comparison of Discrete Fracture Model and Particle-Tracking Abstraction Model: Non-sorbing Solute Injected into the Matrix for Different Values of Diffusion Coefficient 
To further explore the discrepancies for cases with relatively even distribution of flow in the two media, a series of tests are conducted in which the number of grid cells in the path are varied. These tests were performed for $\mathrm{D}=1 . \mathrm{e}-11 \mathrm{~m}^{2} / \mathrm{s}$, no sorption, and solute introduced in the fracture. Figure 7-8 compares the breakthrough curves for different numbers of cells with the DFM results. In all cases the overall flow path characteristics are the same, but the discretization is varied. For one cell, the DFM is replicated virtually exactly, because this case simply reproduces a DFM result that was used to generate the transfer function itself. This curve merely shows that for a single cell, the code finds the correct transfer function and the stochastic particle tracking method is implemented properly. As the number of cells in the path is increased to five or ten, the moderate error observed previously appears. An important point to consider in assessing this grid error is the fact that when flow transitions at interfaces of contrasting hydrologic properties, major transitions in particles from one medium to the other due to advection are likely to occur. Therefore, this type of test really replicates the behavior of the model within a single hydrogeologic unit. Since the number of grid cells within a unit tends to be rather small, the error within a unit is also likely to be small, perhaps of the magnitude shown in the five-cell curve.

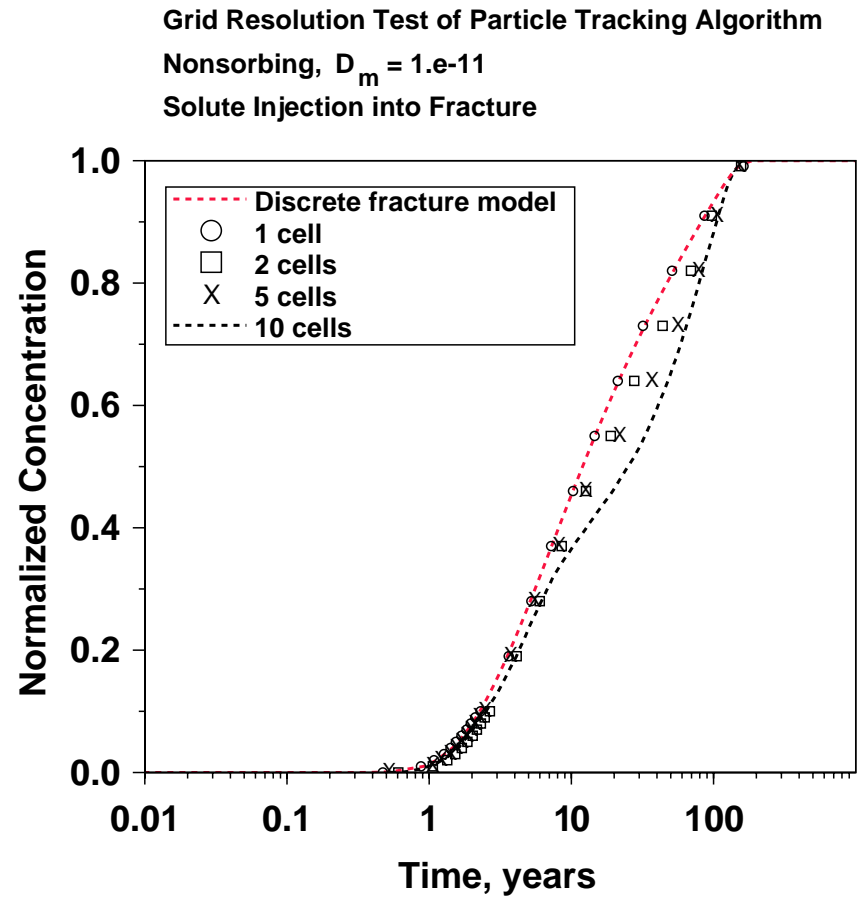

Output DTN: LA0311BR831371.001.

Figure 7-8. Comparison of Discrete Fracture Model and Particle-Tracking Abstraction Model: Sorbing Solute Injected into the Fracture for Different Numbers of Grid Cells in the Flow Path

\subsubsection{Summary of Validation Tests for a Discrete Fracture Model}

To summarize the results of this first validation test suite, the behavior of the particle tracking model agrees well with a DFM over a very broad range of transport conditions. The deviations that have been observed between the two models are very unlikely to influence TSPA model predictions, and the cause of these differences is well-understood. Furthermore, fracture-matrix advective transport has been demonstrated to be properly implemented, and the case of releases 
into the matrix is also shown to be properly implemented. Therefore these comparisons constitute an adequate demonstration of the effectiveness of the particle tracking model for capturing the fracture-matrix interactions that the model is designed to simulate.

\subsubsection{Comparison with the Dual-k and MINC Model Formulations on a Two-Dimensional Cross-Section Model}

Multi-dimensional benchmarking simulations of the UZ transport system is the next step in the validation of the abstraction model. Of course, the system is too complex to enable comparison to analytical solutions. In fact, selecting a code to benchmark against is also difficult because all available codes formulate the transport problem differently. BSC (2004 [DIRS 164500]) showed that these formulations, which constitute ACMs for transport, can produce significantly different results. These differences must be understood to appreciate the differences in the benchmarking results, especially for a complex, multidimensional model. In this section, benchmarking is performing comparing the particle tracking abstraction model developed here to simulations of the system performed using T2R3D, documented by BSC (2004 [DIRS 164500]). Two ACMs have been developed on the two-dimensional cross section model using T2R3D. The simulations called "dual-k" use a finite-volume dual-permeability model formulation in which the fracture-matrix diffusion term is governed by a simple gradient calculated as the difference in concentration between the media divided by a characteristic distance, on the order of the flowing fracture spacing. In addition, in the report by BSC (2004 [DIRS 164500]), the MINC conceptual model employs a series of grid blocks in the matrix. The UZ abstraction model implemented in FEHM is capable of simulating either situation. In the conceptualization called the DFM $\mathrm{f} / \mathrm{m}$ interaction model, sharp concentration gradients are captured through use of a transfer function obtained using a DFM with fine discretization in the matrix, analogous to a MINC formulation. These are the transfer functions used in the comparisons to the DFM in Section 7.2.1. By contrast, a dual-k model can be used to generate transfer functions, and those results might be expected to resemble those of T2R3D when an analogous dual-k formulation is used. These comparisons are performed in this section. A final point on these alternative conceptual models is that in all abstraction model cases, the flow field on which the transport model is run is a dual $^{-} \mathrm{k}$ flow field because the particle tracking abstraction model was formulated with the dual-k flow assumption. Therefore, the transport runs with the DFM formulation for the $\mathrm{f} / \mathrm{m}$ interaction submodel employ a finely discretized matrix block for transport, but a single matrix block for the flow field. This approach should enable sharp gradients likely to be present for solute transport to be captured in the model.

Figure 7-9 plots the comparison results of the particle tracking model and the two ACMs simulated with T2R3D. For the FEHM runs, the two-dimensional flow fields compatible with FEHM were obtained from the TDMS (DTN: LB0310T2FEHMFF.001 [DIRS 166060]). In all cases, particles are released uniformly across all nodes designated as repository nodes in the model. The first case assumes no diffusion and the transfer function option to handle fracturematrix interactions is not used. This comparison is performed to benchmark the particle tracking code in a mode in which particles are routed through the model with dispersion. There is excellent agreement between the particle tracking model and the dual-k, no-diffusion model using T2R3D. Slight differences may be attributable to subtle differences in model formulation, or due to the fact that one of the eleven nodes designated as a repository node in the T2R3D runs was omitted from the particle tracking runs because it was found to be located in the PTn. Even 
with these possible sources for the difference, the agreement provides confidence that particle routing and transit times are properly implemented.

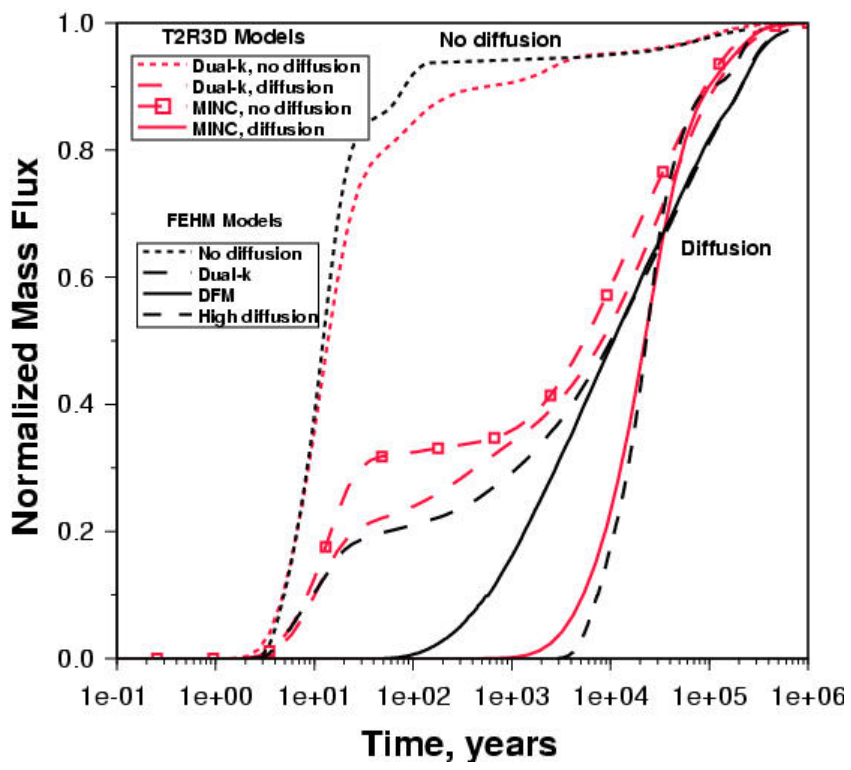

T2R3D Simulations DTN: LB03093RADTRNS.002 [DIRS 166071].

Output DTN: LA0311BR831371.002.

Figure 7-9. Comparison of Particle-Tracking Model with T2R3D Models for a Two-Dimensional, Mountain-Scale Model: with (and without) Diffusion, for Dual-k and DFM Formulations for the $\mathrm{f} / \mathrm{m}$ Interaction Model, Present-Day Mean Infiltration, Representative Parameter Values, and Present-Day Water Table

Colloid transport model results in Section 6.18 of the report by BSC (2004 [DIRS 164500]) indicate that breakthrough of radionuclides bound to colloids are dominated by fracture flow and the lack of diffusion into the matrix. The breakthrough times cited in Table 6-29 above illustrate this effect. Therefore, even though there are no direct comparisons of the abstraction model with T2R3D model results for colloid species, the no-diffusion comparison provides high confidence that colloid-facilitated transport of radionuclides is accurately reproduced in the abstraction model.

Before proceeding to the results with diffusion, a discussion of the MINC simulation with no diffusion is in order. Since transport runs without diffusion depend only on advective processes, it is apparent that the mismatch between the MINC, no diffusion, and the dual-k simulations (both T2R3D and particle tracking) indicates that there are differences in the flow regime for the MINC model. The reasons for this difference stem from the fact that the numerical discretization of this model is different than that of the dual-k model. This discussion does not imply that one model is correct and the other is not, but points out that because of differences in the flow regimes of the MINC and dual-k flow models, the particle tracking runs, which input the dual-k flow field rather than the MINC flow field, will not necessarily match the MINC results precisely. Nevertheless, similar breakthrough curve features should be predicted by the particle tracking and MINC models, when the former are computed with the DFM conceptual model transfer function curves. By contrast, diffusion in the dual-k transport model is expected to predict much earlier breakthrough of a portion of the solute mass. 
The simulations with diffusion in Figure 7-9 confirm this result. In this figure, various FEHM particle tracking simulations are benchmarked against simulations using a dual-k or MINC formulation for the two-dimensional cross section. For the FEHM models, the transfer functions for the various cases are those described in Appendix C. The difference in predicted behavior between the two conceptual models is reflected in the FEHM simulations in a manner similar to that of the T2R3D models. Comparing the MINC and FEHM DFM conceptual model, first arrivals in both cases occur much later in time than the dual-k models. For comparison, a highdiffusion case is also presented to illustrate the upper limit of breakthrough times for this flow field. Regarding the dual-k models, the characteristic feature of early arrival of a significant portion of the mass at times similar to that of pure fracture transport is produced in both the T2R3D and abstraction models. The fraction of the mass arriving early is lower in the FEHM model than in the T2R3D model, but qualitatively, the dual-k transfer function curves yield behavior quite similar to the model result using T2R3D. Also, both the T2R3D model and abstraction model results converge at longer transport times, regardless of the formulation of the $\mathrm{f} / \mathrm{m}$ interaction model or the value of diffusion coefficient used. Finally, the high-diffusion FEHM simulation (run using the dual-k transfer functions) is shown to bracket the behavior of the breakthrough curves in the figure, with results that are very close to that of the MINC model.

These indicators show that the abstraction model compares adequately with the T2R3D models, and properly accounts for the role of conceptual model uncertainty in the $\mathrm{f} / \mathrm{m}$ interaction model. The relatively minor differences of the models employing the dual- $\mathrm{k} f / \mathrm{m}$ conceptual model are probably attributable to subtle differences in model formulation and mathematical techniques for solving the transport problem.

\subsubsection{Comparison with T2R3D Process Model for the Three-Dimensional System}

Full simulation of the three-dimensional UZ transport system is the last step in the validation of the abstraction model. Section 7.2.2 showed that on a system for which the dual-k and MINC $\mathrm{f} / \mathrm{m}$ interaction model results were available for comparison, the FEHM particle tracking results can provide qualitatively similar behavior for these ACMs simply by choosing transfer functions developed for a given conceptualization. In this section, the particle tracking abstraction model is benchmarked against simulations of the system performed using T2R3D, documented by BSC (2004 [DIRS 164500]). The T2R3D simulations use a finite-volume dual-permeability model formulation in which the fracture-matrix diffusion term is governed by a simple gradient calculated as the difference in concentration between the media divided by a characteristic distance, on the order of the flowing fracture spacing. No results are available using a MINC or other formulation that captures sharp gradients into the matrix. Therefore, the principle benchmarking simulations for FEHM will be those using the dual-k transfer functions. However, these results demonstrate that the code can effectively explore uncertainty associated with this conceptual model. Because these comparisons use the same flow model and flow parameters as will be used in the TSPA-LA model, the model comparison provides direct proof of the correct functioning of the model under conditions that will be present in the TSPA model.

\subsubsection{Comparisons of FEHM and T2R3D for the Dual-k Conceptual Model}

These comparisons are conducted for a nonsorbing radionuclide Tc-99, since simulations in Section 7.2.1 above showed that sorption is handled appropriately. For model runs using either 
FEHM or T2R3D, breakthrough at the water table is simulated for a release function consisting of a pulse of radionuclide introduced uniformly across the entire repository. The comparisons between the models are for the cumulative, normalized arrival time distributions at the water table. Of course, these release functions are not realistic representations of how the actual engineered system will behave. Such a release function yields the distribution of transport times for the UZ as a whole for releases across the repository, and, as such, is a useful point of reference for how the UZ behaves, as well as being an appropriate benchmark for comparing the models. From the standpoint of model validation, the benchmarking is appropriate because each of the models uses the same source region. Parameters in the abstraction model are uncertain. For this comparison, values documented by BSC (2004 [DIRS 164500]) are used to perform this comparison, and the present-day climate flow fields are used to make the comparison throughout the entire simulation period. This approach allows testing the model over a significant range of infiltration scenarios, those spanning the uncertainty range for infiltration rate using the three present-day flow fields derived in the report by BSC (2004 [DIRS 169861]).

Figure 7-10 shows the cumulative transport time distributions through the UZ for Tc-99 for the two models for the three flow fields (lower, mean, and upper) developed to capture uncertainty in the present-day infiltration rates. The agreement between FEHM using the dual-k transfer functions and T2R3D is quite good, considering the vast range of infiltration conditions covered in these comparisons. For the lower infiltration scenario, the early arrival of a small fraction of the released mass, and the steepening breakthrough curve after 10,000 years, are observed in both models. The plateau at values between 0.4 and 0.5 at long times is due to radioactive decay of Tc-99. For the mean infiltration flow field, the agreement of the process and abstraction models is also excellent at all transport times. For the upper infiltration scenario, FEHM predicts an earlier arrival for the fastest moving solute, indicating a difference in the way the two models handle diffusion in rapid fracture flow. Nevertheless, in benchmarking exercises of such a complex model, differences are the norm. Note that differences in travel times within the first 100 years of breakthrough are not likely to have a significant influence on predicted performance because the early breakthrough portion effectively bypasses the UZ barrier in either case. In summary, the benchmarking results are very successful, in that all significant features of the UZ transport system are captured with the abstraction model.

\subsubsection{Influence of Diffusion Coefficient and f/m Interaction ACM}

To amplify on the simulations presented in the previous section, Figure 7-11 brackets the behavior of the particle tracking model as a function of diffusion. This figure shows the behavior of the FEHM model over the complete range of diffusion coefficients, from no diffusion to a case in which diffusion is set so high that it effectively yields a composite medium behavior ( $D=1 . e-8 \mathrm{~m}^{2} / \mathrm{s}$ ). The envelope of behavior as a function of diffusion is quite large, whereas the behavior of T2R3D is reproduced when the same parameters and conceptual model for $\mathrm{f} / \mathrm{m}$ interactions is selected. This result, when combined with the $1 \mathrm{D}$ results of Figures $7-2$, $7-3$, and 7-4, and the 2D results of Figure 7-9, illustrates that the abstraction model yields reasonable results over a wide range of diffusion coefficient, one of the key parameter uncertainties in the TSPA-LA model. Also shown in Figure 7-11 is the predicted behavior using the DFM formulation for the $\mathrm{f} / \mathrm{m}$ interaction model. No process model results are available for comparison due to the computational limitations of simulating the full three-dimensional model using an MINC formulation. 
UZ Transport for Different Infiltration Scenarios

99Tc, Black: FEHM Abstraction Model, Red: T2R3D Process Model

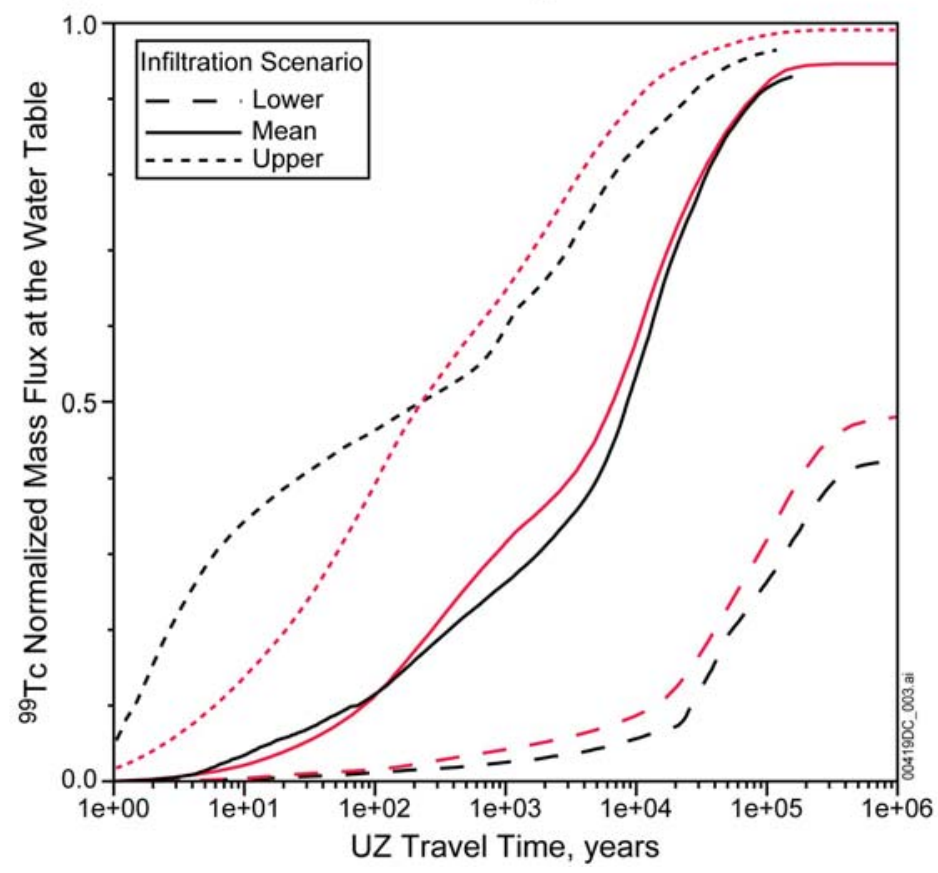

T2R3D Simulations: DTN: LB0307MR0060R1.007 [DIRS 164752].

Output DTN: LA0311BR831371.002.

Figure 7-10. Comparison of Breakthrough Curves for Tc-99 for T2R3D and the UZ Transport Abstraction Model: Simulations for Different Present-Day Infiltration Rate Scenarios (Lower, Mean, and Upper), Representative Parameter Values, and Present-Day Water Table

These limitations are not an issue for the abstraction model, which simply uses a different set of transfer functions as input. The results are reasonable, given the understanding of these models and the comparisons presented in Section 7.2.2 for the smaller two-dimensional cross section model. The main differences for these ACMs are at the earliest arrival times, where the dual-k model predicts much faster arrivals at the water table. For later transport times, the two curves track each other closely, showing that the results are insensitive to the conceptual model. Finally, all breakthrough curves with diffusion, including the high-diffusion case, converge at large transport times. This result is also reasonable, providing additional evidence for the correct functioning of the $\mathrm{f} / \mathrm{m}$ interaction model.

The influence of $\mathrm{f} / \mathrm{m}$ conceptual model is explored more fully in Figure 7-12, a comparison, using only the FEHM particle tracking model, of the dual-k and DFM ACMs for all of the flow scenarios. The choice of ACM is particularly sensitive for the upper infiltration scenario, whereas differences become progressively more subtle for the mean and lower infiltration scenarios, respectively. As the fluid velocity is reduced, the characteristic diffusional distance into the matrix increases. For this situation, the dual-k model becomes more like the DFM in the sense that concentration gradients in the latter are not nearly as steep. With respect to the abstraction model, these comparisons have reasonable qualitative explanations. This result illustrates that the abstraction model can propagate conceptual model uncertainties for $\mathrm{f} / \mathrm{m}$ interactions through the TSPA-LA model. 
Comparison of FEHM Particle Tracking to T2R3D

99Tc: Impact of diffusion on FEHM Results

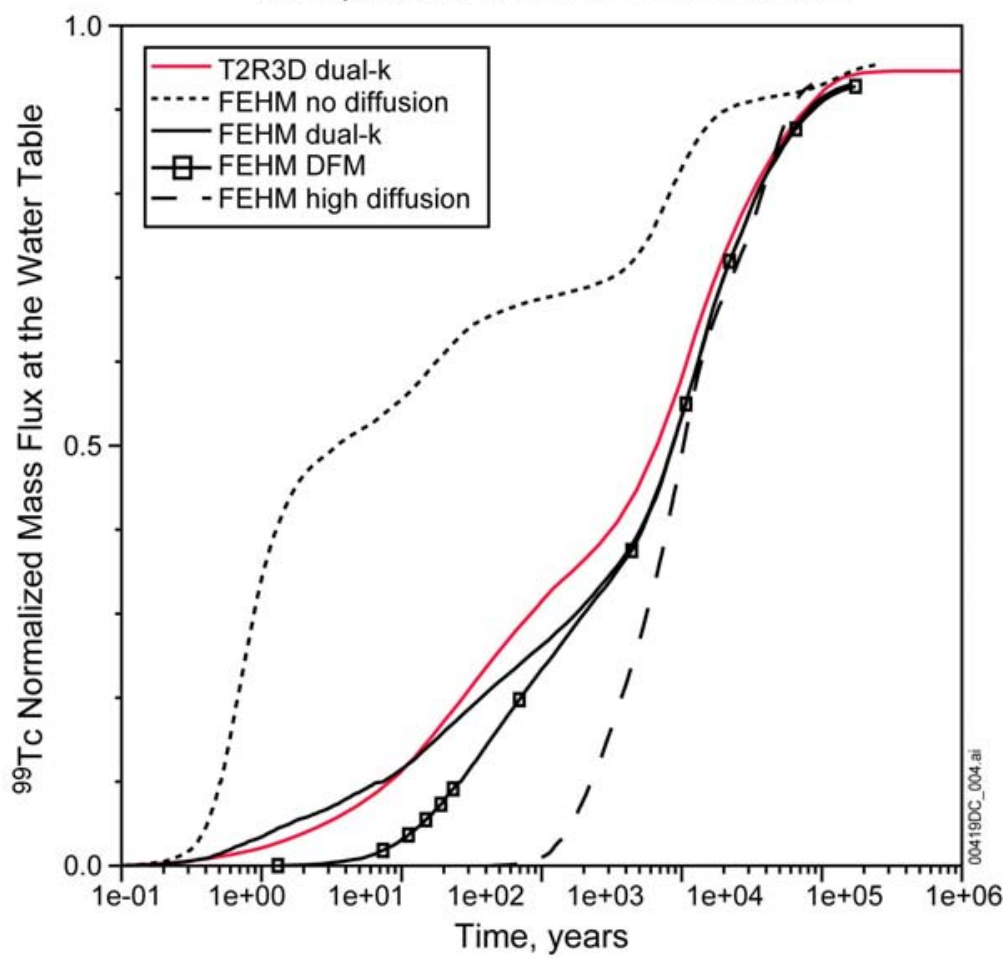

T2R3D Simulations: DTN: LB0307MR0060R1.007 [DIRS 164752].

Output DTN: LA0311BR831371.002.

Figure 7-11. Comparison of Breakthrough Curves for Tc-99 for T2R3D and the UZ Transport Abstraction Model: Present-Day Mean Infiltration Scenario, Diffusion in FEHM Ranging from No Diffusion to High Values, Representative Parameter Values, and Present-Day Water Table

\subsubsection{Tests of the Active Fracture Model Implementation}

The AFM has been identified in the reports by BSC (2004 [DIRS 164500] and 2004 [DIRS 169861]) as a model whose parameters are quite uncertain, and potentially this uncertainty may significantly influence UZ performance predictions. Therefore, it is important to demonstrate that the sensitivity explored in the process model work can be represented in the abstraction model. This section examines the impact of the gamma parameter in the AFM on the results. This set of simulations is intended to confirm that the AFM formulation in FEHM yields results similar to that of the process model, and to extend those results by performing the same analysis for the DFM model for $\mathrm{f} / \mathrm{m}$ interactions. To be completely rigorous, one would need to regenerate flow fields using the alternate AFM model parameters because the AFM influences both flow and transport processes. However, process flow model results (BSC 2004 [DIRS 169861], Section 6.8.1) have demonstrated that the AFM parameters have very little influence on the relevant flow model parameters for transport, namely the fluid saturations and flow rates in the fracture and matrix continua. Therefore, it is an excellent approximation to simply apply AFM parameter changes to the transport model using flow model results obtained from the base case flow simulation. 
UZ Transport Times, Comparison of Dual-k and DFM Models

$99 \mathrm{Tc}$, Curves with symbols denote DFM Models

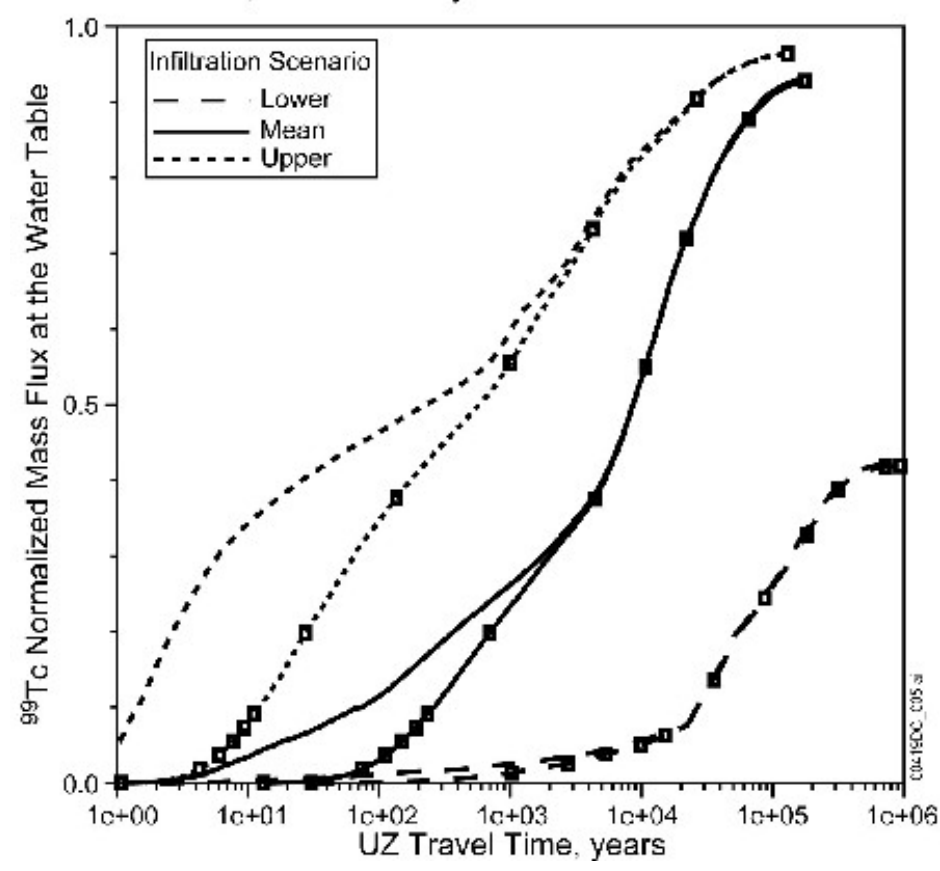

Output DTN: LA0311BR831371.002.

Figure 7-12. Breakthrough Curves for Tc-99 Using the UZ Transport Abstraction Model to Investigate the Role $f / m$ Interaction Conceptual Model: Simulations for Different Present-Day Infiltration Rate Scenarios (Lower, Mean, and Upper), Representative Parameter Values, and Present-Day Water Table

Figure 7-13 illustrates the impact of lowering the gamma parameter in the same fashion as was done in Section 6.8.2 of the report by BSC (2004 [DIRS 169861]). Note the close qualitative similarity of the simulation results with that of Figure 6.8-3 of that report. Lowering the gamma parameter in the TSw in the same manner as in BSC (2004 [DIRS 169861]) yields a trend toward longer arrival times for the earliest arriving solute. The curves converge at longer transport times. The fact that the lowering of gamma in additional units below the repository has no further effect indicates that the principle sensitivity is for the AFM parameters in the TSw. For the purposes of the abstraction model validation, this qualitative comparison to the results of the report by BSC (2004 [DIRS 169861], Figure 6.8-3) provides strong evidence that the implementation in FEHM with respect to the AFM replicates the behavior of the process model. 


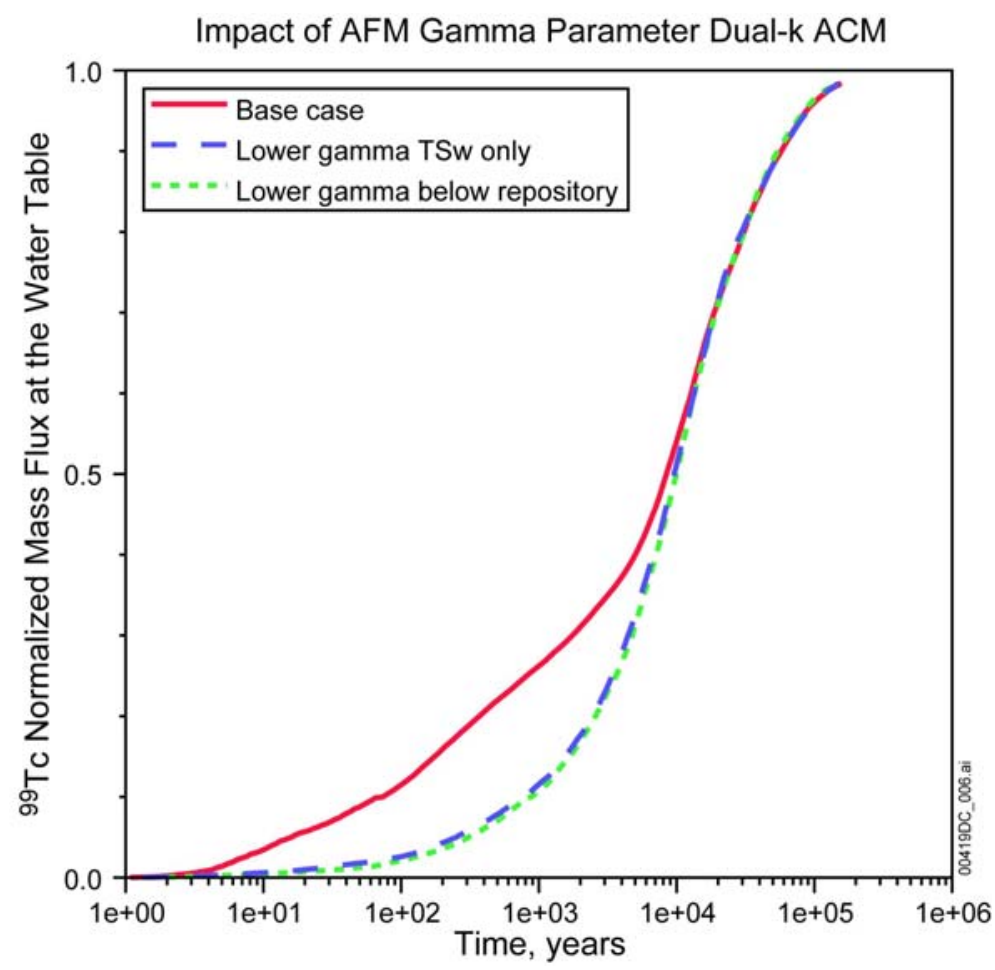

T2R3D Simulations: DTN: LB0307MR0060R1.007 [DIRS 164752].

Output DTN: LA0311BR831371.002.

NOTE: The colors, line types, and legend descriptors are chosen to facilitate a direct visual comparison to the simulation results presented in BSC 2004 [DIRS 169861], Figure 6.8-3.

Figure 7-13. Breakthrough Curves for Conservative Solute Using the UZ Transport Abstraction Model to Investigate the Role of AFM Parameter Gamma: Dual-k ACM, Simulation for Different Values of Gamma in Rock Units Beneath the Repository, Present-Day Mean Infiltration, Representative Parameter Values, and Present-Day Water Table

Finally, Figure 7-14 shows a similar investigation of the role of AFM model parameters for the DFM conceptualization. Note that in comparison to the dual-k DFM, gamma has smaller influence on the transport behavior. This result is a consequence of the way in which the two ACMs simulate the early-time behavior of the breakthrough curves. When a more refined grid is used to resolve gradients in the matrix, the role of flowing fracture spacing and interface area is less important than for the case in which a single matrix grid block is used to represent diffusion. The implication of this conclusion is that AFM model parameters will have a relatively smaller influence on predicted UZ behavior for the DFM conceptualization. By contrast, a larger sensitivity to AFM gamma parameter is predicted for the dual-k conceptual model. These differences must be recognized when interpreting sensitivity studies involving the AFM and the $\mathrm{f} / \mathrm{m}$ interaction models. In general, the diffusion coefficient itself, rather than the AFM model parameters, is a much more sensitive parameter controlling the UZ performance. 


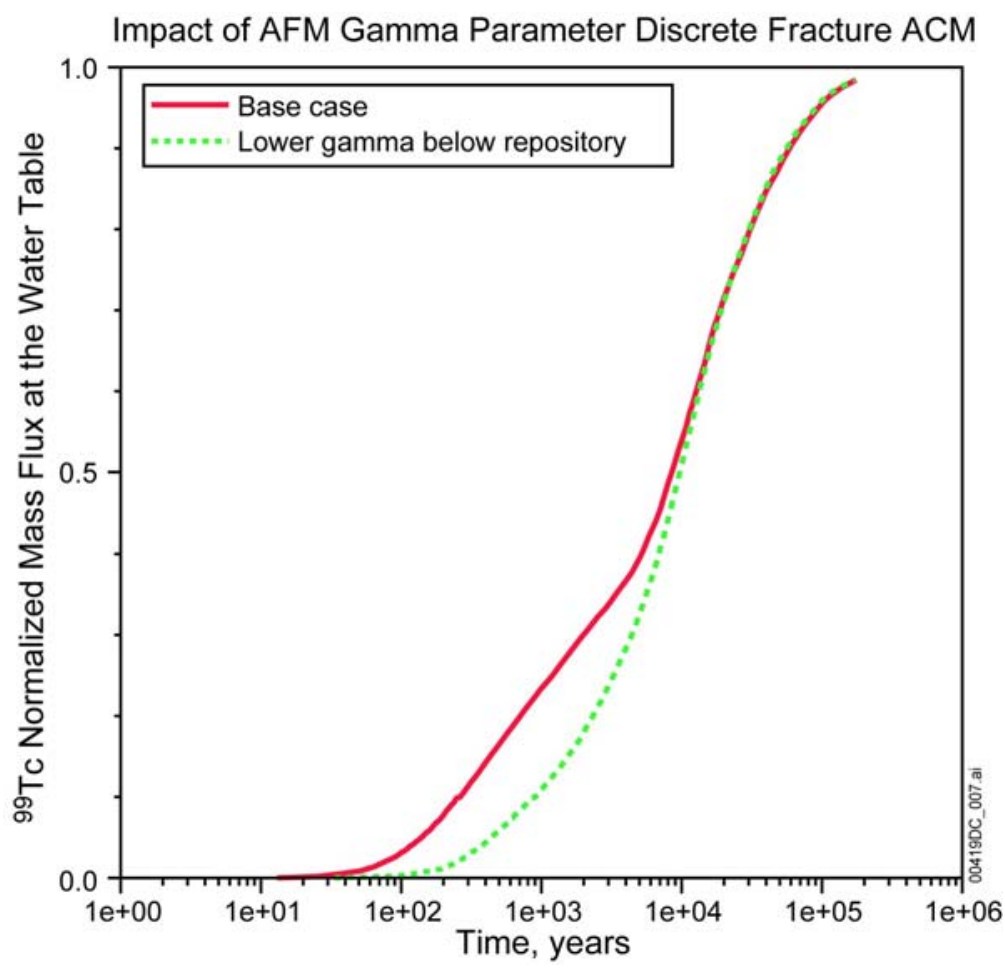

Output DTN: LA0311BR831371.002.

Note: The colors, line types, and legend descriptors are chosen to facilitate a direct visual comparison to the simulation results presented in BSC 2004 [DIRS 169861], Figure 6.8-3.

Figure 7-14. Breakthrough Curves for Conservative Solute Using the UZ Transport Abstraction Model to Investigate the Role of AFM Parameter Gamma: Discrete Fracture ACM, Simulation for Different Values of Gamma in Rock Units Beneath the Repository, Present-Day Mean Infiltration, Representative Parameter Values, and Present-Day Water Table

\subsection{SUMMARY OF VALIDATION ACTIVITIES}

As outlined in Section 7, the intended use of the radionuclide transport abstraction model calls for Level II validation activities that demonstrate that the basic physical principles are appropriately represented in the model and that a single post-development model validation method is implemented. In this case, the post-development model validation method used is corroboration with alternative mathematical models. Confidence building during model development is described in Section 7.1. Post-development activities are discussed in Section 7.2 and summarized below. Post-development model validation was conducted through a series of model comparison studies. Comparisons were made with a discrete fracture model, a dual-k and MINC model formulations on a two-dimensional, site-scale cross-sectional model, and a dual-k model for the three-dimensional site-scale model domain.

The series of simulations presented in this section, along with additional simulations performed to test the performance of the model in the report by LANL (2003 [DIRS 166306]), provide assurance that the UZ transport system is adequately captured in the abstraction model that is the subject of this report. Direct numerical comparisons with quantitative criteria would be inappropriate for these comparisons because the modeling approach is designed to capture the 
essential features of the transport behavior over an extremely broad range of conditions (flow rates, transport parameters, relative flow rates in the two media, and the conceptual model for $\mathrm{f} / \mathrm{m}$ interactions). Furthermore, analytical solutions do not exist to perform the comparisons made in this study, so the issue of whether the model is "correct" is not answerable by simply comparing to another code. Rather, the sort of benchmarking performed in this section is designed to build confidence in the adequacy of the abstraction model through a series of comparisons designed to probe the key features of the model that will be exercised during its use in TSPA simulations. In addition to the lack of exact solutions to use as absolute benchmarks, there is no unique way to establish a suitable quantitative criterion that is guaranteed to be appropriate. The complete problem involves nine distinct flow fields and numerous different radioelements (some with chain decay) and two different colloid types. Releases can occur at different points in time relative to the sequence of climate changes. These complexities lead to the use of qualitative comparisons.

Adequate visual comparisons for benchmarking against the DFM simulations illustrate that the algorithms have been implemented to handle upscaling of dual-k transport processes, for low or high diffusion, sorbing or nonsorbing solutes, and fracture or matrix releases. Discrepancies between the particle tracking and DFMs, though relatively small, were noted and additional investigations were conducted to explain and assess the differences. In this way, the robustness of the model was demonstrated. Therefore, these results show that TSPA simulations using the UZ transport abstraction model will be able to propagate uncertainties in the form of parameter distributions through the UZ portion of the TSPA-LA model. After testing the model in a simple particle tracking setup, the complexities of the system were studied in two and three dimensions through comparisons to the T2R3D based process model. These results are also adequate. Good agreement was observed at a variety of infiltration scenarios and diffusion models and parameters. Where differences were uncovered, the FEHM model results yielded earlier breakthrough at the water table than did the process model. The likely impact of this factor in TSPA analyses is small, given that these breakthroughs are at short travel times, which in any event connote a bypassing of the UZ by radionuclides. The exact timing of this breakthrough is relatively unimportant since the differences are within the first 1 to 100 years of transport.

Note that this validation runs also imply that the model can be used to simulate UZ radionuclide transport behavior under the disruptive event scenarios. These scenarios principally impact the source term, rather than the behavior of the UZ as a transport barrier, so the use of the model under these scenarios is justified.

With regard to the use of this model under a scenario of igneous activity disrupting the UZ flow and transport system, this issue has been treated in the report by BSC (2004 [DIRS 170012]). The impact on the rock properties was excluded on the basis of a low-consequence argument. In essence, the spatial area associated with changes to the rock properties was deemed to be too small to have a significant impact on the rock properties (BSC 2004 [DIRS 170012], Section 6.8.2). By a similar argument, the hydrologic response to igneous activity was determined to be of small spatial extent (BSC 2004 [DIRS 170012], Section 6.8.4), and hence was excluded on the same basis.

In addition, the abstraction model is set up to enable ACMs for $\mathrm{f} / \mathrm{m}$ interaction through the use of a different set of transfer function curves. For the TSPA-LA model, the dual-k formulation 
should be chosen because it was shown in Section 7.2.3.2 (Figure 7-10) to be conservative with respect to the first arrival times at the water table. Finally, the implementation of the AFM in the abstraction model was shown to reproduce the qualitative features of the breakthrough curves documented in the process model reports on which this abstraction is based. In summary, the abstraction model has been compared in the full complexity of the UZ model, and found to be able to represent the system robustly and efficiently for the entire range of parameters and conceptual models required. Therefore, the UZ transport abstraction model is suitable for use in TSPA analyses. 


\section{INTENTIONALLY LEFT BLANK}




\section{CONCLUSIONS}

\subsection{SUMMARY OF MODELING ACTIVITY}

The principal output from this report is an abstraction model for radionuclide transport in the UZ. It is intended for this model to be used directly in the TSPA-LA system model. The code used to implement the model is FEHM V2.21 (LANL 2003 [DIRS 165741]), in the form of a dll callable from GoldSim. Testing of the operation of the dll in a GoldSim model environment has been developed and tested elsewhere (LANL 2003 [DIRS 166306]) and is not repeated here, except to discuss the data structure of the interface between GoldSim and the FEHM dll.

This report pulls together information and data from a variety of sources, creating a simulation model capable of efficiently computing the transport of multiple radionuclides through the UZ. Data sources are listed in Section 4.1, assumptions are discussed in detail in Section 5, and the mathematical formulation and assessment of parameter ranges and distributions are treated in Section 6. The main activity documented in this report is the synthesis of data and models into a simulation tool. The model to be used in TSPA simulations consists of a code (FEHM V2.21, PC dll) and input files to the code that must be present to run the model within GoldSim. Table 8-2 lists the computer files required to run the base-case model, and a brief description of the purpose of each file. Fixed parameters have been inserted into the appropriate FEHM files. Parameter distributions given in Section 6.5 should be used to generate a table of parameters in a text file, which is read using FEHM's capability of reading in parameters from a separate file and inserting those parameters into the simulation at runtime (see the User Documentation for FEHM V2.21 for details). Thus, this set of files provides the template for the TSPA-LA modelers to set up the UZ transport abstraction model in a multiple-realization GoldSim system model. The table of uncertain parameters itself is not generated in this report: this needs to be done by TSPA system modelers to facilitate parameter correlations and to enable the exploration of parameter sensitivities to be studied systematically at the system level. Table 8-1 lists the UZ transport parameters which should be presampled and assembled into a table and for FEHM to read at run time in TSPA.

\subsection{MODEL OUTPUTS}

\subsubsection{Developed Output}

Many of the model outputs (FEHM input files to be used by TSPA system modelers) are derived from results of process models or other studies. For a discussion of the uncertainties of those parameters, the reader is referred to the references cited in Table 8-1. For those outputs in Table 8-2 listed as being developed in this report, the development of the parameter values is discussed in this report (provided in DTN: LA0407BR831371.001 and DTN: LA0311BR831229.001) . The table shows two primary output DTNs. In addition to the files listed in the table, there may be auxiliary files that the TSPA-LA modeling group must develop and document to complete the process of incorporating the UZ transport abstraction model into GoldSim (BSC 2003 [DIRS 161572]). These files, which are the responsibility of the TSPA-LA modeling group to create, may include files such as batch files to copy files at runtime from one filename to another. They will implement features that are documented in FEHM V2.21, and are 
discussed in the User Manual for the code (Zyvoloski et al. 1997 [DIRS 100615]). They will contain no data, so are not required to be documented in this report.

Table 8-1. List of Uncertain Parameters to be Sampled in the TSPA-LA Runs

\begin{tabular}{|l|l|}
\hline \multicolumn{1}{|c|}{ Uncertain Parameters } & \multicolumn{1}{c|}{ Description } \\
\hline $\begin{array}{l}\text { matrix sorption coefficient } \\
(\mathrm{mL} / \mathrm{g})\end{array}$ & $\begin{array}{l}\text { Matrix sorption coefficient will be presampled based on given distributions for } \\
\text { dissolved species in Section 6.5.4, Table 6-5. }\end{array}$ \\
\hline $\begin{array}{l}\text { matrix diffusion coefficient } \\
\left(\mathrm{m}^{2} / \mathrm{sec}\right)\end{array}$ & $\begin{array}{l}\text { Matrix water content and effective permeability will first be sampled based on given } \\
\text { distribution in Section 6.5.5, Table 6-6. Then, the sampled water content and } \\
\text { effective permeability are used in Eq. 6.19 for estimating matrix diffusion coefficients. }\end{array}$ \\
\hline $\begin{array}{l}\text { fracture porosity, fracture } \\
\text { frequency, and fracture } \\
\text { aperture }(\mathrm{m})\end{array}$ & $\begin{array}{l}\text { If desired, fracture porosity, fracture frequency, and fracture aperture can be } \\
\text { sampled based on given distribution in Table 6-13 and Eq. 6-26. }\end{array}$ \\
\hline colloid $\mathrm{K}_{\mathrm{c}}$ & $\begin{array}{l}\text { Colloid concentration and colloid } \mathrm{K}_{\mathrm{d}} \text { are sampled based on given distribution in } \\
\text { Tables 6-19 and 6-20. The sampled colloid concentration and } \mathrm{K}_{\mathrm{d}} \text { are then used in } \\
\text { Section 6.5.12, Eq. 6-27 for calculating colloid } \mathrm{K}_{\mathrm{c} .}\end{array}$ \\
\hline colloid $\mathrm{R}_{\mathrm{c}}$ & Colloid $\mathrm{R}_{\mathrm{c}}$ is sampled based on given distribution in Section 6.5.13, Table 6-22. \\
\hline
\end{tabular}

Table 8-2. Computer Files Comprising the UZ Transport Abstraction Model

\begin{tabular}{|l|l|l|l|}
\hline $\begin{array}{l}\text { Computer Files } \\
\text { Comprising the } \\
\text { UZ Transport } \\
\text { Process Model }\end{array}$ & \multicolumn{1}{|c|}{$\begin{array}{c}\text { Qualitative Description and } \\
\text { Intended Use }\end{array}$} & $\begin{array}{c}\text { Data Tracking Number Used } \\
\text { to Develop }\end{array}$ & Product Output DTN \\
\hline \multicolumn{3}{|c|}{ Files Developed in Other Studies That Feed This Abstraction Model } \\
\hline $\begin{array}{l}\text { fehmn.grid } \\
\text { fehmn.stor }\end{array}$ & $\begin{array}{l}\text { Numerical model grid files } \\
\text { required for UZ transport } \\
\text { abstraction model. }\end{array}$ & $\begin{array}{l}\text { LB0305TSPA18FF.001 } \\
\text { [DIRS 165625] }\end{array}$ & N/A \\
\hline $\begin{array}{l}\text { fehmn.zone } \\
\text { fehmn.zone2 }\end{array}$ & $\begin{array}{l}\text { File that indexes each grid } \\
\text { node number to a hydrologic }\end{array}$ & $\begin{array}{l}\text { LB0305TSPA18FF.001 } \\
\text { [DIRS 165625] }\end{array}$ & N/A \\
\hline $\begin{array}{l}\text { zone. Input zone list file for UZ } \\
\text { transport abstraction model. } \\
\text { preqma.ini } \\
\text { prequa.ini } \\
\text { glaqla.ini } \\
\text { glaqma.ini } \\
\text { glaqua.ini } \\
\text { monla.ini } \\
\text { monma.ini } \\
\text { monua.ini } \\
\text { glaqlA_wtrise.ini } \\
\text { glaqma_wtrise.ini } \\
\text { glaquA_wtrise.ini } \\
\text { monIA_wtrise.ini } \\
\text { monmA_wtrise.ini } \\
\text { monuA_wtrise.ini }\end{array}$ & $\begin{array}{l}\text { Steady state flow fields used to } \\
\text { set the fluid flow rates in the UZ } \\
\text { transport abstraction model. }\end{array}$ & $\begin{array}{l}\text { LB0305TSPA18FF.001 } \\
\text { [DIRS 165625] } \\
\text { LB0312TSPA06FF.001 }\end{array}$ & N/A \\
[DIRS 166671] & \\
& & & \\
\end{tabular}


Table 8-2. Computer Files Comprising the UZ Transport Abstraction Model (Continued)

\begin{tabular}{|c|c|c|c|}
\hline $\begin{array}{l}\text { Computer Files } \\
\text { Comprising the } \\
\text { UZ Transport } \\
\text { Process Model }\end{array}$ & $\begin{array}{l}\text { Qualitative Description and } \\
\text { Intended Use }\end{array}$ & $\begin{array}{c}\text { Data Tracking Number Used } \\
\text { to Develop }\end{array}$ & Product Output DTN \\
\hline \multicolumn{4}{|c|}{ Files Developed in This Report } \\
\hline $\begin{array}{l}\text { fehm_amr_base.ro } \\
\text { ck }\end{array}$ & $\begin{array}{l}\text { Rock properties for all zones } \\
\text { defined in fehm.zone - bulk } \\
\text { rock density, heat capacity } \\
\text { (placeholder, not used in the } \\
\text { model), and porosity. File is } \\
\text { part of the UZ transport } \\
\text { process model. }\end{array}$ & $\begin{array}{l}\text { LB0305TSPA18FF.001 } \\
\text { [DIRS 165625] } \\
\text { LB0210THRMLPRP.001 } \\
\text { [DIRS 160799] }\end{array}$ & LA0407BR831371.001 \\
\hline $\begin{array}{l}\text { fehm_amr_base.d } \\
\text { pdp }\end{array}$ & $\begin{array}{l}\text { Dual permeability model } \\
\text { parameters - fracture volume } \\
\text { fraction, characteristic distance } \\
\text { into the matrix between } \\
\text { fractures. File is part of the UZ } \\
\text { transport process model. }\end{array}$ & $\begin{array}{l}\text { LB0205REVUZPRP.001 } \\
\text { [DIRS 159525] } \\
\text { LB0207REVUZPRP.001 } \\
\text { [DIRS 159526] }\end{array}$ & LA0407BR831371.001 \\
\hline $\begin{array}{l}\text { fehm_amr_base.m } \\
\text { ptr. }\end{array}$ & $\begin{array}{l}\text { All solute transport parameters } \\
\text { for the multiple radionuclide } \\
\text { simulations. File is part of the } \\
\text { UZ transport process model. }\end{array}$ & $\begin{array}{l}\text { LA0408AM831341.001 } \\
\text { [DIRS 171584] } \\
\text { LB0302UZDSCPUI.002 } \\
\text { [DIRS 161787] } \\
\text { LB0305TSPA18FF.001 } \\
\text { [DIRS 165625] } \\
\text { LL000122051021.116 } \\
\text { [DIRS 142973] } \\
\text { SN0306T0504103.005 } \\
\text { [DIRS 164132] } \\
\text { SN0306T0504103.006 } \\
\text { [DIRS 164131] } \\
\text { LA0303HV831352.002 } \\
\text { [DIRS 163558] }\end{array}$ & LA0407BR831371.001 \\
\hline repo.zon.xls & $\begin{array}{l}\text { Zone lists containing node } \\
\text { numbers of repository nodes in } \\
\text { each infiltration bin. Used in } \\
\text { UZ transport abstraction model } \\
\text { as part of radionuclide release } \\
\text { model in GoldSim (BSC } 2003 \\
\text { [DIRS 161572]) system model. }\end{array}$ & $\begin{array}{l}\text { LL030610323122.029 } \\
\text { [DIRS 164513] }\end{array}$ & LA0407BR831371.001 \\
\hline wt.zone & $\begin{array}{l}\text { Zone lists containing node } \\
\text { numbers of grid nodes in each } \\
\text { collection node at the water } \\
\text { table. }\end{array}$ & $\begin{array}{l}\text { LB03023DSSCP9I.001 } \\
\text { [DIRS 163044] }\end{array}$ & LA0407BR831371.001 \\
\hline fehm_la.zone2 & $\begin{array}{l}\text { Zone files containing node } \\
\text { numbers in different rock layers } \\
\text { and the repository and water } \\
\text { table collection bins from } \\
\text { repo.zone.xls and wt.zone. }\end{array}$ & $\begin{array}{l}\text { LB0305TSPA18FF.001 } \\
\text { [DIRS 165625] repo.zone.xls } \\
\text { and wt.zone }\end{array}$ & LA0407BR831371.001 \\
\hline fracture_pf.doc & $\begin{array}{l}\text { File contains developed } \\
\text { fracture porosity and frequency } \\
\text { distribution data to be used in } \\
\text { LA. }\end{array}$ & $\begin{array}{l}\text { LB0205REVUZPRP.001 } \\
\text { [DIRS 159525] } \\
\text { LB0207REVUZPRP.001 } \\
\text { [DIRS 159526] }\end{array}$ & LA0407BR831371.001 \\
\hline matrix_ekwc.doc & $\begin{array}{l}\text { Matrix water content and } \\
\text { effective permeability } \\
\text { distributions developed for } \\
\text { estimating matrix diffusion } \\
\text { coefficient. }\end{array}$ & $\begin{array}{l}\text { LB03023DSSCP9I.001 } \\
\text { [DIRS 163044] }\end{array}$ & LA0407BR831371.001 \\
\hline
\end{tabular}


Table 8-2. Computer Files Comprising the UZ Transport Abstraction Model (Continued)

\begin{tabular}{|c|c|c|c|}
\hline $\begin{array}{c}\text { Computer Files } \\
\text { Comprising the } \\
\text { UZ Transport } \\
\text { Process Model } \\
\end{array}$ & $\begin{array}{l}\text { Qualitative Description and } \\
\text { Intended Use }\end{array}$ & $\begin{array}{c}\text { Data Tracking Number Used } \\
\text { to Develop }\end{array}$ & Product Output DTN \\
\hline \multicolumn{4}{|c|}{ Files Developed in This Report } \\
\hline $\begin{array}{l}\text { uz_tfcurves_nn_3 } \\
960 . i n \\
\text { uz_tfcurves_dual } \\
\text { k_nn_3960.in }\end{array}$ & $\begin{array}{l}\text { Transfer function curves for } \\
\text { implementing the RTTF particle } \\
\text { tracking model for upscaling of } \\
\text { fracture-matrix interaction } \\
\text { process. }\end{array}$ & N/A, developed output & LA0311BR831229.001 \\
\hline $\begin{array}{l}\text { fehm_amr_base. } \\
\text { dat }\end{array}$ & $\begin{array}{l}\text { All control parameters for the } \\
\text { FEHM simulation. Used as main } \\
\text { input file for UZ transport } \\
\text { process model. }\end{array}$ & N/A, developed output & LA0407BR831371.001 \\
\hline
\end{tabular}

DTN=data tracking number; FEHM=finite element heat and mass (model); LA=license application;

RTTF=residence time transfer function; UZ=unsaturated zone

\subsubsection{Output Uncertainty}

The calculation of UZ transport uncertainties in the TSPA-LA model will be performed and documented in the TSPA-LA model report because the radionuclide source term is computed using the system model, of which the UZ transport abstraction model is a part. The goal of the present model report is to ensure that a computational tool is set up for TSPA to perform the simulation modeling, and that the uncertainties of parameters in the abstraction model are fully justified and documented. Those goals have been accomplished, in that the software and computer files needed to perform the modeling have been completed, allowing parameter and conceptual uncertainties in the UZ transport to be propagated through the TSPA-LA model.

The uncertainties associated with transport in the UZ have been documented in the model report for UZ transport (BSC 2004 [DIRS 164500]), and have been summarized briefly in the present model report. Of note is the fact that both parameter and conceptual model uncertainty have been shown to be incorporated into this abstraction. The key ACMs discussed in the report by BSC (2004 [DIRS 164500]) and Section 6.7 of this report relate to the treatment of fracturematrix interactions. Model validation simulations presented in Section 7 suggest strongly that the particle tracking formulation in the abstraction model developed in FEHM replicates the behavior of the process model, and does so in a computationally efficient manner. In addition, simulations using transfer function curves implemented with a dual-k or DFM conceptual model for $\mathrm{f} / \mathrm{m}$ interactions were shown to yield reasonable results. Thus, both $\mathrm{f} / \mathrm{m}$ interaction models could conceivably be investigated in TSPA simulations. However, due to the fact that process model validation activities were performed based on a dual-k model, the dual-k transfer functions (file uz_tfcurves_dualk_nn_3960.in) should be used in TSPA analyses. The transfer functions based on the DFM conceptual model (file uz_tfcurves_nn_3960.in), are provided because the DFM was required to test the implementation of the particle tracking model through comparison to other numerical models. The DFM representation, though perhaps a more physically realistic scenario for diffusion between the media, should only be used for code validation or sensitivity analyses unless a parallel validation effort of the process model using a DFM formulation is successfully carried out in the future. 


\subsection{HOW THE APPLICABLE ACCEPTANCE CRITERIA ARE ADDRESSED}

The pertinent requirements and acceptance criteria for this report are identified in Section 2.2.1.3.7.3 of the Yucca Mountain Review Plan, Final Report (NRC 2003 [DIRS 163274]). This section describes how the applicable acceptance criteria identified in Section 4.2 have been addressed in this report. In most cases, the applicable acceptance criteria are not addressed solely by this report; rather, the acceptance criteria are fully addressed when this report is considered in conjunction with other analysis and model reports that describe radionuclide transport in the unsaturated zone. Where a subcriterion includes several components, only some of those components may be addressed. How these components are addressed is summarized below.

\section{Acceptance Criterion 1: System Description and Model Integration Are Adequate.}

(1) Total system performance assessment adequately incorporates important design features, physical phenomena, and couplings, and uses consistent and appropriate assumptions throughout the radionuclide transport in the unsaturated zone abstraction process;

Adequacy of the incorporation of important features and phenomena in the TSPA-LA and of the technical bases for their descriptions is demonstrated by the scope and discussion of the issues addressed. Section 6.4 describes the construction of the UZ transport abstraction model, including the model formulation (Section 6.4.1); physical phenomena such as dispersion (6.4.2), sorption and matrix diffusion (Section 6.4.3); decay/ingrowth (Section 6.4.4); and radionuclide transport via colloids (Section 6.4.5). Consistent and appropriate assumptions are used throughout the abstraction process as illustrated by incorporation of the following factors: UZ radionuclide transport is controlled by UZ flow, which is integrated into the transport model through the use of steady state flow fields (Section 6.5.1); long-term transients caused by climate change are also incorporated (Section 6.4.8), as are the impacts of water table rise (Section 6.4.8). This report also describes the coupling of the UZ transport model to the EBS release model (Section 6.4.7) and the SZ transport model (Section 6.5.16).

(2) The description of the aspects of hydrology, geology, geochemistry, design features, physical phenomena, and couplings that may affect radionuclide transport in the unsaturated zone is adequate. For example, the description includes changes in transport properties in the unsaturated zone, from water-rock interaction. Conditions and assumptions in the total system performance assessment abstraction of radionuclide transport in the unsaturated zone are readily identified, and consistent with the body of data presented in the description;

Adequacy of the description of important features that may affect radionuclide transport in the unsaturated zone is demonstrated by the discussion of the issues addressed, as enumerated above. Assumptions specific to the UZ transport abstraction model are listed in Section 5. In addition, the UZ transport abstraction model incorporates many assumptions and conditions from the coupling to the UZ flow model. For example, the use of pregenerated steady state flow fields from the UZ flow model implies that the same hydrogeologic features developed in the flow modeling effort (BSC 2004 [DIRS 169861]) are automatically built into the UZ transport abstraction model. Hydrogeologic features 
and layering, fluid flow rates and their uncertainties, the role of fractures, and the largescale flow patterns though the UZ are therefore included in the TSPA-LA abstraction and are consistent with those developed in the flow model.

(3) The abstraction of radionuclide transport in the unsaturated zone uses assumptions, technical bases, data, and models that are appropriate and consistent with other related U.S. Department of Energy abstractions. For example, assumptions used for radionuclide transport in the unsaturated zone are consistent with the abstractions of radionuclide release rates and solubility limits and flow paths in the unsaturated zone (Sections 2.2.1.3.4 and 2.2.1.3.6 of the Yucca Mountain Review Plan, respectively). The descriptions and technical bases provide transparent and traceable support for the abstraction of radionuclide transport in the unsaturated zone;

The basic model formulation employed in the UZ transport abstraction model is consistent with those of other components of the TSPA-LA model. Radionuclide releases from the EBS are treated as aqueous and colloidal species. The UZ transport abstraction model tracks these species through the UZ model as aqueous and colloidal species using consistent assumptions regarding their mobility. This is evidenced by the consistent treatment used to estimate sorption coefficients (Section 6.5.4) in the UZ and SZ transport models and the consistent treatment of colloid properties in the EBS, UZ, and SZ models (Sections 6.5.12 and 6.5.13). The UZ and SZ transport models also adopt similar transport mechanisms where applicable: fracture flow and matrix diffusion are treated in a similar fashion in the two models. Thus, the descriptions and technical bases provide transparent and traceable support for the abstraction of radionuclide transport in the unsaturated zone.

(4) Boundary and initial conditions used in the abstraction of radionuclide transport in the unsaturated zone are propagated throughout its abstraction approaches. For example, the conditions and assumptions used to generate transport parameter values are consistent with other geological, hydrological, and geochemical conditions in the total system performance assessment.

Boundary conditions in terms of the extent of the model domain in three-dimensional space is the same as that of the UZ flow model (see Section 6.5). Regarding the consistency of the UZ transport abstraction model with the UZ flow model, this occurs automatically by directly incorporating flow model results into the transport model. In addition, the release of radionuclides to the UZ model is controlled, in part, by the local infiltration patterns across the repository. The spatial dependence of these releases is included in a consistent fashion in the UZ transport abstraction model by using "bins" of similar infiltration rates in the EBS and UZ transport models (Section 6.5.15).

(5) Sufficient data and technical bases for the inclusion of features, events, and processes related to radionuclide transport in the unsaturated zone in the total system performance assessment abstraction are provided;

Features, events, and processes included in the UZ transport abstraction model are discussed in Section 6.2 of this report. 
(6) Guidance in NUREG-1297 and NUREG-1298 (Altman et al. 1988 [DIRS 103597]; Altman et al. 1988 [DIRS 103750]), or other acceptable approaches, is followed for peer review and data qualification.

All input data have been used in accordance with applicable quality assurance procedures developed consistently with the Quality Assurance Requirements and Description, which commits to these NUREGs.

\section{Acceptance Criterion 2: Data Are Sufficient for Model Justification.}

(1) Geological, hydrological, and geochemical values used in the license application are adequately justified (e.g., flow-path length, sorption coefficients, retardation factors, colloid concentrations, etc.). Adequate descriptions of how the data were used, interpreted, and appropriately synthesized into the parameters are provided;

Section 6.5 of this model report provides a detailed discussion of the underlying data used to develop parameter uncertainty ranges for all transport parameters. Data uncertainties also are addressed. The sufficiency of the data to support the models is demonstrated by the scope of issues addressed: dispersivity in Section 6.5.2, matrix porosity and rock density in Section 6.5.3, matrix sorption in Section 6.5.4, matrix diffusion in Section 6.5.5, fracture residual saturation and active fracture model gamma parameters in Section 6.5.6, fracture porosity, fracture spacing and fracture aperture in Section 6.5.7, fracture surface retardation in Section 6.5.8, colloid filtration at matrix interface in Section 6.5.9, colloid size exclusion in Section 6.5.10, colloid size distribution in Section 6.5.11, colloid concentration and colloid equilibrium sorption in Section 6.5.12, fraction of colloids traveling unretarded and colloid retardation factor in Section 6.5.13, radionuclide half lives and daughter products in Section 6.5.14, repository radionuclide release bins in Section 6.5.15, and radionuclide collecting bins at UZ/SZ interface in Section 6.5.16. These sections also provide adequately transparent and traceable descriptions of how the data were used, interpreted, and appropriately synthesized in model parameters.

(2) Sufficient data have been collected on the characteristics of the natural system to establish initial and boundary conditions for the total system performance assessment abstraction of radionuclide transport in the unsaturated zone;

Because the UZ transport abstraction model incorporates the flow fields from the UZ flow model, initial and boundary conditions in three-dimensional space are the same as that of the UZ flow model (see Section 6.5). Those flow fields are based on sufficient data, including hydrogeologic layering, structural features, rock hydrologic properties, fluid saturations, flow velocities, extent of fracture flow, and large-scale flow patterns. Discussion of the underlying development of the data used to develop the basic characteristics of the natural system is presented in UZ Flow Models and Submodels (BSC 2004 [DIRS 169861]) and documents referred to therein.

(3) Data on the geology, hydrology, and geochemistry of the unsaturated zone, including the influence of structural features, fracture distributions, fracture properties, and stratigraphy, used in the total system performance assessment abstraction are based on appropriate 
techniques. These techniques may include laboratory experiments, site-specific field measurements, natural analogue research, and process-level modeling studies. As appropriate, sensitivity or uncertainty analyses used to support the U.S. Department of Energy total system performance assessment abstraction are adequate to determine the possible need for additional data.

As discussed above, because the UZ transport abstraction model incorporates the flow fields from the UZ flow model, data on geology, hydrology, and geochemistry of the unsaturated zone, including the influence of structural features, fracture distributions, fracture properties, and stratigraphy, used in the total system performance assessment abstraction are based on appropriate techniques.

\section{Acceptance Criterion 3: Data Uncertainty Is Characterized and Propagated Through the Model Abstraction.}

(1) Models use parameter values, assumed ranges, probability distributions, and bounding assumptions that are technically defensible, reasonably account for uncertainties and variabilities, and do not result in an under-representation of the risk estimate;

Section 6.5 of this model report provides a detailed discussion of the development of parameter values, uncertainty ranges, probability distributions, and, where applicable, bounding assumptions, showing that they are technically defensible, reasonably account for uncertainties and variabilities, and do not result in an under-representation of the risk estimate for all transport parameters.

(2) For those radionuclides where the total system performance assessment abstraction indicates that transport in fractures and matrix in the unsaturated zone is important to waste isolation: (i) estimated flow and transport parameters are appropriate and valid, based on techniques that may include laboratory experiments, field measurements, natural analogue research, and process-level modeling studies conducted under conditions relevant to the unsaturated zone at Yucca Mountain; and (ii) models are demonstrated to adequately reproduce field transport test results. For example, if a sorption coefficient approach is used, the assumptions implicit in that approach are verified;

The techniques used to estimate flow and transport parameters were conducted under conditions relevant to the unsaturated zone at Yucca Mountain, as described in Section 6.5. The method used to validate the UZ transport abstraction model is to benchmark its predictions against the validated UZ transport process model as presented in Radionuclide Transport Models Under Ambient Conditions (BSC 2004 [DIRS 164500]). The series of simulations presented in Section 7, along with additional simulations performed to test the performance of the model in the FEHM verification and validation documentation, provide assurance that the $\mathrm{UZ}$ transport system is adequately captured in the abstraction model that is the subject of this report. Three classes of comparisons of increasing complexity were made. The least complex showed the validity of the particle tracking method by a comparison with a discrete fracture model in Section 7.2.1. These comparisons tested advective transport between continua (Section 7.2.1.1), diffusion for fracture-dominated flow (Section 7.2.1.2), and diffusion and sorption in the intermediate flow case (Section 
7.2.1.3). A more complex comparison between the particle tracking model and simulations in a two-dimensional cross sectional model in section 7.2.2 showed the ability of the model to replicate the behavior of the comparable process models. This included use of the dual-k and MINC model formulations. Finally, the full complexity of the full three-dimensional transport model used in TSPA-LA was compared to the abstraction model in Section 7.2.3 and the quality of the agreement is discussed in Section 7.2.3.1. The conclusion that the abstraction model robustly and efficiently represents the system over the entire range of parameters is explained in Section 7.3.

(4) Uncertainty is adequately represented in parameter development for conceptual models, process-level models, and alternative conceptual models considered in developing the abstraction of radionuclide transport in the unsaturated zone. This may be done either through sensitivity analyses or use of conservative limits;

In the UZ transport abstraction model, uncertainties are represented as uncertain transport parameters (Section 6.5), as well as the use of different steady state flow fields to capture uncertainty in the flow conditions. In a few cases, such as the assumption that there is no sorption onto fracture walls, approaches that are clearly conservative were adopted to treat a process for which insufficient data exists to establish parameter uncertainty ranges (Section 6.5.8).

\section{Acceptance Criterion 4: Model Uncertainty Is Characterized and Propagated Through} the Model Abstraction.

(1) Alternative modeling approaches of features, events, and processes are considered and are consistent with available data and current scientific understanding, and the results and limitations are appropriately considered in the abstraction;

Most instances of alternative conceptual models of UZ transport have been examined at the process model stage as presented in Radionuclide Transport Models Under Ambient Conditions (BSC 2004 [DIRS 164500]) and have not been carried forth into this abstraction model. An exception is the fracture/matrix interaction model, which has been shown to be consistent with site conditions, as discussed in Section 6.4.3.

(2) Conceptual model uncertainties are adequately defined and documented, and effects on conclusions regarding performance are properly assessed;

Uncertainties in alternative models for fracture/matrix interaction are defined, documented and assessed in Section 7.2.3.2.

(3) Consideration of conceptual model uncertainty is consistent with available site characterization data, laboratory experiments, field measurements, natural analogue information and process-level modeling studies; the treatment of conceptual mode uncertainty does not result in an under-representation of the risk estimate;

The UZ transport process model presented in Radionuclide Transport Models Under Ambient Conditions (BSC 2004 [DIRS 164500]) contains a discussion of conceptual model uncertainty as it relates to characterization data, laboratory experiments, and field 
measurements. This abstraction model report implements the key conceptual model components developed in Radionuclide Transport Models Under Ambient Conditions (BSC 2004 [DIRS 164500]).

(4) Appropriate alternative modeling approaches are consistent with available data and current scientific knowledge, and appropriately consider their results and limitations, using tests and analyses that are sensitive to the processes modeled. For example, for radionuclide transport through fractures, the U.S. Department of Energy adequately considers alternative modeling approaches to develop its understanding of fracture distributions and ranges of fracture flow and transport properties in the unsaturated zone.

The UZ transport process model presented in Radionuclide Transport Models Under Ambient Conditions (BSC 2004 [DIRS 164500]) contains a discussion of alternative modeling approaches for important model uncertainties in the areas of fracture flow and transport, colloid-facilitated transport, and sorption. This abstraction model report implements the key model assumptions and processes developed in Radionuclide Transport Models Under Ambient Conditions (BSC 2004 [DIRS 164500]).

\section{Acceptance Criterion 5: Model Abstraction Output Is Supported by Objective Comparisons.}

(1) The models implemented in this total system performance assessment abstraction provide results consistent with output from detailed process-level models and/or empirical observations (laboratory and field testing and/or natural analogues);

The direct comparisons to the UZ transport process model presented in Section 7 show that this total system performance assessment abstraction provide results consistent with output from detailed process-level models.

(2) Outputs of radionuclide transport in the unsaturated zone abstractions reasonably produce or bound the results of corresponding process-level models, empirical observations, or both. The U.S. Department of Energy abstracted models for radionuclide transport in the unsaturated zone are based on the same hydrological, geological, and geochemical assumptions and approximations, shown to be appropriate for closely analogous natural systems or experimental systems;

The satisfactory results of the direct comparisons to the UZ transport process model are presented in Section 7 as discussed above. The use of the same model grid, formulation, and steady state flow fields as the UZ transport process model ensures that this criterion is satisfied.

(3) Well-documented procedures that have been accepted by the scientific community to construct and test the mathematical and numerical models are used to simulate radionuclide transport through the unsaturated zone;

Several leading members of the scientific community, including personnel from the National Laboratories, have participated in the construction and testing of the mathematical and numerical models used to simulate radionuclide transport through the SZ. These 
scientists use methods based on their education and training. The procedures have been published in peer-reviewed journals and discussed at scientific meetings. Thus, the procedures are well-documented and have been accepted by the scientific community. Moreover, applicable quality assurance procedures and project guidance have been followed to test the UZ transport abstraction model. The process used in Section 7 to benchmark the model results against a similarly constructed numerical model that uses different numerical solution procedures is a scientifically valid, well accepted technique for assuring the correct functioning of the UZ transport abstraction model.

(4) Sensitivity analyses or bounding analyses are provided, to support the total system performance assessment abstraction of radionuclide transport in the unsaturated zone, that cover ranges consistent with site data, field or laboratory experiments and tests, and natural analogue research.

Model sensitivity to a variety of flow and transport parameters are included in this report: infiltration rate and flow conditions (Section 7.2.3.1); diffusion behavior (Sections 7.2.1.2 and 7.2.3.2); fracture flow focusing parameters (Section 7.2.3.3); and sorption coefficient (Section 7.2.1.3). A representative case that includes radionuclide species with a variety of transport parameters as well as both colloidal and aqueous species, is also presented (Section 6.6.2). These analyses support the determination that the model uses ranges consistent with available data. 


\section{INTENTIONALLY LEFT BLANK}




\section{INPUTS AND REFERENCES}

The following is a list of the references cited in this document. Column 2 represents the unique six-digit numerical identifier (the Document Input Reference System [DIRS] number), which is placed in the text following the reference callout (e.g., BSC 2004 [DIRS 171282]). The purpose of these numbers is to assist the reader in locating a specific reference in the DIRS database. Within the reference list, multiple sources by the same author (e.g., BSC 2002) are sorted alphabetically by title.

\subsection{DOCUMENTS CITED}

Akindunni, F.F.; Gillham, R.W.; Conant, B.; and Franz, T. 1995. "Modeling of

101378

Contaminant Movement Near Pumping Wells: Saturated-Unsaturated Flow with Particle Tracking.” Ground Water, 33, (2), 264-274. Worthington, Ohio: National Water Well Association. TIC: 226455.

Altman, W.D.; Donnelly, J.P.; and Kennedy, J.E. 1988. Peer Review for High-Level

103597 Nuclear Waste Repositories: Generic Technical Position. NUREG-1297. Washington, D.C.: U.S. Nuclear Regulatory Commission. TIC: 200651.

Altman, W.D.; Donnelly, J.P.; and Kennedy, J.E. 1988. Qualification of Existing 103750 Data for High-Level Nuclear Waste Repositories: Generic Technical Position. NUREG-1298. Washington, D.C.: U.S. Nuclear Regulatory Commission. TIC: 200652.

BSC (Bechtel SAIC Company, LLC) 2002. Radionuclide Screening. 160059 ANL-WIS-MD-000006 REV 01. Las Vegas, Nevada: Bechtel SAIC Company. ACC: MOL.20020923.0177.

BSC 2003. Analysis of Hydrologic Properties Data. MDL-NBS-HS-000014 161773 REV 00. Las Vegas, Nevada: Bechtel SAIC Company.

ACC: DOC.20030908.0001.

BSC 2004. Analysis of Hydrologic Properties Data. ANL-NBS-HS-000042

REV 00. Las Vegas, Nevada: Bechtel SAIC Company.

ACC: DOC.20041005.0004.

BSC 2004. Calibrated Properties Model. MDL-NBS-HS-000003 REV 02.

Las Vegas, Nevada: Bechtel SAIC Company. ACC: DOC.20041006.0004.

BSC 2004. Conceptual Model and Numerical Approaches for Unsaturated Zone

Flow and Transport. MDL-NBS-HS-000005 REV 01. Las Vegas, Nevada: Bechtel SAIC Company. ACC: DOC.20040922.0006.

BSC 2004. Drift-Scale Coupled Processes (DST and TH Seepage) Models. 170338 MDL-NBS-HS-000015 REV 01. Las Vegas, Nevada: Bechtel SAIC Company. ACC: DOC.20040930.0003. 
BSC 2004. Drift-Scale Radionuclide Transport. MDL-NBS-HS-000016 REV 01. 170040 Las Vegas, Nevada: Bechtel SAIC Company. ACC: DOC.20040927.0031.

BSC 2004. Features, Events, and Processes in UZ Flow and Transport.

170012 ANL-NBS-MD-000001, Rev. 03. Las Vegas, Nevada: Bechtel SAIC Company.

BSC 2004. Future Climate Analysis. ANL-NBS-GS-000008 REV 01. Las Vegas, Nevada: Bechtel SAIC Company. ACC: DOC.20040908.0005.

BSC 2004. Initial Radionuclide Inventories. ANL-WIS-MD-000020 REV 01. Las Vegas, Nevada: Bechtel SAIC Company. ACC: DOC.20040921.0003.

BSC 2004. Mountain-Scale Coupled Processes (TH/THC/THM). 169866 MDL-NBS-HS-000007 REV 02. Las Vegas, Nevada: Bechtel SAIC Company.

BSC 2004. Multiscale Thermohydrologic Model. ANL-EBS-MD-000049 REV 02. Las Vegas, Nevada: Bechtel SAIC Company. ACC: DOC.20041014.0008.

BSC 2004. Q-List. 000-30R-MGR0-00500-000-000 REV 00. Las Vegas, Nevada: 168361 Bechtel SAIC Company. ACC: ENG.20040721.0007.

BSC 2004. Radionuclide Transport Models Under Ambient Conditions.

164500 MDL-NBS-HS-000008, Rev. 02. Las Vegas, Nevada: Bechtel SAIC Company.

BSC (Bechtel SAIC Company) 2004. Saturated Zone Colloid Transport. 170006 ANL-NBS-HS-000031 REV 02. Las Vegas, Nevada: Bechtel SAIC Company. ACC: DOC.20041008.0007.

BSC 2004. Saturated Zone Flow and Transport Model Abstraction. 170042 MDL-NBS-HS-000021, Rev. 02. Las Vegas, Nevada: Bechtel SAIC Company.

BSC 2004. Saturated Zone In-Situ Testing. ANL-NBS-HS-000039, Rev. 01. 170010 Las Vegas, Nevada: Bechtel SAIC Company.

BSC 2004. Saturated Zone Site-Scale Flow Model. MDL-NBS-HS-000011, 170037 Rev. 02. Las Vegas, Nevada: Bechtel SAIC Company.

BSC 2004. Technical Work Plan for: Unsaturated Zone Transport Model Report 171282 Integration. TWP-MGR-HS-000002 REV 00 ICN 01. Las Vegas, Nevada: Bechtel SAIC Company. ACC: DOC.20040816.0001.

BSC 2004. Thermal Conductivity of the Potential Repository Horizon. 169854 MDL-NBS-GS-000005 REV 01. Las Vegas, Nevada: Bechtel SAIC Company. ACC: DOC.20040928.0006.

BSC 2004. UZ Flow Models and Submodels. MDL-NBS-HS-000006, Rev. 02. Las Vegas, Nevada: Bechtel SAIC Company. 
BSC 2004. Waste Form and In-Drift Colloids-Associated Radionuclide

170025

Concentrations: Abstraction and Summary. MDL-EBS-PA-000004, Rev. 01.

Las Vegas, Nevada: Bechtel SAIC Company.

Canori, G.F. and Leitner, M.M. 2003. Project Requirements Document.

166275

TER-MGR-MD-000001 REV 02. Las Vegas, Nevada: Bechtel SAIC Company.

ACC: DOC.20031222.0006.

Chiang, C.Y.; Wheeler, M.F.; and Bedient, P.D. 1989. “A Modified Method of

Characteristics Technique and Mixed Finite Elements Method for Simulation of Groundwater Solute Transport.” Water Resources Research, 25, (7), 1541-1549.

Washington, D.C.: American Geophysical Union. TIC: 226452.

Cordes, C. and Kinzelbach, W. 1992. “Continuous Groundwater Velocity Fields

and Path Lines in Linear, Bilinear, and Trilinear Finite Elements.” Water Resources

Research, 28, (11), 2903-2911. Washington, D.C.: American Geophysical Union.

TIC: 226449.

CRWMS (Civilian Radioactive Waste Management) M\&O (Management and

154071

Operating Contractor) 2001. Colloid-Associated Radionuclide Concentration

Limits: ANL. ANL-EBS-MD-000020 REV 00 ICN 01. Las Vegas, Nevada:

CRWMS M\&O. ACC: MOL.20010216.0003.

Czarnecki, J.B. 1984. Simulated Effects of Increased Recharge on the Ground-

Water Flow System of Yucca Mountain and Vicinity, Nevada-California.

Water-Resources Investigations Report 84-4344. Denver, Colorado: U.S.

Geological Survey. ACC: HQS.19880517.1750.

D'Agnese, F.A.; O'Brien, G.M.; Faunt, C.C.; and San Juan, C.A. 1999. Simulated Effects of Climate Change on the Death Valley Regional Ground-Water Flow System, Nevada and California. Water-Resources Investigations Report 98-4041.

Denver, Colorado: U.S. Geological Survey. TIC: 243555.

Desbarats, A.J. 1990. “Macrodispersion in Sand-Shale Sequences.” Water 101386

Resources Research, 26, (1), 153-163. Washington, D.C.: American Geophysical Union. TIC: 236576.

DOE (U.S. Department of Energy) 1998. Overview - Viability Assessment of a Repository at Yucca Mountain. DOE/RW-0508. Washington, D.C.: U.S. Department of Energy, Office of Civilian Radioactive Waste Management. ACC: MOL.19981007.0027.

Fabriol, R.; Sauty, J.P.; and Ouzounian, G. 1993. "Coupling Geochemistry with a 101387 Particle Tracking Transport Model.” Journal of Contamination Hydrology, 13, 117-129. New York, New York: Elsevier. TIC: 222395. 
Flint, L.E. 1998. Characterization of Hydrogeologic Units Using Matrix

100033

Properties, Yucca Mountain, Nevada. Water-Resources Investigations Report

97-4243. Denver, Colorado: U.S. Geological Survey. ACC: MOL.19980429.0512.

Forester, R.M.; Bradbury, J.P.; Carter, C.; Elvidge-Tuma, A.B.; Hemphill, M.L.;

109425

Lundstrom, S.C.; Mahan, S.A.; Marshall, B.D.; Neymark, L.A.; Paces, J.B.;

Sharpe, S.E.; Whelan, J.F.; and Wigand, P.E. 1999. The Climatic and Hydrologic

History of Southern Nevada During the Late Quaternary. Open-File Report 98-635.

Denver, Colorado: U.S. Geological Survey. TIC: 245717.

Freeze, R.A. and Cherry, J.A. 1979. Groundwater. Englewood Cliffs, New Jersey:

101173

Prentice-Hall. TIC: 217571.

Grathwohl, P. 2000. Diffusion in Natural Porous Media: Contaminant Transport, Sorption/Desorption and Dissolution Kinetics. Boston, Massachusetts: Kluwer Academic Publishers. TIC: 247983.

Hogg, R.V. and Craig, A.T. 1978. Introduction to Mathematical Statistics.

163236

$4^{\text {th }}$ Edition. New York, New York: Macmillan. TIC: 254311.

Johnson, J.A.; Ravi, V.; and Rumery, J.K. 1994. "Estimation of Solute

Concentrations Using the Pathline Counting Method." Ground Water, 32, (5),

719-726. Worthington, Ohio: National Water Well Association. TIC: 226453.

Kinzelbach, W. 1988. The Random Walk Method in Pollutant Transport

101402

Simulation. Groundwater Flow and Quality Modelling. Pages 227-245. Norwell, Massachusetts: D. Reidel Publishing Company. TIC: 224064.

LANL (Los Alamos National Laboratory) 2003. Validation Test Plan (VTP) for the FEHM Application Version 2.21. 10086-VTP-2.21-00. Los Alamos, New Mexico:

Los Alamos National Laboratory. ACC: MOL.20031031.0264;

MOL.20031031.0265.

Latinopoulos, P. and Katsifarakis, K. 1991. “A Boundary Element and Particle

101408

Tracking Model for Advective Transport in Zoned Aquifers." Journal of Hydrology, 124, 159-176. Amsterdam, The Netherlands: Elsevier. TIC: 226466.

Levy, S.S. 1991. "Mineralogic Alteration History and Paleohydrology at Yucca 100053 Mountain, Nevada." High Level Radioactive Waste Management, Proceedings of the Second Annual International Conference, Las Vegas, Nevada, April 28-May 3, 1991. 1, 477-485. La Grange Park, Illinois: American Nuclear Society.

TIC: 204272.

Liu, H.H.; Doughty, C.; and Bodvarsson, G.S. 1998. "An Active Fracture Model for Unsaturated Flow and Transport in Fractured Rocks.” Water Resources Research, 34, (10), 2633-2646. Washington, D.C.: American Geophysical Union. TIC: 243012. 
Lu, N. 1994. "A Semianalytical Method of Path Line Computation for Transient

101413

Finite-Difference Groundwater Flow Models.” Water Resources Research, 30, (8), 2449-2459. Washington, D.C.: American Geophysical Union. TIC: 211997.

Maloszewski, P. and Zuber, A. 1991. "Influence of Matrix Diffusion and Exchange Reactions on Radiocarbon Ages in Fissured Carbonate Aquifers.” Water Resources Research, 27, (8), 1937-1945. Washington, D.C.: American Geophysical Union. TIC: 247494.

Marshall, B.D.; Peterman, Z.E.; and Stuckless, J.S. 1993. "Strontium Isotopic Evidence for a Higher Water Table at Yucca Mountain.” High Level Radioactive Waste Management, Proceedings of the Fourth Annual International Conference, Las Vegas, Nevada, April 26-30, 1993. 2, 1948-1952. La Grange Park, Illinois: American Nuclear Society. TIC: 208542.

Neretnieks, I. 1980. "Diffusion in the Rock Matrix: An Important Factor in 101148 Radionuclide Retardation.” Journal of Geophysical Research, 85, (B8), 4379-4397. Washington, D.C.: American Geophysical Union. TIC: 221345.

Neuman, S.P. 1984. “Adaptive Eulerian-Lagrangian Finite Element Method for 101463 Advection-Dispersion.” International Journal for Numerical Methods in Engineering, 20, 321-337. New York, New York: John Wiley \& Sons. TIC: 226440.

Neuman, S.P. 1990. "Universal Scaling of Hydraulic Conductivities and 101464 Dispersivities in Geologic Media.” Water Resources Research, 26, (8), 1749-1758. Washington, D.C.: American Geophysical Union. TIC: 237977.

NRC (U.S. Nuclear Regulatory Commission) 2003. Yucca Mountain Review Plan, Final Report. NUREG-1804, Rev. 2. Washington, D.C.: U.S. Nuclear Regulatory Commission, Office of Nuclear Material Safety and Safeguards. TIC: 254568.

Parrington, J.R.; Knox, H.D.; Breneman, S.L.; Baum, E.M.; and Feiner, F. 1996. Nuclides and Isotopes, Chart of the Nuclides. 15th Edition. San Jose, California: General Electric Company and KAPL, Inc. TIC: 233705.

Pollock, D.W. 1988. "Semianalytical Computation of Path Lines for 101466 Finite-Difference Models.” Ground Water, 26, (6), 743-750. Worthington, Ohio: National Water Well Association. TIC: 226464.

Reimus, P.W. 1995. The Use of Synthetic Colloids in Tracer Transport 101474 Experiments in Saturated Rock Fractures. Ph.D. dissertation. LA-13004-T. Los Alamos, New Mexico: Los Alamos National Laboratory. TIC: 240694. 
Reimus, P.W.; Adams, A.; Haga, M.J.; Humphrey, A.; Callahan, T.; Anghel, I.; and 126243 Counce, D. 1999. Results and Interpretation of Hydraulic and Tracer Testing in the Prow Pass Tuff at the C-Holes. Milestone SP32E7M4. Los Alamos, New Mexico: Los Alamos National Laboratory. TIC: 246377.

Reimus, P.W.; Ware, S.D.; Benedict, F.C.; Warren, R.G.; Humphrey, A.; Adams, A.; Wilson, B.; and Gonzales, D. 2002. Diffusive and Advective Transport of ${ }^{3} \mathrm{H}$, ${ }^{14} \mathrm{C}$, and ${ }^{99}$ Tc in Saturated, Fractured Volcanic Rocks from Pahute Mesa, Nevada. LA-13891-MS. Los Alamos, New Mexico: Los Alamos National Laboratory. TIC: 253905.

Robinson, B.A. 1994. “A Strategy for Validating a Conceptual Model for Radionuclide Migration in the Saturated Zone Beneath Yucca Mountain.” Radioactive Waste Management and Environmental Restoration, 19, (1-3), 73-96. Yverdon, Switzerland: Harwood Academic Publishers. TIC: 222513.

Robinson, B.A.; Li, C.; and Ho, C.K. 2003. "Performance Assessment Model Development and Analysis of Radionuclide Transport in the Unsaturated Zone, Yucca Mountain, Nevada.” Journal of Contaminant Hydrology, 62-63, 249-268. New York, New York: Elsevier. TIC: 254205.

Rousseau, J.P.; Kwicklis, E.M.; and Gillies, D.C., eds. 1999. Hydrogeology of the 102097 Unsaturated Zone, North Ramp Area of the Exploratory Studies Facility, Yucca Mountain, Nevada. Water-Resources Investigations Report 98-4050. Denver, Colorado: U.S. Geological Survey. ACC: MOL.19990419.0335.

Schafer-Perini, A.L. and Wilson, J.L. 1991. "Efficient and Accurate Front Tracking for Two-Dimensional Groundwater Flow Models.” Water Resources Research, 27, (7), 1471-1485. Washington, D.C.: American Geophysical Union. TIC: 226448.

Scheibe, T.D. and Cole, C.R. 1994. "Non-Gaussian Particle Tracking: Application to Scaling of Transport Processes in Heterogeneous Porous Media.” Water Resources Research, 30, (7), 2027-2039. Washington, D.C.: American Geophysical Union. TIC: 226446.

Sudicky, E.A. and Frind, E.O. 1982. "Contaminant Transport in Fractured Porous 105043 Media: Analytical Solutions for a System of Parallel Fractures.” Water Resources Research, 18, (6), 1634-1642. Washington, D.C.: American Geophysical Union. TIC: 217475.

Tompson, A.F.B. and Gelhar, L.W. 1990. "Numerical Simulation of Solute Transport in Three-Dimensional, Randomly Heterogeneous Porous Media.” Water Resources Research, 26, (10), 2541-2562. Washington, D.C.: American Geophysical Union. TIC: 224902. 
van Genuchten, M.T. 1985. "Convective-Dispersive Transport of Solutes Involved in Sequential First-Order Decay Reactions.” Computers in Geosciences, 11, (2), 129-147. New York, New York: Pergamon Press. TIC: 245188.

Wang, J.S. 2003. "Scientific Notebooks Referenced in Model Report U0065, 166070 Particle Tracking Model and Abstraction of Transport Process, MDL-NBS-HS-000020 REV 00.” Letter from J.S. Wang (BSC) to File, December 4, 2003, with attachment. ACC: MOL.20031208.0348.

Wang, J.S. 2003. "Scientific Notebooks Referenced in Model Report U0090, 161654 Analysis of Hydrologic Properties Data, MDL-NBS-HS-000014 REV 00” Interoffice correspondence from J.S. Wang (BSC) to File, February 28, 2003, with attachments. ACC: MOL.20030306.0535.

Wolfsberg, A.V. and Freyberg, D.L. 1994. "Efficient Simulation of Single Species and Multispecies Transport in Groundwater with Local Adaptive Grid Refinement." 101498 Water Resources Research, 30, (11), 2979-2991. Washington, D.C.: American Geophysical Union. TIC: 226450.

Yamashita, R. and Kimura, H. 1990. "Particle-Tracking Technique for Nuclide Decay Chain Transport in Fractured Porous Media.” Journal of Nuclear Science and Technology, 27, (11), 1041-1049. Tokyo, Japan: Nihon Genshryoku Gakkai. TIC: 236573.

Yeh, G.T. 1990. “A Lagrangian-Eulerian Method with Zoomable Hidden FineMesh Approach to Solving Advective-Dispersion Equations.” Water Resources Research, 26, (6), 1133-1144. Washington, D.C.: American Geophysical Union. TIC: 224067.

Zheng, C. 1993. "Extension of the Method of Characteristics for Simulation of 101502 Solute Transport in Three Dimensions.” Ground Water, 31, (3), 456-465. Worthington, Ohio: Water Well Publishing Company. TIC: 226465.

Zheng, C. 1994. "Analysis of Particle Tracking Errors Associated with Spatial Discretization.” Ground Water, 32, (5), 821-828. Dublin, Ohio: Water Well Publishing Company. TIC: 226463.

Zimmerman, R.W.; Chen, G.; Hadgu, T.; and Bodvarsson, G.S. 1993. “A 100614 Numerical Dual-Porosity Model with Semianalytical Treatment of Fracture/Matrix Flow.” Water Resources Research, 29, (7), 2127-2137. Washington, D.C.: American Geophysical Union. TIC: 236571.

Zyvoloski, G.; Dash, Z.; and Kelkar, S. 1992. FEHMN 1.0: Finite Element Heat 101026 and Mass Transfer Code. LA-12062-MS, Rev. 1. Los Alamos, New Mexico: Los Alamos National Laboratory. ACC: NNA.19910625.0038. 
Zyvoloski, G.A.; Robinson, B.A.; Dash, Z.V.; and Trease, L.L. 1997. User's

Manual for the FEHM Application-A Finite-Element Heat- and Mass-Transfer Code. LA-13306-M. Los Alamos, New Mexico: Los Alamos National Laboratory. TIC: 235999.

\subsection{CODES, STANDARDS, REGULATIONS, AND PROCEDURES}

10 CFR 63. Energy: Disposal of High-Level Radioactive Wastes in a Geologic

Repository at Yucca Mountain, Nevada. Readily available.

AP-2.22Q, REV 1, ICN 0. Classification Analyses and Maintenance of the Q-List. Washington, D.C.: U.S. Department of Energy, Office of Civilian Radioactive Waste Management. ACC: DOC.20030807.0002.

AP-2.27Q, Rev. 1, ICN 4. Planning for Science Activities. Washington, D.C.: U.S. Department of Energy, Office of Civilian Radioactive Waste Management.

ACC: DOC.20040610.0006.

AP-SIII.10Q, REV 2 ICN 7. Models. Washington, D.C.: U.S. Department of Energy, Office of Civilian Radioactive Waste Management.

ACC: DOC.20040920.0002.

LP-SI.11Q-BSC, Rev. 0, ICN 1. Software Management. Washington, D.C.: U.S. Department of Energy, Office of Civilian Radioactive Waste Management.

ACC: DOC.20041005.0008.

\subsection{SOURCE DATA, LISTED BY DATA TRACKING NUMBER}

LA0002PR831231.003. Probabilities from C-Wells Microsphere Data. Submittal date: $02 / 17 / 2000$.

LA0002SK831352.003. Colloid Size Distribution and Total Colloid Concentration in INEEL Groundwater Samples. Submittal date: 02/25/2000.

LA0003JC831362.001. Preliminary Matrix Diffusion Coefficients for Yucca Mountain Tuffs. Submittal date: 4/10/2000.

LA0003MCG12213.002. Cumulative Probabilities for Colloid Transport Between 147285 One Matrix and Another Calculated from Interpolation of Pore Volume Data from Yucca Mountain Hydrologic (Stratigraphic) Samples. Submittal date: 03/10/2000.

LA0303HV831352.002. Colloid Retardation Factors for the Saturated Zone 163558 Fractured Volcanics. Submittal date: 03/31/2003. date: 03/31/2003. 
LA0408AM831341.001. Unsaturated Zone Distribution Coefficients (Kds) for U, 171584 Np, Pu, Am, Pa, Cs, Sr, Ra, and Th. Submittal date: 08/24/2004.

LB0205REVUZPRP.001. Fracture Properties for UZ Model Layers Developed 159525 from Field Data. Submittal date: 05/14/2002.

LB0207REVUZPRP.001. Revised UZ Fault Zone Fracture Properties. Submittal 159526 date: 07/03/2002.

LB0207REVUZPRP.002. Matrix Properties for UZ Model Layers Developed from Field and Laboratory Data. Submittal date: 07/15/2002.

LB0208UZDSCPLI.002. Drift-Scale Calibrated Property Sets: Lower Infiltration Data Summary. Submittal date: 08/26/2002.

LB0208UZDSCPMI.002. Drift-Scale Calibrated Property Sets: Mean Infiltration Data Summary. Submittal date: 08/26/2002.

LB0210THRMLPRP.001. Thermal Properties of UZ Model Layers: Data Summary. Submittal date: 10/25/2002.

LB03023DSSCP9I.001. 3-D Site Scale UZ Flow Field Simulations for 9 163044 Infiltration Scenarios. Submittal date: 02/28/2003.

LB0302UZDSCPUI.002. Drift-Scale Calibrated Property Sets: Upper Infiltration 161787 Data Summary. Submittal date: 02/05/2003.

LB0305TSPA18FF.001. Eighteen 3-D Site Scale UZ Flow Fields Converted from TOUGH2 to T2FEHM Format. Submittal date: 05/09/2003.

165625

LB0307MR0060R1.007. Ambient Radionuclide Transport - TSPA Deliverable 164752 Extractions. Submittal date: 07/19/2003.

LB03093RADTRNS.002. Three Way Transport Model Comparison: Data 166071 Summaries. Submittal date: 09/24/2003.

LB0310T2FEHMFF.001. 1-D and 2-D Site Scale UZ Flow Fields Converted from TOUGH2 to T2FEHM Format. Submittal date: 10/20/2003.

166060

LB0312TSPA06FF.001. Six Flow Fields with Raised Water Tables. Submittal 166671 date: $12 / 23 / 2003$.

LB0402THRMLPRP.001. Thermal Properties of UZ Model Layers: Data 168481 Summary. Submittal date: 02/20/2004.

LL000122051021.116. Summary of Analyses of Glass Dissolution Filtrates. 142973 Submittal date: 01/27/2000. 
LL030610323122.029. Multiscale Thermohydrologic Model Output to TSPA and

164513

WAPDEG for the Mean Infiltration Case. Submittal date: 06/27/2003.

LL991109751021.094. Data Associated with the Detection and Measurement of

142910

Colloids in Scientific Notebook SN 1644. Submittal date: 01/10/2000.

MO0407SEPFEPLA.000. LA FEP List. Submittal date: 07/20/2004.

170760

SN0206T0503102.005. Thermal Conductivity of the Non-Repository Layers of

Yucca Mountain. Submittal date: 06/27/02.

SN0208T0503102.007. Thermal Conductivity of the Potential Repository Horizon

160257

Rev 3. Submittal date: 08/26/2002.

SN0306T0502103.006. Data Spreadsheets to Support Parameter Uncertainty

163944

Development. Submittal date: 06/05/2003.

SN0306T0504103.005. Revised Groundwater Colloid Mass Concentration

Parameters for TSPA (Total System Performance Assessment). Submittal date:

06/30/2003.

SN0306T0504103.006. Revised Sorption Partition Coefficients (Kd Values) for

164131

Selected Radionuclides Modeled in the TSPA (Total System Performance

Assessment). Submittal date: 06/30/2003.

\subsection{OUTPUT DATA, LISTED BY DATA TRACKING NUMBER}

LA0311BR831229.001. UZ Transport Abstraction Model, Transfer Function Calculation Files. Submittal date: 11/17/2003.

LA0311BR831371.001. UZ Transport Abstraction Model, Validation Simulations for the Discrete Fracture Comparison Problem. Submittal date: 11/202003.

LA0311BR831371.002. UZ Transport Abstraction Model, Validation Simulations for the Comparison to T2R3D. Submittal date: 11/202003.

LA0407BR831371.001. UZ Transport Abstraction Model, Transport Parameters and Base Case Simulation Results. Submittal date: 07/27 /2004.

\subsection{SOFTWARE CODES}

BSC 2003. Software Code: GoldSim. V7.50.100. PC. 10344-7.50.100-00.

161572

BSC 2004. Software Code: GoldSim. V 8.02. PC, Windows 2000. 10344-8.02-00.

169844

LANL 2003. Software Code: discrete_tf. V1.1. SUN, SunOS 5.8; PC, Windows

165742 2000 and Linux 7.1. 11033-1.1-00. 
LANL 2003. Software Code: FEHM. V2.21. SUN, SunOS 5.8; PC, Windows 2000 and Linux 7.1. 10086-2.21-00.

LANL 2003. Software Code: fehm2post. V1.0. SUN, SunOS 5.8 and 5.7; PC,

165754 Windows 2000 and Redhat Linux 2.4.18. 11031-1.0-00.

LANL 2003. Software Code: ppptrk. V1.0. SUN, SunOS 5.8 and 5.7; PC, 165753 Windows 2000 and Linux 7.1. 11030-1.0-00.

LBNL (Lawrence Berkeley National Laboratory) 1999. Software Code: T2R3D. V1.4. FORTRAN 77, SUN, DEC/ALPHA. 10006-1.4-00.

LBNL 1999. Software Code: TOUGH2. V1.11 MEOS9nTV1.0. MAC, SUN, 113943 DEC/Alpha, PC. 10065-1.11MEOS9NTV1.0-00.

LBNL 2002. Software Code: DCPT. V2.0. PC, Windows. 10078-2.0-00.

154342

LBNL 2003. Software Code: WTRISE. V2.0. PC/WINDOWS 2000/98; DEC ALPHA/OSF1 V5.1. 10537-2.0-00.

146654

163453 


\section{INTENTIONALLY LEFT BLANK}


APPENDIX A

DERIVATION OF THE DISTRIBUTION OF WATER CONTENT AND EFFECTIVE PERMEABILITY FOR SAMPLING MATRIX DIFFUSION COEFFICIENT 
Matrix diffusion is linked through the correlation given by Reimus et al. (2002 [DIRS 163008]) to porosity and permeability. For unsaturated conditions, this relationship is extended to water content and effective permeability. This is done in segments from the output file from rows 61001-122000, 122001-184000, and 184001-245506, and repeated for each of the nine flow fields. Rows 1-61000 are not needed because none of these cells lie within the repository footprint.

Starting with the flow output file for saturation and relative permeability discussed earlier, the file is first sorted on column $\mathrm{T}$ to sort out the cells not in the repository footprint. This approximation is made to simplify the procedure, and is a reasonable approach since, for the most part, transport is vertically downward. After sorting, the matrix data is copied into a new file. The rock types in column $\mathrm{K}$ are compared with the rock types that exist in or beneath the repository horizon. This is done using the following formulas, implemented as formulas in Excel spreadsheets:

$$
\begin{aligned}
& \text { Urn = IF(Krn=“bf3Md”,1,IF(Krn=“tr3Md”,1,0)) } \\
& \text { Vrn = IF(Krn=“pp2Md”,2,IF(Krn=“pp1Mz”,2,IF(Krn=“pp4Mz”,2,0))) } \\
& \text { Wrn = } \\
& \text { IF(Krn=“ch2Mz”,3,IF(Krn=“ch3Mz”,3,IF(Krn=“ch4Mz”,3,IF(Krn=“ch5Mz”,3,IF(Krn=“ch6Mz } \\
& \text {,3,0))))) } \\
& \text { Xrn = } \\
& \text { IF(Krn=“pcM1z”,3,IF(Krn=“pcM2z”,3,IF(Krn=“pcM39”,3,IF(Krn=“pcM4p”,3,IF(Krn=“pcM5z”, } \\
& \text { 3,IF(Krn=“pcM6z”,3,0)))))) } \\
& \text { Yrn = IF(Krn=“ch2Mv”,4,IF(Krn=“ch3Mv”,4,IF(Krn=“ch4Mv”,4,IF(Krn=“ch5Mv”,4,0)))) } \\
& \text { Zrn = IF(Krn=“tswMv”,5,IF(Krn=“ch1Mv”,5,IF(Krn=“ch6Mv”,5,IF(Krn=“pp3Md”,5,0)))) } \\
& \text { AArn = IF(Krn=“tswMz”,6,IF(Krn=“ch1Mz”,6,IF(Krn=“bf2Mz”,6,0))) } \\
& \text { ABrn = IF(Krn=“tswM8”,7,IF(Krn=“pcM38”,7,0)) } \\
& \text { ACrn = IF(Krn=“tswM4”,8,IF(Krn=“tswM6”,8,IF(Krn=“tswM7”,8,0))) } \\
& \text { ADrn = IF(Krn=“"tswM3”,9,IF(Krn=“tswM5”,9,0)) } \\
& \text { AErn = SUM(U1:AD1) }
\end{aligned}
$$


The sum of the columns in column AE identifies, by number, the rock group from 1 to 9 . Table A-1 shows a table of the rock groups:

Table A-1. Crosswalk between Rock Groups and Model Units

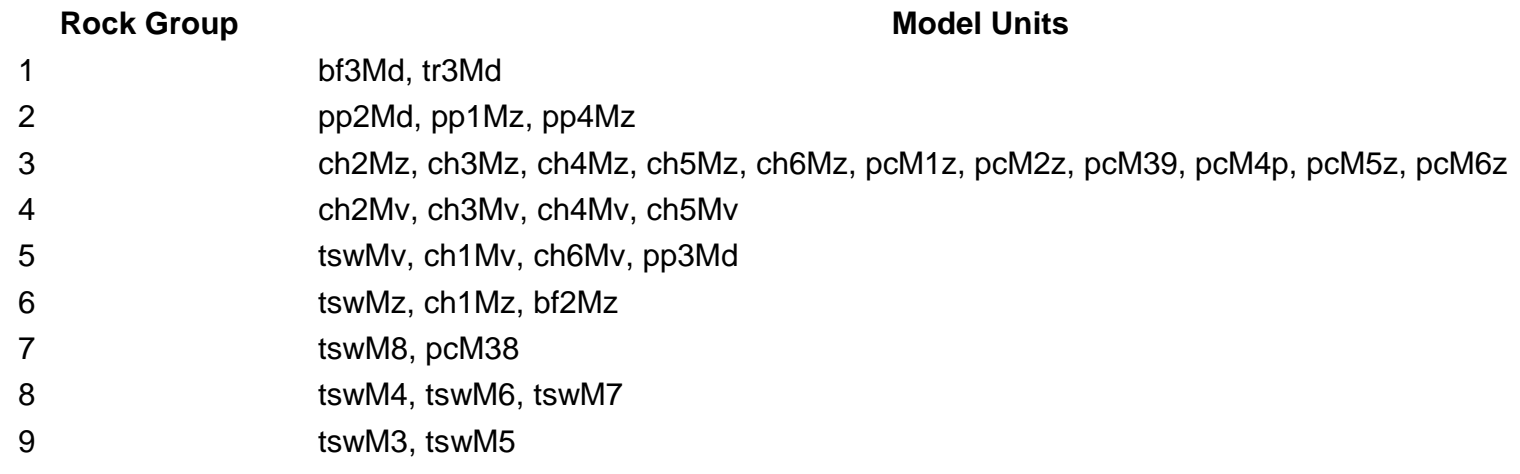

The groupings are based on similarities in porosity and permeability, as shown in Table A-2:

Table A-2. Porosity and Permeability of Model Units and Associated Rock Group

\begin{tabular}{|c|c|c|c|}
\hline Model Unit & Porosity & Permeability $\mathrm{m}^{2}$ & Rock Group \\
\hline bf3Md & 0.175 & $3.55 E-14$ & 1 \\
\hline pp2Md & 0.221 & 1.7E-15 & 2 \\
\hline pp1Mz & 0.297 & 2.57E-15 & 2 \\
\hline pp4Mz & 0.321 & $1.02 \mathrm{E}-15$ & 2 \\
\hline ch6Mz & 0.271 & 8.2E-19 & 3 \\
\hline pcM39 & 0.275 & $6.2 \mathrm{E}-18$ & 3 \\
\hline pcM1z & 0.285 & 9.3E-20 & 3 \\
\hline pcM2z & 0.322 & $2.4 \mathrm{E}-18$ & 3 \\
\hline ch5Mz & 0.322 & $5.2 E-18$ & 3 \\
\hline $\operatorname{ch} 4 \mathrm{Mz}$ & 0.322 & $5.2 E-18$ & 3 \\
\hline ch3Mz & 0.322 & $5.2 \mathrm{E}-18$ & 3 \\
\hline $\operatorname{ch} 2 \mathrm{Mz}$ & 0.322 & $5.2 E-18$ & 3 \\
\hline ch5Mv & 0.346 & 4.9E-11 & 4 \\
\hline ch4Mv & 0.346 & 4.9E-11 & 4 \\
\hline ch3Mv & 0.346 & 4.9E-11 & 4 \\
\hline ch2Mv & 0.346 & 4.9E-11 & 4 \\
\hline tswMv & 0.229 & $2.24 \mathrm{E}-13$ & 5 \\
\hline pp3Md & 0.318 & $1.26 \mathrm{E}-13$ & 5 \\
\hline ch1Mv & 0.331 & $1.39 \mathrm{E}-12$ & 5 \\
\hline tswMz & 0.275 & $3.5 \mathrm{E}-17$ & 6 \\
\hline $\operatorname{ch} 1 \mathrm{Mz}$ & 0.285 & $3.5 E-17$ & 6 \\
\hline pcM38 & 0.043 & 3E-19 & 7 \\
\hline tswM8 & 0.043 & 7.4E-18 & 7 \\
\hline tswM7 & 0.103 & 7.41E-19 & 8 \\
\hline tswM6 & 0.103 & 7.41E-19 & 8 \\
\hline tswM4 & 0.111 & 2.96E-19 & 8 \\
\hline tswM5 & 0.131 & 8.55E-18 & 9 \\
\hline tswM3 & 0.155 & 2.39E-179 & 9 \\
\hline
\end{tabular}


The rock type identification files are stored as:

gt upper rock type identification 61001-122000.xls

gt upper rock type identification 122001-184000.xls

gt upper rock type identification 184001-245506.xls

gt mean rock type identification 61001-122000.xls

gt mean rock type identification 122001-184000.xls

gt mean rock type identification 184001-245506.xls

gt lower rock type identification 61001-122000.xls

gt lower rock type identification 122001-184000.xls

gt lower rock type identification 184001-245506.xls

ms upper rock type identification 61001-122000.xls

ms upper rock type identification 122001-184000.xls

ms upper rock type identification 184001-245506.xls

ms mean rock type identification 61001-122000.xls

ms mean rock type identification 122001-184000.xls

ms mean rock type identification 184001-245506.xls

ms lower rock type identification 61001-122000.xls

ms lower rock type identification 122001-184000.xls

ms lower rock type identification 184001-245506.xls

pd upper rock type identification 61001-122000.xls

pd upper rock type identification 122001-184000.xls

pd upper rock type identification 184001-245506.xls

pd mean rock type identification 61001-122000.xls

pd mean rock type identification 122001-184000.xls

pd mean rock type identification 184001-245506.xls

pd lower rock type identification 61001-122000.xls

pd lower rock type identification 122001-184000.xls

pd lower rock type identification 184001-245506.xls

Columns $\mathrm{U}$ through $\mathrm{AD}$ are deleted and the file is sorted on column $\mathrm{U}$ (Rock Type) in descending order. Those with rock type " 0 " are deleted.

These files are saved as

gt upper sort by rock type 61001-122000.xls

gt upper sort by rock type 122001-184000.xls

gt upper sort by rock type 184001-245506.xls 
gt mean sort by rock type 61001-122000.xls gt mean sort by rock type 122001-184000.xls gt mean sort by rock type 184001-245506.xls

gt lower sort by rock type 61001-122000.xls gt lower sort by rock type 122001-184000.xls gt lower sort by rock type 184001-245506.xls

ms upper sort by rock type 61001-122000.xls ms upper sort by rock type 122001-184000.xls ms upper sort by rock type 184001-245506.xls

ms mean sort by rock type 61001-122000.xls ms mean sort by rock type 122001-184000.xls ms mean sort by rock type 184001-245506.xls

ms lower sort by rock type 61001-122000.xls ms lower sort by rock type 122001-184000.xls ms lower sort by rock type 184001-245506.xls

pd upper sort by rock type 61001-122000.xls pd upper sort by rock type 122001-184000.xls pd upper sort by rock type 184001-245506.xls

pd mean sort by rock type 61001-122000.xls pd mean sort by rock type 122001-184000.xls pd mean sort by rock type 184001-245506.xls

pd lower sort by rock type 61001-122000.xls pd lower sort by rock type 122001-184000.xls pd lower sort by rock type 184001-245506.xls

The results for each climate scenario are compiled into a single file and ordered by column $\mathrm{V}$ in descending order. The files are stored as:

gt upper composite by rock type.xls gt mean composite by rock type.xls gt lower composite by rock type.xls

ms upper composite by rock type.xls ms mean composite by rock type.xls ms lower composite by rock type.xls pd upper composite by rock type.xls pd mean composite by rock type.xls pd lower composite by rock type.xls 
Similarities between rock groups 1, 2, 4, 5, and 6 led to making this a single group. The same was also found for groups 7, 8, and 9. This reduces the groupings to 3 composite groups:

$$
\begin{aligned}
& \text { 1, 2, 4, 5, and } 6 \\
& 3 \\
& 7,8 \text {, and } 9 \text {. }
\end{aligned}
$$

The first analysis for the glacial-transition upper climate scenario was conducted on the individual rock groups 1-9. Porosity was randomly sampled because the flow fields and resulting saturations and effective permeabilities are independent of porosity under steady-flow conditions. Porosity sampling was conducted for each model unit according to the mean and standard deviation for the model unit and a minimum and maximum of 9 and 1, respectively, using a beta distribution. The sampling methodology is described on pages 55 through 59 of the report by Wang (2003 [DIRS 166070], SN-LBNL-SCI-236-V1). Once the sampled porosities were generated on separate worksheets in the same file, the porosities were copied and pasted into column $\mathrm{T}$ on the main worksheet. Water content for each cell is generated by multiplying column D by column $\mathrm{T}$ as follows:

$$
\operatorname{Urn}=\operatorname{Drn} * \operatorname{Trn}
$$

After generating the water content for each model unit, the combined units were assembled and the main worksheet was ordered by rock type (descending order) and secondarily by cell name (ascending order).

Statistics for the water content and effective permeability were assembled from the data based on a volume-weighted average. The cell volumes are given in column L. The total sum of cell volumes are computed as follows:

$$
\text { X1 = SUM(L1:Lre) }
$$

Where "re" stands for the last row of data on the worksheet. The statistics for water content are derived from the following:

$$
\begin{aligned}
& \text { Yrn }=\text { Urn*Lrn/W\$1 } \\
& \text { Zrn }=\left((U r n-Z \$ 1)^{\wedge}\right)^{*} \operatorname{Lrn} / \mathrm{W} \$ 1 \\
& \text { AA1 }=\text { SUM(X1:Xre) } \\
& \text { AB1 }=\text { SQRT(SUM(Y1:Yre) }) \\
& \text { AC1 = MAX(U1:Ure) } \\
& \text { AD1 = MIN(U1:Ure) }
\end{aligned}
$$

where Yrn and Zrn are the sums to determine the volume weighted mean and variance of the water content. AA1 is then the mean water content, AB1 is the standard deviation of water content, AC1 is the maximum water content, and AD1 is the minimum water content. 
Statistics for the effective permeability are based on a log-normal distribution. The statistics are derived through the following formulas:

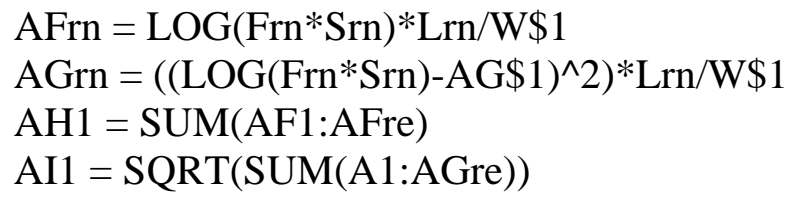

Where AFrn and AGrn are the sums to determine the volume weighted mean and variance of the logarithm of the effective permeability. AH1 is then the mean of the logarithm of the effective permeability, and AI1 is the standard deviation of the logarithm of the effective permeability.

This was carried out for each of the nine flow fields. The files containing the results are stored as:

gt upper group 6-5-4-2-1 diffusion parameters.xls
gt upper group 3 diffusion parameters.xls
gt upper group 9-8-7 diffusion parameters.xls
gt mean group 6-5-4-2-1 diffusion parameters.xls
gt mean group 3 diffusion parameters.xls
gt mean group 9-8-7 diffusion parameters.xls
gt lower group 6-5-4-2-1 diffusion parameters.xls
gt lower group 3 diffusion parameters.xls
gt lower group 9-8-7 diffusion parameters.xls
ms upper group 6-5-4-2-1 diffusion parameters.xls
ms upper group 3 diffusion parameters.xls
ms upper group 9-8-7 diffusion parameters.xls
ms mean group 6-5-4-2-1 diffusion parameters.xls
ms mean group 3 diffusion parameters.xls
ms mean group 9-8-7 diffusion parameters.xls
ms lower group 6-5-4-2-1 diffusion parameters.xls
ms lower group 3 diffusion parameters.xls
ms lower group 9-8-7 diffusion parameters.xls
ps upper group 6-5-4-2-1 diffusion parameters.xls
ps upper group 3 diffusion parameters.xls
ps upper group 9-8-7 diffusion parameters.xls
ps mean group 6-5-4-2-1 diffusion parameters.xls
ps mean group 3 diffusion parameters.xls
ps mean group 9-8-7 diffusion parameters.xls
ps lower group 6-5-4-2-1 diffusion parameters.xls
ps lower group 3 diffusion parameters.xls
ps lower group 9-8-7 diffusion parameters.xls 
Summary files for each climate were created. These are stored as:

Summary of matrix diffusion for glacial-transition climate.xls

Summary of matrix diffusion for monsoon climate.xls

Summary of matrix diffusion for present day climate.xls

Averages were conducted across the climate/infiltration scenarios to create categories based on rock type only. Simple arithmetic averages of the results from each climate infiltration scenario were computed for the mean and variance of water content and logarithm of the effective permeability. Composite Distributions for all climate scenarios segregated only by the higher level rock groupings (6-5-4-2-1, 3, 9-8-7) are given in the following file:

Matrix diffusion summary with averages by rock type.xls

And a summary file with only the results is given in:

Matrix diffusion - summary values only.xls 


\section{INTENTIONALLY LEFT BLANK}




\section{APPENDIX B}

\section{DERIVATION OF WATER TABLE COLLECTING BINS}


The water table bins were calculated starting with grid information for the unsaturated zone (UZ) flow fields available in DTN: LB03023DSSCP9I.001 [DIRS 163044]. This data contains the cell name and coordinates for each node in the site-scale UZ flow model. Because the number of elements is 245506, the file is split into 4 groups as follows such that the data fits onto an excel worksheet:

$$
\begin{aligned}
& \text { Group A } \\
& \text { 1-62000.xls } \\
& \text { 62001-124000.xls } \\
& \text { 124001-186000.xls } \\
& \text { 186001-245506.xls }
\end{aligned}
$$

The "BT" cells in the UZ flow model comprise the bottom boundary of the model at the presentday water table. These are cells in the file 186001-245506.xls from row 57465 to row 59506. The "BT" cell coordinates were put into columns I, J, and K of the following files:

$$
\begin{aligned}
& \text { Group B } \\
& \text { 1-62000 with exact WT picks.xls } \\
& 62001-124000 \text { with exact WT picks.xls } \\
& \text { 124001-186000 with exact WT picks.xls } \\
& \text { 186001-245506 with exact WT picks.xls }
\end{aligned}
$$

Columns $\mathrm{L}$ and $\mathrm{M}$ were generated using the following relationship:

$$
\begin{aligned}
& \text { Lrn = Ern\&Frn } \\
& \text { Mrn = Irn\&Jrn }
\end{aligned}
$$

where the "rn" subscripts stand for "row number". The character strings in columns L and M represent, respectively, a unique $\mathrm{x}-\mathrm{y}$ coordinate character for the grid nodes and for the "BT" cells. Each grid node was then checked for a match with a "BT" cell. The index for the match was recorded in Column N,

$$
\text { Nrn }=\text { MATCH(Lrn,M\$1:M\$end,0) }
$$

where M\$end represents the last occupied cell in column M.

The index in column $\mathrm{N}$ is then used to extract the local water table elevation in column $\mathrm{H}$ as follows:

$$
\operatorname{Hrn}=\operatorname{INDEX}(\mathrm{K}: \mathrm{K}, \mathrm{Nrn})
$$

In roughly 10 percent of the cells, no match was found, in which case a value of \#N/A was returned. To evaluate a value of the local water table for these cells, columns A through $\mathrm{H}$ were copied into a second worksheet in the files listed above. A column was inserted into column A for a sequential number for each cell. Therefore, the local water table resided in column I. The worksheet was sorted on column I to group the cells without local water table values. The cells without local water table values were copied into the following file: 


\section{Stragglers.xls}

Cells without local water table values were found for each of the following cell ranges:

$1-62000$

$62001-124000$

$186001-245506$

and these cells were kept on separate worksheets in the Straggles.xls file.

To identify an appropriate local water table elevation for these cells, the following file was developed:

WT identification for stragglers.xls

Columns A, B, and C from row 3 to row 4086 contain the coordinates of the "BT" cells. Up to $250 \mathrm{x}-\mathrm{y}$ coordinates for cells without an exact water table value were put in rows 1 and 2, columns D through IS. Then the square of the distance between each cell and each "BT" cell was computed for each $\mathrm{x}-\mathrm{y}$ coordinate as follows:

$$
\operatorname{COLrn}=(\operatorname{COL} \$ 1-\$ A r n)^{\wedge} 2+(\operatorname{COL} \$ 2-\$ B r n)^{\wedge} 2
$$

where COL represents a column label and rn the row number. Each column represents the $x-y$ distance from a cell without an exact local water table value to each of the "BT" cells. The minimum distance was determined in row 4087 using the following formula:

$$
\text { COL4087 = MIN(COL3:COL4086) }
$$

The index of the "BT" cell associated with the minimum distance was determined in row 4088 as follows:

$$
\text { COL4088 = MATCH }(\text { COL4087,COL3:COL4086,0) }
$$

And the water table elevation associated with the index is determined in row 4089 as follows:

$$
\text { COL4089 = INDEX }(\$ C 3: \$ C 4086, C O L 4088)
$$

These water table elevations were included in the third worksheet of the Group B files.

Files 62001-124000 wt bins.xls, 124001-186000 wt bins.xls, and 186001-245506 wt bins.xls contain the extracted water table collection cells in TOUGH2 columns using conditional if statements and the definition of the collection bin boundary data.

File 62001-124000 wt bins with fehm nodes .xls, 124001-186000 wt bins with fehm nodes.xls, and 124001-186000 wt bins with fehm nodes.xls contain extracted collection bin nodes in finite element heat and mass model grid format.

The final extracted water table collection bins are stored in file collect_zone which only contains the fracture nodes as required by FEHM. 
All the files used in the extraction of water table collection bins are included in zip file wtbin.zip. The file names are listed below in Figure B-1.

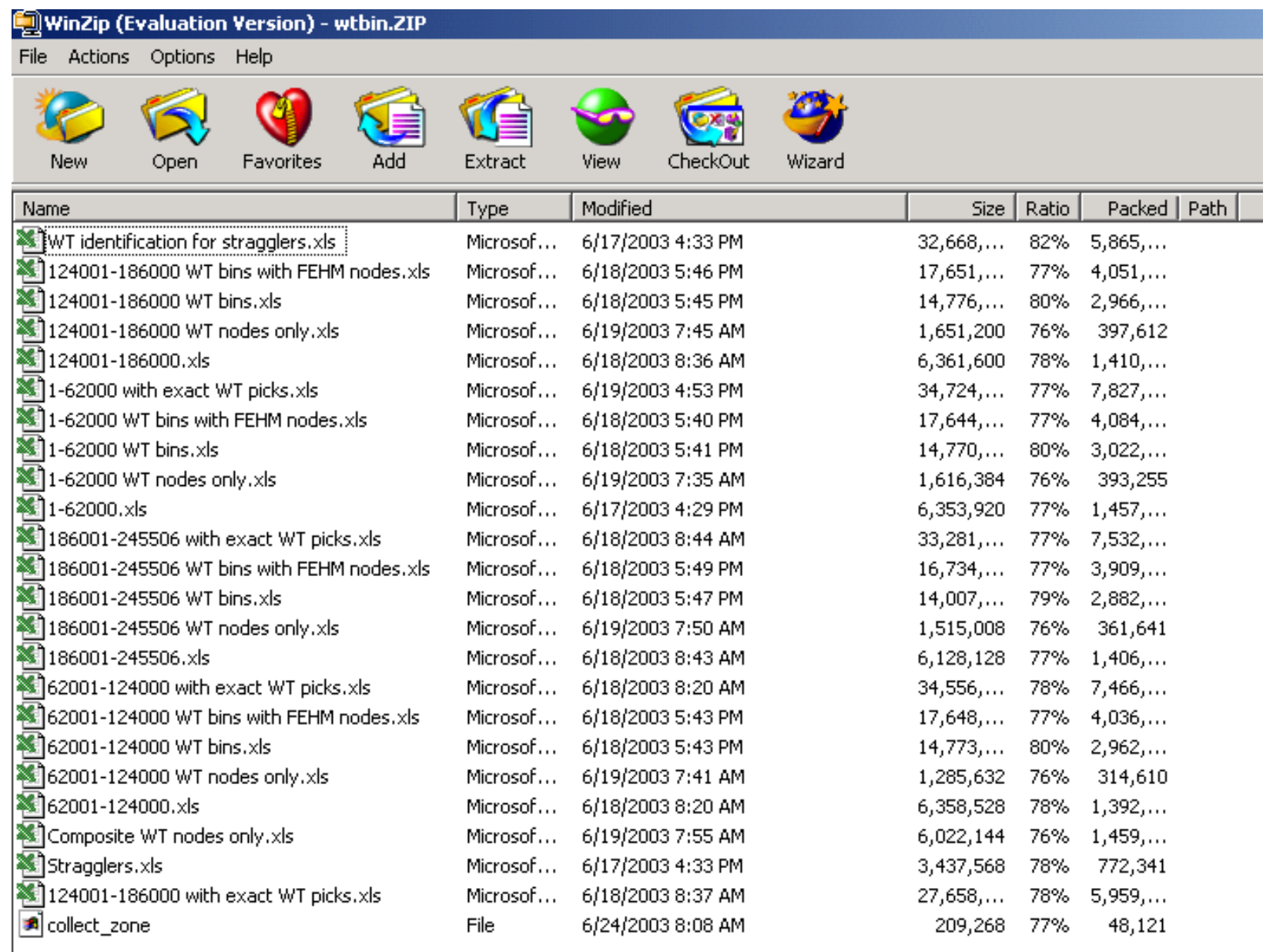

Figure B-1. L Listing of Files Used to Develop the Water Table Binning 


\section{INTENTIONALLY LEFT BLANK}


APPENDIX C

DERIVATION OF FRACTURE-MATRIX INTERACTION SUBMODEL AND GENERATION OF TRANSFER FUNCTIONS 


\section{C1. DERIVATION OF FRACTURE-MATRIX INTERACTION SUBMODEL}

The governing equations required for the fracture-matrix interaction submodel is a solute transport system in a domain consisting of parallel flow in a fracture and adjacent matrix, with fracture-matrix solute interaction via molecular diffusion in the rock matrix. This model is, therefore, an extension of the model by Sudicky and Frind (1982 [DIRS 105043]), which assumed the water in the matrix is stagnant. For simplicity, longitudinal dispersion is not considered in either medium, advection is considered only in the $\mathrm{z}$ direction, and diffusion is considered only normal to the flow direction. The rationales for these simplifications are as follows. With regard to longitudinal dispersion, this submodel is intended only to capture the impact of diffusion because dispersion is captured separately in the particle tracking algorithm. Likewise, the advection from fracture to matrix (or the reverse) is implemented in the particle tracking algorithm separately. Therefore, the remaining processes to be included as part of the transfer functions are advection and diffusion in the z-direction only.

Starting with a derivation of the transport equation for the fracture, a variant of this equation with longitudinal dispersion and decay was presented by Sudicky and Frind (1982 [DIRS 105043], Eq. 1). This derivation is presented here from first principles to demonstrate the means by which terms in the dimensionless groups must be altered to include the effects of the active fracture model (AFM). Taking a control volume in the fracture of width $b$ (half of the full aperture), depth $d$, and length $\Delta z$, the terms of the transient solute mass balance (units of each of these terms are solute mass per time) are:

Accumulation: $\quad b d \Delta z \theta_{f} R_{f} \frac{\left(C-C_{p r e v}\right)}{\Delta t}$

where $C_{\text {prev }}$ represents the concentration at the previous time step, $\theta_{f}$ is the volumetric water content in the fracture, and $R_{f}$ is the fracture retardation factor.

Advection:

$$
b d \bar{V}_{z}\left(C_{z+\Delta z}-C_{z}\right)
$$

where $\bar{V}_{z}$ is the Darcy velocity in the fracture, equal to volumetric flow rate divided by the total cross sectional area in the fracture.

Diffusion into Matrix:

$$
\left.d \Delta z \theta_{m} D_{m} \frac{\partial C_{m}}{\partial x}\right|_{x=b}
$$

where $D_{m}$ is the effective diffusion coefficient in the matrix and $\theta_{m}$ is the matrix volumetric water content. These terms form the overall solute mass balance equation:

$$
b d \Delta z \theta_{f} R_{f} \frac{\left(C-C_{p r e v}\right)}{\Delta t}=-b d \bar{V}_{z}\left(C_{z+\Delta z}-C_{z}\right)+\left.d \Delta z \theta_{m} D_{m} \frac{\partial C_{m}}{\partial x}\right|_{x=b}
$$


Dividing by $b d \Delta z \theta_{f}$, making use of the relation for the fracture interstitial pore-water velocity $V_{f}=\bar{V}_{z} / \theta_{f}$, and taking the limit as $\Delta z$ and $\Delta t$ go to 0 :

$$
R_{f} \frac{\partial C_{f}}{\partial t}=-V_{f} \frac{\partial C_{f}}{\partial z}+\left.\frac{\theta_{m} D_{m}}{\theta_{f} b} \frac{\partial C_{m}}{\partial x}\right|_{x=b}
$$

Note also that the subscript " $\mathrm{f}$ " on the concentration is adopted to denote the fracture.

Given the assumptions listed at the beginning of this derivation, the differential equation governing transport in the matrix is:

$$
R_{m} \frac{\partial C_{m}}{\partial t}=D_{m} \frac{\partial^{2} C_{m}}{\partial x^{2}}-V_{m} \frac{\partial C_{m}}{\partial z}
$$

where $V_{m}$ is the interstitial pore-water velocity in matrix, and $D_{m}$ is the matrix retardation factor. The initial and boundary conditions for the system are:

$$
\begin{gathered}
C_{f}(z, 0)=0 \\
C_{m}(x, z, 0)=0 \\
C_{f}(0, t)=C_{o, f} \\
C_{m}(x, 0, t)=C_{o, m} \\
C_{m}(b, z, t)=C_{f}(z, t) \\
\frac{\partial C_{m}}{\partial x}(B, z, t)=0
\end{gathered}
$$

Here the terms $C_{o, f}$ and $C_{o, m}$ for the fracture and matrix, respectively, are nonzero if mass is being introduced into that medium, and 0 if mass is being introduced in the other medium.

Nondimensionalization of these equations can be accomplished by introducing the following dimensionless variables:

$$
\begin{gathered}
\hat{C}_{f}=C_{f} / C_{o} \\
\hat{C}_{m}=C_{m} / C_{o} \\
\hat{z}=z / L \\
\hat{x}=x / B
\end{gathered}
$$




$$
\hat{t}=\frac{V_{f} t}{R_{f} L}=\frac{t}{\tau_{f} R_{f}}
$$

where $L$ is the length of the flow path. Eq. C-19 uses the definition of $\tau_{f}=L / V_{f}$; a corresponding relation is also used for the matrix fluid transport time $\left(\tau_{m}=L / V_{m}\right)$. Note that because the equations are nondimensionalized with respect to transport times through the fracture and matrix, the physical dimensions of the flow path, including the length, is unimportant to the final implementation in the code. Next, substituting Equations C-15 to C-19 into Equations C-7 and C-8:

$$
\begin{gathered}
\frac{\partial \hat{C}_{f}}{\partial \hat{t}}=-\frac{\partial \hat{C}_{f}}{\partial \hat{z}}+\left.\frac{\theta_{m} D_{m} \tau_{f}}{\theta_{f} b B} \frac{\partial \hat{C}_{m}}{\partial \hat{x}}\right|_{\hat{x}=b / B} \\
\frac{\partial \hat{C}_{m}}{\partial \hat{t}}=\frac{D_{m} \tau_{f} R_{f}}{B^{2} R_{m}} \frac{\partial^{2} \hat{C}_{m}}{\partial \hat{x}^{2}}-\frac{\tau_{f} R_{f}}{\tau_{m} R_{m}} \frac{\partial \hat{C}_{m}}{\partial \hat{z}}
\end{gathered}
$$

The boundary and initial conditions (Equations C-3 to C-8) are transformed to

$$
\begin{gathered}
\hat{C}_{f}(\hat{z}, 0)=0 \\
\hat{C}_{m}(\hat{x}, \hat{z}, 0)=0 \\
\hat{C}_{f}(0, \hat{t})=1 \text { (or } 0 \text { if injection is into the matrix) } \\
\hat{C}_{m}(\hat{x}, 0, \hat{t})=1 \text { (or } 0 \text { if injection is into the fracture) } \\
\hat{C}_{m}(b / B, \hat{z}, \hat{t})=\hat{C}_{f}(\hat{z}, \hat{t}) \\
\frac{\partial \hat{C}_{m}}{\partial \hat{x}}(1, \hat{z}, \hat{t})=0
\end{gathered}
$$

The end result is that Equations C-20 and C-21 illustrate that a when nondimensional form of the model equations are produced, the system is fully characterized by three dimensionless parameters (Eq. 6-9 to 6-11 of the main document):

$$
\begin{aligned}
& p_{1}=\frac{D_{m} \tau_{f} R_{f}}{B^{2} R_{m}} \\
& p_{2}=\frac{D_{m} \tau_{f} \theta_{m}}{b B \theta_{f}}
\end{aligned}
$$




$$
p_{3}=\frac{\tau_{f} R_{f}}{\tau_{m} R_{m}}
$$

where the retardation factor $R_{m}$ is related to the sorption coefficient $K_{d}$ using Eq. 6-2. This derivation shows that a series of transfer function curves generated based on a model with parallel flow in the fractures and matrix can capture the range of behavior of the unsaturated zone transport fracture-matrix interaction submodel as long as the curves span the ranges of the parameters in the vector $\left(p_{1}, p_{2}, p_{3}\right)$. The documentation for the finite element heat and mass model (FEHM) V2.21 (LANL 2003 [DIRS 165741]) contains information on the formatting of the input files to invoke this portion of the particle tracking transport model.

\section{C2. GENERATION OF TRANSFER FUNCTIONS}

This section describes the process for generating the transfer function curves. This is accomplished through a numerical solution of the model domain depicted in Figure 6-5. As described in Section 6.4.3, both a discrete fracture model (DFM) and a dual permeability model conceptualization is implemented as part of the abstraction. For the DFM, a two-dimensional DFM was set up to perform transport simulations using the advection-dispersion module of FEHM V2.21 (LANL 2003 [DIRS 165741]). The model consists of a regular grid domain consisting of regular spacing of $6 \mathrm{~m}$ in the $\mathrm{z}$ direction (51 grid points in this direction for a total length of $300 \mathrm{~m}$ ), and increasing grid spacing into the matrix in the $\mathrm{x}$ direction, starting with the first column of nodes of width equal to that of a fracture (22 grid points in this direction). In the model simulations, fracture properties are given to the nodes of the first column, and the remaining nodes are given matrix properties. To ensure that parallel flow occurs in the fracture and matrix in the $\mathrm{z}$ direction, a flow permeability barrier is established between the fracture and matrix. Furthermore, for injection into the matrix, water is input and output from the boundary nodes in proportion to the volume of that cell. This model design ensures that flow streamlines remain completely in the $\mathrm{z}$ direction. Finally, although the transfer functions being used are for unsaturated transport, there is no requirement that this submodel use unsaturated flow to generate them, as long as the water content values are known. Therefore, for simplicity, these simulations were performed for saturated flow conditions, with the fracture and matrix porosities used instead of water contents. For the dual-k model, a simple grid was constructed with identical spacings in the $\mathrm{x}$ direction, but only one matrix cell in the $\mathrm{y}$ direction. Aside from the different grid, cell numbering, and application of boundary conditions, the process for generating the breakthrough curves and transfer functions is the same for the dual-k model. Furthermore, the use of these curves in an FEHM particle tracking simulation is completely transparent, requiring only a choice of which transfer function file to use.

In the simulations to generate the transfer functions, parameter $p_{3}$ is varied systematically from fracture-dominated to matrix-dominated flow by varying the relative water flux values in the fractures and matrix. Ranges of other parameter values consistent with the span of those parameters required for the UZ transport model are also selected. Table C-1 lists the variations of each parameter that were used in the formulation of the transfer function curves. Note that for the sorption coefficient $K_{d}$, the fact that the range of values only goes to 100 does not imply that the model is incapable of accurately simulating transport behavior for higher values of $\mathrm{K}_{\mathrm{d}}$. In 
Section C-4 below, a procedure for normalizing the transfer function curves is described whereby higher values of $\mathrm{K}_{\mathrm{d}}$ are properly handled. This procedure allows the code to cover arbitrarily large values of $\mathrm{K}_{\mathrm{d}}$ without the need to include transfer function curves that extend to such large values.

A four-dimensional matrix of parameters was established with the parameter values listed in the table, and the transfer function curves for each were computed, for a total of $11 \times 12 \times 3 \times 10=3960$ values of the parameter vector $\left(p_{1}, p_{2}, p_{3}\right)$.

Table C-1. List of Parameter Values Used to Compute Transfer Function Curves

\begin{tabular}{|l|l|l|}
\hline \multicolumn{1}{|c|}{ Parameter } & $\begin{array}{c}\text { \# of } \\
\text { Values }\end{array}$ & \multicolumn{1}{c|}{ List of Values } \\
\hline$F_{f}=f_{f} /\left(f_{f}+f_{m}\right)$ & 11 & $0.01,0.1,0.2,0.3,0.4,0.5,0.6,0.7,0.8,0.9,0.99$ \\
\hline$D_{m}$ & 12 & $\begin{array}{l}1 . \mathrm{e}-8,3 . \mathrm{e}-9,1 . \mathrm{e}-9,3 . \mathrm{e}-10,1 . \mathrm{e}-10,3 . \mathrm{e}-11,1 . \mathrm{e}-11,3 . \mathrm{e}-12, \\
1 . \mathrm{e}-12,3 . \mathrm{e}-13,1 . \mathrm{e}-13,1 . \mathrm{e}-20\end{array}$ \\
\hline$\theta_{f}$ & 3 & $0.01,0.1,0.5$ \\
\hline$K_{d}$ & 10 & $0 ., 0.3,0.5,1 ., 3 ., 5 ., 10 ., 30 ., 50 ., 100$. \\
\hline Total: $11 \times 12 \times 3 \times 10$ & 3960 & $\left(p_{1}, p_{2}, p_{3}\right)$ in excel spreadsheet parameter runs.xls \\
\hline
\end{tabular}

${ }^{a} K_{d}$ range of 0-100 does not mean that the model is limited to $K_{d}$ values of 100 or less. See Section III-4 for details on the normalization procedure for handling higher values of $K_{d}$.

Two runs of the model are performed for each parameter set: one where solute mass is injected in the fracture, and another where mass is injected in the matrix. The list of parameter values $\left(p_{1}, p_{2}, p_{3}\right)$ are given in the Excel spreadsheet parameter runs 3960.xls, along with the underlying FEHM input parameters for each simulation. The code fehm2post V1.0 (LANL 2003 [DIRS 165754]) was used to execute the multiple realizations and to postprocess the results to obtain the transfer functions. The postprocessing itself (executed by fehm2post) was performed using the software discrete_tf V1.1 (LANL 2003 [DIRS 165742]). The resulting output from these runs is then concatenated by hand and the appropriate header information inserted by hand to conform to the input required by FEHM. The file called uz_tfcurves_nn_3960.in is the transfer function file for the DFM formulation, whereas the corresponding file for the dual-k formulation is uz_tfcurves_dualk_nn_3960.in. These files, along with the excel spreadsheet mentioned above, and the control files required for execution of these runs are available as DTN: LA0311BR831229.001.

\section{C3. DISCUSSION OF FRACTURE-MATRIX SUBMODEL BEHAVIOR}

This section explores the behavior of the fracture-matrix submodel for the two alternate formulations, DFM and dual-k. In contrast to the discrete fracture based transfer function model, the dual-k formulation has a single matrix block for each fracture block. All other aspects of the parameterization are kept the same. Figures C-1 and C-2 compare the DFM and dual permeability transport models for a flow situation consisting of 60 percent fracture flow, 40 percent matrix flow, over a range of diffusion coefficients given in Table C-2. Breakthrough curves from the fracture are presented for solute injection into the fracture at the inlet. Also 
shown are vertical, dotted red lines representing the limiting behavior expected for fracture transport and no diffusion (dimensionless time of 1) and composite medium behavior for the case of infinitely large diffusion. Composite medium behavior is attained when the time for diffusion across the model domain $B$ is of that same order or smaller than transport time along the flow path. Under these conditions, the transport time through the system reduces to

$$
\tau_{\text {comp }}=\frac{R_{f} m_{f}+R_{m} m_{m}}{f_{f}+f_{m}}
$$

where $m_{f}$ and $m_{m}$ are the fluid masses in a cell for the fracture and matrix, respectively, and $f_{f}$ and $f_{m}$ are the fluid mass fluxes for the fracture and matrix, respectively. Intuitively, Eq. C-29 is derived by picturing a solute molecule traveling with fluid of total flux given by the denominator, with total storage volume (including sorption sites) given by the numerator. The time $\tau_{\text {comp }}$ is an important characteristic time for this system, and serves as a reference for understanding the behavior and deriving the detailed method for using transfer function, described in the next section.

Table C-2. Diffusion Coefficients Used in Simulations

\begin{tabular}{|l|l|}
\hline \multicolumn{1}{|c|}{ Curve Label } & Diffusion Coefficient $\left(\mathbf{m}^{2} / \mathbf{s}\right)$ \\
\hline a & $1 . e-8$ \\
\hline b & $1 . e-10$ \\
\hline c & $1 . e-11$ \\
\hline d & $1 . e-12$ \\
\hline e & $1 . e-13$ \\
\hline$f$ & $1 . e-20$ \\
\hline
\end{tabular}


Injection in Fracture, Breakthrough in Fracture DFM Conceptual Model

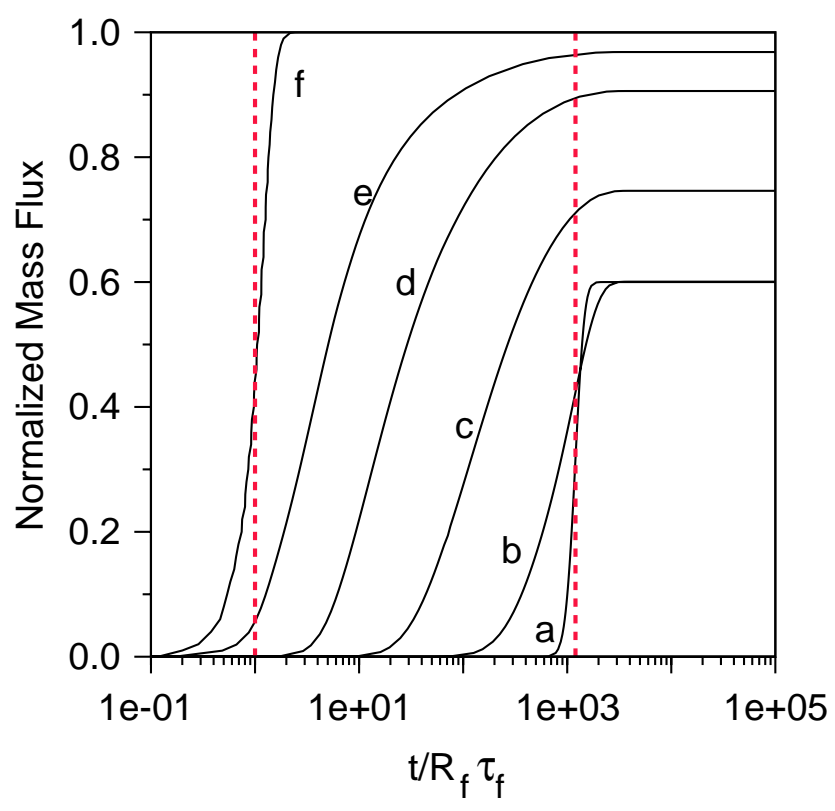

Output DTN: LA0311BR831229.001.

Figure C-1. Transfer Function Computed for the Discrete Fracture Model Formulation: Solute Injection in Fracture, Breakthrough in Fracture, Diffusion Coefficients Given in Table C-2

Injection in Fracture, Breakthrough in Fracture Dual-k Conceptual Model

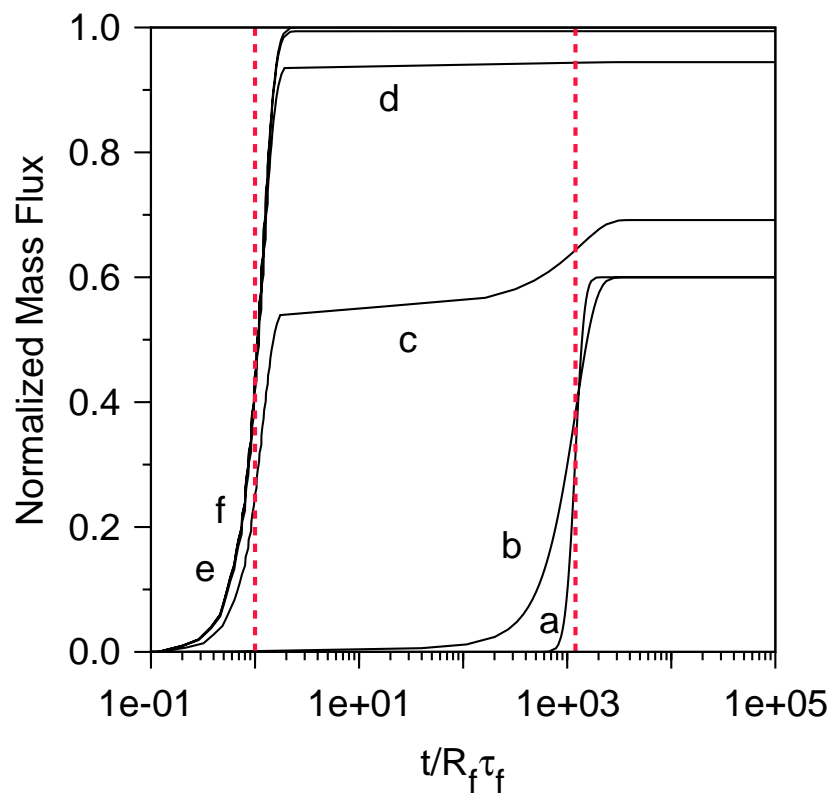

Output DTN: LA0311BR831229.001.

Figure C-2. Transfer Function Computed for the Dual-k Model Formulation: Solute Injection in Fracture, Breakthrough in Fracture, Diffusion Coefficients Given in Table C-2 
For each model, the behavior at the extremes of low and high diffusion are similar. For negligible diffusion, transport times approach a dimensionless time of 1 , and the normalized mass flux attains a plateau at 1 , which is to say that all mass injected in the fracture leaves via the fracture. By contrast, at high diffusion, transport times approach $\tau_{\text {comp }}$, and the plateau of normalized mass flux approaches a value of $F_{f}$ (0.6 in this example), meaning that at this extreme, the probability of mass in the fracture leaving via the fracture equals the fraction of the total flow traveling through the fracture. It is at the intermediate values of diffusion coefficient that the two models diverge. Specifically, the dual-k formulation tends to predict early breakthrough due to rapid transport through the fracture for a significant portion of the mass, compared to the DFM formulation, for which smooth breakthrough curves at progressively longer transport times are predicted for increasing diffusion coefficients. This means that the dual-k formulation ought to predict earlier breakthrough for the first-arriving mass if the parameter ranges of the model are in this intermediate range. Conversely, the models should be similar behavior for high diffusion or low diffusion.

\section{C4. ADDITIONAL IMPLEMENTATION CONSIDERATIONS}

This section addresses some additional details concerning the implementation of the transfer function methodology. These considerations concern the nondimensionalization of the transfer function curves, and the method by which the model handles cases in which some parameters are selected that fall at or outside the range of values assumed when generating the transfer function curves.

Figures C-1 and C-2 demonstrated that, in addition to the fracture transport time $R_{f} \tau_{f}$ used to nondimensionalize time in the transfer function curves, the composite transport time $\tau_{\text {comp }}$ is a natural parameter for bracketing the behavior of the $\mathrm{f} / \mathrm{m}$ interaction submodel. Time in the transfer functions supplied to FEHM is $t / R_{f} \tau_{f}$, which contains no information relevant to the extreme of long transport times, which approach $\tau_{\text {comp }}$. To make the method more robust, an improved nondimensionalization for time can be made as follows:

$$
\bar{t}=\frac{t-R_{f} \tau_{f}}{\tau_{\text {comp }}-R_{f} \tau_{f}}
$$

Assuming, as is the case for the unsaturated zone transport model, that $\tau_{\text {comp }}>>R_{f} \tau_{f}$, Eq. C-26 normalizes the breakthrough times to values in the approximate range of 0 and 1 in Figures C-1 and C-2. Because FEHM reads in time values of $t / R_{f} \tau_{f}$, an expression is required for converting these to dimensionless times given by Eq. C-30. This is done by first dividing the top and bottom of Eq. C-30 by $R_{f} \tau_{f}$ :

$$
\bar{t}=\frac{t / R_{f} \tau_{f}-1}{\tau_{\text {comp }} / R_{f} \tau_{f}-1}
$$


The FEHM input time $t / R_{f} \tau_{f}$ minus 1 is the numerator, so the requirement is to determine a relation involving the dimensionless parameters $\left(p_{1}, p_{2}, p_{3}\right)$ that can be used to express the denominator. For this the following relation is obtained from simple algebra from Equations C-26 to C-28:

$$
\frac{p_{2} p_{3}}{p_{1}}=\left(\frac{\tau_{f}}{b \theta_{f}}\right)\left(\frac{\theta_{m} B}{\tau_{m}}\right)
$$

Alternatively, recognizing that $b \theta_{f}$ and $\theta_{m} B$ are proportional to the fluid mass in the fracture and matrix, respectively, then this expression reduces to:

$$
\frac{p_{2} p_{3}}{p_{1}}=\frac{f_{m}}{f_{f}}
$$

An equivalent expression using the definition $F_{f}=f_{f} /\left(f_{f}+f_{m}\right)$ is

$$
F_{f}=\frac{p_{1}}{p_{1}+p_{2} p_{3}}
$$

Returning to the definition of $\tau_{\text {comp }}$ (Eq. C-29), the following algebraic manipulations can be performed:

$$
\tau_{\text {comp }}=\frac{R_{f} m_{f}+R_{m} m_{m}}{f_{f}+f_{m}}=F_{f}\left(R_{f} \tau_{f}+R_{m} \tau_{m} \frac{f_{m}}{f_{f}}\right)=F_{f} R_{f} \tau_{f}\left(1+\frac{R_{m} \tau_{m}}{R_{f} \tau_{f}} \frac{p_{2} p_{3}}{p_{1}}\right)=F_{f} R_{f} \tau_{f}\left(1+\frac{p_{2}}{p_{1}}\right)
$$

This series of steps is conducted using Equations C-30, C-33, and C-28, along with the definitions $F_{f}=f_{f} /\left(f_{f}+f_{m}\right), \tau_{f}=m_{f} / f_{f}$, and $\tau_{m}=m_{m} / f_{m}$. Finally, the denominator $\tau_{\text {comp }} / R_{f} \tau_{f}-1$ in Eq. C-33 is obtained through further algebra and the use of Eq. C-34:

$$
\tau_{\text {comp }} / R_{f} \tau_{f}-1=\frac{p_{2}\left(1-p_{3}\right)}{p_{1}+p_{2} p_{3}}
$$

The important point here is that the transformation of Eq. C-31 can be made by subtracting 1 from the input dimensionless time and dividing by the expression in Eq. C-36. This operation is performed by FEHM upon reading in the transfer function curves. Then, after the normalized time for a particle $\bar{t}$ is obtained in the particle tracking algorithm, Eq. C-30 is used to back out the dimensional value of time of the particle. This approach takes advantage of the self-similarity of the family of curves such as those in Figures C-1 or C-2. That is, even if the 
parameters $\left(p_{1}, p_{2}, p_{3}\right)$ at a given location in the model are not exactly those used to generate the transfer function, the use of the times $R_{f} \tau_{f}$ and $\tau_{\text {comp }}$ from the model at a given grid cell provide a means for scaling the transfer function accordingly. Also, because a relatively large number of transfer function curves (3960) are used, it is likely that in most instances a curve fairly close to the parameters used in the transfer function will be found.

Despite the effectiveness of this method, there are a few cases for which special consideration needed to be made. This is because of the extraordinarily wide range of parameter values required to be covered in the total system performance assessment for license application model. As a result, the way in which the model handles some of the extreme values of certain parameters is through the use of special rules designed to achieve accuracy. These methods, described below, all call for the adjustment of one or more of the parameters $\left(p_{1}, p_{2}, p_{3}\right)$ at a given location in the model so as to yield the desired behavior. Details are given below.

Low Diffusion Coefficient: It is often desirable to lower the diffusion coefficient to extremely low values to examine this end-member case. Furthermore, colloids are low-diffusion species that require accuracy at low values of $D_{m}$. The most fool-proof way to do this is to not use the transfer function model all, but instead to simply route the particles through the model with advection and dispersion only. However, if this option is not chosen, the model still must perform properly at the low end of diffusion. The diffusion coefficient only affects parameters $p_{1}$ and $p_{2}$, so the search algorithm needs to account for the fact that below a minimum value of $D_{m}\left(10^{-18} \mathrm{~m}^{2} / \mathrm{s}\right.$ in the code), the precise values of these parameters are not important. To ensure that the search algorithm locates a curve with the correct value of $p_{3}, p_{1}$, and $p_{2}$, are assigned values that were actually used in the generation of the low-diffusion transfer function curves (see Table C-1), so that during the search, $p_{1}$ and $p_{2}$ are de-emphasized, and $p_{3}$ is, in essence, the only parameter considered. In doing so, this approach ensures that the code finds the portion of the parameter space with the correct values for $p_{3}$. If this is not done, the least squares method for selecting the correct transfer function curve can sometimes compensate for the extreme parameters chosen by selecting an undesirable part of the parameter space. With the approach just described, the method is forced to select a low-diffusion regime while obtaining the correct ratio of transport times in the fracture and matrix.

High Matrix Sorption: Similar to the case just described, an extremely large value of $R_{m}$ beyond the range used in the transfer functions causes problems for the search algorithm. When searching for the closest transfer function, the uncorrected method compensates for a large $R_{m}$ by selecting a fracture-dominated flow case to attain as low a value of $p_{3}$ as possible. Similarly, the calculation of $p_{1}$ is also affected. Thus, to correct for this case, the maximum value of $R_{m}$ used in the transfer function curve generation (1000) is used as an upper limit when searching for the correct transfer function curve. However, note that this does not mean that the matrix retardation is limited to that value in the particle tracking transport time calculation. Recall that the transfer function curves themselves are normalized using Eq. C-30, which includes $\tau_{\text {comp }}$. In contrast to the determination of the closest transfer function curve, the actual value of $R_{m}$ is used 
in computing $\tau_{\text {comp }}$, which results in a determination of transport time that is scaled by the actual sorption set in the matrix. Thus the correction is applied only to find an appropriate transfer function curve, and the method for nondimensionalizing those curves ensures that an appropriately large transport time is reproduced for the case of high matrix sorption.

Fracture-Dominated Flow: The parameterization of the transfer function curves is based on a model that has some flow within both the fracture and matrix. When the flow is fracture dominated $\left(F_{f}>0.99\right)$, the details of the actual fraction of flow should be unimportant, since advective transport in the matrix should be negligible. However, without correction for cases where $F_{f}>0.99$, the algorithm for finding the transfer function will inappropriately attempt to select curves with high $R_{m}$ to compensate for the fact that transfer functions with extremely large $F_{f}$ are not included. To correct for this problem, the code makes use of the following rearranged form of Eq. C-30:

$$
p_{3}=\frac{p_{1}}{p_{2}} \frac{\left(1-F_{f}\right)}{F_{f}}
$$

When $F_{f}>0.99$, the code uses 0.99 and the values of $p_{1}$ and $p_{2}$ to compute $p_{3}$ for the purposes of selecting the transfer function curve. This assures that a fracture-dominated transfer function is chosen with appropriate values for the other diffusion and sorption parameters.

Matrix-Dominated Flow: For this extreme, it is desirable to bypass the transfer function method altogether, since the transport time is trivially found to be $R_{m} \tau_{m}$. Allowing the transfer function algorithm to be used for this case causes problems because the normalization procedure implicitly assumes that the matrix transport time is longer than the fracture transport time. To cover the special case of essentially no flow in the fracture, the transport time is assigned a value of $\tau_{\text {comp }}$, which reduces to $R_{m} \tau_{m}$ under these conditions.

\section{C5. ADAPTING THE ACTIVE FRACTURE MODEL FOR TRANSPORT}

The AFM of the report by Liu et al. (1998 [DIRS 105729]) is formulated on the basis that only a fraction of the fractures flow. This requires that adjustments be applied to the interface area and the mean spacing between flowing fractures. These adjusted parameters can then be used in the transport model calculations. Examining the individual terms of the mass balance for the fracture derived in Section C-1, the accumulation term (Eq. C-1) is unchanged by the AFM, because it is based on the storage volume in the fracture, as well as sorption parameters. Storage volumes in the dual-k flow fields are fully defined by the fracture volume fractions and the fluid saturations in the fracture continuum. Fluid saturations are model output from the flow simulations, and no further correction for transport is required for the accumulation term. Likewise, the Darcy velocity in the advection term (Eq. C-2) is fully defined by the flux through the fracture continuum, so no AFM corrections are required for advection either. The diffusion term (Equation C-3) consists of a flux $\left.\theta_{m} D_{m} \frac{\partial C_{m}}{\partial x}\right|_{x=b}$ times an interfacial area, which on 
geometrical grounds for the simple geometry of the transfer function model is $d \Delta z$. This interfacial area term, according to the AFM, should be reduced to account for the fact that not all fractures are flowing. Liu et al. (1998 [DIRS 105729], Eq. 12), gives the following reduction factor for correcting the advective flux term [note: nomenclature from the report by Liu et al. (1998 [DIRS 105729]) is used in this equation]:

$$
R=\left(\frac{A_{f m, a}}{A_{f m}}\right)\left(\frac{n_{f, a}}{n_{f}}\right)\left(\frac{d}{d_{a}}\right)
$$

Although Liu et al. (1998 [DIRS 105729]) refer to $R$ as the F-M interface area reduction factor, it is clear from their derivation that the term represents the ratio of the fluxes for the uncorrected and corrected cases, correcting for both the interface area and the transport length scale associated with the distance between the flowing fractures (the third term on the right hand side of this equation). Therefore, in the FEHM simulations, AFM-based adjustments should be applied to both the interface area and the spacing $B$. The term $d / d_{a}$ is the adjustment to the fracture spacing, and is accounted for by adjusting the spacing $B$ in the FEHM transport simulations using the following relation (Liu et al. 1998 [DIRS 105729], Eq. 17):

$$
\frac{d}{d_{a}}=S_{e}^{\gamma}
$$

Thus, the geometric spacing is divided by $S_{e}^{\gamma}$ to obtain the spacing between flowing fractures. The interface-area portion of the adjustment consists of the first two terms on the right hand side of Eq. C-38, the first to account for the reduction in wetted area within an individual fracture, and the second to account for the reduction in area associated with a smaller number of wetted fractures. This term can be related to the AFM parameters using Equations 13 and 14 of the report by Liu et al. (1998 [DIRS 105729]):

$$
\left(\frac{A_{f m, a}}{A_{f m}}\right)\left(\frac{n_{f, a}}{n_{f}}\right)=S_{e}^{1-\gamma} S_{e}^{\gamma}=S_{e}
$$

To implement this area reduction term in FEHM, the geometrically defined aperture $b$ is divided by $S_{e}$. The adjustment to $b$ is for convenience, and actually arises from the need to adjust the interface area in the fracture transport equation. These adjustment factors have been incorporated into FEHM so that for given AFM model parameters, $B$ and $b$, input as geometrically defined parameters, are converted to hydrologic parameters for use in the transfer function methodology. 